The Fermilab

\title{
Antiproton Source
}

Design Report

\author{
April, 1981 \\ Second Printing May, 1981
}

Fermi National Accelerator Laboratory

Batavia, Illinois

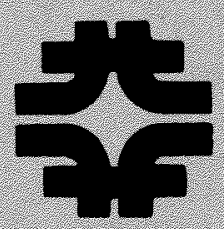




\section{The \\ Fermilab \\ Antiproton Source}

Design Report

April, 1981

Second Printing May, 1981

Fermi National Accelerator Laboratory

Batavia, Illinois

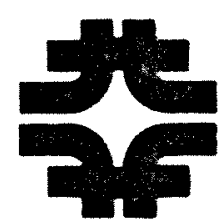




\section{Contents}

$\underline{\text { Page }}$

1. Introduction and summary

1.I Purpose of the Antiproton Source I

1.2 Overview of the system

2. General Scenario

2.1 Introduction

2.2 Scenario Listing

2.3 Other Scenarios

3. Targeting and Transport

3.1 Main Ring Extraction 8

3.2 Proton Transport 10

$3.2 .1 \overline{\mathrm{p}}$ Target Hall 12

3.3 p Production Rate 13

3.4 Antiproton Target 15

3.4.I Material Choice 15

3.4.2 Energy Deposition 15

3.4.3 Target Design 17

3.4.4 The Lithium Lens Collector 18

3.5 Antiproton Transport to Precooler 18

4. Precooler Design

4.1 General Structure and layout 26

4.1.1 Lattice 26

4.1.2 Nomenclature 29

4.2 Injection and stacking 30

4.2.1 Injection 30

4.2 .2 stacking 32

4.3 Magnets 34

4.3.1 Main Magnets 35

4.3.2 Main Magnet Power Supply 36

4.3.3 Correction Elements 38

4.4 Vacuum System 39

4.5 Stochastic Cooling system 40

4.5.1 Stochastic Cooling Sequence 40

4.5.2 Hardware 41

4.6 Deceleration and Rebunching 42

4.6.1 Deceleration 42

4.6.2 Bunching for Extraction 45

4.7 Transfer to and from the Electron Accumulator 46

4.8 Acceleration in the Precooler 47

4.9 8-GeV Extraction and Transport 47 
5. Electron Cooling Accumulator

5.1 General Structure and Layout 52

5.1.1 Lattice 52

5.1 .2 Layout 56

5.2 Injection 56

5.3 Magnets 56

5.4 Electron Cooling System 56

5.4.1 Equipment Description 56

5.4.2 Electron Cooling and Accumulation Rates 58

5.5 RF Stacking and Unstacking 59

5.5.I Injection and Stacking 59

5.5.2 RF Unstacking and Extraction 60

6. Colliding Scenario

6.1 General Plan 62

6.2 Coalescence Scenario 62

7. Buildings and structures

7.1 Below - Ground Structures 65

7.2 Above - Ground Structures 66

7.3 utilities and Roads 66

8. Experimental Areas

8.1 EO Experimental Area 67

8.2 Do Experimental Area 68

Appendix A Parameters

Appendix B Precooler Orbit Listing

Appendix C Accumulator Orbit Listing 


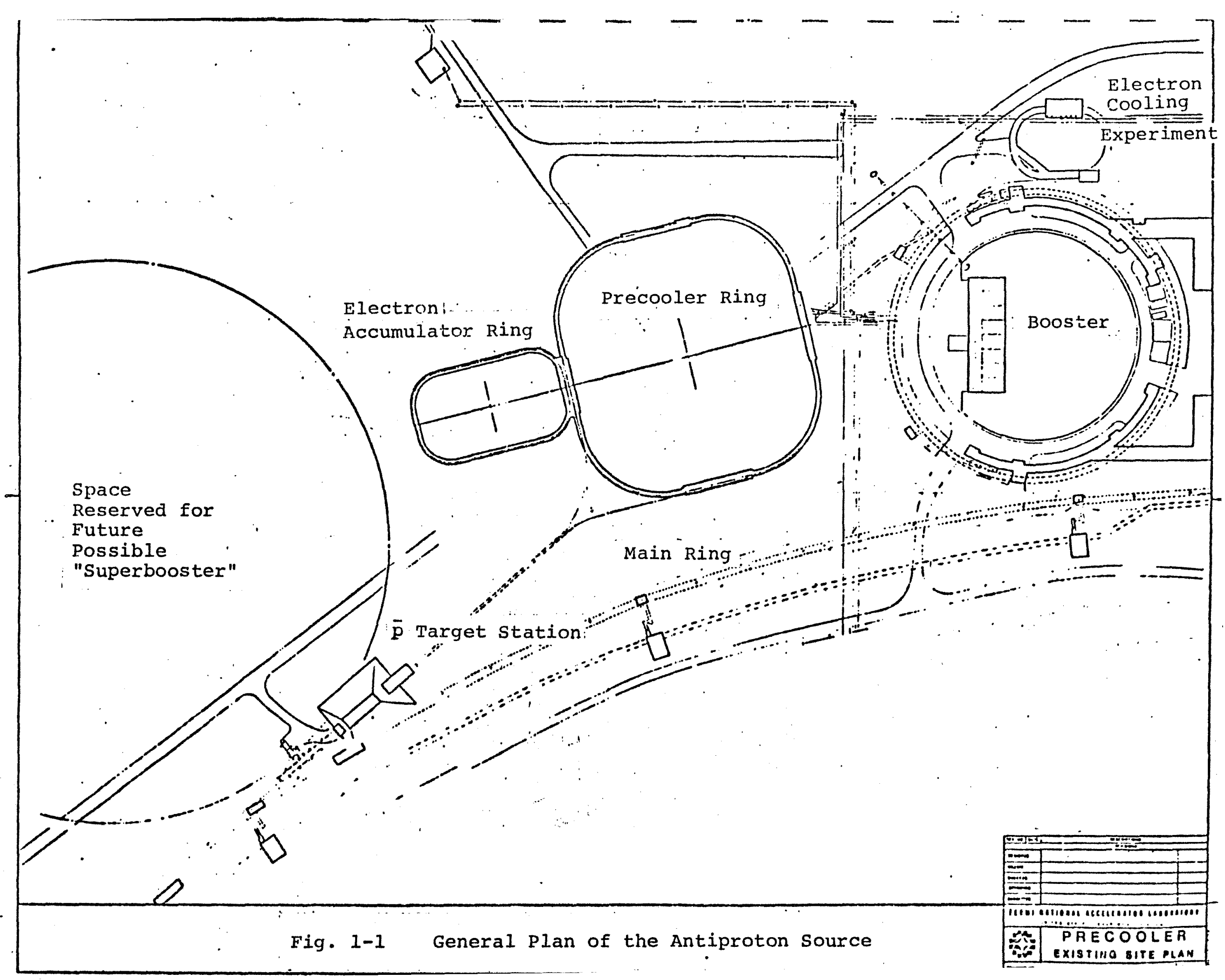




\section{Introduction and Summary}

\subsection{Purpose of the Antiproton Source}

The purpose of the Fermilab Antiproton source is to provide at least $10^{11}$ cooled, accumulated antiprotons for acceleration in the Main Ring and Tevatron for colliding-beams experiments with 1-TeV protons. This will provide the highest available energy in the world for particle-physics experiments through at least the 1980 's. Collisions at $2 \mathrm{TeV}$ in the center of mass will provide a unique experimental tool in a new energy range.

The design of the Antiproton Source has been carried out by the Colliding Beams Department of the Accelerator Division in collaboration with Argonne National Laboratory, Lawrence Berkeley Laboratory, the Institute of Nuclear Physics at Novosibirsk, and the University of Wisconsin.

A project of similar purpose is under way at CERN. Its objective is to achieve colliding proton-antiproton beams at 540 $\mathrm{GeV}$ in the center of mass in the CERN SPS. The Antiproton Accumulator ( $A A$ ), a ring that is roughly equivalent in function to the Precooler and Accumulator described here, has been built and is in operation. The $A A$ is a different design solution to different design problems. The most important reason for the differences between the two projects is the different length of the proton beam that is the original source of antiprotons. The CERN PS beam proton beam is approximately 628 meters long, but the Fermilab Main Ring beam is 6280 meters long, a factor 10 larger. The larger size of our Precooler comes from the fundamental need to fold this longer beam into small pieces. It would be possible to extract the Main Ring beam in more batches and fill a Precooler of smaller radius, but the momentum spread of the $\bar{p}$ beam would increase and would soon go beyond what is possible to cool.

\subsection{Overview of the System}

Accumulation of antiprotons in a small enough phase-space volume to be usefully accelerated requires beam cooling. The system designed and described here makes use of both electron cooling and stochastic cooling in the energy and intensity ranges for which they are best suited, electron cooling at low energy and higher intensity both longitudinally and transversely, stochastic cooling longitudinally and at higher energy. and low intensity.

Protons are accelerated to $80 \mathrm{GeV}$ in the Main Ring in the time-honored fashion and the ring is flat-topped. The $80-G e V$ proton beam is extracted sequentially at F17 in Booster-length batches at $100-\mathrm{msec}$ intervals, while the remalning batches circulate in the Main Ring. Each extracted batch is transported to the Antiproton Target Hall and targeted. Antiprotons of 4.5-GeV kinetic energy are collected and focused by a lithium lens 
and transported to the Precooler, a storage ring of Booster length ( 75.47 m average radius) to be built on a presently unoccupied site next to the Main Ring, as shown in Fig. 1-1. Each batch of beam is rotated in phase space to reduce its momentum spread and stacked with the previous antiproton batches. Depletion of the target by shock heating during the pulse limits the combination of intensity, pulse length, and spot size on the target. We have therefore split up the Main Ring pulse into batches of smaller length to preserve the target. The proton and antiproton beams will also be scanned approximately $0.5 \mathrm{~mm}$ across the target during the pulse to spread the heating. This will make possible a smaller proton beam spot size. Within the limits imposed by target integrity, it is estimated that approximately $1.6 \times 10^{7}$ antiprotons per Main Ring pulse can be collected and stacked in the Precooler within a total relative momentum spread of $2 \%$ and transverse emittances of $5 \pi \mathrm{mm}$-mrad in each plane.

The batch is now taken through a sequence of longitudinal stochastic cooling and deceleration steps. Each cooling step is continued until the cooling rate slows significantly because of bad mixing, then decelerated to re-establish mixing. After three such steps, the $\bar{p}$ batch is at $200 \mathrm{MeV}$ with a total relative momentum spread of $0.55 \%$ and transverse emittances of $40 \pi \mathrm{mm}-\mathrm{mrad}$ from adiabatic antidamping during deceleration. At this point, the batch is transferred into the Electron Cooling Accumulator, a smaller ring ( $32.35 \mathrm{~m}$ average radius) to be located south of the Precooler as show in Fig. 1-1. This ring will be built in a new tunnel using magnets and other components taken from the present Electron Cooling Ring.

In the Electron Cooling Accumulator, the $\bar{p}$ batch will be injected, cooled both longitudinally and transversely by an electron cooling system, then accumulated with other $\bar{p}$ batches in a stack and cooled continually by the electron system. The cycle time for each batch is $9.85 \mathrm{sec}$ and we therefore expect to accumulate $10^{11}$ antiprotons in 18 hours. The stack will have a total relative momentum spread of $0.1 \%$ and an emittance of $1 \pi$ $\mathrm{mm}-\mathrm{mrad}$ in each plane.

After accumulation has been completed, the antiprotons will be sequentially unstacked in 3 bunches. Each bunch is sequentially transferred to the Precooler and accelerated to 8 $\mathrm{GeV}$, transferred to the Main Ring in the atypical (counterclockwise) direction, accelerated to $150 \mathrm{GeV}$, then transferred to the Tevatron. Protons will have been previously injected and accelerated to $150 \mathrm{GeV}$ in the clockwise direction, then coalesced into three bunches and transferred to the Tevatron. After all three $\bar{p}$ bunches are stored in the Tevatron, the $\bar{p}$ and $p$ bunches are accelerated together to $1 \mathrm{TeV}$ for colliding-beams experiments. The luminosity goal of $10^{30} / \mathrm{cm}^{2}-\mathrm{sec}$ will be reached in 23 hours of accumulation. We will shorten this time by electron cooling at $400 \mathrm{MeV}$, rather than $200 \mathrm{MeV}$. 
It should be noted that there is a large amount of flexibility possible in this system. The Electron Accumulator Ring will hold antiprotons up to $1 \mathrm{GeV}$ in energy and it is possible to vary the cooling steps within wide limits to optimize the process. It is also possible to use the same rings in different electron and stochastic cooling scenarios. 


\section{General Scenario}

\subsection{Introduction}

In this chapter, we give for reference a sequential listing of the scenario of antiproton accumulation and comment on possible variations.

\subsection{Scenario Listing}

(i) Proton Acceleration in Main Ring
Proton energy
No. of protons
$80 \mathrm{GeV}$
Total no. of occupied buckets
$2.6 \times 10^{13}$
Harmonic no.
975
1113
Flat-top length
$1.3 \mathrm{sec}$
Total cycle time
$9.85 \mathrm{sec}$

(1i) Proton Beam Extraction and Transport

Septum location

No. of sequential batches

Batch interval

No. of bunches per batch

No. of protons per batch

Extraction style

Transport to target

F17

13

$100 \mathrm{msec}$

75

$2 \times 10^{12}$

Single-batch

18 EPB dipoles

11 quadrupoles

\section{(111) Targeting \\ Target \\ Target length \\ Target diameter}

Projected rms spot size

$\overline{\mathbf{p}}$ momentum

(protons)

Tungsten-rhenium

$5 \mathrm{~cm}$

$8 \mathrm{~cm}$, rotating

at $47 \mathrm{rpm}$

$0.22 \mathrm{~mm}$

$\bar{p}$ kinetic energy

$\bar{p}$ momentum spread (full)

$\overline{\mathrm{p}}$ emittance (each plane)

$\overline{\mathbf{p}}$ bunch area

Invariant $\bar{p}$ cross section per nucleus

$5.3567 \mathrm{GeV} / \mathrm{C}$

$4.5 \mathrm{GeV}$

$1 \%$

$5 \pi \mathrm{mm} \mathrm{mrad}$

$0.15 \mathrm{eV}-\mathrm{sec}$

$0.0206 / \mathrm{GeV}^{2}-\mathrm{W}$ nucleus

Proton absorption length

$9.86 \mathrm{~cm}$

$\bar{p}$ absorption length

Yleld N $\bar{p} / \mathrm{Np}$

(Includes $\mathrm{LI}$ lens loss)

Total $\bar{p}$ per MR cycle

$9.09 \mathrm{~cm}$

$0.6 \times 10^{-6}$

Accumulation rate

$1.56 \times 10^{7}$

$5.7 \times 10^{9} \overline{\mathrm{p}} / \mathrm{hr}$ 
(iv) RF Rotation in Precooler

\begin{tabular}{|c|c|}
\hline $\begin{array}{l}\text { Initial rms bunch length } \\
\text { Harmonic number }\end{array}$ & $\begin{array}{l}21 \mathrm{~cm} \\
84\end{array}$ \\
\hline $\mathrm{RF}$ capture voltage at $53 \mathrm{MHz}$ & $400 \mathrm{kV}$ \\
\hline Phase-oscilla & $367 \mu \mathrm{sec}$ \\
\hline $\begin{array}{l}\text { Phase-space rotation time } \\
\text { Momentum displacement in }\end{array}$ & 91 usec \\
\hline Energy cha & \\
\hline $\begin{array}{l}\text { Stacl } \\
\text { Fina] } \\
\text { Tota] }\end{array}$ & $\begin{array}{c}85 \mathrm{msec} \\
2.16 \% \\
1.56 \times 10^{7}\end{array}$ \\
\hline
\end{tabular}

(v) Stochastic Momentum Cooling and Deceleration

(a) Cooling step 1

$\begin{array}{ll}\text { Energy } & 4.5 \mathrm{GeV} \\ \text { Initial momentum spread } & 2.1 \% \\ \text { Final momentum spread } & 0.28 \% \\ \text { Cooling time } & 4.5 \mathrm{sec}\end{array}$

(b) Deceleration 1

$\begin{array}{ll}\text { Initial eñergy } & 4.5 \mathrm{GeV} \\ \text { Harmonic number } & 9 \\ \text { Peak rf voltage } & 84.4 \mathrm{kV} \\ \text { Final energy } & 2.4 \mathrm{GeV} \\ \text { Deceleration time } & 0.54 \mathrm{sec}\end{array}$

(c) Cooling step 2

Energy

$2.4 \mathrm{GeV}$

Initial momentum spread

$0.5 \%$

Final

$0.13 \%$

Cooling time

$1.25 \mathrm{sec}$

(d) Deceleration 2

Initial energy

Harmonic number

$2.4 \mathrm{GeV}$

Peak rf voltage

10

Final energy

$45.5 \mathrm{kV}$

$0.9 \mathrm{GeV}$

Deceleration time

$0.435 \mathrm{sec}$

(e) Cooling step $\underline{3}$

Energy

$0.85 \mathrm{GeV}$

Initial momentum spread

$0.28 \%$

Final momentum spread . $\quad 0.046 \%$

Cooling time

$0.75 \mathrm{sec}$

(f) Deceleration 3

Initial energy

Harmonic number

Peak of voltage

Final energy

Deceleration time

$0.85 \mathrm{GeV}$

14

$11.8 \mathrm{kV}$

$0.204 \mathrm{GeV}$

$0.4 \mathrm{sec}$ 
(g) 200-MeV bunching

$\begin{array}{ll}\text { Harmonic number } & 1 \\ \text { RF voltage } & 4 \mathrm{kV} \\ \text { Final momentum spread } & 0.44 \% \\ \text { Elnal bunch length } & 1.0 \mu \mathrm{sec} \\ \text { Bunching time } & 5 \mathrm{msec} \\ \text { cle time } & 9.85 \mathrm{sec}\end{array}$

Total cycle time

(v1) Electron Cooling and Accumulation

Kinetic energy

Initial momentum spread

Initial emittance (each plane)

Precooling

Final momentum spread

Final emittance

Cooling time
$0.2 \mathrm{GeV}$

$0.44 \%$

$40 \pi \mathrm{mm}-\operatorname{mrad}$

$0.1 \%$

$1 \pi \mathrm{mm}-\mathrm{mrad}$

$2 \mathrm{sec}$

Stack is cooled between precoolings to maintain $\Delta \mathrm{p} / \mathrm{p}=10^{-3}$ and emittances of $1 \pi \mathrm{mm}-\mathrm{mrad}$ $\overline{\mathrm{p}}$ per cycle $\quad 1.56 \times 10^{7}$ Total accumulation time $23 \mathrm{hr}$ time for $L=10^{30} / \mathrm{cm}^{2}-\mathrm{sec}$

(vii) Reacceleration

Number of $\bar{p}$ bunches 3

Method of rebunching

Precooler acceleration time

Harmonic number

Frequency range
3

RF unstacking

$1 \mathrm{sec}$

14

5.01-8.80 MHz

The 3 bunches are individually recooled, accelerated to 8 GeV, transferred to the Main Ring, accelerated to $150 \mathrm{GeV}$ and injected into the Tevatron. Protons have previously been accelerated, rebunched, and stored in the Tevatron.

(viii) Colliding Scenario

Number of $\bar{p}$ bunches

Number of $p$ bunches

Number of $\bar{p}$ per bunch

Number of $p$ per bunch

$B^{*}$

RMS $\bar{p}$ beam size

3

RMS $\mathrm{p}$ beam size

Luminosity per intersection

region

$4 \times 10^{10}$

$10^{11}$

$2 \mathrm{~m}$

$<0.1 \mathrm{~mm}$

$0.1 \mathrm{~mm}$

Luminosity lifetime

RMS bunch length $(\bar{p})$

RMS bunch length (p)

$10^{30} / \mathrm{cm}^{2}-\mathrm{sec}$

several days

$<45 \mathrm{~cm}$

$45 \mathrm{~cm}$

Beam-beam tune shift

0.003 


\subsection{Other Scenarios}

There is a great deal of inherent flexibility in the design discussed in this report. It is believed that this is a considerable advantage of the design, because knowledge of beam cooling is expanding rapidly, both theoretically and experimentally.

This flexibility can be used in other cooling schemes with the same equipment. One such scheme that has been investigated would inject antiprotons into the Precooler, stack them, and cool the stack by stochastic cooling without precooling or deceleration. The performance of this scheme is limited because the stochastic cooling rate decreases as the number of antiprotons in the stack increases. Estimates show that the cooling rate becomes unmanageably long when the number of antiprotons accumulated is of the order of $3 \times 10^{9}$, with a collection time of the order of 1 hour. Such a beam will give a luminosity of approximately $2 \times 10^{28} / \mathrm{cm}^{2} \mathrm{sec}$, which can be valuable for initial exploratory experiments. Higher-luminosity all-stochastic schemes would require a separate Accumulator ring.

It is also possible to vary the energy of electron cooling and accumulation. It is believed that $400 \mathrm{MeV} \overline{\mathrm{p}}$ energy may be a practical upper limit without extensive electron-gun development; the Electron Accumulator Ring can store antiprotons up to $1 \mathrm{GeV}$. If development of a 550-keV electron gun (corresponding to $1-\mathrm{GeV}$ antiprotons) appears feasible, the present rings will be adequate for this higher-energy cooling. 


\section{Targeting and Transport}

\subsection{Main Ring Extraction}

Extraction of $80 \mathrm{GeV}$ protons from the Main Ring for the production of antiprotons is to take place at location F17. At this location, a Lambertson magnet will deflect the extracted beam vertically towards the transport line, located imediately above the Main Ring magnets.

The geometry and expected beam sizes at the Lambertson location are shown in Fig. 3-1. The relevant parameters of the Main Ring Lattice are listed in Table 3-I.

TABLE 3-I PROPERTIES OF SELECTED MAIN RING MINISTRAIGHTS

Radial Plane Lattice Functions

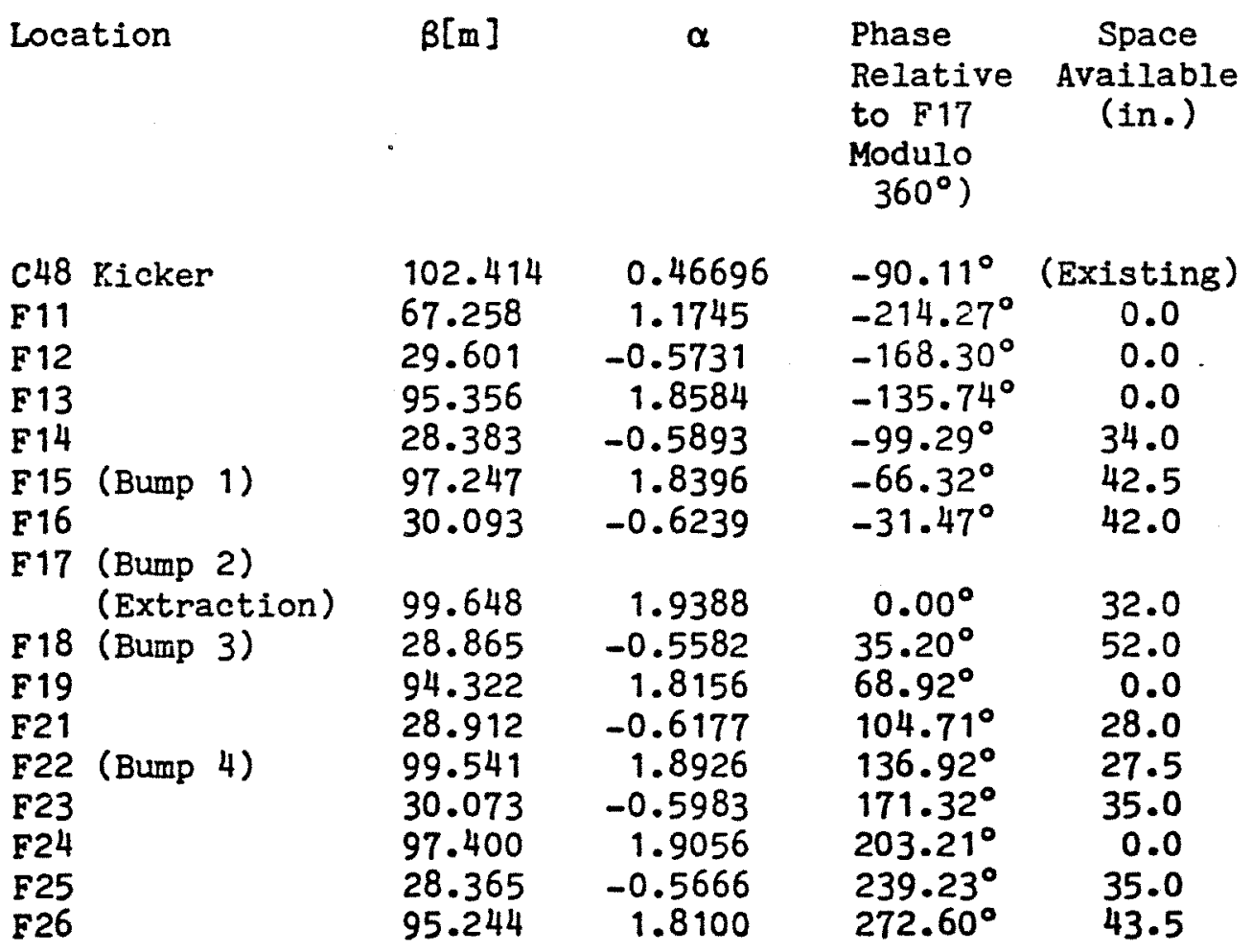




\section{F 17 LAMBERTSON}

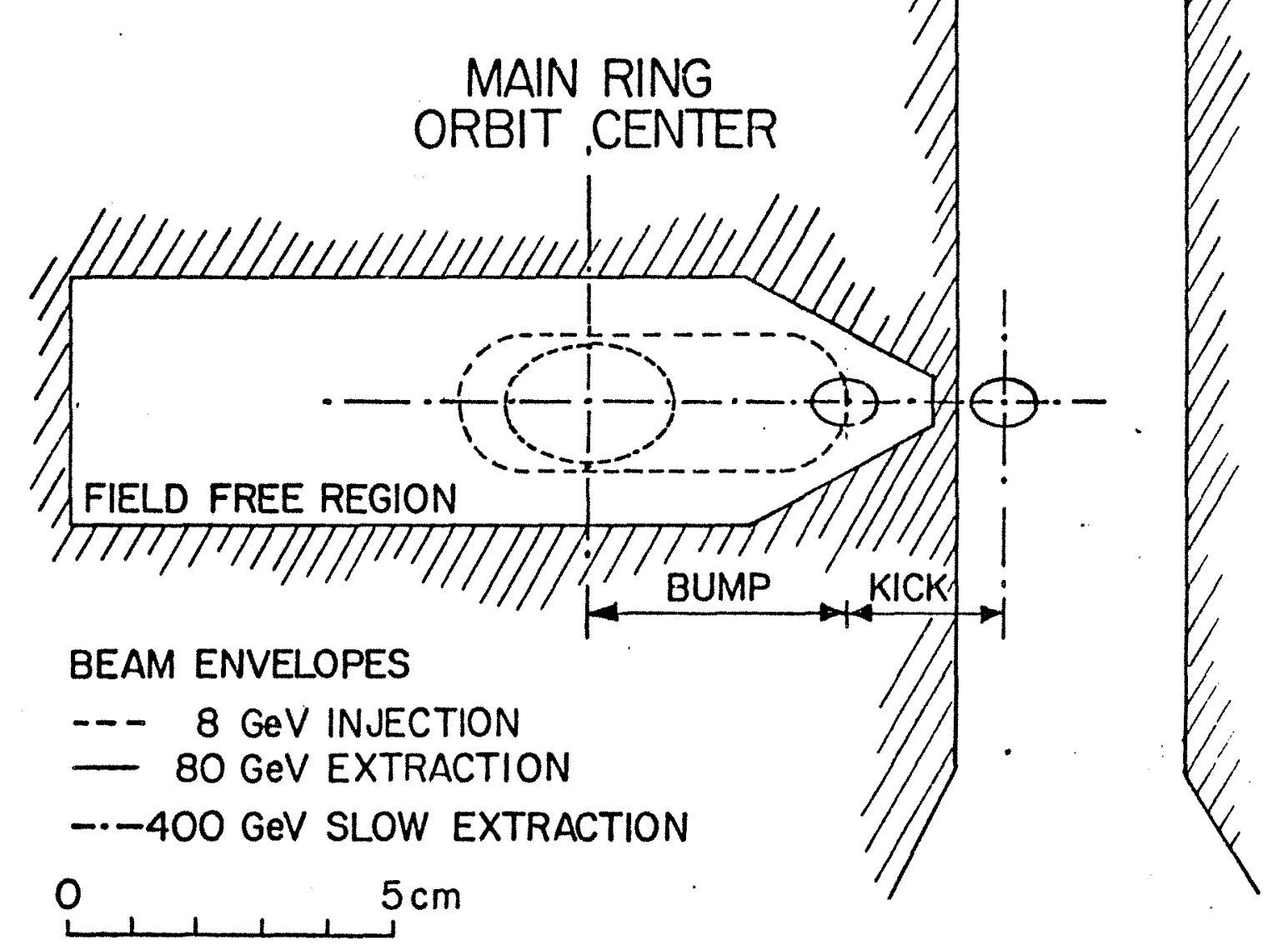

Fig. 3-1 Main Ring Extraction Geometry 
The existing kicker at location $\mathrm{C} 48$ will be utilized to provide the necessary horizontal displacement of approximately 25 $\mathrm{mm}$ to jump the Lambertson septum. The present kicker power supply is designed for single-turn Main Ring extraction. A simple modification is required to shorten this pulse to extract $1 / 13$ of the Main Ring circumference at a time, a batch $1.6 \mu \mathrm{sec}$ long. The required angular kick at $\mathrm{C} 48$ is $-0.238 \mathrm{mrad}$ or a voltage at the supply of $21.0 \mathrm{kV}$, well within the present operating range. Given the Main Ring lattice characteristics, the displacement at $\mathbf{F 1 7}$ will result also in an angular displacement of $0.467 \mathrm{mrad}$.

In order to compensate for the angle resulting from the kick across the septum and to have flexibility in the location of the Main Ring beam with respect to the $F 17$ Lambertson during $8-\mathrm{GeV}$ injection prior to $80-\mathrm{GeV}$ extraction, and to allow for room during 400-GeV extraction (see Fig. 3-1) we have designed a local 4-magnet slow orbit bump to be installed at locations F15, F17, F18 and F22. This 4-magnet combination will permit independent adjustment of the beam position and angle at F17. For the. configuration of $-38 \mathrm{~mm}$ displacement and compensation for the angle resulting from the $\mathrm{C} 48 \mathrm{kick}(-25 \mathrm{~mm}$ at $\mathrm{F} 17)$ the required angular kicks and magnets bending power are indicated in Table 3-II. The required apertures in Main Ring have been measured during machine studies.

TABLE 3-II FOUR-MAGNET ORBIT-BUMP PARAMETERS

$\begin{array}{lcc}\text { MR Location } & \text { Bump angle (mrad) } & \text { Bend strength (kG-m) } \\ \text { F15 } & -.42 & -1.134 \\ \text { F17 } & -1.04 & -2.808 \\ \text { F18 } & +1.04 & +2.808 \\ \text { F22 } & -1.03 & -2.781\end{array}$

The configuration described here will permit the two following modes of operation:

(1) Dedicated 80-GeV running: The Main Ring will operate on a $80-\mathrm{GeV}$ ramp. Allowance is to be made at F17 for $8-\mathrm{GeV}$ injection aperture. Only the desired number of Booster batches to be extracted towards the $\bar{p}$ target will be injected.

(11) Parasiting on 400-GeV operation: Probably only 1 Booster batch could be extracted towards the $\bar{p}$ target at 80 $\mathrm{GeV}$ for tests. Allowance is to be made at Fi7 for 8-GeV injection aperture and $400-\mathrm{GeV}$ extraction aperture requirements. 
The F17 Lambertson has been installed and operated in the wain Ring since January, 1981. It is equipped with remote positioning devices, beam monitors and loss monitors. Power supply, controls and electronics are located in service building I. Extraction studies are to take place during June and October 1981 to determine the best Lambertson location with respect to the center of the Main Ring orbit. Although the Lambertson can be Eoved away from the orbit, its location will remain fixed during 80-GeV extraction, due to the fixed location of the $80-\mathrm{GeV}$ transport line; the variations in operating modes will be accomodated by the four-magnet bump to position the Main Ring orbit with respect to the Lambertson septum.

Vertical extraction was chosen at F17 to minimize the angular deflection required to clear the first Main Ring magnet downstream of the Lambertson. The return coil on the upstream end of this aagnet has been modified to permit the extracted $80-\mathrm{GeV}$ beam pipe to be located close to the magnet steel. This space restriction iil limit the maximum energy that can be extracted at F17 to below $125 \mathrm{GeV}$. An upgrade to $125 \mathrm{GeV}$ would require a second Lambertson magnet and major modifications of the upstream end of the transport line described below.

\subsection{Proton Transport}

The layout of the $80-\mathrm{GeV}$ proton-beam transport is shown in Fig. 3-2. From the extraction point at F17, the line extends to location F25. The transport elements are located just above the Yain Ring magnets. At location F25, the $80-\mathrm{GeV}$ beam exits the Main Ring tunnel toward the pretarget area, $\bar{p} \mathrm{Hall}$, and the antiproton target area, $\overline{\mathrm{p}}$ Target Hall.

The transport line is assembled from External Proton Beam (EPB) type magnets. Two dipoles, V1 and V2, are utilized to set the beam horizontal ( 19.0 in. above the Main Ring orbit) following the extraction Lambertson. Thirteen dipoles are utilized to follow the Main Ring radius by distributing them uniformly between locations F18 and F23. Five dipoles are used to provide the reverse bend to exit the Main Ring tunnel at a convenient place in location F25. This last requirement forces the beam to the inside of the Main Ring between F23 and F25, reducing some of the tunnel free space. A small-diameter pipe connects the Main Ring tunnel to the upstream end of $\bar{p}$ Hall, where a remotely operated beam stop vill permit access to most of $\bar{p}$ Hall, and $\bar{p}$ Target Hall during Hain Ring operation.

The transport line includes eleven EPB quadrupoles with water-cooled coils upgraded to match the power supplies obtained to power them. Element Q7B is a type 5036 (ANL) quadrupole. The location of the elements in $\bar{p}$ Hall is shown in Fig. 3-3. 


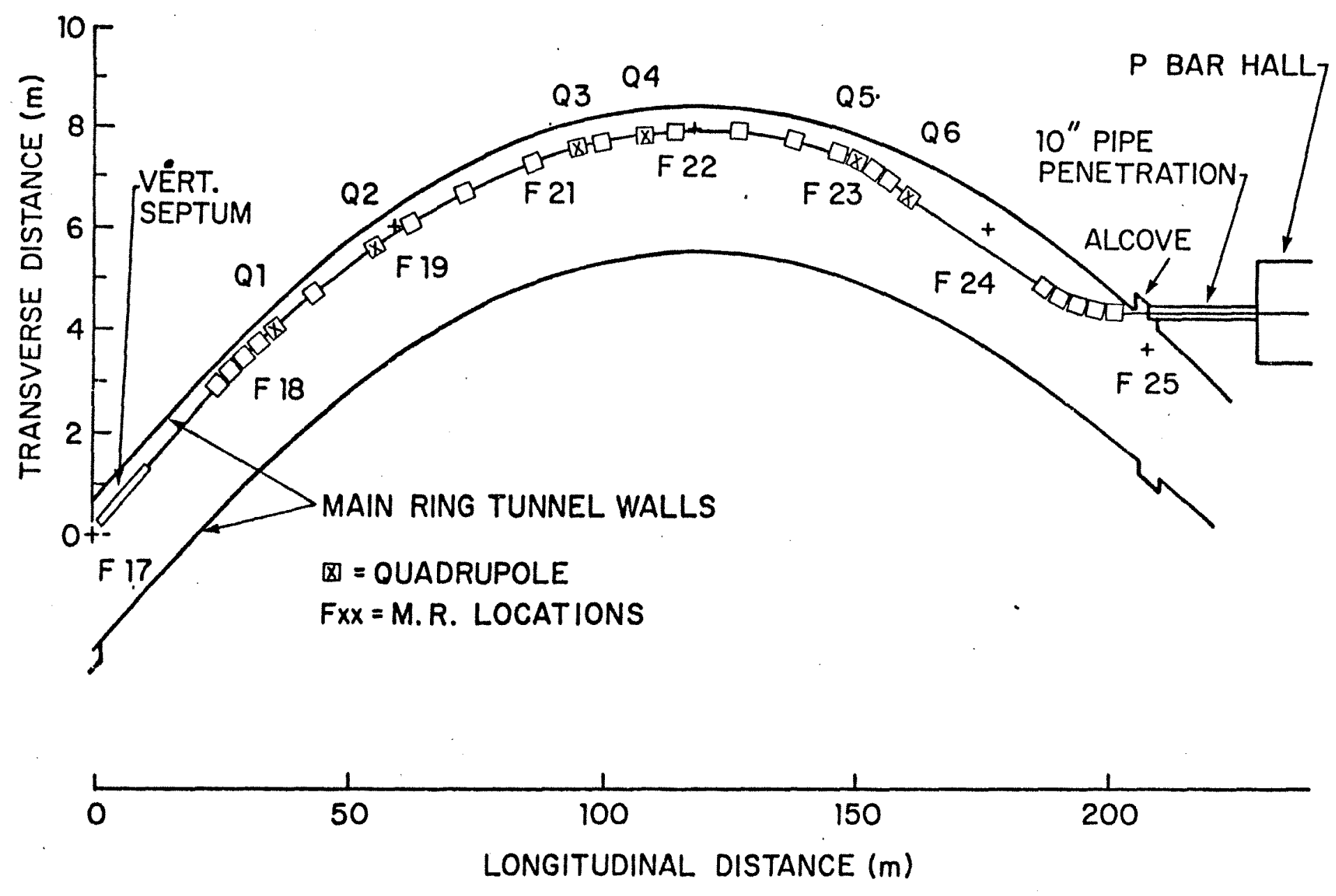

Fig. 3-2 EXTRACTED-PROTON BEAM-TRANSPORT LAYOUT 


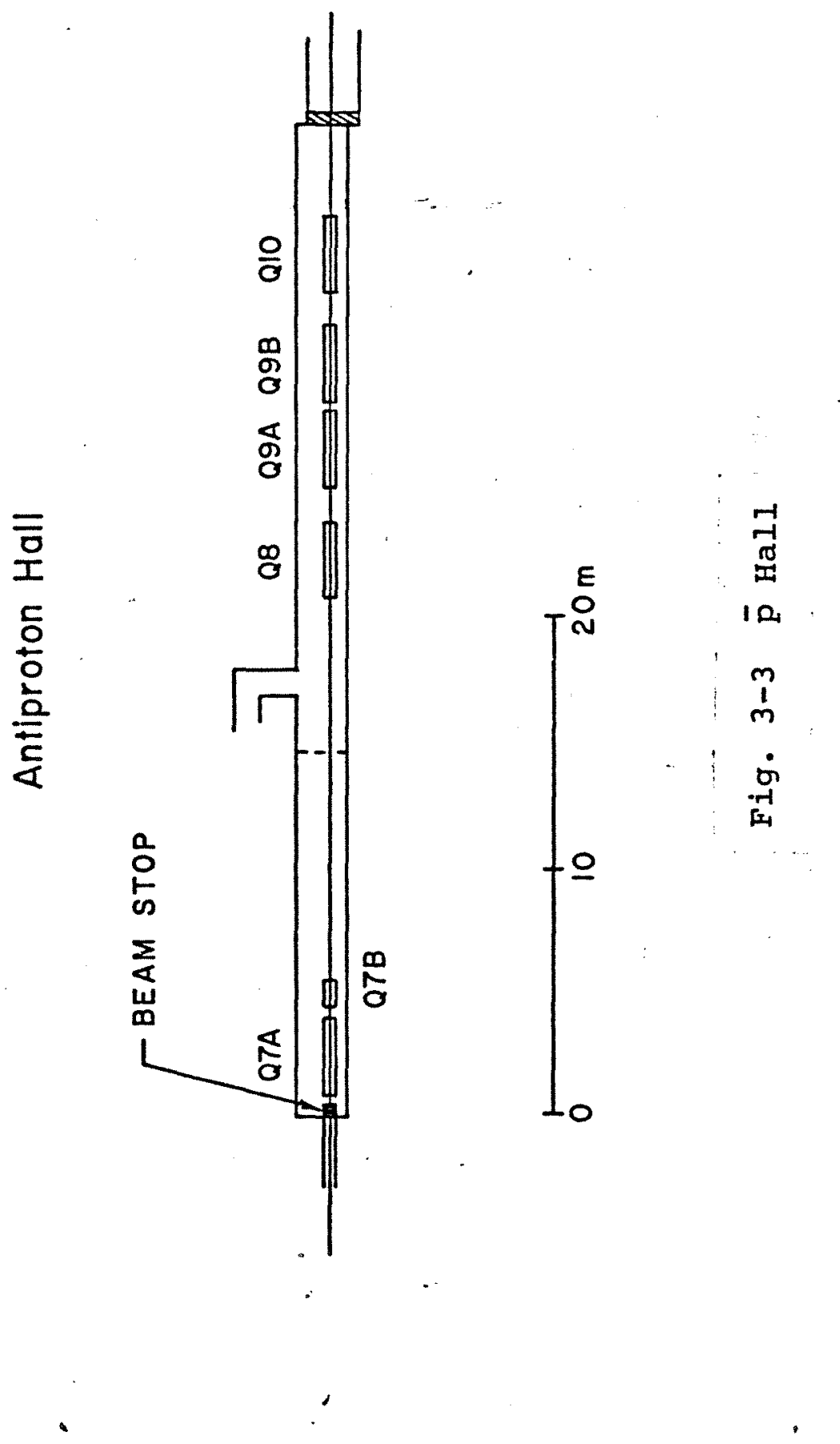


The detalls of the transport line are given in Table 3-III.

TABLE 3-III PROTON TRANSPORT LINE

\begin{tabular}{|c|c|c|c|c|}
\hline $\begin{array}{l}\text { Distance to } \\
\text { F17(inches) }\end{array}$ & Element & Type & $\begin{array}{l}\text { Field/Gradient } \\
(\mathrm{T}) /(\mathrm{T} / \mathrm{m})\end{array}$ & Bend \\
\hline 210 & Lambertson & & 1.083 & UP \\
\hline 916 & H1 & EPB & 1.272 & RIGHT \\
\hline 1048 & V1 & EPB & 0.920 & DOWN \\
\hline 1180 & v2 & EPB & 0.920 & DOWN \\
\hline 1312 & $\mathrm{H} 2$ & EPB & 1.272 & RIGHT \\
\hline 1444 & Q1 & $3 Q 120 A$ & -5.07 & \\
\hline 1706 & H3 & EPB & 1.272 & RIGHT \\
\hline 2126 & Q2 & 3Q120A & 5.07 & \\
\hline 2426 & $\mathrm{H} 4$ & EPB & 1.272 & RIGHT \\
\hline 2946 & $\mathrm{H} 5$ & EPB & 1.272 & RIGHT \\
\hline 3466 & $\mathrm{H} 6$ & EPB & 1.272 & RIGHT \\
\hline 3854 & Q3 & 3Q120A & -5.07 & \\
\hline 3986 & H7 & EPB & 1.272 & RIGHT \\
\hline 4246 & Q4 & $3 Q 120 A$ & 3.88 & \\
\hline 4506 & H8 & & 1.272 & RIGHT \\
\hline 5033 & H9 & EPB & 1.272 & RIGHT \\
\hline 5559 & $\mathrm{H} 10$ & EPB & 1.272 & RIGHT \\
\hline 5944 & H11 & EPB & 1.272 & RIGHT \\
\hline 6142 & Q5 & $30120 \mathrm{~A}$ & -3.88 & \\
\hline 6274 & $\mathrm{H} 12$ & EPB & 1.272 & RIGHT \\
\hline 6406 & H13 & EPB & 1.272 & RIGHT \\
\hline 6646 & Q6 & $30120 \mathrm{~A}$ & 3.88 & \\
\hline 7453 & $\mathrm{H} 14$ & EPB & 1.272 & LEFT \\
\hline 7585 & H15 & EPB & 1.272 & LEFT \\
\hline 7717 & H16 & EPB & 1.272 & LEFT \\
\hline 7849 & $\mathrm{H} 17$ & EPB & 1.272 & LEFT \\
\hline 7981 & H 18 & EPB & 1.272 & LEFT \\
\hline 9185 & Q7A & $3 Q 120 A$ & 15.20 & \\
\hline 9280 & Q7B & 5036 & 14.81 & \\
\hline 9968 & Q8 & 3Q120A & $-15 \cdot 20$ & \\
\hline 10142 & Q9A & $3 Q 120 A$ & 9.96 & \\
\hline 10274 & Q9B & $30120 A$ & 14.34 & \\
\hline 10448 & Q10 & $3 Q 120 A$ & -15.20 & \\
\hline 10688 & arget & & & \\
\hline
\end{tabular}

As shown, six quadrupoles in $\bar{p}$ Hall are utilized to produce the desired beam spot at the target. Alternative designs including a Lithium lens in the proton beam have also been considered. For the present requirements, the quadrupole solution suffices, because the minimum spot size at the target is expected to be limited by target ilfetime. 
One above-ground power-supply service bullding at location F23 houses power supplies, controls, instrumentation, vacuum and water for the section of transport line within the Main Ring tunnel. A second above-ground building at location F27 will provide services for the $\bar{p}$ Hall and $\bar{p}$ Target Hall enclosures.

Access to $\bar{p}$ Hall is by a hatch and labyrinth. Because of the limited amount of earth between the upstream end of the hall and the Main Ring tunnel, that end will not be accessible during Main Ring operation. The downstream end will be sealed by a $30 \mathrm{~cm}$ thick iron shield required to minimize soil exposure due to backward radiation from the target. Residual radiation levels in $\bar{p}$ Hall are expected to be low enough to permit maintenance in place.

Completion of the $80-\mathrm{GeV}$ beam transport line to F25 is expected by summer 1981, and to the target station by october, 1981.

3.2.1 $\overline{\mathrm{p}}$ Target Hall. The antiproton producing target, proton beam dump and antiproton collection system will be located in an existing vault downstream of $\bar{p} \mathrm{Hall}$ of dimensions $1.5 \mathrm{~m}$ wide and $40 \mathrm{~m}$ long. The floor is $6.4 \mathrm{~m}$ below ground with a beam elevation $1.2 \mathrm{~m}$ above it. An elevation view is shown in Fig. 3-4.

The upstream end of the hall, containing the target, vertical bend, and dump will be an area of high residual radiation and limited access. During normal operation of the $\bar{p}$ source, greater than $2 \times 10^{12}$ protons per second are to be incident on the target and dump. Shielding configurations, taking into account soil irradiation, outdoor dose rate and muon fluxes have been studied to permit operation with average intensities of up to $10^{13}$ protons per sec.

The target will be just downstream of the thick iron shield separating $\overline{\mathrm{p}}$ Target Hall from $\overline{\mathrm{p}} \mathrm{Hall}$. The target design and the $\overline{\mathrm{p}}$ collection system are described in detail below. As shown in Fig. 3-4, antiprotons are collected by a lithium lens before a vertical bend up (BV 1) of $6^{\circ}$ separates them from the $80-\mathrm{GeV}$ protons $\left(-0.4^{\circ}\right)$. A vertical translation by $2.485 \mathrm{~m}$, required to get to the level appropriate for Precooler injection, takes place within $\bar{p}$ Target $\mathrm{Hall}$. The antiprotons emerge from the LI Lens as a nearby parallel beam.

The proton beam dump will be made of steel, approximately $5 \mathrm{~m}$ long, 1.5 wide and of a helght to accomodate the antiproton transport line. It will contain a water-cooled graphite core capable of absorbing in excess of the $25 \mathrm{~kW}$ presently required. A closed loop water cooling system will be located in $\bar{p}$ Hall.

Access to the elements in the Target Hall is from above, possible within a structure, that will straddle the present roof hatch. As part of this structure an additional $1.8 \mathrm{~m}$ of shielding 


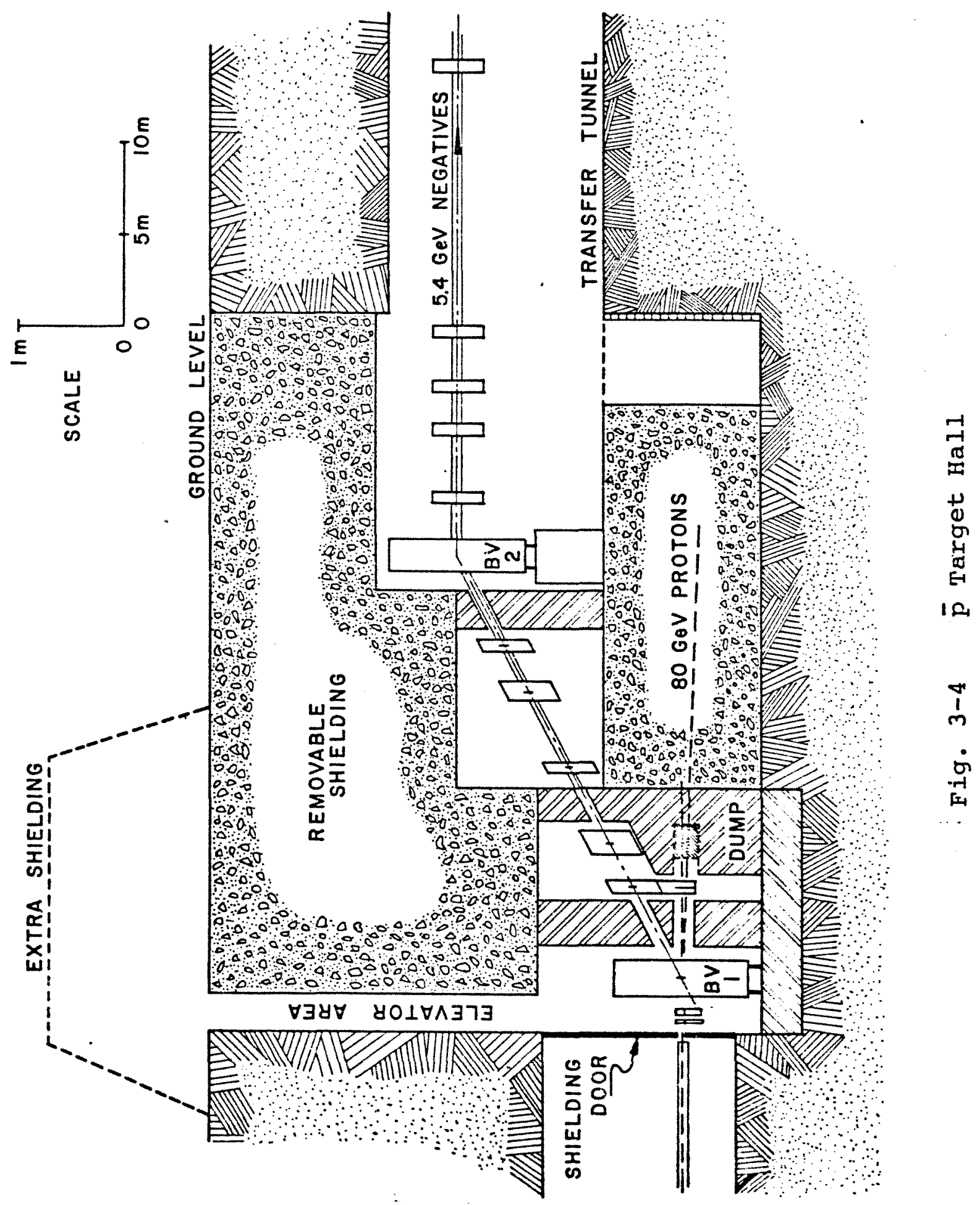


will be incorporated to keep the above-ground dosage level well below $50 \mathrm{mrem} / \mathrm{hour}$.

From the point of view of accessibility, we have identified two different regions within $\bar{p}$ Target Hall:

(1) Upstream of BV1: This area contains the target itself, the lithium lens, instrumentation to monitor target performance, target, lens remote-positioning mechanism and lens electrical devices. We expect the need of relatively frequent accesses, especially during the commissioning phases of the project. Elements are to be located within elevators that will include that section of the shielding directly above them. Services are to be through the shielding. In the down position, the elevator platform will rest on alignment pins on the floor. In the up position, the elevator will place the radioactive elements for remote transfer to shielded containers. These containers, with relatively light and small components, can then be transferred to the Neutrino area remote-handling facility for maintenance. Highly radioactive components can be stored within $\bar{p}$ Target Hall shielding for cooling.

(ii) Downstream and including BV1: This region contains only dipole and quadrupole magnets. Access is expected to be very infrequent both during and after commissioning. Access for maintenance will require the removal of shielding blocks and lifting of the beam-transport elements with a crane.

\section{3 $\overline{\mathrm{p}}$ Production Rate}

Several independent calculations exist that estimate the number of antiprotons to be captured within a given precooler acceptance. These calculations have been extended with a Monte Carlo program that includes a fit to available data on antiproton production cross sections, hadronic shower development in the target, multiple scattering, absorption and a lithium lens collector. The result of these calculations are summarized in Table 3-IV.

TABLE 3-IV PARAMETERS FOR ANTIPROTON FLUXES INTO PRECOOLLER ACCEPTANCE

\author{
Precooler acceptance (each plane) \\ Proton beam momentum \\ Proton beam B: \\ Proton beam size \\ Antiproton momentum \\ Target material \\ Target length
}

\author{
$5 \pi \mathrm{mm}-\mathrm{mrad}$ \\ $80 \mathrm{GeV} / \mathrm{c}$ \\ $1 \mathrm{~m}$ \\ $\sigma x=\sigma y=0.02 \mathrm{~cm}$ \\ $5.39 \mathrm{GeV} / \mathrm{c}$ \\ Tungsten \\ $5 \mathrm{~cm}$
}




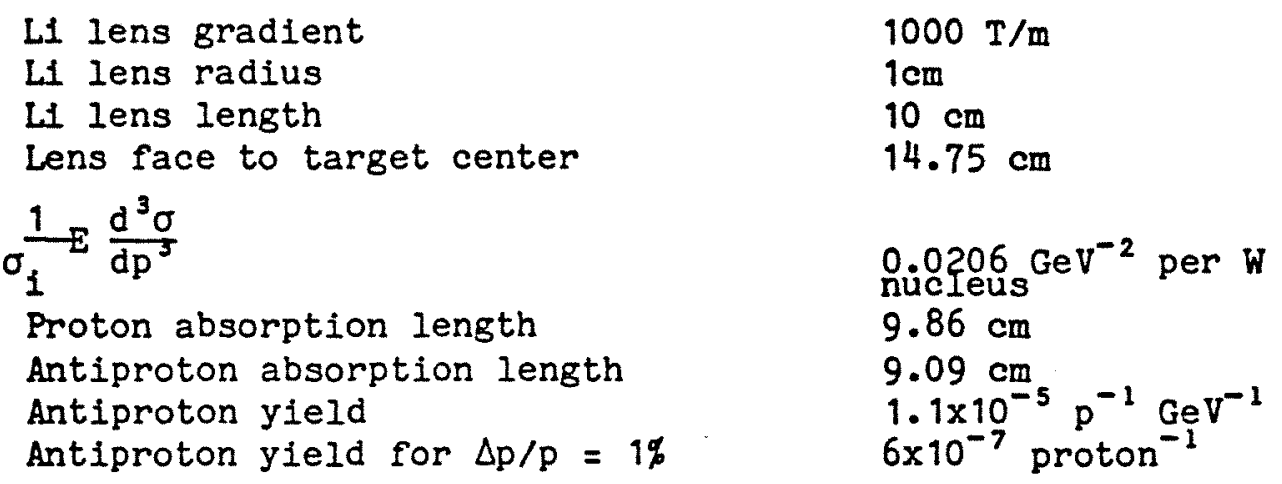

- The antiproton yield increases with decreasing proton beam size. The choice of $\sigma=0.02 \mathrm{~cm}$ is based on the limiting behaviour of the target due to the energy density deposited (see below).

The choice of a 5-cm long high-density target (tungsten) is dictated by a 20\% increase in antiproton yield of shower development vs the depth of field effect due to the very short focal distance of the lithium lens.

The antiproton yield increases with increasing $\mathrm{Li}$ lens gradient. An increase of $5 \%$ to $10 \%$ could be achieved by increasing this gradient. The choice of $1000 \mathrm{~T} / \mathrm{m}$ permits a reasonable distance between the target and the lens.

A reduction on the lithium lens radius from $1 \mathrm{~cm}$ to $0.25 \mathrm{~cm}$ will result in a $20 \%$ decrease of yield for a $5 \pi \times 10^{-6} \mathrm{~m}$ acceptance.

The yield in Table 3-IV corresponds to an invariant cross section per inelastic interaction of $s 0.66 \mathrm{mb} \mathrm{GeV}{ }^{-2}$ other estimates of antiproton yields have been previously based on 0.80 $\mathrm{mb} / \mathrm{GeV}^{-2}$. This difference reflects the uncertainties in the production cross sections, including the dependence on the target nucleus and the scaling variable $x$. 


\subsection{Antiproton Target}

The yield of antiprotons into a given precooler acceptance increases as the proton beam spot decreases, until multiple scattering in the target material starts to contribute to beam-size growth. Smaller proton beam sizes will result in increasing energy density deposition in the target material. A compromise must be made between the brightness of the antiproton beam and the expected lifetime of the target itself.

3.4.1 Material Choice. With the requirements that the target material be of high density and high melting point a compilation of mechanical properties for different materials was performed. A figure of merit to compare the mechanical properties was obtained from the yield stress divided by the coefficient of thermal expansion and the modulus of elasticity. On this basis rhenium, tungsten and tungsten-rhenium alloys are in increasing order for this figure of merit. The coefficient of heat conductivity could also be included in the figure of merit without significant altering the choice of material.

The high-temperature behavior of tungsten-rhenium alloys shows considerable increase of yield stresses with respect to tungsten, but little change on the coefficient of thermal expansion or the modulus of elasticity.

Tungsten-rhenium alloys are utilized in industry for high-temperature applications (e.g. incandescent-lamp wire and targets for high-power $\mathrm{x}$-ray tubes) and a significant amount of experience and technology for their fabrication exist. other tungsten and/or rhenium alloys exhibit interesting mechanical properties. Tungsten will be used for the following calculation, although a number of target configurations are to be tested during the $R$ \& $D$ phase of the target-station development.

3.4.2 Energy Deposition. The energy deposition in tungsten was calculated using the computer code CASIM. The total energy deposited per proton vs target length is shown in Fig. 3-5.

The energy density deposited vs radius for Gaussian beams, is shown for $\sigma_{x}=\sigma_{y}=0.02 \mathrm{~cm}$ in Fig. 3-6, $0.03 \mathrm{~cm}$ in Fig. 3-7, and $0.04 \mathrm{~cm}$ in $\mathrm{F}^{\mathrm{x}} \mathrm{g}$. 3-8. The radial distribution is wider on the downstream face of the target due to the shower development. Also shown is the energy density expressed in (Joules $\mathrm{gm}^{-1}$ pulse ${ }^{-1}$ ) for $2 \times 10^{12}$ protons per pulse, to be compared with the integral of the enthalpy reserve for tungsten. This quantity, the integral of the heat capacity from $20^{\circ} \mathrm{C}$ to a given temperature, is shown in F1g. 3-9. A summary of this data is presented in Table 3-V. 


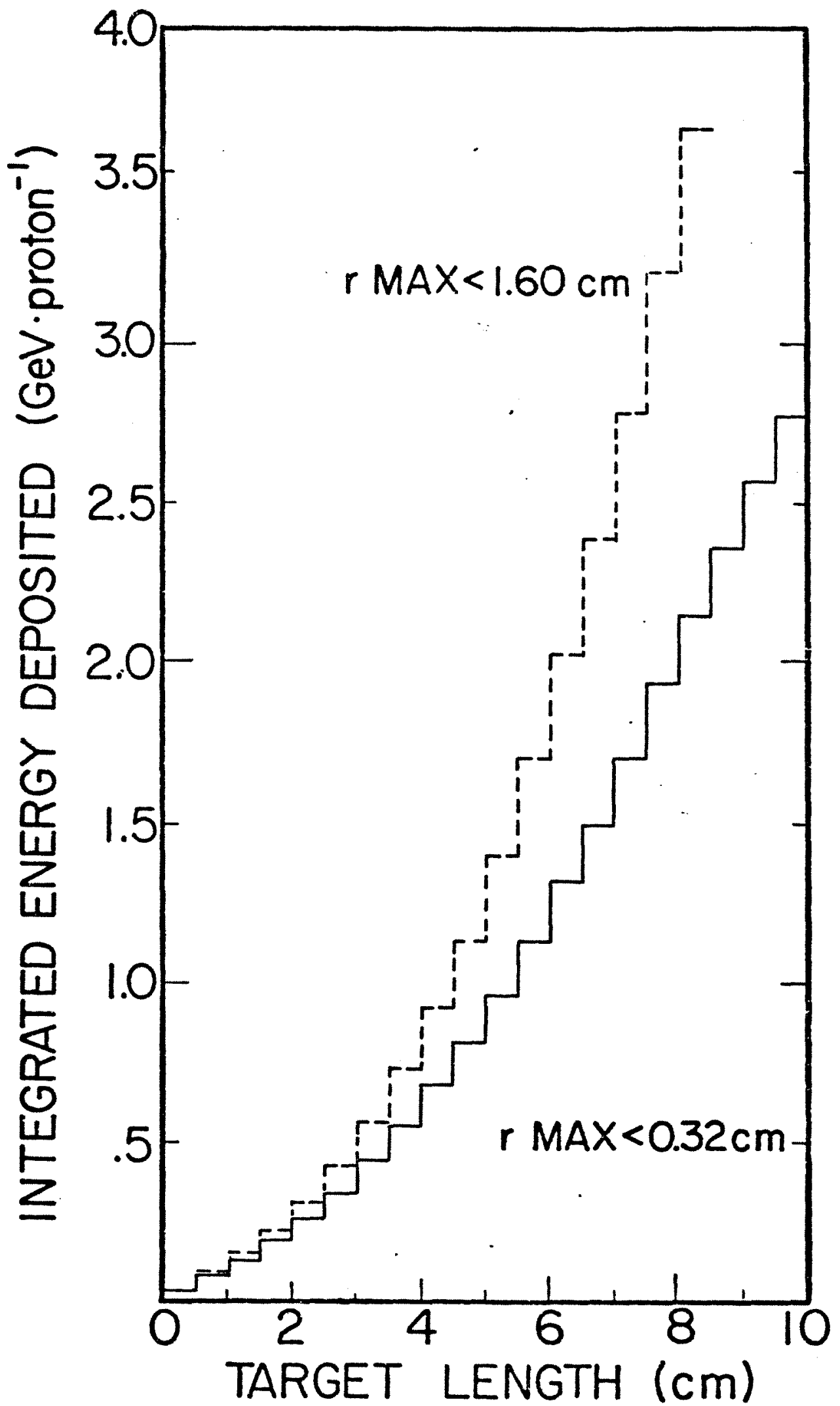

Fig. 3-5 Energy Deposition by Protons vs Target Length 


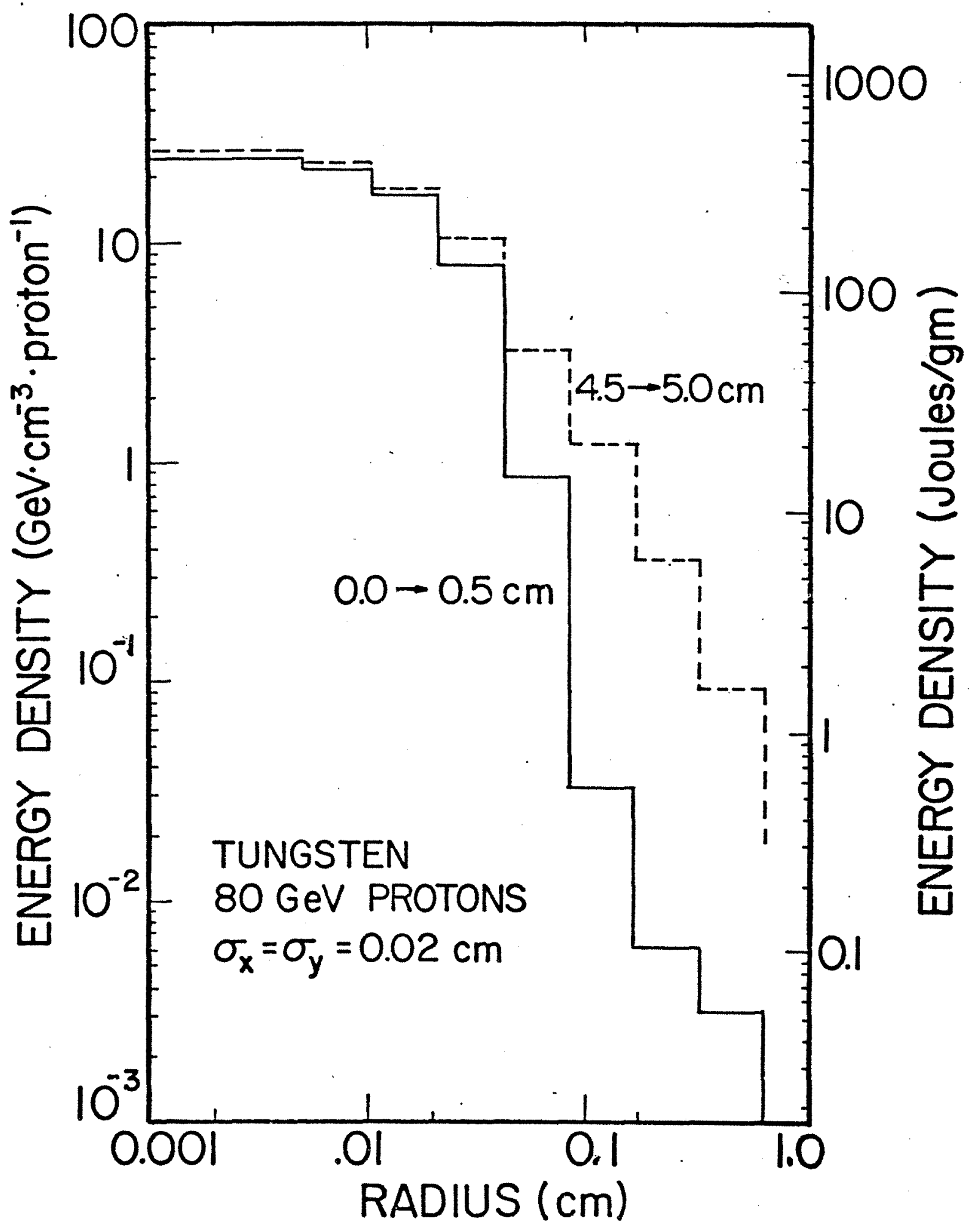

Fig. 3-6 Energy Deposition by Protons vs Radius; $\sigma=0.2 \mathrm{~mm}$ 


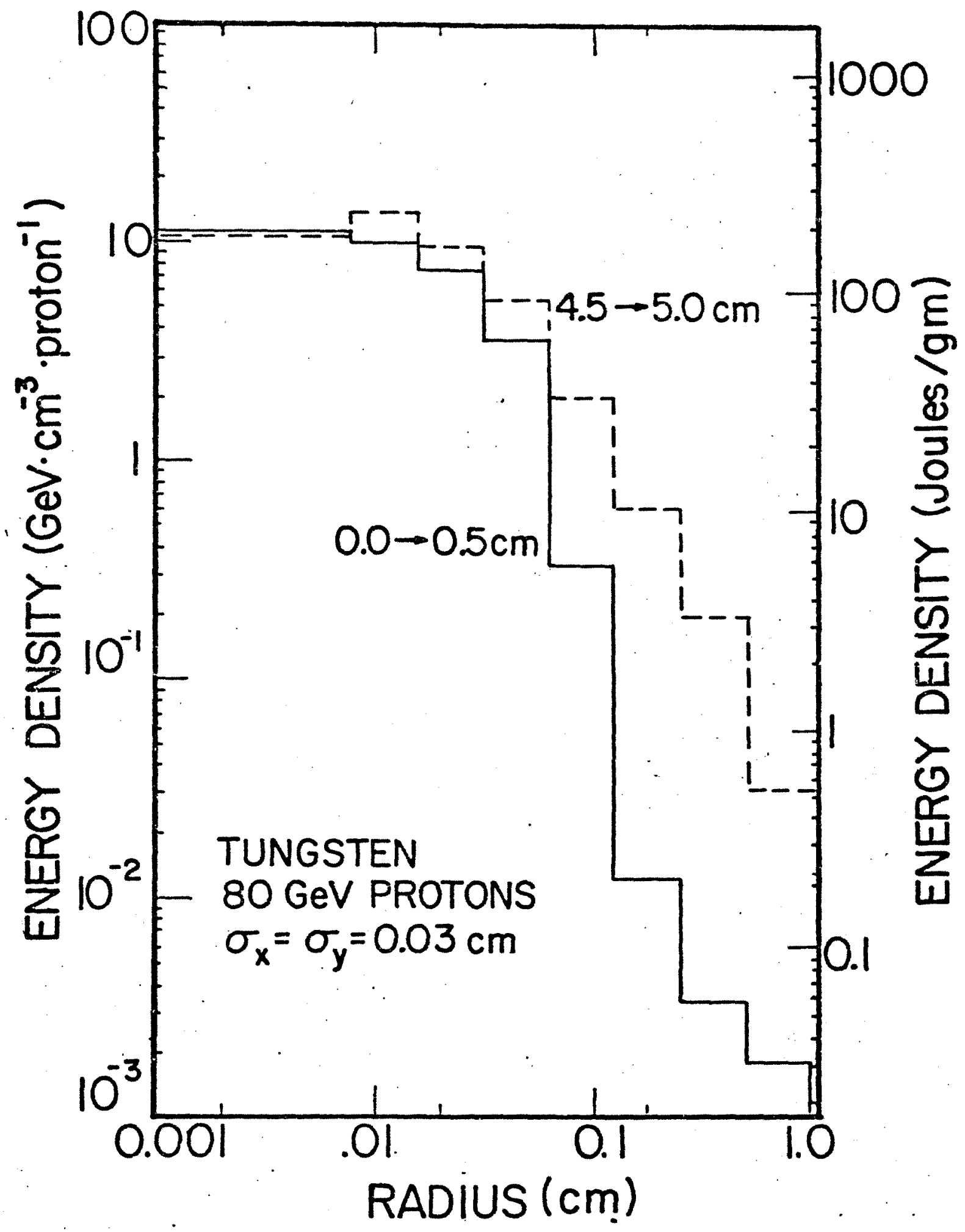

Fig. 3-7 Energy Deposition by Protons vs Radius; $\sigma=0.3 \mathrm{~mm}$ 


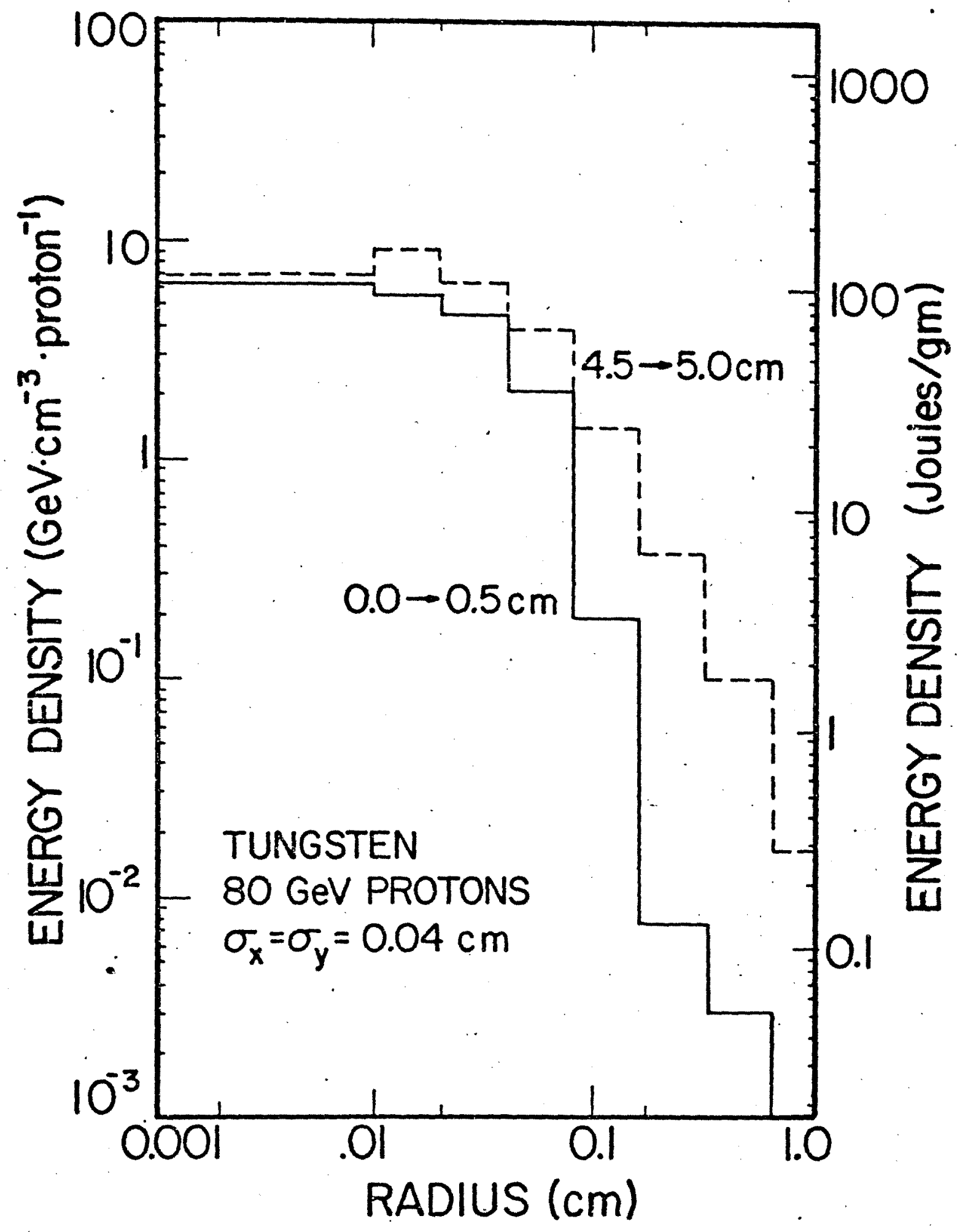

Fig. 3-8 Energy Deposition by Protons vs Radius; $\sigma=0.4 \mathrm{~mm}$ 


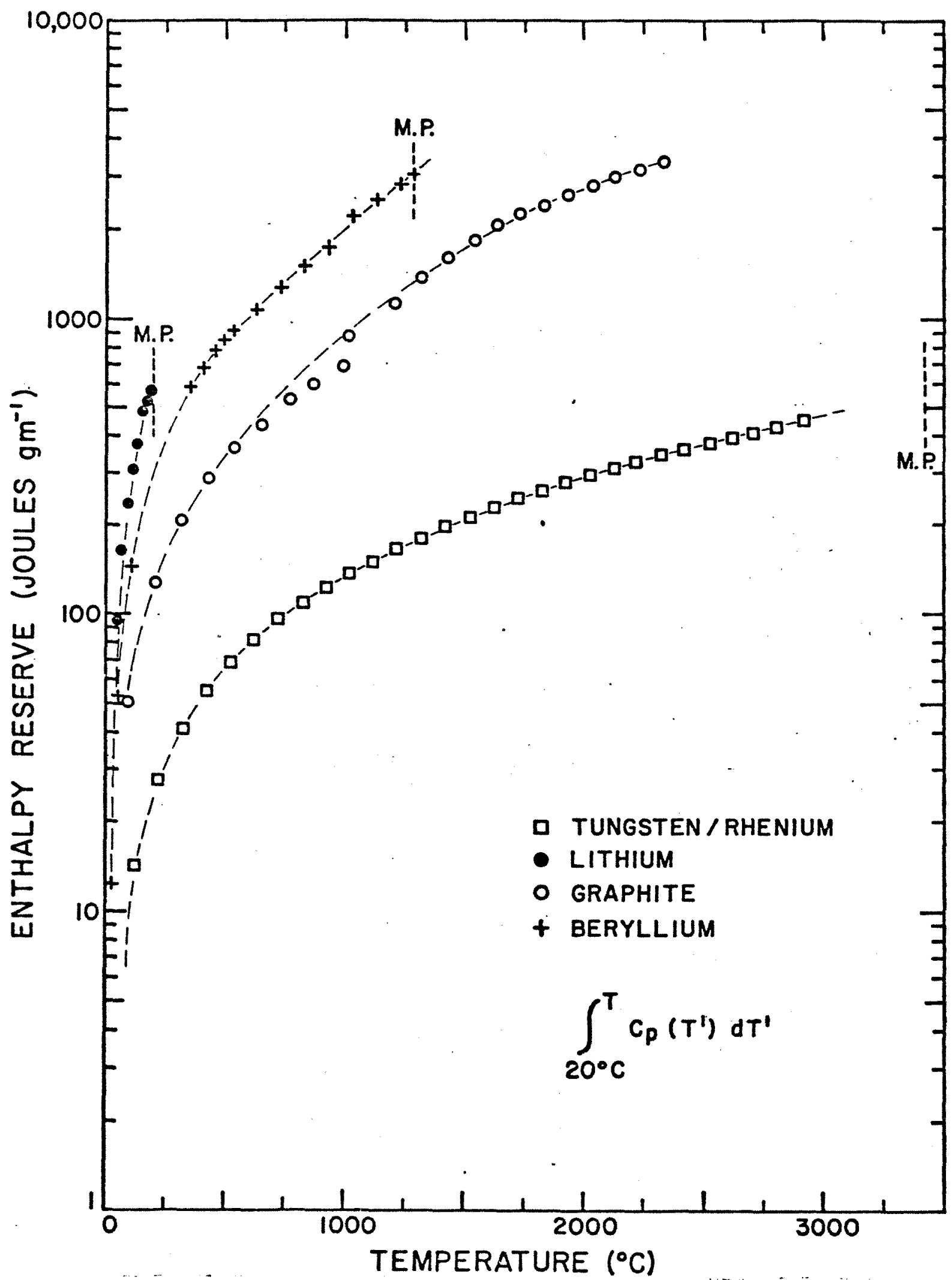

Fig. 3-9 Enthalpy Reserve for Several Materials 
TABLE 3-V ENERGY DEPOSITION IN TARGET

Target Material

Length

$80 \mathrm{GeV}$ protons/pulse

Total Beam Energy

Pulses/Burst

Burst Interval

Beam Pulse Duration

Emergy Deposited/proton

Energy Deposited/pulse

Energy Deposited/burst

Average Energy Deposited

Average Temperature

$\mathrm{dE} / \mathrm{dx}$

Beam Size $(\sigma x=\sigma y)$

Peak Energy Density/proton

Peak Energy Density/pulse

Peak Temperature rise

CERN Peak Energy Density

Peak Temperature rise

Average Temperature

SLAC Peak Energy Density

Peak Temperature rise

Average Temperature
Tungsten/Tungsten Alloys

$5 \mathrm{~cm}$

$2.0 \times 10^{12}$

25960 Joules

13

$11 \mathrm{~s}$

$1.6 \times 10^{-6} \mathrm{~s}$

$1.13 \mathrm{GeV} \quad 1.82 \times 10^{-10}$ Joules

368 Joules

4778 Joules

434 Watts

$<100^{\circ} \mathrm{C}$

$376.6 \mathrm{~J} / \mathrm{gm}$

$\begin{array}{lll}0.02 & 0.03 \quad 0.04 \mathrm{~cm}\end{array}$

$25 \quad 11.0 \quad 9.0 \mathrm{GeV} . \mathrm{cm}^{-3}$

$430.0210 .0 \quad 150.0$ Joules. $\mathrm{gm}^{-1}$

2800

1500.

825. ${ }^{\circ} \mathrm{C}$

$>185$ Joules $\mathrm{gm}^{-1}$

$1500^{\circ} \mathrm{C}$

$800^{\circ} \mathrm{C}$

\author{
81 Joules $\mathrm{gm}^{-1}$ \\ $600^{\circ} \mathrm{C}$ (SLAC Report $480^{\circ} \mathrm{C}$ ) \\ $600^{\circ} \mathrm{C}$
}

The operational target at the CERN Antiproton Source has been

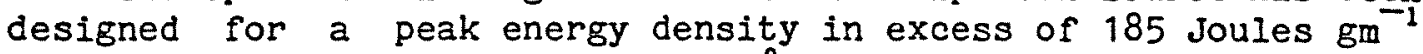
and a peak temperature rise of $1500^{\circ} \mathrm{C}$ above an average temperature of $800^{\circ} \mathrm{C}$. This rhenium target has been operational for some time with no reported failures.

The SLAC Linear Collider will use a tungsten-rhenium target with peak energy densities of up to 81 joules $\mathrm{gm}^{-1}$ and peak temperature rise of $600^{\circ} \mathrm{C}$ over an average temperature of $600^{\circ} \mathrm{C}$.

High energy density-deposition in targets was the subject of a workshop at Fermilab. Energy-density depositions well in excess of the ones considered here are expected to result in melting, vaporization and the depletion of the target material in a time short compared with the beam pulse of 1.6 usec. General rules indicate the onset of shock waves for energy densities in excess of 200 Joules $\mathrm{gm}^{-1}$ and energy deposition in the nanosecond range.

We will lower the energy density to less than $200 \mathrm{~J} / g$ m by sweeping the proton beam across the target during the pulse by 
several beam diameters. The acceptance of the antiproton beam will be similarly pulsed to follow.

Based on the discussion above, the expectation is that after some target-development effort, one should be able to operate with beam spot $\sigma_{x}=\sigma_{y}$ of less than $0.03 \mathrm{~cm}$.

3.4.3 Target Design. Elastic stress calculations for Tungsten-Rhenium alloys, utilizing the temperature profiles resulting from the energy-density deposition discussed above will result in the formation of a plastic zone (material compressed to above yield point) concentric to the beam. The diameter of this zone is expected to be of the order of $0.3 \mathrm{~mm}$ for a beam of $\sigma_{x}=$ $\sigma_{\mathrm{y}}=0.4 \mathrm{~mm}$, and grow to approximately $0.5 \mathrm{~mm}$ for $\sigma_{x}=\sigma_{y}=0.2$

The failure mechanism for a solid target will probably be the following:

1. Development of a plastic zone with each heat pulse.

2. Flow of material within the plastic zone with each repeated pulse. The flow direction will be from inside to face of target.

3. Swelling at target face followed by surface cracking.

4. Surface cracks extending into the volume of the material.

In order to decrease the thermal cycling of the same volume of material, targets will bo rotated at approximately $46 \mathrm{rpm}$, during the 13 beam-pulse sequence, resulting in a distribution of the beam impact point around the circumference. Target translation could provide an even larger number of impact points.

The target geometry of Fig. 3-10 is composed of a number of wedges to decrease the cost of the target manufacturing with respect to a circular rim. During the development stage, wedges could contain different designs for comparative testing. The target geometry of Fig. 3-11 results from available powder technology for the construction of high-power $x$-ray tubes. Because of the low average, power deposited in the target, forced-air cooling should suffice for both geometries.

In order to achleve targets that would survive smaller beam spots (larger energy density deposited) the following approaches to target design are under study:

Laminated targets with the plane of the laminations perpendicular to the proton beam. The purpose would be to decrease the amount of material flow within the plastic zone. 


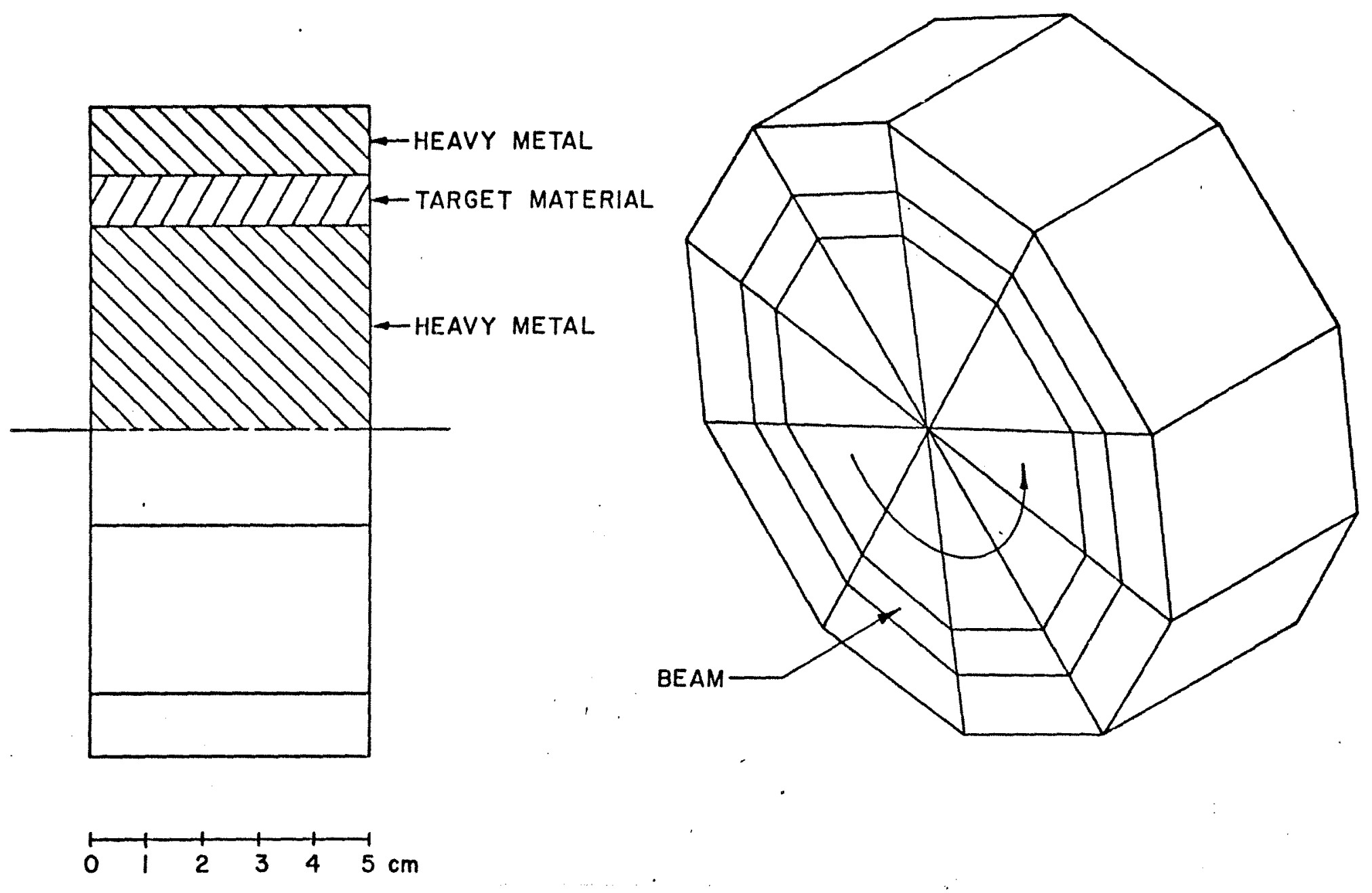

Fig. 3-10 Target.Geometry 


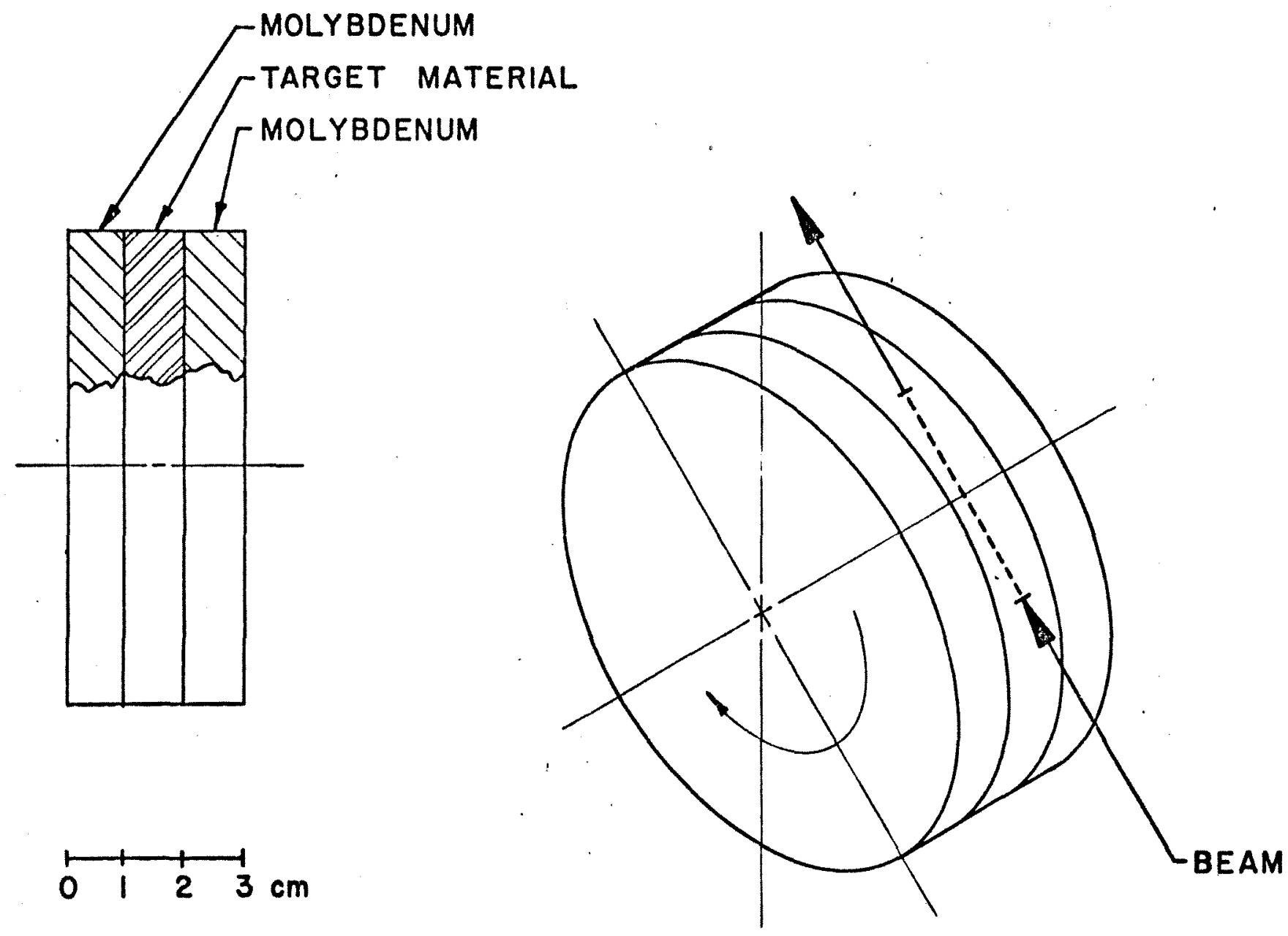

Fig. 3-11 Target Geometry using. Powder Technology 
Filamented targets will allow the introduction of slip planes across large temperature gradients, resulting in a lowering of the stresses.

Powder targets high density particles embedded in graphite by powder metallurgy would incorporate the excellent shock and high-temperature properties of graphite, allowing enough energy deposition to melt the metal particles. The lower antiproton yield resulting from the lower average target density could be overcome by the much smaller beam spot.

A research and development program is underway to test these ideas. Beam is expected to be available after October 1981.

3.4.4 The Lithium Lens Collector. Antiprotons diverging from the target are to be collected by a 10-cm long lithium lens of $1 \mathrm{~cm}$ radius. The basic principle of this device is that an electric current uniformly distributed in a cylindrical conductor produces an azimuthal magnetic field with a constant radial gradient inside the conductor. Thus, such a conductor is an axially symmetric focusing device for a particle beam passing through the conductor axially. To produce the desired gradient of $1000 \mathrm{~T} / \mathrm{m}$, current pulses of $0.5 \mathrm{MA}$ are required. Current uniformity is secured by adjusting the pulse length to make the skin depth close to the radius; nearly $1 \mathrm{msec}$ full width is required for a sinesoidal pulse. A lens capable of handling such pulses at a $10 \mathrm{~Hz}$ repetition rate has not yet been built, and its design will in fact require some extension of the present technology. The lens now under development at the Institute for Nuclear Physics (Novosibirsk) is intended for operation at a maximum of $0.5 \mathrm{~Hz}$. On the other hand, Fermilab has already received from INP four lenses of $0.25 \mathrm{~cm}$ radius that are conservatively rated for the required gradient and a $13 \mathrm{~Hz}$ cycle. These lenses cannot fulfill the plan to provide an antiproton transport system with $20 \mathrm{~m} \mathrm{~mm}$ mrad acceptance, but do in fact serve rather well to meet the more immediate need for $5 \pi$. A lens of this design and its immediate appurtenances have been life tested for $>10^{7}$ pulses, and destructive testing has established that the short-term maximum sustainable gradient is about $50 \%$ above the operating value. Tests of the optical performance and beam effect on service life will be made in the fall of 1981 when protons are brought to the target station.

\subsection{Antiproton Transport to Precooler}

The antiproton beam from the target is collected by the lithium lens and made close to parallel as input to the transport system. The entire transport system is designed to contain an antiproton beam of transverse emittance $20 \pi \mathrm{mm}$-mrad in each plane and momentum spread $4 \%$. 
The transport line can be thought of as two distinct sections:

(1) a vertical translation of $2.485 \mathrm{~m}$ using 6-deg bends followed by a periodic array of quadrupoles. This section is also utilized for the return journey of cooled $8-\mathrm{GeV}$ antiprotons;

(1i) a horizontal bend (essentially a section of a Precooler quadrant) followed by a vertical translation of 1.966 in to put the beam parallel to the Precooler and 50 in. above it. The beam is then bent down and injected in the South straight section. Elements and strengths of the elements are given in Table 3-VI. 
Beam Enittances ( $H$ and $V$ ): $\varepsilon=20 \pi 10^{-6} \mathrm{~m}$ Momentum Spread: $\Delta p / p=4 \%$ full

\section{Sequence of Magnets}

1. Vertical Translation After Target

2. Matching and FODO Transport

3. Matching

4. Dispersion Suppressors

5. Two Regular Cells

6. 1 Cell With 2 Missing Dipoles

7. 1 and ? 1/2 Regular Cells

8. Long Straight Matching

9. Vertical Translation

1. Vertical Translation after Target

$\begin{array}{lllllll}\text { D1 } & \text { V1 } & \text { D2 } & \text { Q1 } & \text { D3 } & \text { Q2 } & \text { D4 }\end{array}$

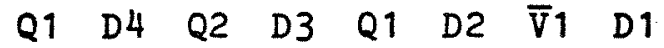

Drifts Length $(m)$

$\begin{array}{ll}\text { D1 } & -0.915 \\ \text { D2 } & 3.8359 \\ \text { D3 } & 1.5 \\ \text { D4 } & 3.50\end{array}$

Quadrupoles Effective Length(ft) Strength $\left(\mathrm{B}^{\prime} / \mathrm{Bp}\right)\left(\mathrm{m}^{-2}\right)$

Q1

Q2
2

4
0.5025

$-0.41262$

Vertical Dipoles Effective Length $(\mathrm{m})$ Strength $(\mathrm{B} / \mathrm{Bp})\left(\mathrm{m}^{-1}\right)$

$\begin{array}{lll}V 1 & 1.83 & \text { (up) } 0.05726 \\ V_{1} & 1.83 & \text { (down) } 0.05726\end{array}$

2. Matching and FODO Transport

D5 (In the middle of $\bar{v}$ ) Q3 D6 Q4

D7 QD $D 8$ QF $\quad$ D9 $\quad$ QD ${ }^{1} \mathrm{Dg}$

QF D9 QD D9 $Q F / 2$ 


\begin{tabular}{ccc} 
Drifts & Lengths $(\mathrm{m})$ \\
\cline { 2 - 3 } D5 & 3.0 & \\
D6 & 3.1962 & \\
D7 & 1.6916 & \\
D8 & 2.574 & \\
D9 & 14.0757 & \\
& & \\
Quadrupoles & Effective Strength(ft) & Strength $\left(\mathrm{B}^{\prime} / \mathrm{Bp}^{\prime}\right)\left(\mathrm{m}^{-2}\right)$ \\
\hline \multirow{2}{*}{ QF/2 } & & 0.1602 \\
Q3 & 1 & -0.52436 \\
Q4 & 2 & 0.34452 \\
QD & 2 & -0.1602 \\
QF & 2 & 0.1602
\end{tabular}

3. Matching

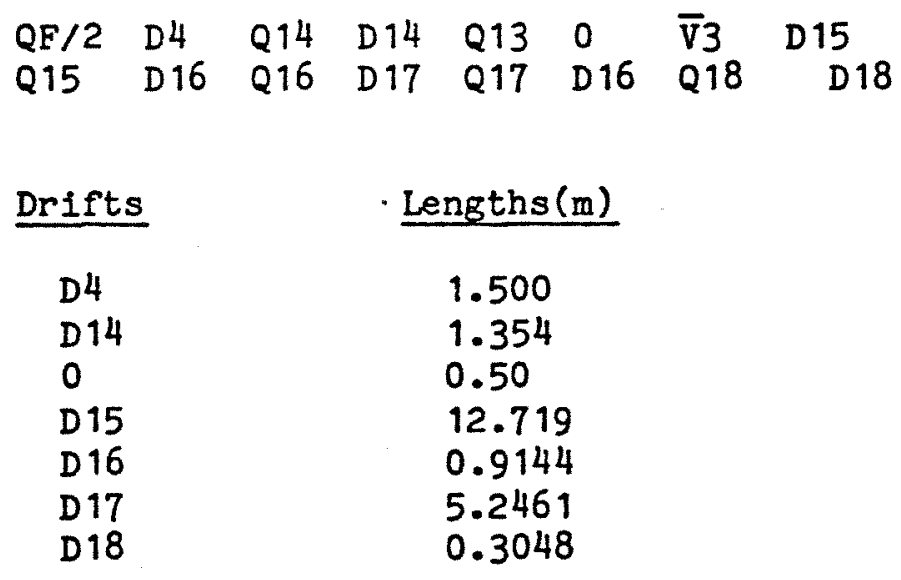

Quadrupoles Effective Length(ft) Strength $\left(B^{\prime} / B^{\prime}\right)\left(m^{-2}\right)$

QF/2

Q14

Q13

Q15

Q16

Q17

Q18

2
2
2
2
2
2
2

2

2

2

2

2
0.1502

$-0.005054$

not energized

$-0.5$

0.47270

$-0.1662$

0.2584

Vertical Bends Effective Length(m) Strength (B/Bp)

$\overline{\mathrm{v}}$

1.3716

not energized 
4. Dispersion Suppressor

$\begin{array}{lllllllll}06 & \text { B } & 0 & \text { B } & 05 & \text { QD } & 04 & \text { B } & 03\end{array}$

QF $02 \quad \mathrm{~B} \quad 01 \quad \mathrm{QD} / 2$

Drifts

01
02
03
04
05
06
Lengths (m)

0.450

2.2609

1.8025

0.9083

0.2172

0.8172

4. Dispersion Suppressor

$\begin{array}{lllllllll}06 & \text { B } & 0 & \text { B } & 05 & \text { QD } & 04 & \text { B } & 03\end{array}$

QF $02 \quad \mathrm{~B} \quad 01 \quad \mathrm{QD} / 2$

Drifts

01

02

03

04

05

06
Lengths ( $\mathrm{I}$ )

0.450

2.2609

1.8025

0.9083

0.2172

0.8172

Quadrupoles Effective Length(ft) Strength $\left(\mathrm{B}^{\prime} / \mathrm{Bp}^{\mathrm{p}}\right)\left(\mathrm{m}^{-2}\right)$

QD
QF

Dipole

B
2

Effective Length $(\mathrm{m})$

1.3716
$-0.53522$

0.54216

Strength $(B / B p)\left(m^{-1}\right)$

0.0409

5. Two Regular Cells

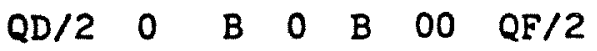

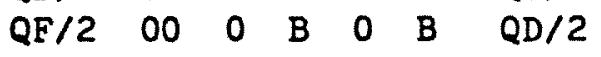

This is repeated twice. 


$\begin{array}{ll}\text { Drifts } & \text { Lengths (m) } \\ 0 & 0.3048 \\ 00 & 0.72963\end{array}$

Quadrupole Effective Length(ft) Strength $\left(\mathrm{B}^{\prime} / \mathrm{Bp}^{\mathrm{p}}\right)\left(\mathrm{m}^{-2}\right)$
QF
$Q D$
2
0.54216
$-0.53522$

Dipole

Effective Length $(m)$

Strength $(B / B p)\left(\mathrm{m}^{-1}\right)$

B

1.3716

.0 .0409

6. 1 Cell with 2 Dipoles Missing

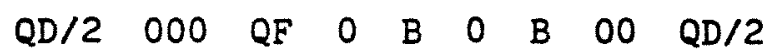

\begin{tabular}{ll} 
Drifts & Lengths(m) \\
\hline 0 & 0.3048 \\
00 & 0.72963 \\
000 & 4.08243
\end{tabular}

Quadrupoles Effective Length(ft) Strensth $\left(\mathrm{B}^{\prime} / \mathrm{Bp}^{\mathrm{N}}\right)\left(\mathrm{m}^{-2}\right)$
QF
2
QD
2
0.54216
$-0.53522$
Dipole Effective Length $(\mathrm{m})$ Strength $(B / B p)\left(m^{-1}\right)$
$\begin{array}{lll}\text { B } & 1.3716 & 0.0409\end{array}$

7. 1 and $1 / 2$ Regular Cells

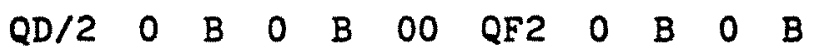

OO QD2 0 B 0 B

Quadrupoles Effective Length(ft) Strength $\left(\mathrm{B}^{\prime} / \mathrm{Bp}\right)\left(\mathrm{m}^{-2}\right)$

$\begin{array}{lrr}\text { QD2 } & 2 & -0.42353 \\ \text { QF2 } & 0.40420 \\ \text { QD } & 2 & -0.53522\end{array}$


Dipole

B
Effective Length(ft)

1.3716
Strength $(\mathrm{B} / \mathrm{Bp})\left(\mathrm{m}^{-1}\right)$
8. Long Straight Matching

D19 Q19 D20 Q20 D21 Q21

D22 Q22 $\mathrm{D} 21 \quad \mathrm{Q} 23 \quad \mathrm{D} 22$

Drifts

D 19

D20

D21

D22

Quadrupoles Effective Length(ft) Strength $\left(B^{\prime} / \mathrm{Bp}\right)\left(\mathrm{m}^{-2}\right)$
Q19

Q20

Q21

Q22

Q23
Lengths $(m)$

0.75

5.32814

1.250

3.00
0.0409

2
2
4
4
2

2

4

2
0.47357
$-0.7990$
0.82195
0.62407
$-0.8490$

9. Vertical Translation

$\begin{array}{llllll}\text { V4 } & \text { D23 } & \text { Q24 } & \text { D24 } & \text { Q25 } & \text { D25 }\end{array}$

$\begin{array}{llllll}\text { Q26 } & \text { D26 } & \text { Q27 } & \text { D27 } & \text { Q28 } & \text { D28 }\end{array}$

V5 D29

Drifts

D23

D24

D25

D26

D27

D28

D29

Quadrupoles Effective Length(ft) Strength $\left(\mathrm{B}^{\prime} / \mathrm{Bp}^{\mathrm{S}}\right)\left(\mathrm{m}^{-2}\right)$

$\begin{array}{llr}\text { Q24 } & 2 & 0.82608 \\ \text { Q25 } & 4 & -0.80589 \\ \text { Q26 } & 0.78407 \\ \text { Q27 } & 2 & -0.89608 \\ \text { Q28 } & 4 & 0.72807\end{array}$


Septum Dipole Effective Length(m) Strength $(B / B p)\left(m^{-1}\right)$

$\begin{array}{lll}\text { v5 } & 3.6576 & \text { (up) } 0.021884\end{array}$




\section{PRECOOLER DESIGN}

\subsection{General Structure and Layout}

4.1.1 Lattice. The Precooler is a storage ring for antiprotons of energy between $200 \mathrm{MeV}$ and $4.5 \mathrm{GeV}$. It must be capable of slow acceleration and deceleration for antiproton energies between 200 $\mathrm{MeV}$ and $8 \mathrm{GeV}$ in order to be able to inject into the Main Ring at a suitable energy. The Precooler is to have large acceptances, $40 \pi \times 10^{-6} \mathrm{~m}$-rad in each transverse plane and a momentum spread $\Delta \mathrm{p} / \mathrm{p}$ of 4.5\%. These acceptances are chosen to give flexibility for later development in injection and cooling methods.

The general size of the Precooler is determined by its relation to the Main Ring. A smaller Precooler would require that the Main Ring proton beam be split into smaller segments for targeting, which would in turn increase the momentum spread of the collected antiproton beam in the Precooler, making cooling more difficult (in fact impossible for a momentum spread much larger than 4\%). Within the limits of feasibility, it is economical to keep the Precooler as small as possible. A radius of approximately $75 \mathrm{~m}$ appears to be optimal and we choose $R=75.4717 \mathrm{~m}$ (exactly the Booster radius) in order to match rf frequencies exactly with the Main Ring. Long straight-section space is also required for injection, stochastic cooling, acceleration, deceleration, and extraction and is available at this radius.

Parameters of the lattice design that has evolved are given in Table 4-I.

\section{TABLE 4-I PRECOOLER PARAMETERS}

\section{A. GENERAL}

Peak Kinetic Energy

Momentum

Magnetic Rigidity

Bending Field

Bending Radius

Average Radius

Revolution Time: $8.0 \mathrm{GEV}$

$4.5 \mathrm{GEV}$

$200 \mathrm{MEV}$

Superperiodicity

Focusing Structure

Normal Cell Structure

Horlzontal Betatron Tune

Vertical Betatron Tune

Transition Energy $\gamma_{m}$

Natural Chromaticito: Horizontal

Vertical

$8.0 \mathrm{GeV}$
$8.8889 \mathrm{GeV} / \mathrm{c}$
$296.5 \mathrm{kG}-\mathrm{m}$
$12.127 \mathrm{kG}$
$24.449255 \mathrm{~m}$
$75.4717 \mathrm{~m}$
$628.71 \mathrm{kHZ}$
$622.72 \mathrm{kHZ}$
$357.93 \mathrm{kHZ}$
2
Separated Function
FODO
11.415
11.393
10.246
-18.35
-17.68


B. Magnets

Number of Dipoles

Length of Dipoles

Effective Length of Dipoles

Sagitta

Quadrupoles:

Type

Number

Effect. Length

Strength
$B^{\prime} / B \rho\left(m^{-2}\right)$

QF
QD
1Q1
1Q2
1Q3
QD1
QF1
QD2
QF2
QF9
2Q1
$2 Q 2$
2Q3

C. Drift Lengths (m)

0

00

000

LL

L11

L1

L2

L3

01

02

03

04

05

06
112

$1.3716 \mathrm{~m}$

$0.962 \mathrm{~cm}$

$\begin{array}{ll}24 & 2 \\ 18 & 2 \\ 4 & 4 \\ 4 & 4 \\ 4 & 4 \\ 4 & 4 \\ 4 & 2 \\ 4 & 2 \\ 4 & 2 \\ 4 & 4 \\ 4 & 4 \\ 4 & 4 \\ 4 & 4\end{array}$

.542162

$-.535217$

. 325417

$-.352206$

.552459

$-.371853$

.518653

$-.42353$

.40420

.308953

$-.359801$

.361397

$-.406104$

$\begin{array}{lc}00 & .3048 \\ 00 & .72963 \\ L & 4.08243 \\ 11 & 10.00000 \\ 1 & 1.96582 \\ 2 & 1.1159 \\ 3 & 2.67062 \\ 1 & .3048 \\ 2 & .45 \\ 3 & 2.26083 \\ 4 & 1.80250 \\ 5 & 0.90833 \\ 6 & 0.217213 \\ & .817217\end{array}$


D. Lattice Structure

D1. Cells:

\begin{tabular}{|c|c|c|c|c|c|c|c|}
\hline . BB: & 00 & B & 0 & B & 0 & & \\
\hline .c: & QD & . BB & $\mathrm{QF}$ & $Q F$ &. $\mathrm{BB}$ & QD & \\
\hline .c1: & QD1 & 000 & QF1 & QF1 &. $\mathrm{BB}$ & QD2 & \\
\hline .C2: & QD2 & . BB & QF2 & QF2 & . BB & $Q D$ & \\
\hline .C3: & QD & . BB & $\mathrm{QF}$ & $Q F$ & 000 & QD & \\
\hline \multirow[t]{2}{*}{.c8: } & QD & 01 & B & 02 & $Q F$ & & \\
\hline & $\mathrm{QF}$ & 03 & B & 04 & $Q D$ & & \\
\hline .DF9: & $Q D$ & 05 & B & 0 & B. & 06 & QF9 \\
\hline
\end{tabular}

D2. Long Straight Section:

With Dispersion

$\begin{array}{lllllll}. S 1 & L L & 1 Q 1 & 1 Q 1 & 0 & 1 Q 2 & 1 Q 2\end{array}$

$\begin{array}{llllll}\text { L1 } & \text { L2 } & 1 \text { Q3 } & 1 \text { Q3 } & \text { L3 } & \text { QD1 }\end{array}$

Without Dispersion

$\begin{array}{lllllll}.52 & \text { QF9 } & \text { L3 } & 2 Q 3 & 2 Q 3 & \text { L2 } & \text { L11 } \\ & 2 Q 2 & 2 Q 2 & 0 & 2 Q 1 & \text { LL } & \end{array}$

D3. Arc Sector:

$\begin{array}{llllll}. \text { Arc } & . C 1 & . C 2 & . C 3 & . C & \\ & . C & . C & . C & . C 8 & . D F 9\end{array}$

D4. Quadrant Structure:

$\begin{array}{llll}. S p h & . S 1 \quad \text { Arc } \quad . S 2\end{array}$

D5. Superperiod:

.Sph $\quad$ Reflect (.Sph) 
E. Lattice Functions

$$
\beta_{\mathrm{H}}(m) \quad \quad \beta_{\mathrm{V}}(m) \quad n(m)
$$

$\begin{array}{cccc}\text { Maxima } & 60.22 & 55.76 & -2.74 \\ \text { Regular Cell: } & & & \\ \text { Max } & 16 . & 16 . & 1.3 \\ \text { Min } & 2.5 & 2.5 & 0.6\end{array}$

Middle of long straight with dispersion (.S1)

$$
9.9854 \quad 10.05 ! 2 \quad \mathbf{- 2 . 7 4 2 6}
$$

Middle of long straight without dispersion (.S2)

$$
\begin{array}{lll}
10.3516 & 6.0185 & 0.00
\end{array}
$$

The lattice is shown in Fig. 4-1 where the locations of functions are labelled. The orbit functions are graphed in Fig. 4-2. A normal cell is shown in Fig. 4-3. The long straight section insertions are shown in Figs. 4-4 through 4-7. The detailed SYNCH output is included as Appendix 2.

The lattice has 2-fold symmetry; it is symmetric about the center of each long straight section. In addition to the Iong straight-section insertions, there are missing magnets in the first, third, and eighth cells in each direction from the south and North straight sections.

4.1.2 Nomenclature. Locations and components in the Precooler are labelled by a four-place code. The meaning of each place is:

(1) Place 1: Quadrant label

Each quadrant begins at the center of a long straight section and ends at the center of the next long straight section. Quadrant 1 begins at the center of the South (injection) straight section.

(11) Place 2: Device Label

B: bending magnet

Q: quadrupole

L: straight section

S: sextupole

T: trim magnet

(11i) Place 3: Period Label

a. In long straight sections, this label is $S, W, N$, or $E$.

b. In bending sections, this label is 1 through 9 


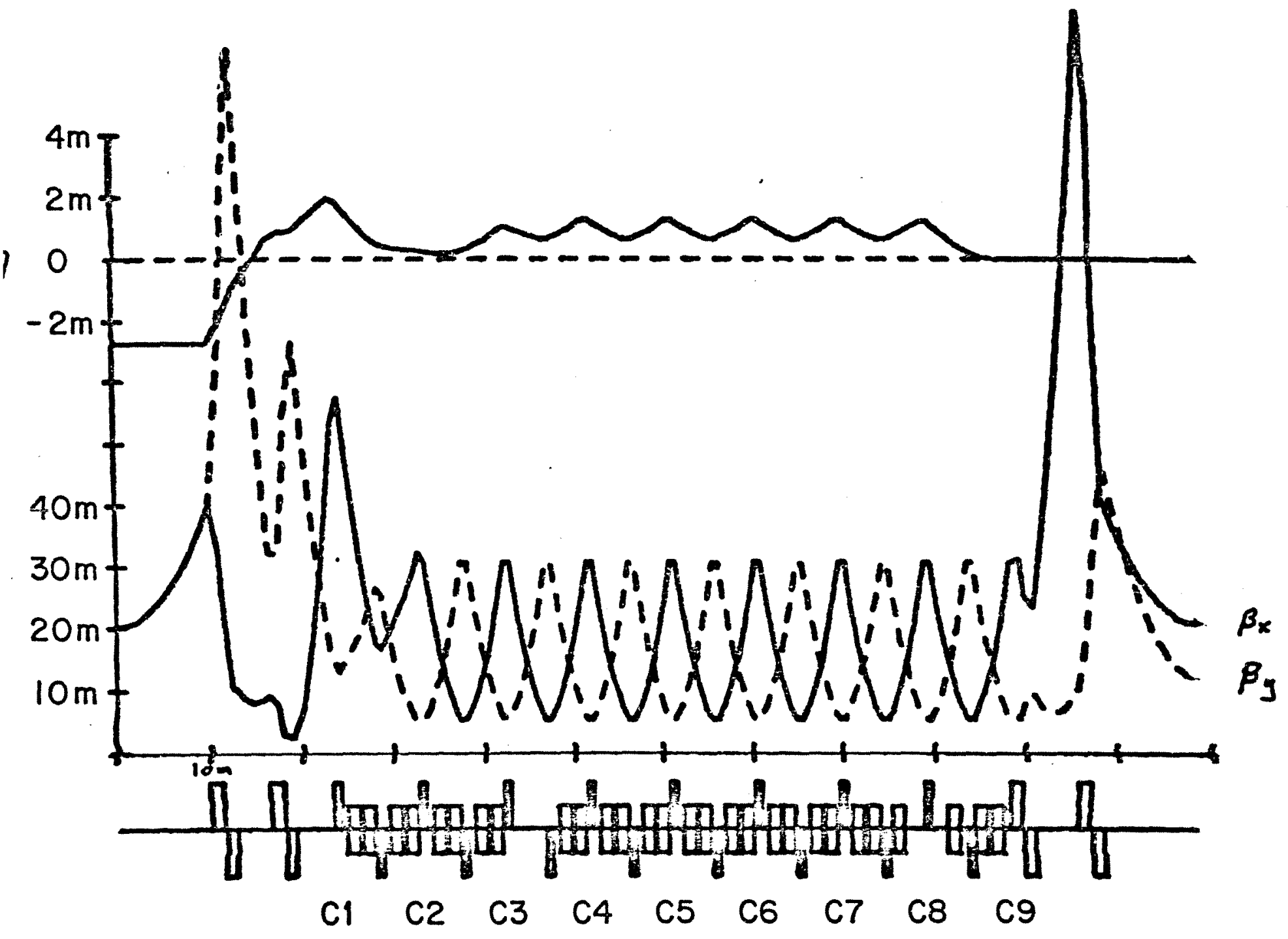

Fig. 4-2 Precooler Orbits

a) Amplitude and dispersion functions 


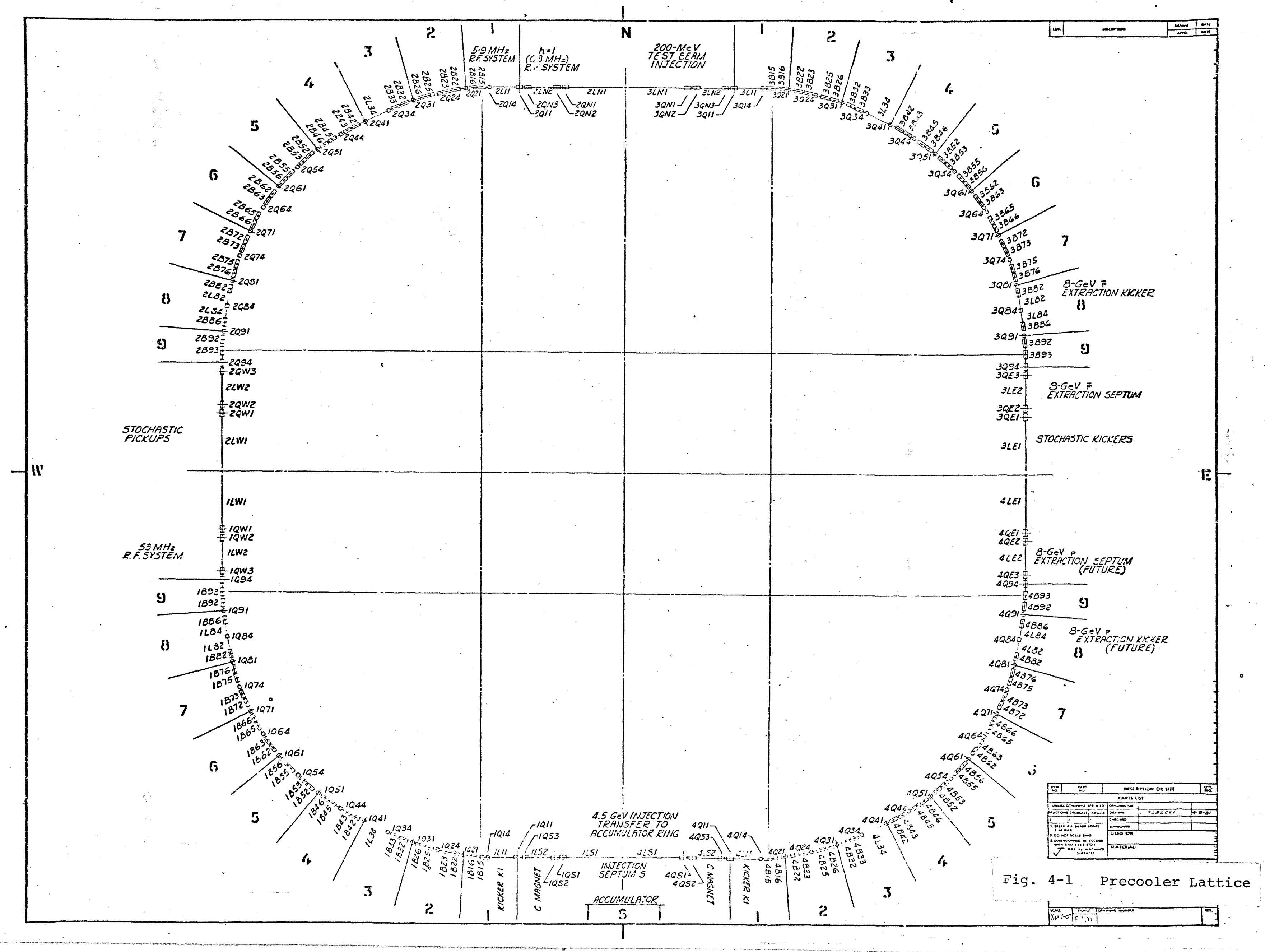




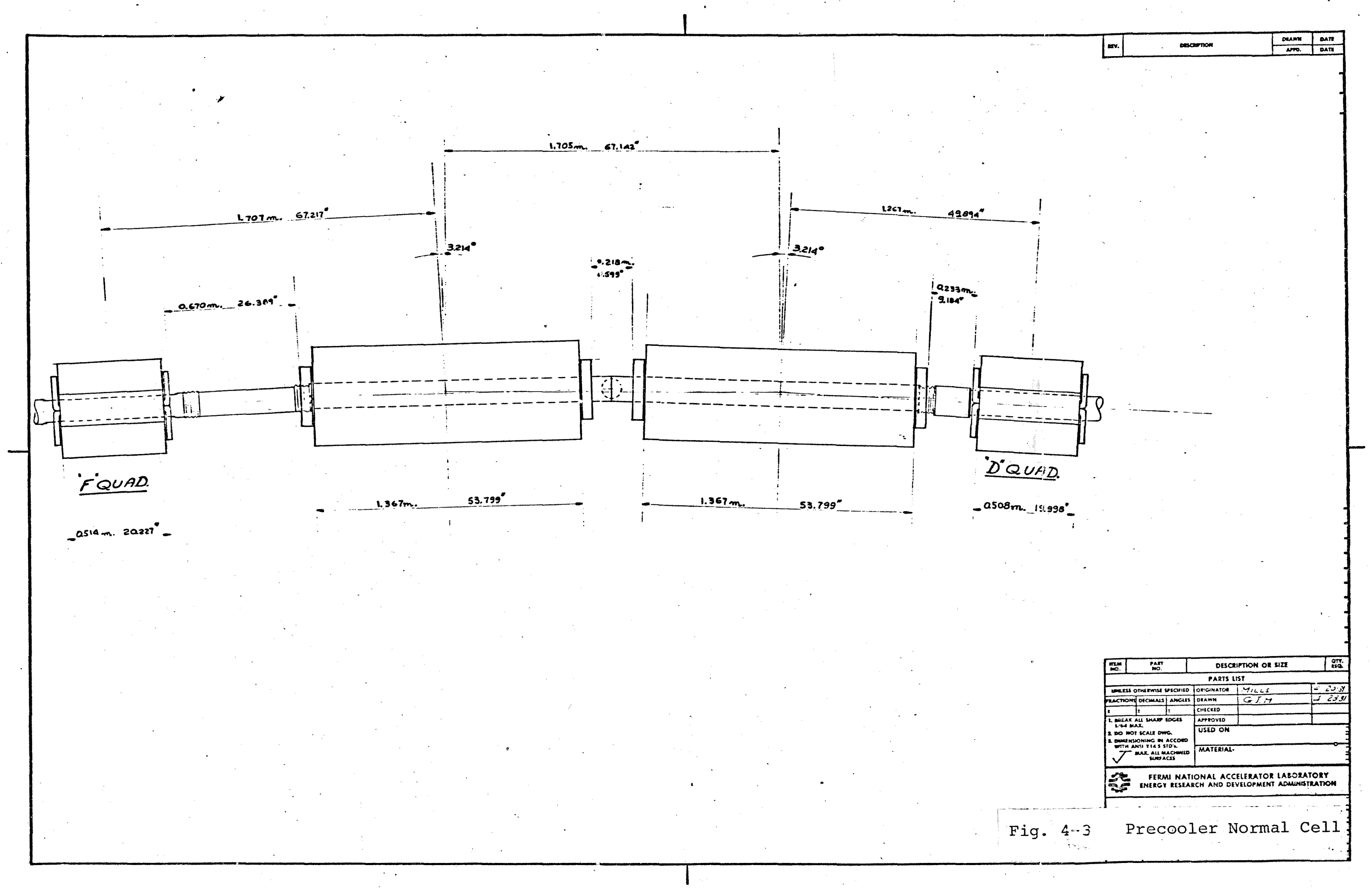




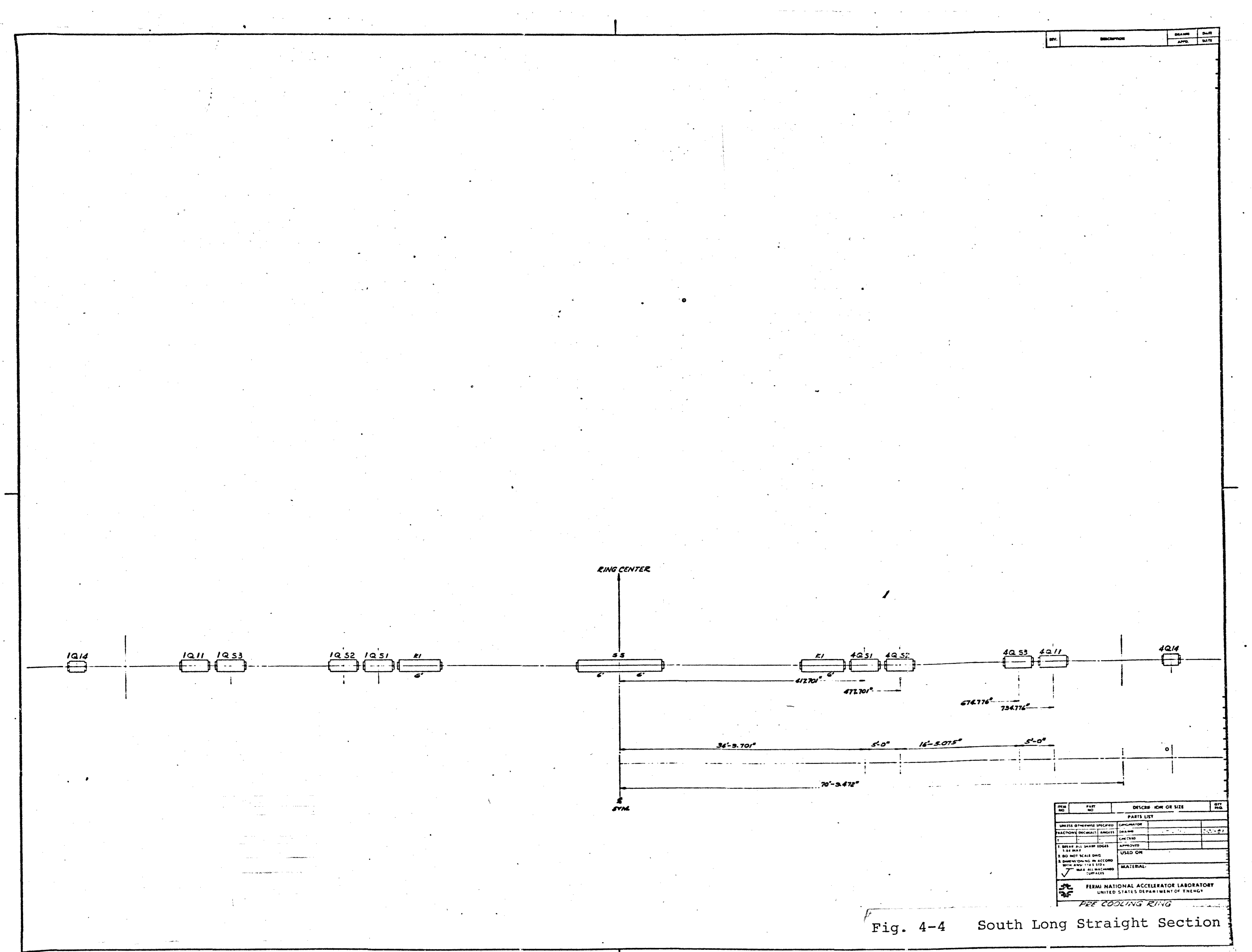


$\because$
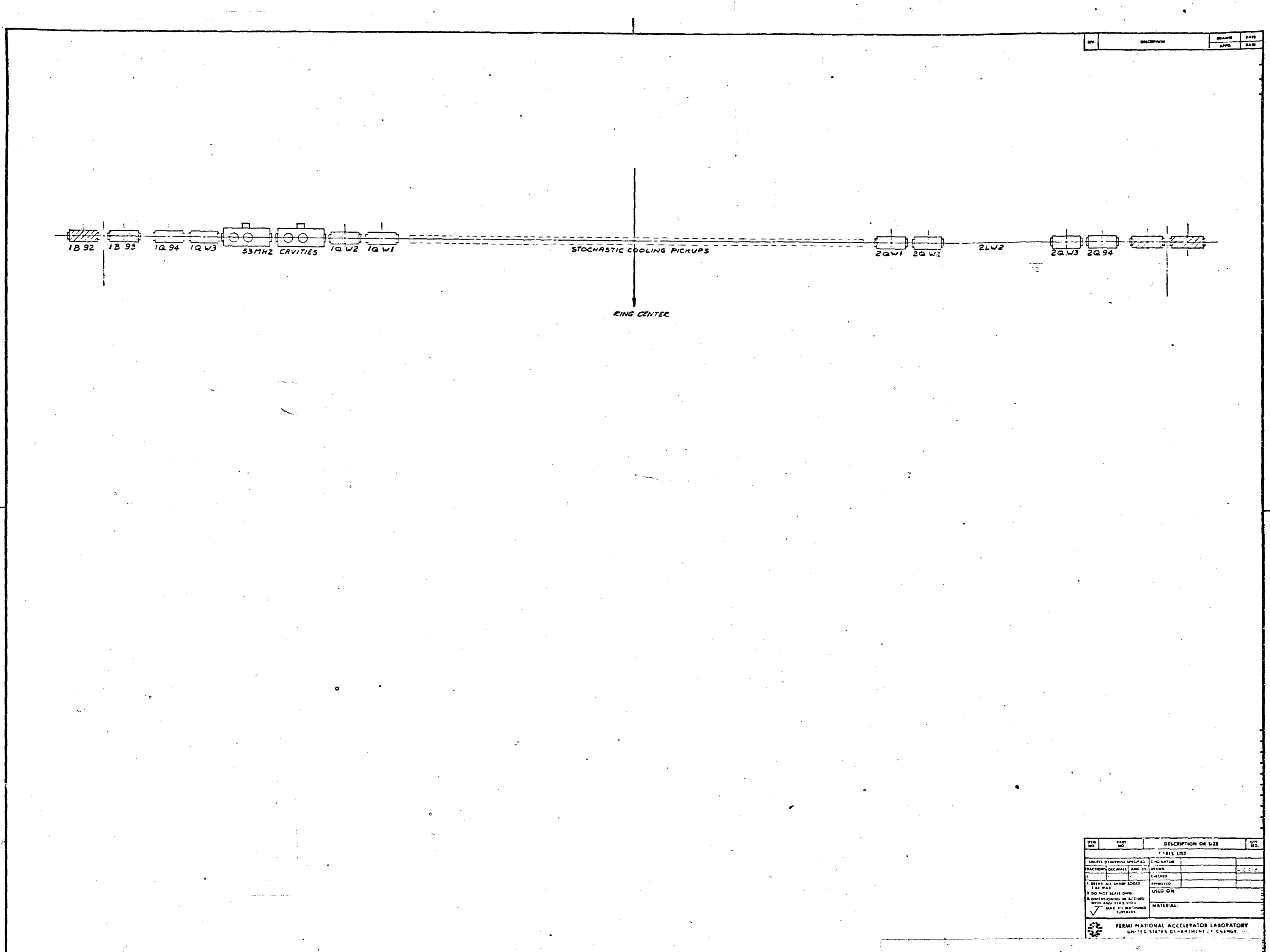

Fig. 4-5 West Long Straighi Section 


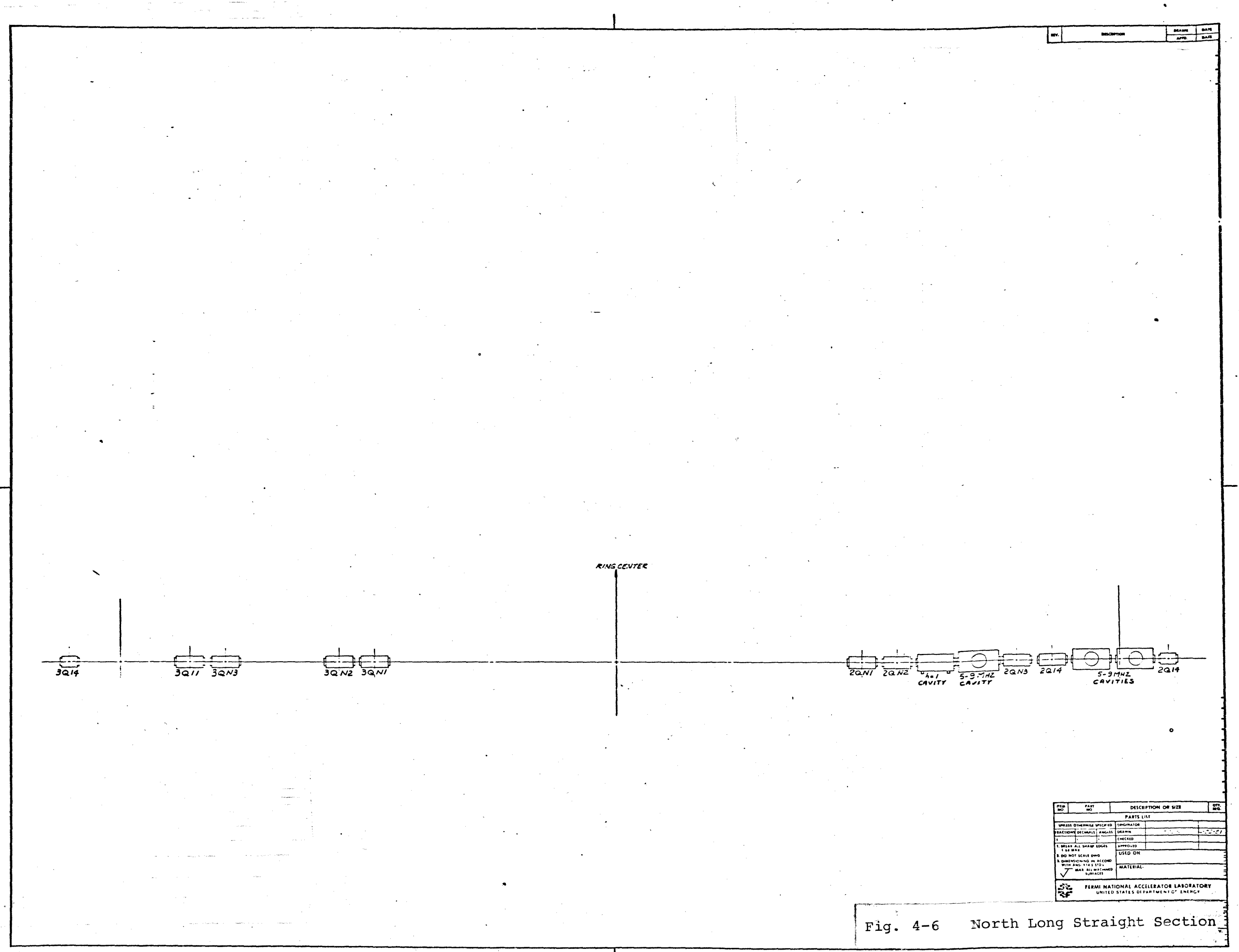




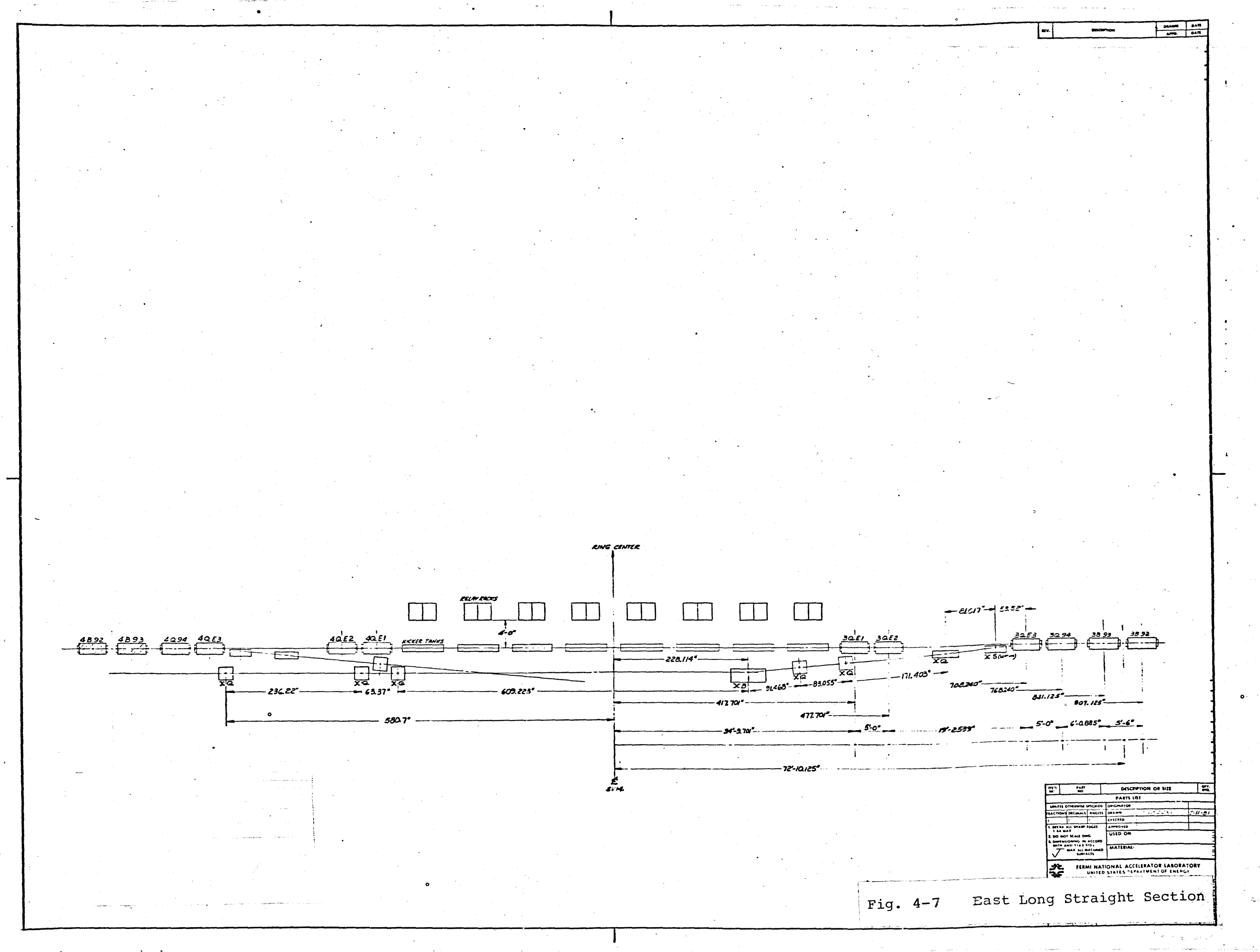



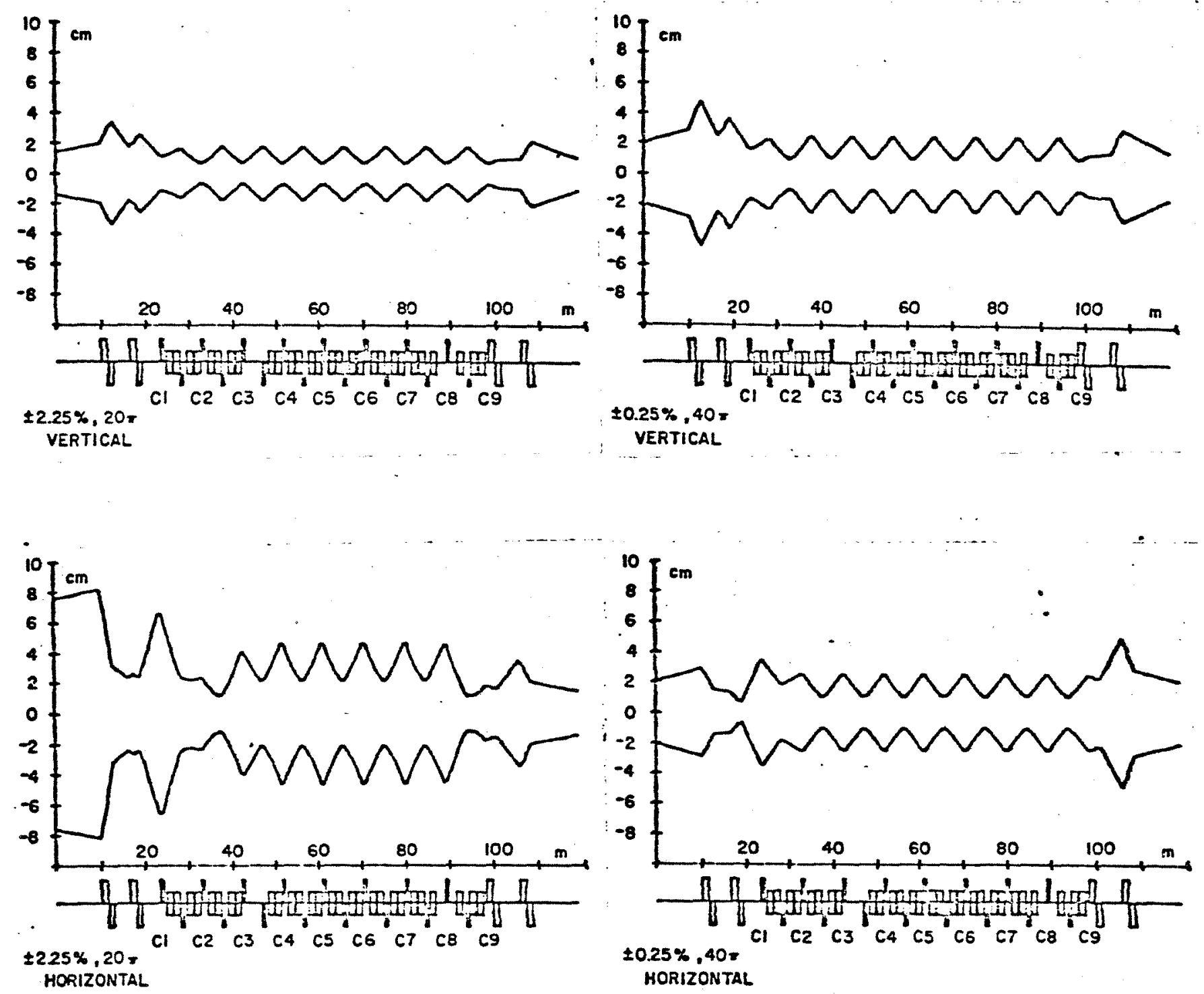

b) Horizontal and vertical beam envelopes: 
for the cell number. Note that as one proceeds in the direction of beam, the period label increases from 1 to 9 in quadrant 1, decreases from 9 to 1 in quadrant 2, increases from 1 to 9 in quadrant 3, then decreases from 9 to 1 in quadrant 4. This reflects the symmetry of the lattice.

(Iv) Place 4: Location Label

This label is sequential within a cell. Note that all radially focusing quads have even numbers and all radially defocusing quad have odd numbers. These labellings are shown in Figure 4-1.

\subsection{Injection and Stacking}

4.2.1 Injection. The 4.5-GeV injection transport line is shown in Fig. $4-4$ and its parameters are given in Table 4-II. 


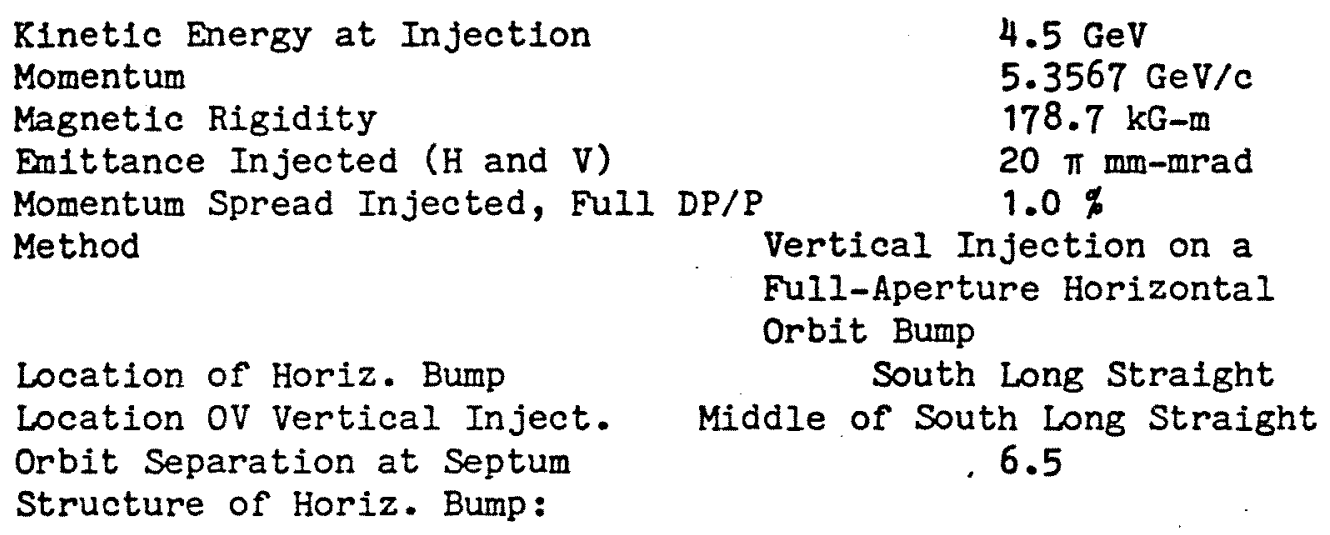$$
\text { 2(QF1) } \quad K 3 \quad 0 \quad K 2 \quad 2(Q D 1) \quad 0 \quad 2(1 Q 3) \quad \text { L2 } \quad \text { L1 }
$$$$
\text { 2(1Q2) } 0 \text { 2(1Q1) } 0 \mathrm{KI} L L^{*} \mathrm{~S} / 2 \text {-- Reflect }
$$

Kickers: $\mathrm{K} 1, \mathrm{~K} 2, \mathrm{~K} 3$

$\begin{array}{ll}\text { Effective Length } & 6 \mathrm{ft} \\ \text { Strength } & 600 \mathrm{G} \\ \text { Rise Time } & 150 \mathrm{nsec} \\ \text { Horiz. Aperture, Full } & 9 \text { in. } \\ \text { Vertic. Aperture, Full } & 3 \mathrm{in} .\end{array}$

Septum Magnet: S

Septum Thickness $10 \mathrm{~mm}$

Effective Length $12 \mathrm{ft}$

Strength $4 \mathrm{kG}$

Vertical Separation Between Beam Axes 50 in.

Drift Elements:

$0 \quad$ L1 L2

$L L *$

Quadrupoles:

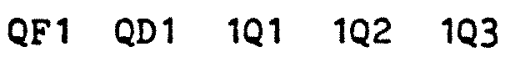

(See Table 4-I)

$8.1712 \mathrm{~m}$ 
4.2.2 Stacking. After each of the 13 bunches is injected, it is captured by the $53-\mathrm{MHz}$ of system, rotated in longitudinal phase space through one-fourth of a phase-osclilation period to reduce 1ts momentum spread from 1\% to $0.24 \%$, then moved to the stack and deposited. The loss of $\bar{p}$ in this process is less than 5\%. The process is outlined step-by-step in Table 4 -III. 
TABLE 4-III RF ROTATION AND STACKING

Kinetic Energy
Momentum
Magnetic Rigidity
Precooler Ring Radius
RF Frequency
Harmonic Number
Transition Energy $Y_{\mathrm{T}}$

Capture:

Bunch Area ( $95 \%$ of Beam)

Momentum Spread (Full Uniform Distr.)

Bunch Length

RF Voltage at Capture

(Stationary Bucket)

Phase-Oscillation Period

Bunch Rotation:

Time Period for Rotation

Bucket Reduction:

Final Voltage (Stationary Bucket)

Bucket Half-height

Bucket Area

Time to Drop Voltage to Final Value At the End of Rotation

Phase Oscillation Period

Transformation to Moving Bucket:

RF Voltage for Moving Bucket

RF Phase for Moving Bucket

Moving Bucket Area

Moving Bucket Half-Height, DP/P

Phase Oscillation Period

TIme for Transformation
$4.5 \mathrm{GeV}$

$5.3567 \mathrm{GeV} / \mathrm{c}$

178.7

75.4717

$52.31 \mathrm{MHz}$

84

10.24624
$0.15 \mathrm{eV}-\mathrm{sec}$

$1.0 \%$

$21.0 \mathrm{~cm}$

$400 \mathrm{kV}$

$0.367 \mathrm{msec}$

$94 \mu \mathrm{sec}$

$19 \mathrm{kV}$

$0.12 \%$

$0.154 \mathrm{eV}-\mathrm{sec}$

8 usec

$1.68 \mathrm{msec}$
$33.0 \mathrm{kV}$

$173 \mathrm{deg}$

$0.154 \mathrm{eV}-\mathrm{sec}$

$0.18 \%$

$1.29 \mathrm{msec}$

$1.6 \mathrm{msec}$ 
Stacking With Moving Bucket:

\begin{tabular}{|c|c|}
\hline $\begin{array}{l}\text { Momentum Variation Swept } \\
\text { Energy Varlation } \\
\text { Energy Gain Per Turn } \\
\text { No. of Revolution During Stacking } \\
\text { Time for Stacking } \\
\text { Relative Frequency Swing } \\
\text { Variation of RF Frequency }\end{array}$ & $\begin{array}{l}4.0 \% \\
213 \mathrm{MeV} \\
4 \mathrm{keV} \\
53,000 \\
85 \mathrm{msec} \\
8.0 \cdot 10^{-4} \\
500 \mathrm{~Hz} / \mathrm{msec}\end{array}$ \\
\hline \multicolumn{2}{|l|}{ Transformation to Stationary Bucket: } \\
\hline $\begin{array}{l}\text { RF Voltage for Stationary Bucket } \\
\text { RF Phase for Stationary Bucket } \\
\text { Stationary Bucket Area } \\
\text { Stationary Bucket Half-Height, DP/P } \\
\text { Phase Oscillation Period } \\
\text { Time for Transformation }\end{array}$ & $\begin{array}{l}19 \mathrm{kV} \\
180 \mathrm{deg} \\
0.154 \mathrm{eV}-\mathrm{sec} \\
0.12 \% \\
1.68 \mathrm{msec} \\
1.6 \mathrm{msec}\end{array}$ \\
\hline Adiabatic Debunching & \\
\hline $\begin{array}{l}\text { Final Voltage } \\
\text { Time Required to Turn off RF } \\
\text { Final Beam Momentum Spread }\end{array}$ & $\begin{array}{l}0.0 \mathrm{~V} \\
1.5 \mathrm{msec} \\
0.17 \%\end{array}$ \\
\hline Overall Stacking Parameters & \\
\hline $\begin{array}{l}\text { No. of Pulses Stacked/Main Ring Cycle } \\
\text { No. of p's Per Pulse } \\
\text { Final Momentum Spread } \\
\text { Stacking Efficiency (Including } \\
\text { Dilution During Bunch Rotation) } \\
\text { Fraction of Overall Beam Loss }\end{array}$ & $\begin{array}{l}13 \\
1.62 \cdot 10^{6} \\
2.16 \%\end{array}$ \\
\hline RF Cavities Requirement & $\succ$ \\
\hline $\begin{array}{l}\text { No. of Cavities Required } \\
\text { (Voltage Programmed by Paraphasing) } \\
\text { Frequency Tuning Range } \\
\text { Total Length of System }\end{array}$ & $\begin{array}{l}2 \\
10^{-} \\
4.3\end{array}$ \\
\hline
\end{tabular}

There will be surplus Main Ring $r f$ cavities when the Tevatron is in operation and we will use two of these, with associated power amplifiers, bias supplies, modulators, and local controls, for the stacking of system. They will be installed at the upstream end of the West long straight section, so the tunnel has been made wider to provide this access. Experience in the Main Ring has shown that access to the back of the cavities is useful. For purposes of space allocation, we show in Figs. 4-8 an outline drawing of the cavities.

\subsection{Magnets}



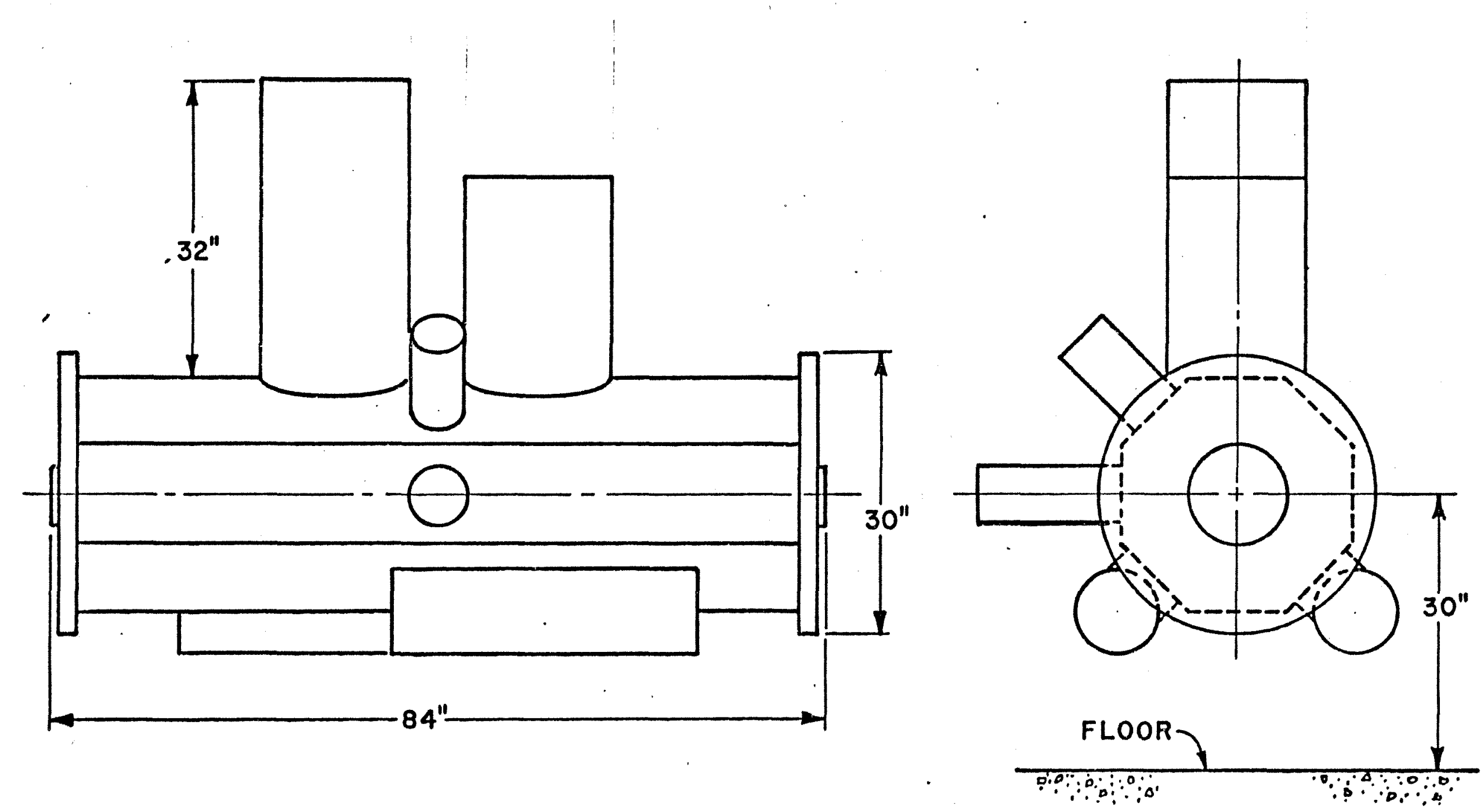

PHYSICAL DIMENSIONS

Fig. 4-8 - 52-MHz RF Cavity BUNCH CAPTURE/ROTATION CAVITY (53 MHZ) (SUPPORTS NOT SHOWN) 
4.3.1 Main Magnets. The Precooler magnet design and plan for construction follow closely the successful magnets of the Electron Coolng Ring (which are to be absorbed into the Electron Accumulator). The same methods of bolted assembly and construction in the Fermilab magnet factory will be followed. The only difference will be that the dipole coil ends will be bent up at $90^{\circ}$ to save space, rather than $45^{\circ}$ as in the Electron Ring dipoles. Table 4-IV gives the parameters of the main dipoles and quadrupoles.

TABLE 4-IV MAIN MAGNET PARAMETERS

\begin{tabular}{ll} 
Dipoles & \\
\hline Number & 112 \\
Length (effective) & $1.3716 \mathrm{~m}$ \\
Length (steel) & $1.2903 \mathrm{~m}$ \\
Steel Weight & $1270 \mathrm{~kg}$ \\
Copper Weight & $175 \mathrm{~kg}$ \\
Gap Height & $6.4 \mathrm{~cm}$ \\
Gap Width & $18 \mathrm{~cm}$ \\
Good Field & $12.8 \times 6$ \\
Width & $48.7 \mathrm{~cm}$ \\
Height & $28.9 \mathrm{~cm}$ \\
No Turns & 40 \\
Peak Field & $1.21 \mathrm{~T}$ \\
Peak Current & $1540 \mathrm{~A}$ \\
& \\
Quadrupoles & \\
\hline & \\
Number & \\
Effective Length & 52 \\
Steel Length & $0.610 \mathrm{~m}$ \\
Peak Gradient & $0.56 \mathrm{~m}$ \\
Poletip Field & $16.6 \mathrm{~T} / \mathrm{m}$ \\
Bore & $0.79 \mathrm{~T}$ \\
Steel Weight & $9.55 \mathrm{~cm}$ \\
Copper Weight & $920 \mathrm{~kg}$ \\
No Turns & $110 \mathrm{~kg}$ \\
Peak Current & 44 \\
& $1540 \mathrm{~A}$ \\
&
\end{tabular}

Average Total Magnet Power in Normal Cycle $2.23 \mathrm{MV}$

The dipole assembly is shown in Fig. 4-9. The quadrupole assembly is shown in Fig. 4-10.

There are in addition special quadrupoles of different length and the same aperture or of larger aperture (bore $=15 \mathrm{~cm}$ ) to accommodate large beam envelopes in stralght sections. These are 


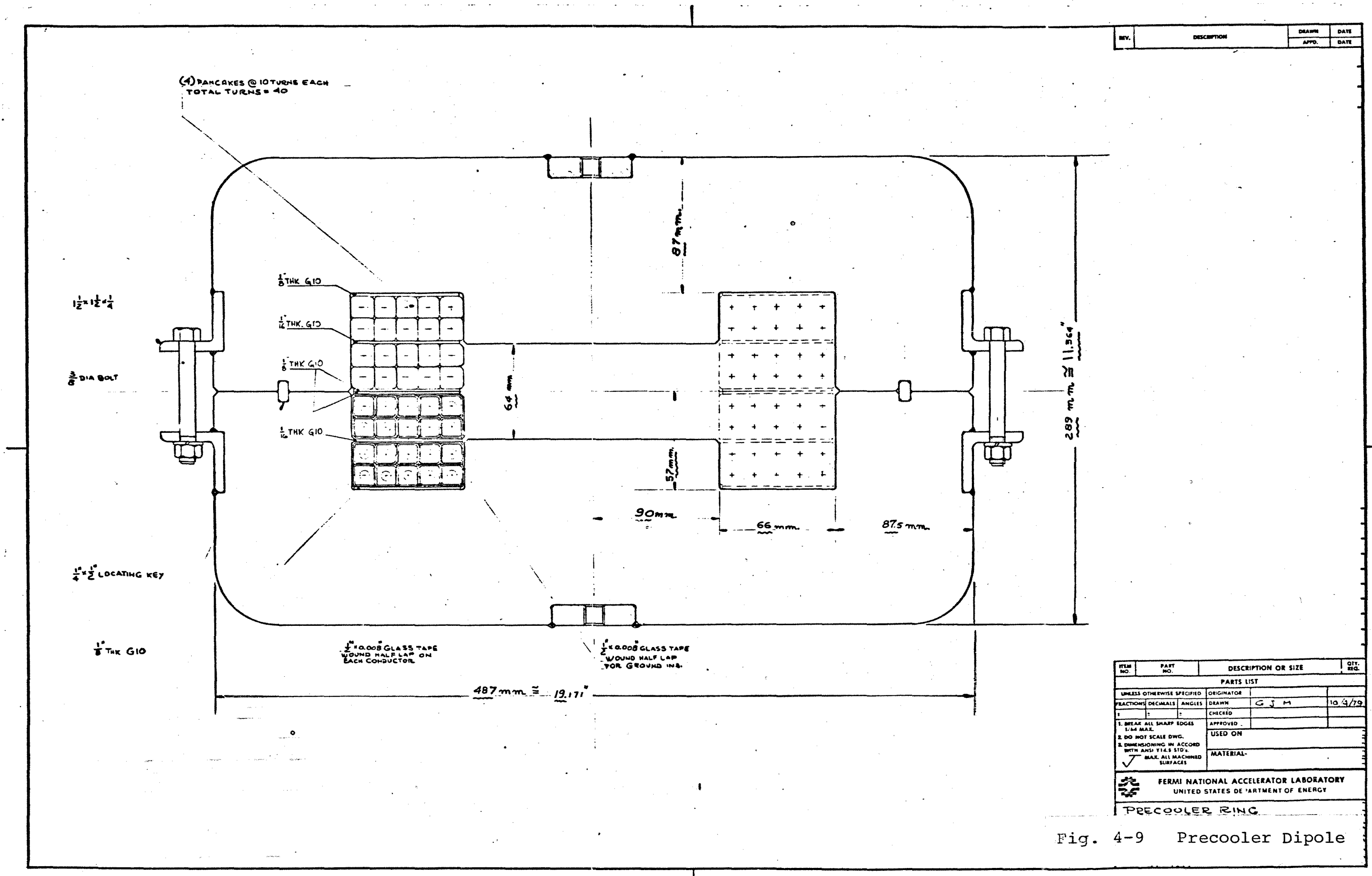




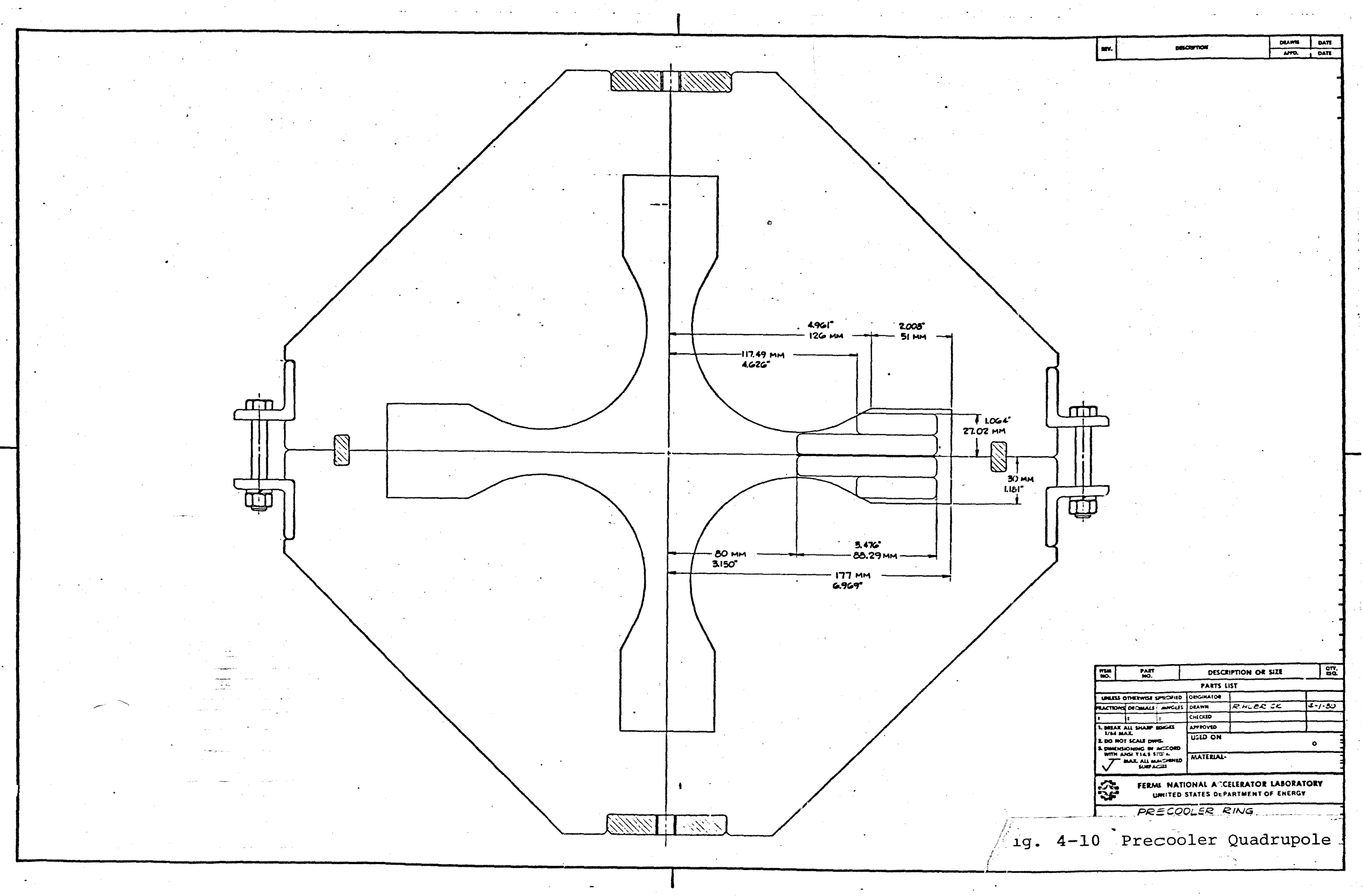


designed to have lower field in order to keep poletip flelds within reasonable limits.

Magnet support and alignment systems will follow the successful Electron Cooling Ring practice.

4.3.2 Main Magnet Power Supply. Eight power supplies will energize the antiproton Precooler ring. There will be two series-connected supplies per quadrant. These supplies will power 32 dipole and 19 quadrupole magnets. The resistance and inductance per quadrant is $R=1.4045 \Omega$ and $L=0.466 \mathrm{H}$. Each power supply will hve 12-phase series bridge rectifiers and will be energized from the $480-V$ 3-phase grid.

The total of eight power supplies are numbered IA, IIA, IIIA, IVA, and IB, IIB, IIIB, and IVB. Each quadrant will contain one "A" and one "B" supply. A block diagram of the Precooler ring with its power supplies is shown in Fig. 4-11. We discuss below the supply use in various cycles.

1. Cooling Cycle

During the cooling cycle, only the "A" supplies will be used. The "B" supplies will be bypassed.

$1.1 \quad 112 \mathrm{~A}(0.2 \mathrm{GeV})$ Flattop (Bunch and transfer to ECR) The injection current level of $112 \mathrm{~A},(0.2 \mathrm{GeV})(8.2 \%$ of peak current), requires a voltage of $130 \mathrm{~V},(8.9 \%$ of peak voltage), per quadrant. This level can be maintained by either charging the power-supply filter capacitors with current spikes or by bypassing most of the power supplies in the other quadrants. We could also operating half the power supplies as rectifiers and half as inverters.

$1.2112 \mathrm{~A}(0.2 \mathrm{GeV})$ to $928 \mathrm{~A}(4.5 \mathrm{GeV})$ (Begin new cycle) To raise the current from $112 \mathrm{~A}$ to $928 \mathrm{~A}$ in $0.5 \mathrm{sec}$ requires a voltage jump from $130 \mathrm{~V}$ to $663 \mathrm{~V}$ and then an exponential voltage rise to $1458 \mathrm{~V}(928 \mathrm{~A})$ per quadrant. The "A" supplies will operate under phase control following a $B$ reference.

1.3928 A (4.5 GeV) Flattop (First Cooling)

To maintain the 928 A current level the "A" supplies will be phased back to $\alpha=50^{\circ}$.

$1.4 \frac{928 \mathrm{~A}(4.5 \mathrm{GeV}) \text { to } 555 \mathrm{~A}(2.4 \mathrm{GeV})}{928}$ To go from 928 A to $555 \mathrm{~A}$ at a rate of $1139 \mathrm{~A} / \mathrm{s}$ requires the voltage per quadrant to drop from $925 \mathrm{~V}$ $\left(\alpha=50^{\circ}\right)$ to $395 \mathrm{~V}\left(\alpha=74^{\circ}\right)$ and then decrease exponentially to $82.5 \mathrm{~V}\left(\alpha=86^{\circ}\right)$. The " $A$ " supplies w1ll operate under phase control from a $B$ reference. 


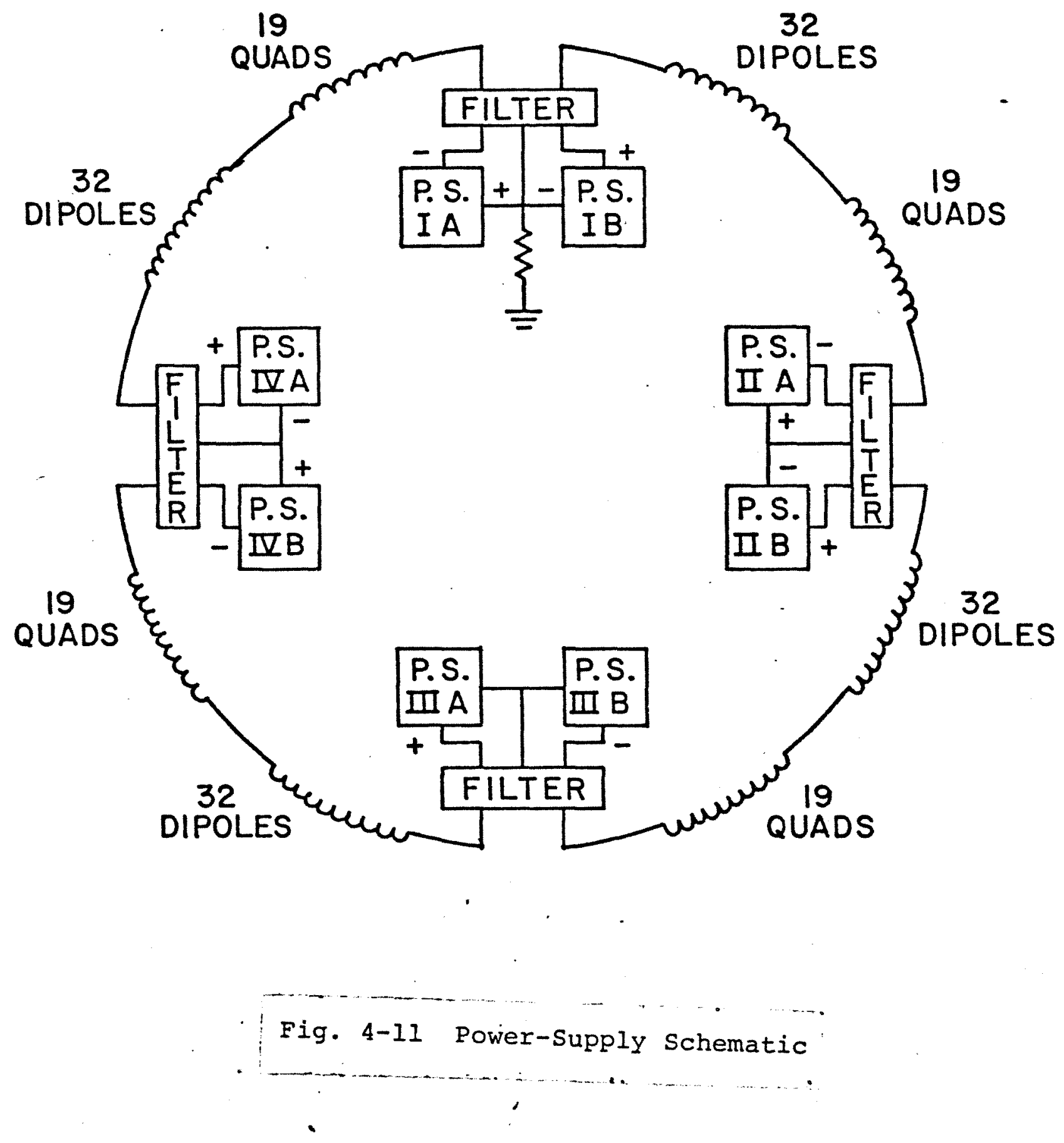


$1.5555 \mathrm{~A}$ (2.4 GeV) Flattop (Second Cooling) When the current reaches 555 A the voltage per quadrant must jump from $82.5 \mathrm{~V}\left(\alpha=86^{\circ}\right)$ to $600 \mathrm{~V}(\alpha$ $\left.=69^{\circ}\right)$. For a better power factor, the supplies in two quadrants could operate as rectifiers while the other two supplies operate as inverters. One could also bypass the supplies in two quadrants and operate the remaining two supplies as rectifiers at a phase angle of $\alpha=35^{\circ}$ providing $1200 \mathrm{~V}$ for two quadrants.

$1.6555 \mathrm{~A}(2.4 \mathrm{GeV})$ to $246 \mathrm{~V}(1.3 \mathrm{GeV})$ (Deceleration)

The voltage across a quadrant of magnets must drop from $600 \mathrm{~V}$ to $82.5 \mathrm{~V}$ and then decrease exponentially to $-185 \mathrm{~V}$. If all four "A" supplies are on and operating at $600 \mathrm{~V}\left(\alpha=69^{\circ}\right)$, the phase angle must increase to $\alpha=86^{\circ}$ for $82.5 \mathrm{~V}$, and then to $\alpha=97^{\circ}$ for $-185 \mathrm{~V}$. If two supplies are bypassed, the remaining two supplies must operate at $\alpha=83^{\circ}$ for $165 \mathrm{~V},(2 \times 82.5 \mathrm{~V})$, and $\alpha=105^{\circ}$ for $-370 \mathrm{~V}$, (2 $\mathrm{x}$ $-165 \mathrm{~V})$. The " $A^{n}$ suplies will operate under phase control for a B reference.

1.7274 A (0.9 GeV) Flattop (Third Cooling)

When the current has decayed to $274 \mathrm{~A}$, the four "A" power supplies are phased to operate with $\alpha=76^{\circ}$ providing $345 \mathrm{~V}$ per quadrant. If only two supplies are operating, the phase angle of each supply would be $\alpha=61^{\circ}$ for $690 \mathrm{~V}$ for two quadrants.

$1.8274 \mathrm{~A}(0.9 \mathrm{GeV})$ to $112 \mathrm{~A}(0.2 \mathrm{GeV})$ (Deceleration) To decrease the current from $274 \mathrm{~A}$ to $112 \mathrm{~A}$ requires a voltage drop from $345 \mathrm{~V}$, per quadrant, to $-185 \mathrm{~V}$ and then an exponentially decreasing voltage to -398 $\checkmark$. With four "A" supplies operating, the phase angle of each supply must go from $\alpha=76^{\circ}$ for $345 \mathrm{~V}$ to $\alpha=97^{\circ}$ for $-185 \mathrm{~V}$, and then to $\alpha=106^{\circ}$ for -398 V. If only two "A" supplies are operating, the phase angle of each supply must go from $\alpha=61^{\circ}$ for $690 \mathrm{~V}$ per two quadrants to $\alpha=105^{\circ}$ for $-370 \mathrm{~V}$ per two quadrants, and then to $\alpha=123^{\circ}$ for $-796 \mathrm{~V}$ per two quadrants. The "An supplies will operate under phase control from a B reference.

2. Once Every 10 Hours Acceleration to $8 \mathrm{GeV}$

2.1 Injection Current of $112 \mathrm{~A}(0.2 \mathrm{GeV})$ (Raise field to injection level)

Either the type "An or the type "B" supplies can be used to obtain the injection current of $112 \mathrm{~A}$. If the "B" supplies are used, they must be phased on to produce a voltage of $530 \mathrm{~V}$ per quadrant $\left(\alpha=37^{\circ}\right)$ and then exponentially increased to produce $663 \mathrm{~V}$ ( $\alpha$ 
$\left.=9^{\circ}\right)$ per quadrant. The current rises from zero to $94 \mathrm{~A}$ in $82 \mathrm{~ms}$ at a rate of $1139 \mathrm{~A} / \mathrm{sec}$.

$2.2112 \mathrm{~A}(0.2 \mathrm{GeV})$ Flattop (Injection) When the current reaches $94 \mathrm{~A}$, the "B" supplies are phased back to produce $130 \mathrm{~V}$ per quadrant $\left(\alpha=78^{\circ}\right)$. Alternatively the voltage for this level can be maintained, as described in 1.1 above.

$2.3112 \mathrm{~A}(0.2 \mathrm{GeV})$ to $1540 \mathrm{~A}(8.0 \mathrm{GeV})$ Acceleration For acceleration to $8 \mathrm{GeV}$, the four "A" and the four "B" supplies are required. The power-supply output voltage per quadrant must jump from $130 \mathrm{~V}$ to $663 \mathrm{~V}$ and then rise exponentially to $2130 \mathrm{~V}$. The current will rise at a rate of $1139 \mathrm{~A} / \mathrm{sec}$. The "A" and "B" supplies will operate under phase control following a $B$ reference signal.

$2.5 \quad 1540$ A to 0 A (Discharge of Magnets) By means of rectifier phase control, the output voltage of the power supplies is reduced, thereby forcing the current to zero at a rate determined by a B reference signal. Some of the $1.2 \mathrm{MJ}$ stored in the magnets is returned to the power grid when the power-supply voltages go negative.

3. Tune-up Cycles

The antiprotons will be collected at $4.5 \mathrm{GeV}$ ( $928 \mathrm{~A}$ ) for precooling and transferred to the Electron Cooling Ring at $0.2 \mathrm{GeV}(112 \mathrm{~A})$. After electron cooling and accumulation, the antiprotons will be transferred back to the Precooler at $0.2 \mathrm{GeV}$, preaccelerated to $8 \mathrm{GeV}(1540 \mathrm{~A})$, and injected into the Main Ring. It may be desirable to experiment at one or more of the above energy levels during tune-up.

4.3.3 Correction Elements. The very large size of the Precooler momentum acceptance $(4.5 \%)$ means that sextupole chromaticity correction will be important (only at lower field, because $\bar{p}$ beam accelerated to $8 \mathrm{GeV}$ will have been cooled). Sextupoles will be located in the straight section downstream of each quadrupole. They will be powered in series with the main magnets and separately powered windings will be provided for adjustment.

The field lengths calculated to bring the chromaticities to zero are $20 \mathrm{~T} / \mathrm{m}$ at $\mathrm{F}$ locations and $35 \mathrm{~T} / \mathrm{m}$ at $\mathrm{D}$ locations. The two kinds of magnets will be built with one cross section, giving $\mathrm{B}^{n}=187 \mathrm{~T} / \mathrm{m}^{2}$ and a poletip field of $0.3 \mathrm{~T}$ for a pipe diameter of 4.5 in. The effective lengths are then 4.15 in. (F) and 7.37 in. (D).

Quadrupole corrections will be provided by trim windings on the regular quadrupoles. Separate horizontal and vertical trim dipole and spew quadrupoles will be located downstream of the sextupole elements. We assume: 
Low Field

D1pole Error

Dipole Tilt

Position Error

Quad Tilt

$10^{-3}$
1 mrad
$5 \times 10^{-4}$
$10^{-3}$

H1gh Field

$5 \times 10^{-4}$

$0.3 \mathrm{mrad}$

$2.5 \times 10^{-4}$

$3 \times 10^{-4}$

The trim dipole strength needed is approximately $2 \times 10^{-3} \mathrm{~T}-\mathrm{m}$ and the skew quad strength needed is $2 \times 10^{-3} \mathrm{~T}$. We are designing a package $10 \mathrm{~cm}$ long to contain these elements.

\subsection{Vacuum System}

Beam will not be stored in the Precoolen for periods of many hours, as is the case in the Electron Accumulator, but for periods of seconds or minutes. One might store for a few hours in the simple initial low-luminosity scenarios briefly mentioned at the end of Chapter 2. We see from the calculated lifetimes collected in Table 4-V that even this possible use does not put any severe constraint on pressure.

\section{TABLE 4-V GAS-SCATTERING MEAN LIFETIMES AT $10^{-8}$ TORR}

\begin{tabular}{|c|c|c|c|}
\hline & $\begin{array}{c}\text { Multiple } \\
\text { Scattering }\end{array}$ & $\begin{array}{c}\text { Single } \\
\text { Scattering } \\
\end{array}$ & $\begin{array}{c}\text { Nuclear } \\
\text { Scattering }\end{array}$ \\
\hline $\begin{array}{l}4.5 \mathrm{GeV} \\
200 \mathrm{MeV}\end{array}$ & $\begin{array}{l}4 \mathrm{hrs} \\
2 \mathrm{~min}\end{array}$ & $\begin{array}{l}21 \mathrm{hrs} \\
11 \mathrm{~min}\end{array}$ & $\begin{array}{r}89 \mathrm{hrs} \\
154 \mathrm{hrs}\end{array}$ \\
\hline
\end{tabular}

An average pressure below $10^{-8}$ Torr, achievable with a Iow-temperature bake, is adequate. Quite aside from this possible low-luminosity use, we desire a pressure in the $10^{-9}$ Torr range in our real scenarios in order that beam broadening from scattering be negligible compared with cooling. The vacuum system designed to achieve this pressure is described in Table 4-VI.

\section{TABLE 4-VI VACUUM-SYSTEM PARAMETERS}

\footnotetext{
Valves - each end of each long straight section 8

- each rf system location

Gauges - 2 per quadrant

Mass spectrometers - 2 per straight section 8

Roughing stations - each long straight section 4

- each rf system location 2

Pumps - one $601 / \mathrm{sec}$ per cell 36

- 8 per long straight section 32
} 
Normal Cell

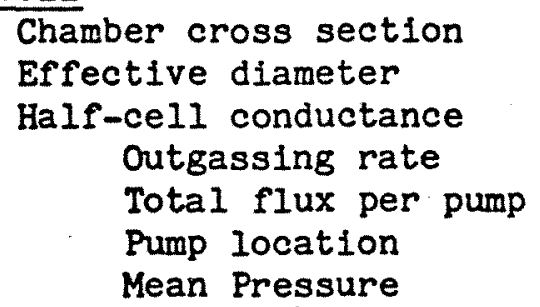

Chamber cross section

Effective diameter

Outgassing rate

Total flux per pump

Mean Pressure

\author{
$5.6 \times 12.5 \mathrm{~cm}^{2}$ \\ $8.9 \mathrm{~cm}$ \\ $18.4 \mathrm{\ell} / \mathrm{sec}$ \\ $3 \times 10^{-12} \mathrm{~T}-\ell / \mathrm{cm}^{2}-\mathrm{sec}$ \\ $16 \times 10^{-9} \mathrm{~T}-\ell / \mathrm{sec}$ \\ between dipoles \\ $10^{-9} \mathrm{~T}$
}

\subsection{Stochastic Cooling System}

\subsubsection{Stochastic Cooling Sequence}

The momentum precooling system must reduce the initial momentum spread of the antiproton beam at the end of $r f$ stacking $( \pm 1 \%)$ in a coordinated manner with deceleration so that the momentum spread of the beam at $200 \mathrm{MeV}$ is compatible with the electron-cooled accumulation process. There is an optimum relationship between energy, momentum spread, lattice characteristics, and hardware placement in the ring for rapid initial cooling. This relationship depends on the frequency spread of the Schottky signals at the highest usable harmonic. As cooling proceeds, the cooling rate decreases quickly as the frequency spread is reduced, so that practical reductions in momentum are 10 or less in a few seconds of cooling time. The cooling sequence to be used in the Precooler calls for cooling periods interspersed with deceleration to lower energies. This re-establishes the desired Schottky signal spread, permitting resumption of rapid cooling.

Table 4-VII gives a sequence of cooling and deceleration which, from the computer simulation shown in Fig. 4-12, produces a more than sufficient amount of cooling.

TABLE 4-VII STOCHASTIC COOLING SEQUENCE

Cooling Steps:

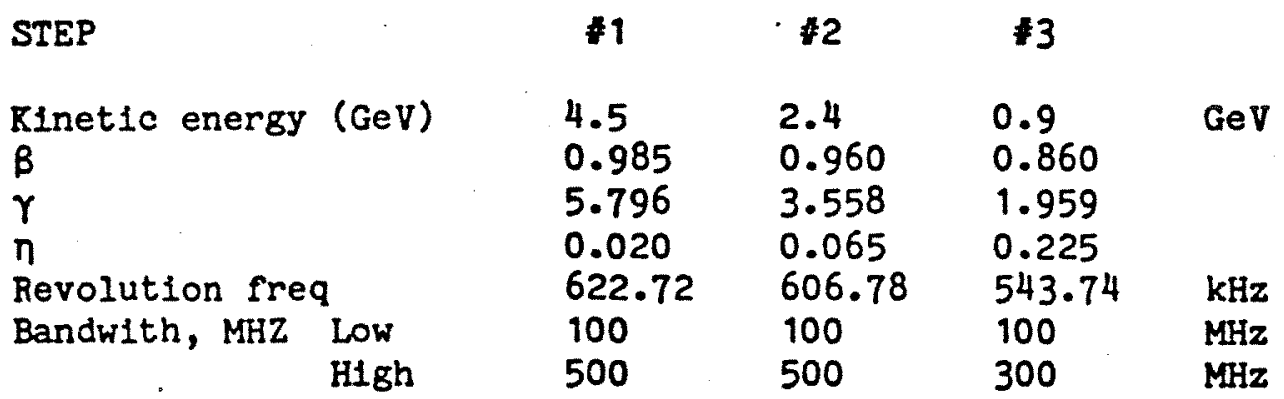




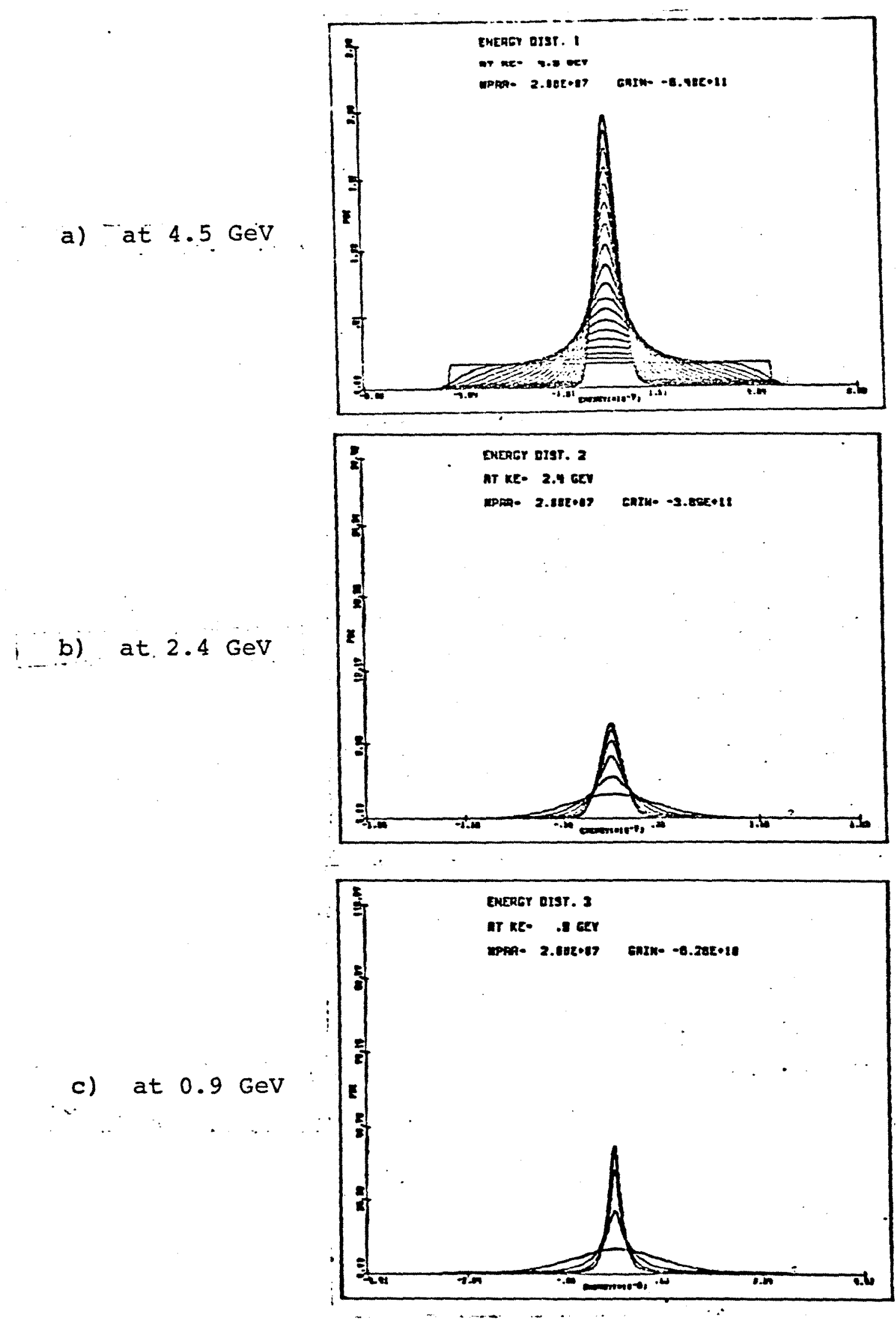

Fig. 4-12 Stochastic Cooling Simulation 


$\begin{array}{lllll}\text { Lower harmonic } & 160 & 164 & 180 & \\ \text { Upper harmonic } & 803 & 823 & 543 & \\ \text { Initial } \Delta p / p, \text { full } & 2.1 & 0.5 & 0.28 & \% \\ \text { Final } \Delta \mathrm{p} / \mathrm{p} \text {, full } & 0.28 & 0.13 & 0.046 & \% \\ \text { Cooling period } & 4.5 & 1.25 & 0.75 & \mathrm{sec} \\ \text { RMS Schottky power } & 0.93 & 0.033 & -- & \mathrm{kW} \\ \text { RMS total power } & 3.62 & 0.97 & 0.04 & \mathrm{~kW} \\ \text { Overall amplifier gain } & 230 & 230 & 220 & \mathrm{db} \\ \text { Total delay required } & 330 & 352 & 434 & \mathrm{nsec}\end{array}$

The inherent flexibility of the process could easily accommodate a fourth cooling step, should it be required, at the expense of having a slightly longer cooling cycle.

4.5.2 Hardware. Hardware for the precooling system is mostly conventional. Parameters are given in Table 4-VIII.

TABLE 4-VIII STOCHASTIC COOLING EQUIPMENT

Mode

Beam

No. of Cooling Steps (See Table 9)

Precooler Radius

Transition Energy $\gamma_{T}$

No. of Cooling Devices

Pickup Long Straight Section

Kicker Long Straight Section

No. of Particles Cooled

Notch Filter

No. of Tanks of Pickups/Kickers

No. of Pickups/Kickers Per Tank

Total No. of Pickups/Kickers

Impedance Per Pickup/Kicker

Length Per Pickup/Kicker

Overall Transverse Dimension of Tanks

No. of Premplifiers

No. of Major Amplification Stations

Amplifier Total Rated Power

Amplifier Delay Time

Distance Between Pickups and Kickers

Normalized to Circumference

Location of Pickup Station

Location of Kicker Station

Time Distance Between Pickups

And Kickers in Straight Line
Momentum

Debunched

3

$75.4717 \mathrm{~m}$

10.24624

1

20. m

20. m

$2.1 \times 10^{7}$

Circumference Length

Shorted

6

32

192

$50 \Omega$

$10 \mathrm{~cm}$

$2 \mathrm{ft}$

6

1

$10 \mathrm{~kW}$

60 nsec

0.5

West Long Straight

East Long Straight

470 nsec

The same pickups, amplifiers, filter, and kicker system can be used for all cooling steps, although elther separate notch filters 
(high-quality long transmission lines) or a tunable system are required because of the variation of $B$, and consequently of the revolution frequency, during deceleration. Similarly, the delay between pickups and kickers, and between groups of pickups, must also be adjusted. This can be accomplished by switching delay lines in the system during the rf deceleration steps.

An effort has been made to use realistic parameters in calculations of expected system performance, particularly for "sensitive" parameters such as effective pickup coupling impedance, kicker impedance, amplifier noise, and so forth. For example, the 30- $\Omega$ impedance that has been assumed for the pickup is close to an experimental value achieved with a crude prototype constructed for cooling studies on the Electron Cooling Ring, and is consistent with (in units of impedance/pickup length) values achieved in the CERN AA cooling system. Similarly, the effective preamplifier noise figure of $1.4 \mathrm{db}$ assumed in the calculations is Justified by the commercial availability of suitable preamplifiers with noise figures of less than $1 \mathrm{db}$ (when cooled). A modest supporting $R$ \& D program will almost certainly yield specific designs that will meet or exceed the assumed performance requirements.

It should be noted that the use of a full-wavelength notch filter is planned. This technique permits rapid cooling without excessive amplifier power and constitutes a distinquishing feature of the precooling system.

The layout of stochastic cooling equipment in the East and West straight sections is shown in Figs. 4-7 and 4-5.

\subsection{Deceleration and Rebunching}

4.6.1 Deceleration. Deceleration and subsequent acceleration of antiprotons in the Precooler is to be done with three slightiy modified PPA accelerating cavities capable of operating over frequency range of 5 to $9 \mathrm{MHz}$. The dimensions of one of these cavities are shown in Fig. 4-13. The locations of these cavities in the North straight section is shown in Fig. 4-6. Each cavity can develop about $28 \mathrm{kV}$ effective gap voltage, so a total voltage of $84 \mathrm{kV}$ will be available. The deceleration will be done in three stages, each separated by a debunching and cooling period so each stage can be done at a different harmonic number. Harmonic numbers are selected such that the required bucket areas and deceleration rates are provided within the voltage and frequency ranges of the $r f$ system. Except for transition periods from stationary field conditions, each deceleration is to be done at a constant rate of change of momentum and guide field.

The first stage of deceleration, from $4.5 \mathrm{GeV}$ to $2.4 \mathrm{GeV}$, w1ll be done at $h=9$ and cover a frequency range of 5.60 to 5.46 $\mathrm{MHz}$. The deceleration rate dp/dt will be $4 \mathrm{GeV} / \mathrm{c}-\mathrm{sec}$. 
PHYSICAL DIMENSIONS

PRECOOLER DECELERATION/ACCELERATION CAVITY (5-9 MHz) (SUPPORTS NOT SHOWN)

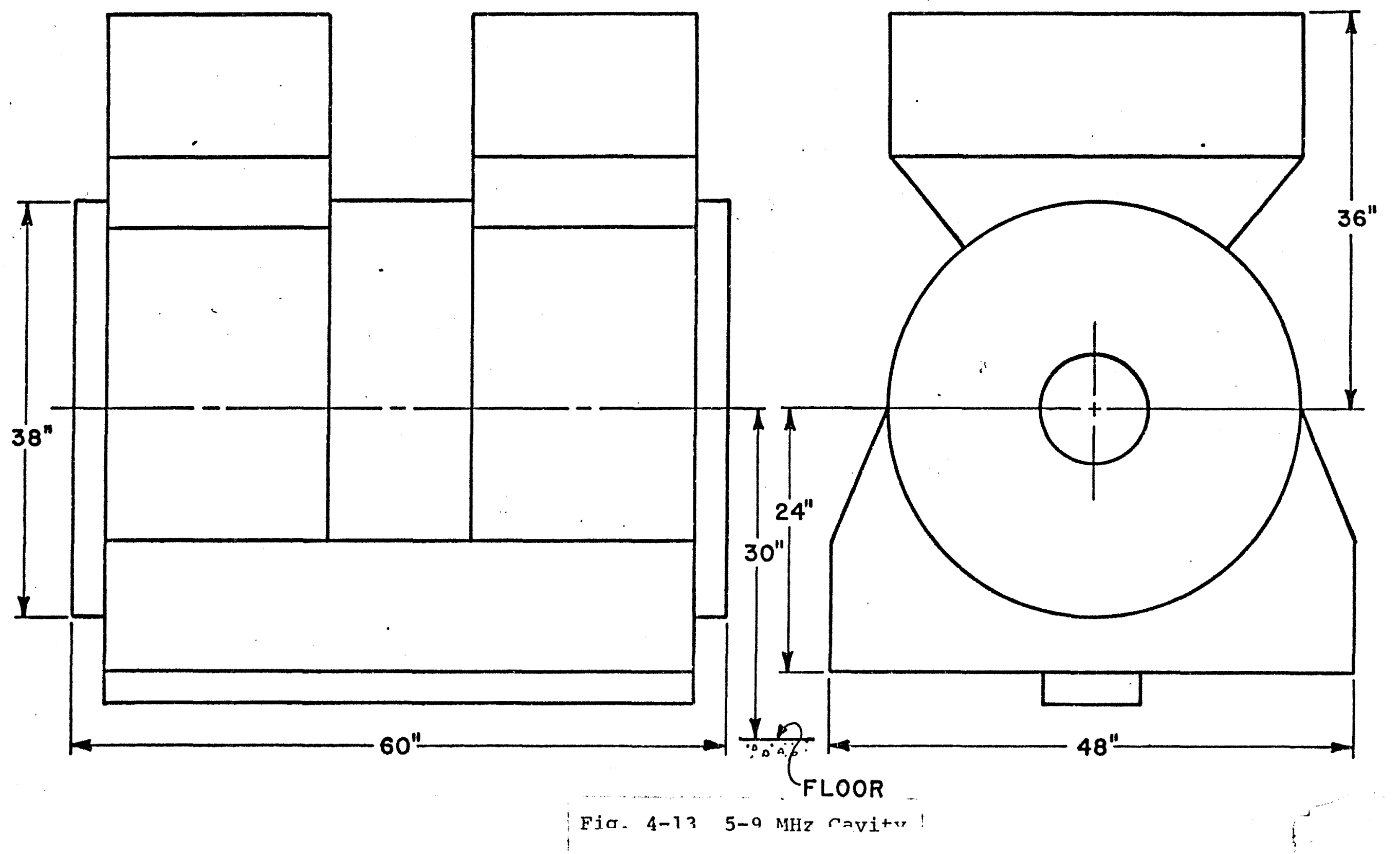


After $4.5 \mathrm{sec}$ of cooling at $\mathrm{T}=4.5 \mathrm{GeV}$, the momentum spread w111 be $0.28 \%$. This results in a total energy spread $\Delta E=17.2 \mathrm{MeV}$ and a longitudinal emittance of $27.6 \mathrm{eV} \mathrm{sec}$.

At $4.5 \mathrm{GeV}$, a $30 \mathrm{eV}$-sec stationary bucket area is established at $h=9$ by $11.6 \mathrm{kV}$. In this case, $\mathrm{T} \phi=6.38 \times 10^{-3} \mathrm{sec}$, so the adiabatic capture period may nominaliy be $25 \mathrm{msec}$. Then Vsin $\phi_{\mathbf{S}}=$ $6.33 \times 10^{3}$ volts.

Based on these considerations, the tabulations given in Table 4-IX are developed for the deceleration stages. 
First Stage

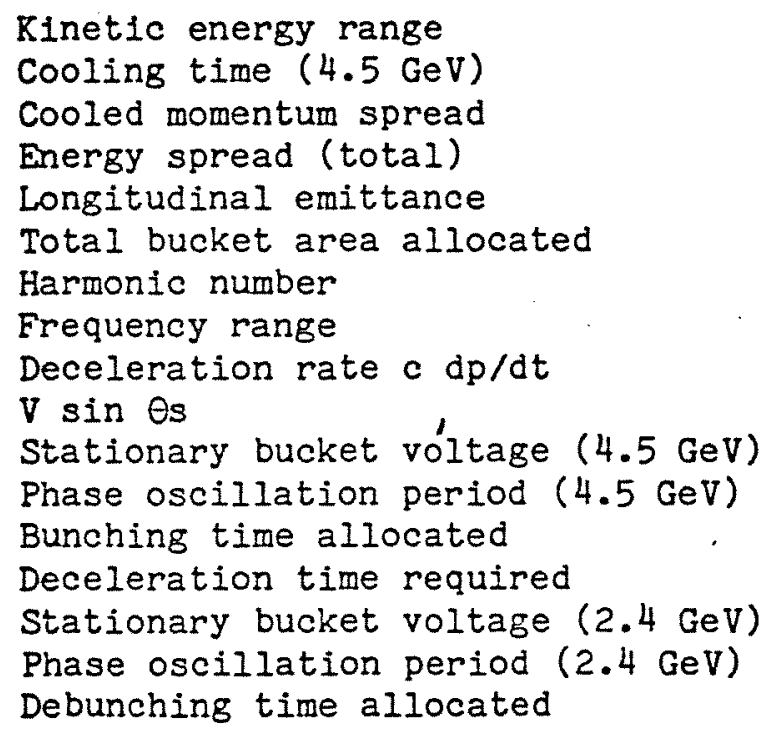

$\begin{array}{ccc}T(\mathrm{GeV}) & \phi s(\mathrm{deg}) & T \\ 4.5 & 0 & 0 \\ 4.4 & 12.3 & 0.213 \\ 4.0 & 10.4 & 0.181 \\ 3.5 & 8 & 0.139 \\ 3.0 & 6 & 0.104 \\ 2.5 & 4.3 & 0.075 \\ 2.4 & 0 & 0\end{array}$

Second Stage

R.E. range

Cooling time

Cooled momentum spread

Energy spread (total)

Longitudinal emittance

Bucket area allocated (total)

Harmonic number

Frequency range

Deceleration rate $c d p / d t$

$v \sin \theta s$

Stationary bucket voltage $(2.4 \mathrm{GeV})$

Phase oscillation period $(2.4 \mathrm{GeV})$

Bunching time

Deceleration time

Stationary bucket voltage ( $800 \mathrm{MeV})$

Phase oscillation period ( $800 \mathrm{MeV})$

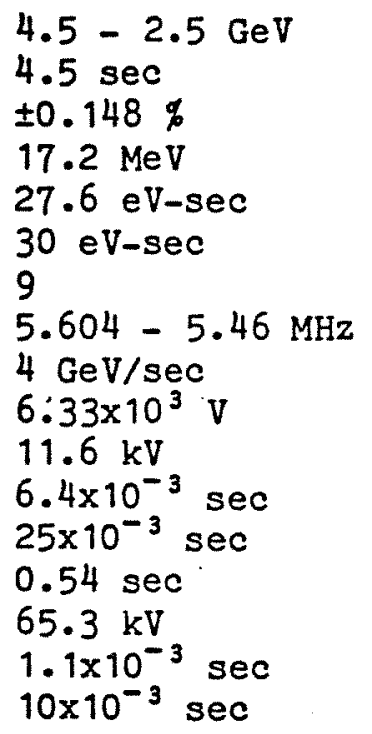

$\mathrm{V}(\mathrm{kV})$

Freq $(\mathrm{MHz})$

$\begin{array}{ll}11.6 & 5.604 \\ 29.7 & 5.601 \\ 34.9 & 5.59 \\ 45.5 & 5.56 \\ 60.8 & 5.52 \\ 84.4 & 5.47 \\ 65.3 & 5.46\end{array}$

$2.5-1.0 \mathrm{GeV}$
$1.5 \mathrm{sec}$
$\pm 0.064 \mathrm{q}$
$4.22 \mathrm{MeV}$
$6.94 \mathrm{eV}-\mathrm{sec}$
$7.5 \mathrm{eV}-\mathrm{sec}$
10
$6.067-5.322 \mathrm{MHz}$
$4 \mathrm{GeV} / \mathrm{sec}$
$6.33 \times 10^{-3} \mathrm{~V}$
$4.54 \mathrm{kV}$
$4.1 \times 10^{-3} \mathrm{sec}$
$20 \times 10^{-3} \mathrm{sec}$
$0.435 \mathrm{sec}$
$35.3 \mathrm{kV}$
$5 \times 10^{-4} \mathrm{sec}$


Debunching time

$\mathrm{T}(\mathrm{GeV})$

2.4

2.0

1.5

1.0

0.8

$$
\phi s(\operatorname{deg})
$$

0

16.8

12.6

8

0

$$
2.5 \times 10^{-3} \mathrm{sec}
$$

$v(k V)$

Freq $(\mathrm{MHz})$

4.54

6.067

21.9

29.0

45.5

35.3
5.99

5.835

5.54

5.322

Third Stage

K.E. range

Cooling time

Cooled momentum spread

Energy spread (total)

Longitudinal emittance

Bucket area allocated (total)

Harmonic number

Frequency range

Deceleration rate $c \mathrm{dp} / \mathrm{dt}$

$v \sin \theta s$

Stationary bucket voltage ( $800 \mathrm{MeV})$

Phase oscillation period

Bunching time

Deceleration time

Stationary bucket voltage (200 MeV)

Phase oscillation period (200 MeV)

Debunching time

$$
\begin{aligned}
& 800-200 \mathrm{MeV} \\
& 1 \mathrm{sec} \\
& \pm 0.0237 \% \\
& 584.1 \mathrm{KeV} \\
& 1.09 \mathrm{eV}-\mathrm{sec} \\
& 1.25 \mathrm{eV}-\mathrm{sec} \\
& 14 \\
& 7.45-5.01 \mathrm{MHz} \\
& 2 \mathrm{GeV} / \mathrm{sec} \\
& 3.17 \times 10^{3} \mathrm{~V} \\
& 1.37 \mathrm{kV} \\
& 2.25 \times 10^{-3} \mathrm{sec} \\
& 13 \times 10^{-3} \mathrm{sec} \\
& 0.409 \mathrm{sec} \\
& 5.0 \mathrm{kV} \\
& 6.2 \times 10^{-4} \mathrm{sec} \\
& 3 \times 10^{-3} \mathrm{sec}
\end{aligned}
$$

$\begin{array}{lcccl}T(\mathrm{GeV}) & \phi \mathrm{s}(\mathrm{deg}) & \Gamma & \mathrm{V}(\mathrm{kV}) & \text { Freq }(\mathrm{MHz}) \\ 0.8 & 0 & 0 & 1.37 & 7.45 \\ 0.7 & 22 & 0.3746 & 8.46 & 7.26 \\ 0.6 & 21 & 0.3584 & 8.84 & 7.01 \\ 0.4 & 17 & 0.2927 & 10.8 & 6.31 \\ 0.3 & 15.5 & 0.2670 & 11.86 & 5.78 \\ 0.2 & 0 & 0 & 5.0 & 5.01\end{array}$

4.6.2 Bunching for Extraction. At the end of the deceleration cycle, the debunched beam must be re-bunched into a single bunch of length and momentum spread suitable for injection into the Electron Cooling Accumulator. A total bunch of 1 usec will allow a kicker fall time in the electron ring of $200 \mathrm{n} \mathrm{sec.} \mathrm{We} \mathrm{assume}$ here a longitudinal emittance for the decelerated beam of 1.3 eV-sec. Such a beam, bunched at harmonic number one will have an energy spread of $\pm 827 \mathrm{kV}$ and a momentum spread of $\pm 2.26 \times 10^{-3}$. 
The bucket half-height required to match such a distribution is $1.55 \mathrm{MeV}$ with $\phi=1.124 \mathrm{rad}$. An rf voltage of $7 \mathrm{kV}$ at $357.9 \mathrm{kHz}$ is required to create such a bucket. The phase oscillation period is $7.8 \times 10^{-4} \mathrm{sec}$, so this bunching will require about $5 \mathrm{msec}$.

The 1-usec bunch can be generated with slightly small $\mathrm{rf}$ voltage by first bunching the beam to $\Delta \phi^{2} \pm \pi / 2$, or $1.4 \mu \mathrm{sec}$, then suddenly jumping the voltage slightly to an unmatched bucket in which the beam distribution rotates into the vertical position with a width of 1 usec, one quarter of a phase-oscillation period. The $\mathrm{rf}$ voltages necessary for these two steps are $2 \mathrm{kV}$ and $4 \mathrm{kV}$. The initial phase-oscillation period is $3.7 \mathrm{msec}$, so $10 \mathrm{msec}$ will be allowed for initial bunching. The final phase-oscillation period is $2.7 \mathrm{msec}$, so the quarter rotation will occur in about $670 \mu \mathrm{sec}$. Dimensions of the $\mathrm{h}=1$ cavity are shown in Fig. $4-14$ and its location was shown in Fig. 4-6.

\subsection{Transfer to and from the Electron Accumulator}

The lines used to transfer $200-\mathrm{MeV}$ beam from the Precooler to the Electron Accumulator and the line used to transfer cooled beam back to the Precooler are symmetric with each other, as can be seen in the layout of Fig. 4-15. Elements and parameters of the line back to the Precooler are given in Table 4-X, which could become the other line with only relabeliing of elements.

TABLE 4-X TRANSFER-LINE ELEMENTS FROM

ELECTRON ACCUMULATOR TO PRECOOLER

\begin{tabular}{|c|c|c|c|}
\hline & element & length & $\frac{\text { strength }}{(200 \mathrm{MeV})}$ \\
\hline $\begin{array}{l}\text { electron } \\
\text { cooling } \\
\text { ring }\end{array}$ & $\begin{array}{l}\text { 1B21 } \\
\text { 1K21 } \\
\text { 1QD2 } \\
\text { 1QF1 } \\
\text { C-magnet }\end{array}$ & $\begin{array}{l}\text { (m) } \\
1.5240 \mathrm{~m} \\
0.6767 \\
0.6787 \\
1.5240\end{array}$ & $\begin{array}{l}-240 \mathrm{G} \\
-10.97 \mathrm{kG} / \mathrm{m} \\
5.73 \mathrm{kG} / \mathrm{m} \\
1.33 \mathrm{kG}\end{array}$ \\
\hline $\begin{array}{l}\text { transfer } \\
\text { line }\end{array}$ & $\begin{array}{l}X Q 1 \\
X Q 2 \\
X Q 3 \\
X Q 4\end{array}$ & $\begin{array}{l}0.6767 \\
0.6767 \\
0.6767 \\
0.6767\end{array}$ & $\begin{array}{l}2.21 \mathrm{kG} / \mathrm{m} \\
-8.20 \mathrm{kG} / \mathrm{m} \\
12.88 \mathrm{kG} / \mathrm{m} \\
-7.96 \mathrm{kG} / \mathrm{m}\end{array}$ \\
\hline precooler & $\begin{array}{l}\text { C-magnet } \\
103\end{array}$ & $\begin{array}{l}1.5240 \\
1.5240\end{array}$ & $\begin{array}{l}1.76 \mathrm{kG} \\
9.80 \mathrm{kG} / \mathrm{m}\end{array}$ \\
\hline & $\begin{array}{l}\text { QD1 } \\
\text { Rick } \\
\text { Kick } \\
\text { QF1 }\end{array}$ & $\begin{array}{l}0.9905 \\
1.5967 \\
1.5967\end{array}$ & $\begin{array}{l}-10.08 \mathrm{kG} / \mathrm{m} \\
88.8 \mathrm{G} \\
88.8 \mathrm{G}\end{array}$ \\
\hline
\end{tabular}



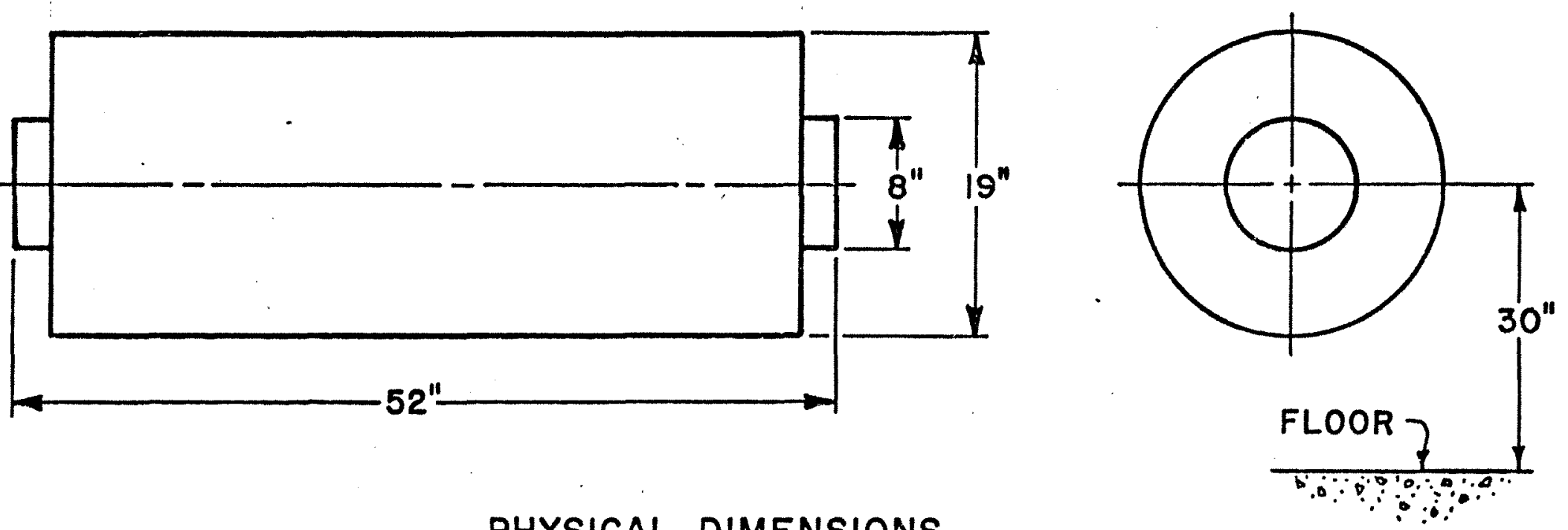

PHYSICAL DIMENSIONS

FIRST HARMONIC BUNCHING CAVITY

FOR BOTH PRECOOLER \& ELECTRON COOLING RING

(SUPPORTS NOT SHOWN)

Fig. $4-14 \quad h=1$ Cavity 
Exact values for $X Q 1-X Q 4$ w1ll change slightly due to detalled watching.

\subsection{Acceleration in the Precooler}

Single antiproton bunches with longitudinal emittance of approximately $0.075 \mathrm{eV}-\mathrm{sec}$ are to be accelerated from $204 \mathrm{MeV}$ to 8 $\mathrm{GeV}$ in the Precooler at harmonic number 14. The acceleration system consists of three PPA rf cavities operating over the frequency range 5.01 to $8.802 \mathrm{MHz}$. This is the same system used for Precooler deceleration.

The stationary bucket necessary to match the bunch shape extracted from the Electron Ring requires $3.8 \mathrm{kV}$ at $5.0 i \mathrm{MHz}$. The acceleration rate will be $8 \mathrm{GeV}$ per second and a bucket area of at least $0.09 \mathrm{eV}-\mathrm{sec}$ will be maintained during acceleration. The net accelerating voltage $\mathrm{V}$ Sin $\phi_{\mathrm{s}}$ will be $12.7 \mathrm{kV}$ per turn. The acceleration will require about 1 second.

At the beginning of acceleration, just above $204 \mathrm{MeV}$, a maximum voltage of $30 \mathrm{kV}$ and a synchronous phase angle of 25 degrees are required. As acceleration progresses, the voltage and phase angle both change so that just below $8 \mathrm{GeV}$ the required voltage becomes $13 \mathrm{kV}$ and the synchronous phase angle 75 degrees.

At $8 \mathrm{GeV}$, a stationary bucket of sufficient size must be established so that the antiproton bunch length is shorter than the Main Ring bucket length $(18.9 \mathrm{nsec})$ into which it is to be injected. If the voltage is raised to $15 \mathrm{kV}, \mathrm{a} 0.09 \mathrm{eV}-\mathrm{sec}$ bunch in equilibrium with the bucket will have a bunch length of 8 nsec, which can be matched easily by a stationary bucket in the Main Ring. The phase-oscillation period in this bucket will be 1.5 msec, so the stationary bucket can be established in $10 \mathrm{msec}$ at the end of the acceleration cycle.

\subsection{8-GeV Extraction and Transport}

Extraction is carried out in a single-turn mode by a fast kicker and pulsed septum at the upstream end of the east straight section, followed by a non-achromatic horizontal translation to a line parallel to the beam center line in the east straight secction and $1.0668 \mathrm{~m}$ from it. A FODO system located in three manholes leads to a left bend that puts the beam directly underneath the 4.5-GeV injection line. The beam is then translated up $1.9666 \mathrm{~m}$ by an achromatic system to join the other beam line. The system is designed to contain a beam of transverse emittance $2 \pi \mathrm{mm}$-mrad in each plane and momentum spread $0.4 \%$. A list of elements is given in Table 4-XI. 


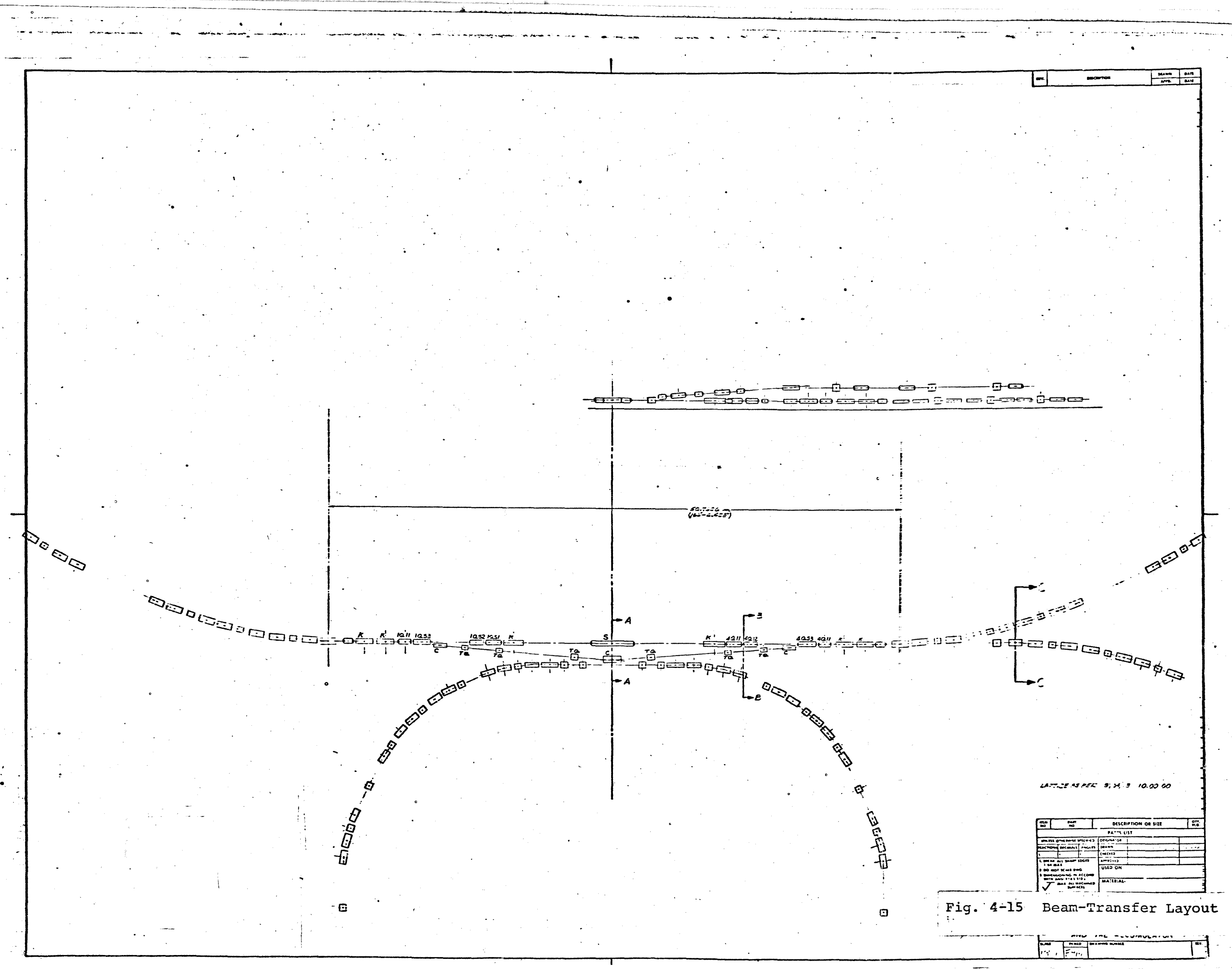


TABLE 4-XI ANTI-PROTON EXTRACTION FROM THE PRECOOLER

\section{Kicker}

$250 \mathrm{G}$

Strength

Rise Time

Aperture

Effective Length $\underline{\text { Kicker }}$

$250 \mathrm{G}$

2m $2 \mathrm{~m}$

Method: Single-turn fast extraction, full-aperture kicker

Extraction occurs horizontally, to outside, at upstream end of East long straight section

Beam Enittances: $\quad E_{H}=E_{V}=7 \pi \quad 10^{-6} \mathrm{~mm}-\mathrm{mrad}$

1

Momentum Spread: $\quad \pm 0.1 \%$

Magnet Sequence:

1. Translator

2. Long Straight Transport

3. Bend Left

4. Matching and Vertical Translation

5. Matching FODO

6. Matching and FODO Transport

7. Vertical Translation to Target

1. Translator

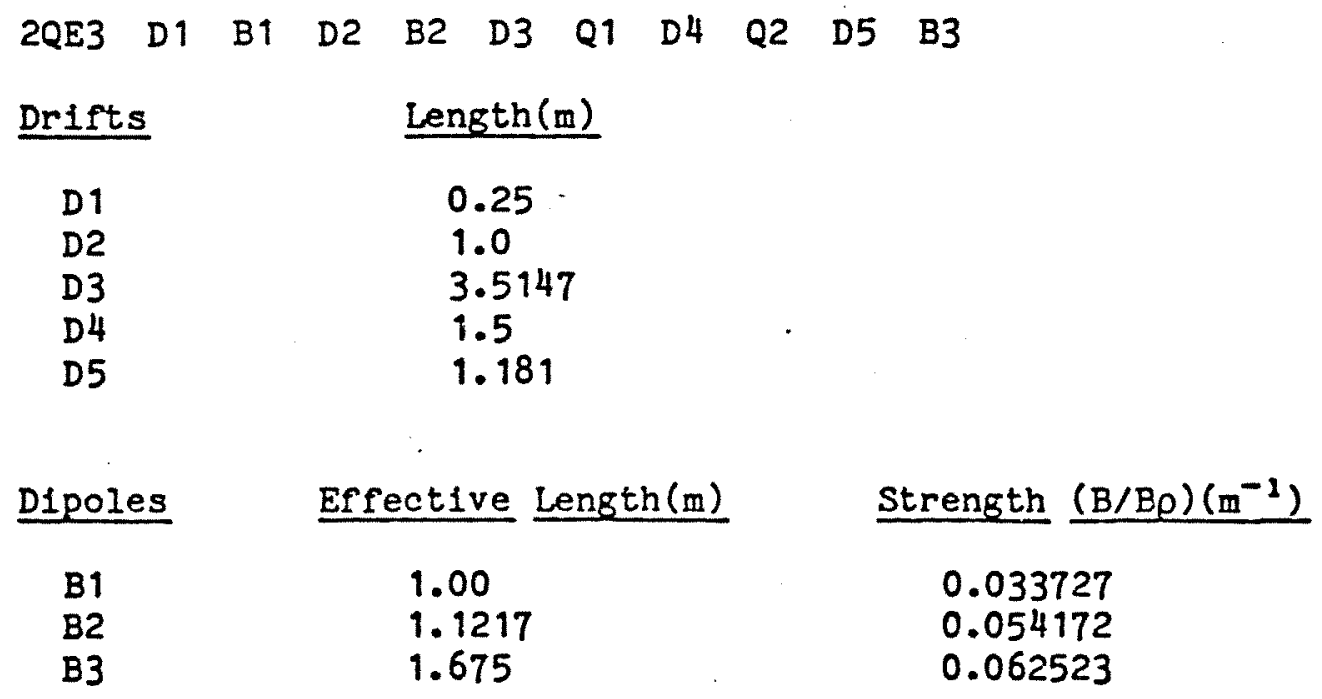


$\begin{array}{ccc}\text { Quadrupoles Effective Length }(f t) & \text { Gradient }\left(B^{\prime} / B_{\rho}\right)\left(m^{-2}\right) \\ \text { Q1 } & 2 & 0.5296 \\ \text { Q2 } & 2 & -0.4697\end{array}$

2. Long Straight Transport

$\begin{array}{lllllllllllll}\text { D6 } & \text { Q3 } & \text { D2 } & \text { Q4 } & \text { D7 } & \text { QF } & \text { D8 } & \text { QD } & \text { D8 } & \text { QF } & \text { D8 } & \text { QD } & \text { D9 }\end{array}$

Drifts $\quad$ Length (m)

D6 14.332

D7 $\quad 5.3904$

D8. $\quad 14.0757$

D9 $\quad 10.2205$

D2 $\quad 1.00$

Quadrupoles Effective Length(ft) Gradient $\left(\mathrm{B}^{\prime} / \mathrm{B} \rho\right)\left(\mathrm{m}^{-2}\right)$

$\begin{array}{llc}\text { Q3 } & 2 & 0.42314 \\ \text { Q4 } & 2 & -0.4295 \\ Q F & 2 & 0.1602 \\ Q D & 2^{1} & -0.1602\end{array}$

3. Bend Left

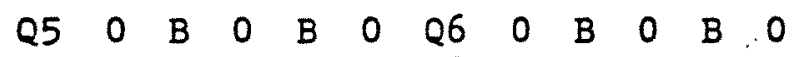

$\begin{array}{lllllllllllll}\text { Q7 } & 0 & \text { B } & 0 & \text { B } & 0 & \text { Q8 } & 0 & \text { B } & 0 & \text { B } & 0 & Q 9 / 2\end{array}$

Drift Depth

$0 \quad 0.5 \mathrm{~m}$

Bending Effective Depth $\quad$ Strength (B/BP)

B $\quad 1.3716 \mathrm{~m} \quad 0.040929 \mathrm{~m}^{-1}$

Quadrupoles Effective Length(ft) Strength $\left(\mathrm{B}^{\prime} / \mathrm{B}^{\mathrm{f}}\right)\left(\mathrm{m}^{-2}\right)$

\begin{tabular}{|c|c|c|}
\hline $\begin{array}{l}\text { Q5 } \\
\text { Q6 } \\
\text { Q7 } \\
\text { Q8 } \\
Q 9 / 2\end{array}$ & $\begin{array}{l}2 \\
2 \\
4 \\
2 \\
2\end{array}$ & $\begin{array}{c}0.4216 \\
-0.3443 \\
0.32715 \\
-0.2784 \\
0.43036\end{array}$ \\
\hline
\end{tabular}

4. Matching and Vertical Translation

$\begin{array}{lllllll}Q 9 / 2 & D 2 & Q 10 & D 11 & V 3 & D 12 & Q 11\end{array}$

$\begin{array}{llllll}D 13 & \text { Q12 } & \text { D13 } & \text { Q11 } & \text { D12 } & \bar{V} 3\end{array}$

Drifts Lengths (m) 
$\begin{array}{ll}\text { D11 } & .6954 \mathrm{~m} \\ \text { D12 } & 5.9185 \\ \text { D13 } & 4.999 \\ \text { D2 } & 1.00\end{array}$

Quadrupole Effective Length(ft) Strength $\left(B^{\prime} / B^{\prime} \rho\right)\left(\mathrm{m}^{-2}\right)$

$\begin{array}{llc}\text { Q9/2 } & 2 & 0.43036 \\ \text { Q10 } & 4 & -0.4687 \\ \text { Q11 } & -0.54850 \\ \text { Q12 } & 2 & 0.4423\end{array}$

Vertical Dipoles Effective Length $(m)$ Strength $(B / B \rho)\left(m^{-1}\right)$
$\frac{\mathrm{v} 3}{\mathrm{~V} 3}$
1.3716
1.3716
(up) 0.036928
(down) 0.036928

5. Matching FODO

$\begin{array}{llllll}0 & \text { Q13 } & \text { D14 } & \text { Q14 } & \text { D4 } & \text { QF/2 }\end{array}$

Drift Lengths(m)

$\begin{array}{ll}0 & 0.5 \\ \text { D } 14 & 1.354 \\ \text { D4 } & 1.5\end{array}$

Quadrupoles Effective Length(ft) Strength $\left(B^{\prime} / B^{\prime} \rho\right)\left(m^{-2}\right)$

$\begin{array}{llc}\text { Q13 } & 2 & -0.45869 \\ \mathrm{Q} 14 & 2 & 0.34931 \\ \mathrm{QF} / 2 & 1 & 0.1602\end{array}$

6. Matching and FODO Transport

QF/2 D9 QD D9 QF

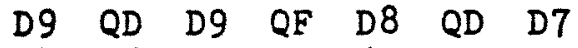

Q4 D6 Q3 D5 (in the middle of $\bar{v}$ )

Drifts Lengths (m)

D5 3.0

D6 $\quad 3.1962$

D7 $\quad 1.6916$

DB $\quad 2.574$

D9 $\quad 14.0757$

Quadrupoles Effective Length(ft) Strength(B//Bp)(m-2)

$\begin{array}{llc}\text { QF/2 } & 1 & 0.1602 \\ \text { Q3 } & 2 & -0.52436 \\ \text { Q4 } & 2 & 0.34452\end{array}$



QD
2
$-0.1602$
QF
2
0.1602

7. Vertical Translation to Target

$\begin{array}{lllllll}\text { D1 } & \bar{V} 1 & \text { D2 } & \text { Q7 } & \text { D3 } & \text { Q2 } & \text { D4 }\end{array}$

Q1 D4 Q2 D3 Q1 D2 V1 D1

Drifts

Length (m)

D1

D2

D3

$-0.915$

3.8359

1.5

D4

3.50

Quadrupoles

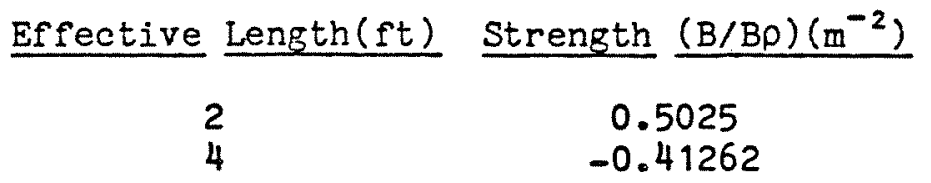

Vertical Dipoles Effective Length $(\mathrm{m})$ Strength $(\mathrm{B} / \mathrm{BP})\left(\mathrm{m}^{-1}\right)$

V1 $\quad 1.83$

(up) 0.05726

V1

1.83

(down) 0.05726 
5. Electron Cooling Accumulator

5.1 General Structure and Layout

5.1.1 Lattice. The design parameters of the Electron Cooling Accumulator have been chosen to allow efficient electron cooling to be carried out in a range between 200 and $450 \mathrm{MeV}$, and possibly as high as 1-GeV antiproton energy.

The overall design of this ring is very similar to that of the present Electron Cooling Ring and has essentially the same constraints. The intended mode of operation is to inject $\bar{p}$ 's from the Precooler into the Accumulator, precool them with electron cooling and then momentum displace the injected beam into a stack, which will also be electron cooled. Thus the ring needs a straight section appropriate for injection and extraction and another one for cooling. For injection and extraction, it is desirable to have large horizontal dispersion and small beam sizes. The length of this straight section need not be too great. The cooling straight section, on the other hand, should be quite long, zero dispersion, and have $\bar{p}$-beam sizes matched to electron-beam sizes, approximately 1 in. in radius. One would like to have as large a percentage of the circumference as possible filled with electron cooling, subject to several considerations. The expense and difficulty of the cooling system, as well as the nonlinear end effects of solenoid, toroids, and electron beam on the $\bar{p}$ 's effectively limit the number of cooling systems to one, and the beam-size variation through the cooling region limits the length of that region. The desire for some superperiodicity produces at least a four-sided figure. The final design of this ring, then, is generally the same as the present cooling ring. It is a racetrack design having two long straight sections. One long straight section will be used for electron cooling; the two short straight sections will be used for injection and extraction and for such functions as a beam dump. The main difference between this new ring and the present one is in the overall circumference, the fraction of the ring used for cooling, and the maximum energy of the ring. The ring has a circumference of some $203 \mathrm{~m}$, and will have $10 \mathrm{~m}$ of electron cooling, compared with $135 \mathrm{~m}$ and $5 \mathrm{~m}$ of cooling the present experiment. The structure and lattice parameters for this ring are listed in Table 5-I, and the lattice functions are piotted in F18. 5-1. Horizontal and vertical aperture requirements are shown in Figs. 5-2 and 5-3.

The ring has been designed to use the same magnets as in the present Electron Cooling Ring, with new ones to be built to piece out the circumference. A total of $444-\mathrm{ft}$ dipoles and $48 \mathrm{f}-\mathrm{ft}$ quadrupoles with sizes and apertures as in the present magnets are needed. At present, 24 dipoles and 32 quadrupoles exist. In addition, two 2-ft special quads with a good-field region of $30 \mathrm{~cm}$ are required for injection. The totals given here include six standard quadrupoles required for transfer to and from the 


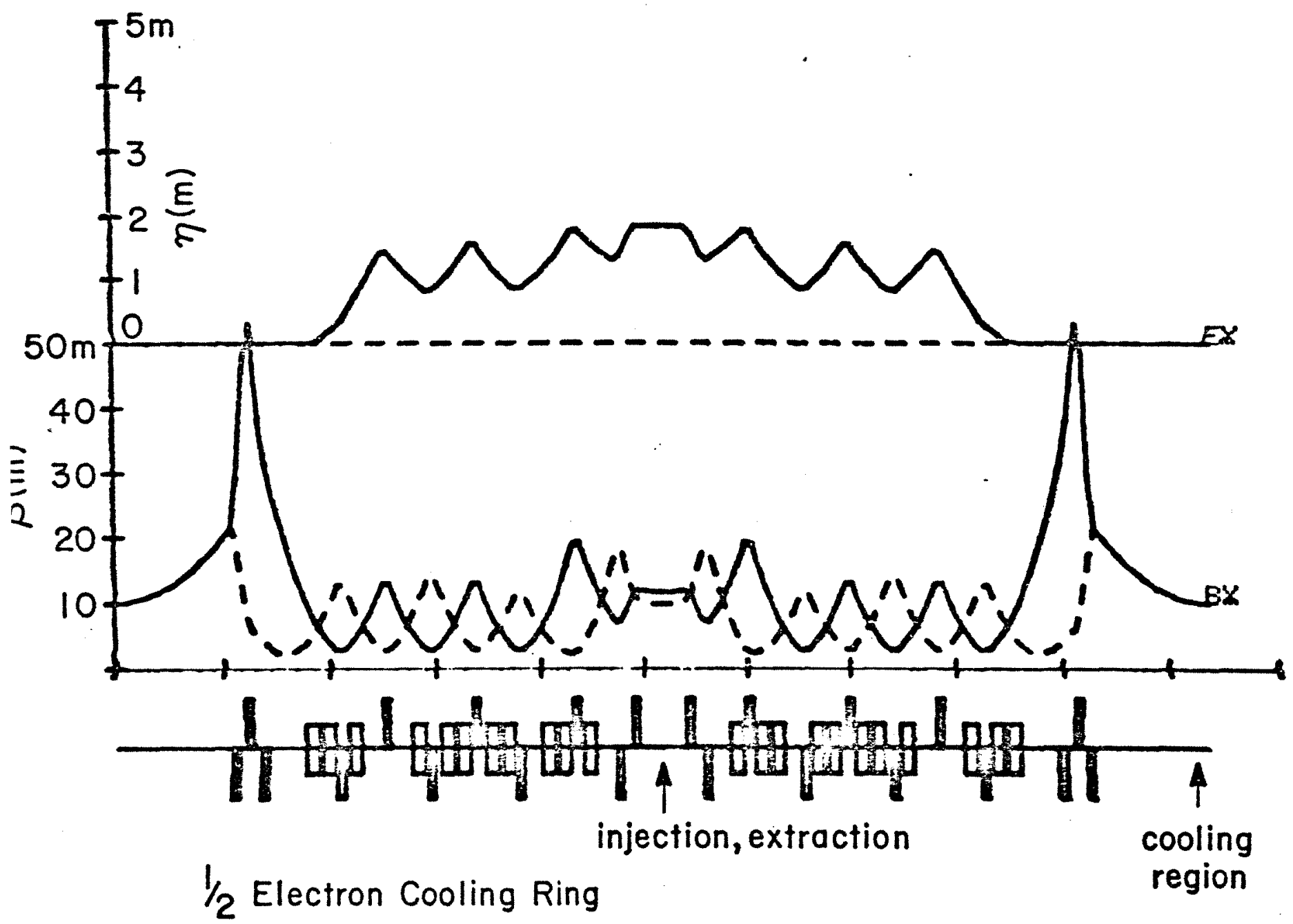

Fig. 5-1 Electron Accumulator Orbit Functions 


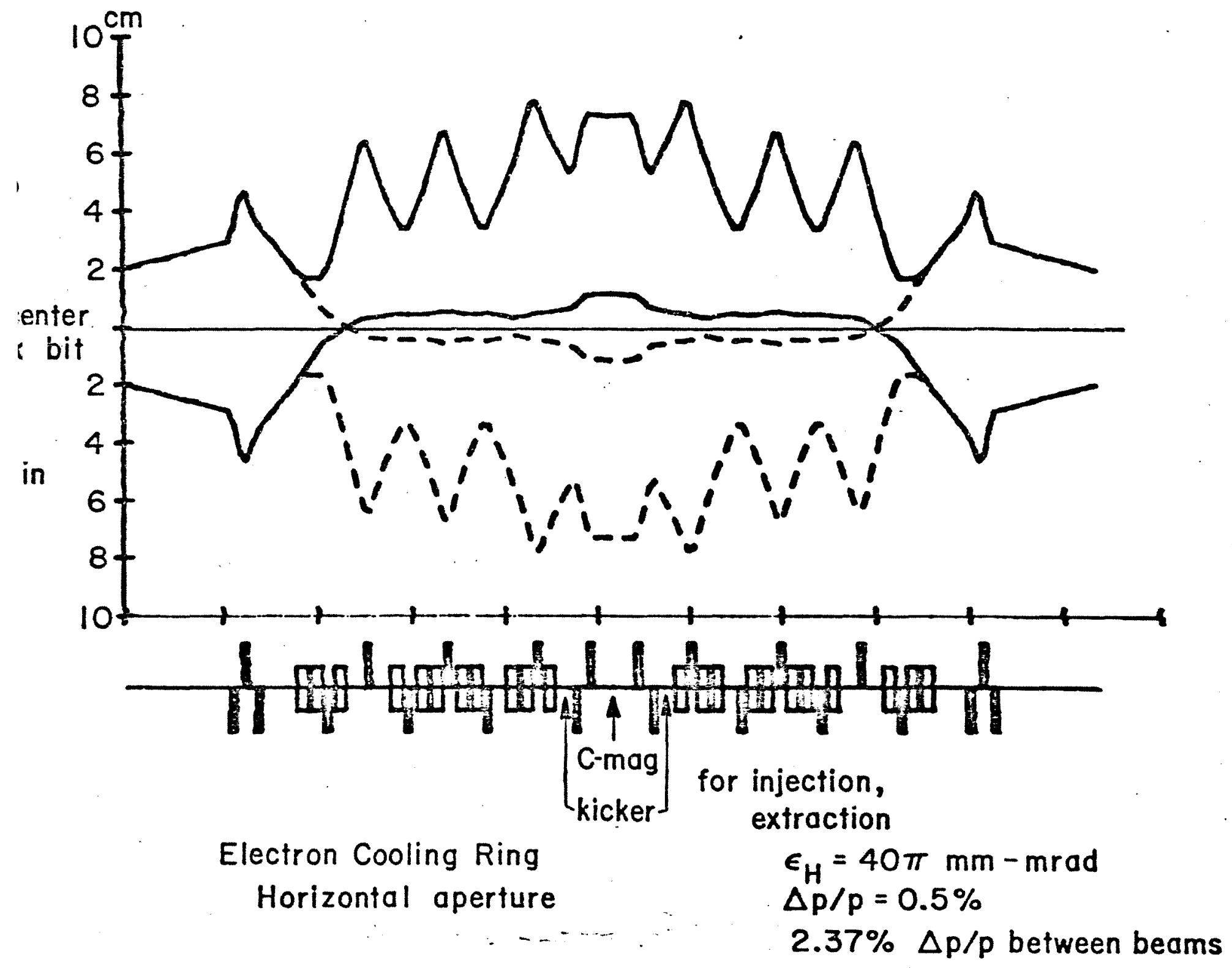

Fig. 5-2 Accumulator Horizontai Aperture Requirements 
TABLE 5-I ELECTRON COOLING RING ACCUMULATOR PARAMETERS

1. General.

$\begin{array}{lc}\text { Energy } & 200 \mathrm{MeV}-1.0 \mathrm{GeV} \\ \text { Corresponding bend field } & 2.35 \mathrm{kG}-6.17 \mathrm{kG} \\ \text { Magnetic bend radius }(\rho) & 9.17 \mathrm{~m} \\ \text { Radius } & 32.35 \mathrm{~m} \\ & =36 / 1113 \mathrm{MR} \text { radius } \\ \text { Revolution time } & 1197-775 \mathrm{nsec} \\ \text { Superperiodicy } \quad & 2 \\ \quad \text { without electron beam } & 1 \\ \quad \text { Hith electron beam } & \text { Separated function } \\ \text { Focusing structure } & \text { FODO normal cell } \\ \text { Nominal working point } & v_{\mathrm{H}} 4.102 \\ & v_{\mathrm{V}}^{\mathrm{H}} 5.367 \\ & \gamma_{\mathrm{T}} 4.084 \\ \text { Natural chromaticity } & \xi_{\mathrm{H}}-6.460 \\ & \xi_{\mathrm{V}}^{\mathrm{H}}-6.096\end{array}$

2. Magnets

$\begin{array}{ll}\text { Number of dipoles } & 44 \\ \text { Length of dipoles } & 48.00 \mathrm{in} . \\ \text { Effective length of dipoles } & 51.52 \mathrm{in} . \\ \text { Number of quadrupoles } & 44 \\ \text { Length of quadrupoles } & 24.00 \mathrm{in} . \\ \text { Effective length of quadrupoles } & 26.64 \mathrm{in} .\end{array}$

Quadrupole gradients at $1.0 \mathrm{GeV}$

$\begin{array}{lr}\text { QF } & 28.70 \mathrm{kG} / \mathrm{m} \\ \text { QD } & -26.47 \\ \text { Q1 } & -37.89 \\ \text { Q2 } & 43.82 \\ \text { Q3 } & -9.90 \\ \text { Q9 } & 22.69 \\ \text { Q10 } & -28.84 \\ \text { Q11 } & 15.07\end{array}$

3. Structure

A. Curved section

Elements in curved section Length

$\begin{array}{lll}\text { Dipole } & (B) & 4 \mathrm{ft} \\ \text { Quadrupole } & (Q) & 2 \mathrm{ft} \\ \text { Drift space } & (0) & 1 \mathrm{ft} \\ \text { Drift space } & (00) & 2 \mathrm{ft}\end{array}$


Cell structure

(QD) 0 (B) 0 (B) 00

(QF) 0 (B) 0 (B) 00

Cell length

$28 \mathrm{ft}$

B. Short straight

$\begin{array}{lll}\text { Drift space } & \text { (SS) } & 6.90 \mathrm{ft} \\ \text { Drift space } & \text { (S1) } & 3.40 \mathrm{ft} \\ \text { Drift space } & \text { (S2) } & 6.56 \mathrm{ft} \\ \text { Drift space } & \text { (S3) } & 5.77 \mathrm{ft}\end{array}$

C. Long straight

$\begin{array}{llr}\text { Drift space } & \text { (LS) } & 31.80 \mathrm{ft} \\ \text { Drift space } & \text { (L1) } & 2.00 \mathrm{ft} \\ \text { Drift space } & \text { (L2) } & 2.62 \mathrm{ft} \\ \text { Drift space } & \text { (L3) } & 12.00 \mathrm{ft}\end{array}$

D. Dispersion suppressor

$\begin{array}{lll}\text { Drift space } & \text { (D1) } & 1.10 \mathrm{ft} \\ \text { Drift space } & \text { (D2) } & 6.90 \mathrm{ft}\end{array}$

E. Quadrant structure (Q)

SS (Q11) S1 (Q10) S2 (B) O (Q9) O (B) O (B)

S3 (QD) 0 (B) 0 (B) 00 (QF) 0 (B) 0 (B)

00 (QD) D1 (B) D2 (QF) D2 (B) D1 (QD) 0 (B)

O (B) L3 (q3) L2 (Q2) L1 (Q1) LS

F. Ring structure

$Q(\bar{Q}) Q(\bar{Q})$

Length of central orbit

$203.2296 \mathrm{~m}$

$666.76 \mathrm{ft}$

4. Aperture and Acceptance

Nominal vacuum chamber aperture

$$
\begin{aligned}
& a_{H}= \pm 89 \mathrm{~mm} \\
& a_{V}= \pm 25 \mathrm{~mm} \\
& 21.8 \mathrm{~mm} \\
& a_{H}= \pm 78 \mathrm{~mm}
\end{aligned}
$$

sagitta

available aperture

Lattice functions

$\begin{array}{lllll} & \text { Maxima } & \text { In dipole } & \text { L.S. } & \text { S.S. } \\ B_{\mathrm{H}} & 48.23 \mathrm{~m} & 19.50 \mathrm{~m} & 12.93 \mathrm{~m} & 10.37 \mathrm{~m} \\ \mathrm{~B}_{\mathrm{V}} & 19.44 & 13.25 & 10.11 & 11.48 \\ \eta_{\mathrm{H}} & 3.65 & 3.65 & 0.06 & 3.51\end{array}$

Acceptance (using beam size in dipoles) 


$$
\begin{array}{lc}
a_{V}= \pm 25 \mathrm{~mm} & A_{V}=47 \pi \mathrm{mm}-\mathrm{mrad} \\
a_{H}= \pm 78 \mathrm{~mm} & A_{H}=40 \pi \mathrm{mm}-\mathrm{mrad} \\
& \Delta p / p) \text { beam }= \pm 0.25 \%
\end{array}
$$

$$
\Delta p / p \text { (beam-to-beam) } 2.37 \%
$$

(This is the acceptance for two beams as given with a separation of $10 \mathrm{~mm}$ at an injection kicker.)

5. Beam angles in electron cooling long straight section

$$
\begin{array}{ll}
\theta_{11}=\sqrt{ } / \pi \beta^{*} \mathrm{LS} & \theta_{\mathrm{H}}=1.76 \mathrm{mrad} \\
\theta \text { perp } \sim \gamma \Delta \mathrm{p} / \mathrm{p} & \theta_{\mathrm{V}}=2.17 \mathrm{mrad} \\
& \theta \text { perp }=6 \mathrm{mrad}-10 \mathrm{mrad}
\end{array}
$$

Precooler ring. 
Precooler ring. Finally, two 5-ft kickers with movable shutters and one 5-ft C-magnet are required for injection and extraction. These need to reach fields of $380 \mathrm{G}$ and $2.4 \mathrm{kG}$, respectively, at an antiproton energy of $450 \mathrm{MeV}$.

5.1.2 Layout. The accumulator is located south of the Precooler, with the beam line in the South straight section of the Precooler separated from the beam line in the North straight section of the accumulator by $2 \mathrm{~m}$., At this junction, they are in a common building (see Chapter 7 .

The North short straight section is occupied by the components for transfer to and from the Precooler described in the previous section. The West straight section is occupied by electron cooling equipment. The first harmonic $\mathrm{rf}$ system is small enough that it can be located in a short straight section. Fig. $5-4$ is a layout of the Accumulator ring.

\subsection{Injection}

Injection into the accumulator is a simple single-turn matter, with tive 5-ft kicker and 5-ft $c$ magnet described in section 5.1 .1 .

\subsection{Magnets}

The Accumulator magnets will be taken from the present Electron Cooling Ring. The 20 additional dipoles and 16 additional quadrupoles will be built from the existing lamination dies and coil forms. The present magnets have shown themselves to be very reliable (none have failed) and of excellent field quality. Measured fields are shown in Figs. 5-5 and 5-6.

\subsection{Electron Cooling System}

5.4.1 Equipment Description. The Electron Cooling System is basically similar to the one in present use. Its design parameters are given in Table 5-II, and Fig. 5-7 shows an over-all view.

Except for problems of reliability, the existing electron cooling system would be adequate for accumulation at $200 \mathrm{MeV}$. Our experience tells us that:

(1) a new solenold design must be adopted to eliminate fallures and cooling limitations in the existing units and, 


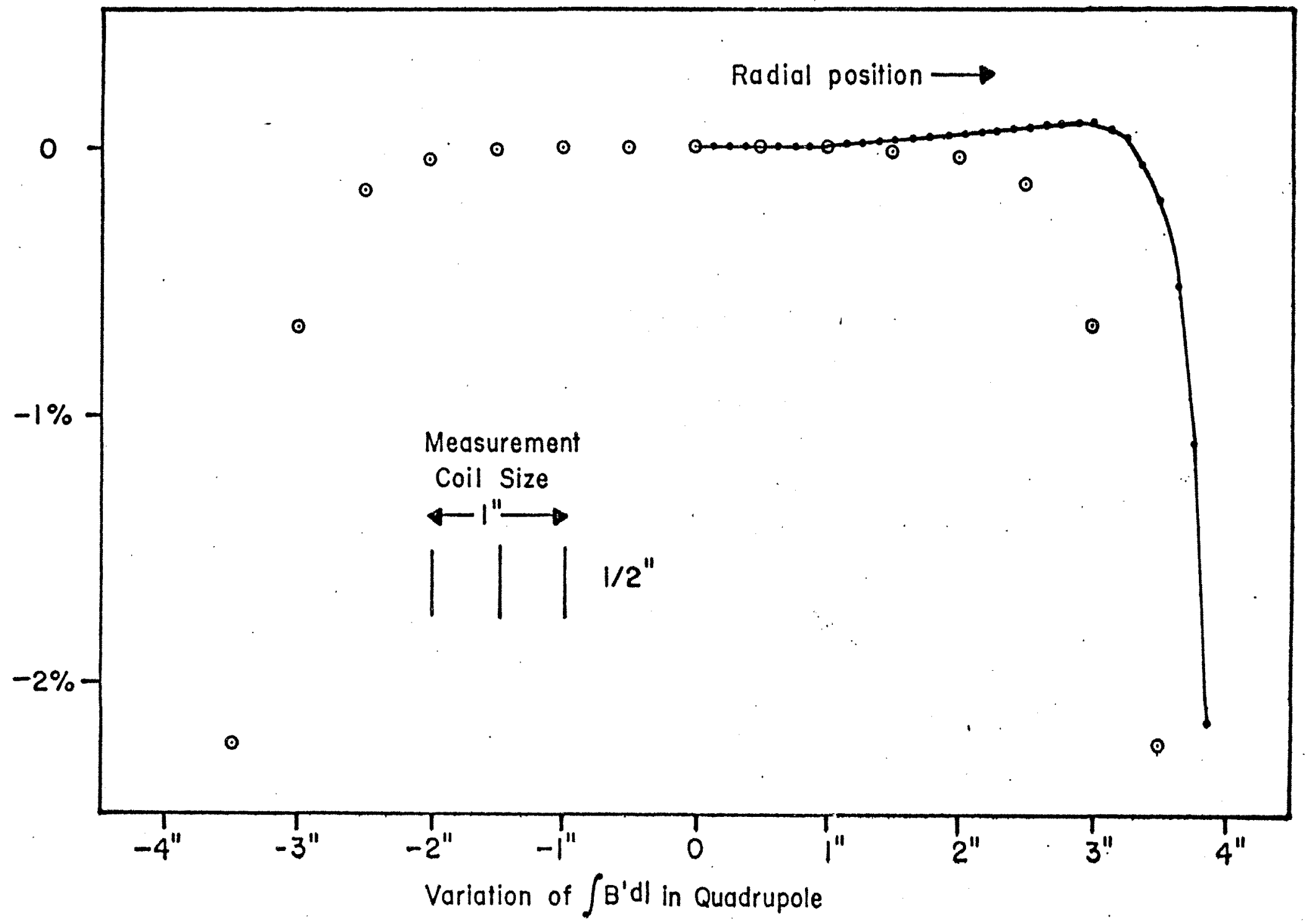

Computed for center of Quadrupole

$\odot \odot \odot$ Measured Integral (Magnet 1037)

Fig. 5-6 Measured Accumulator Quadrupole Fields 


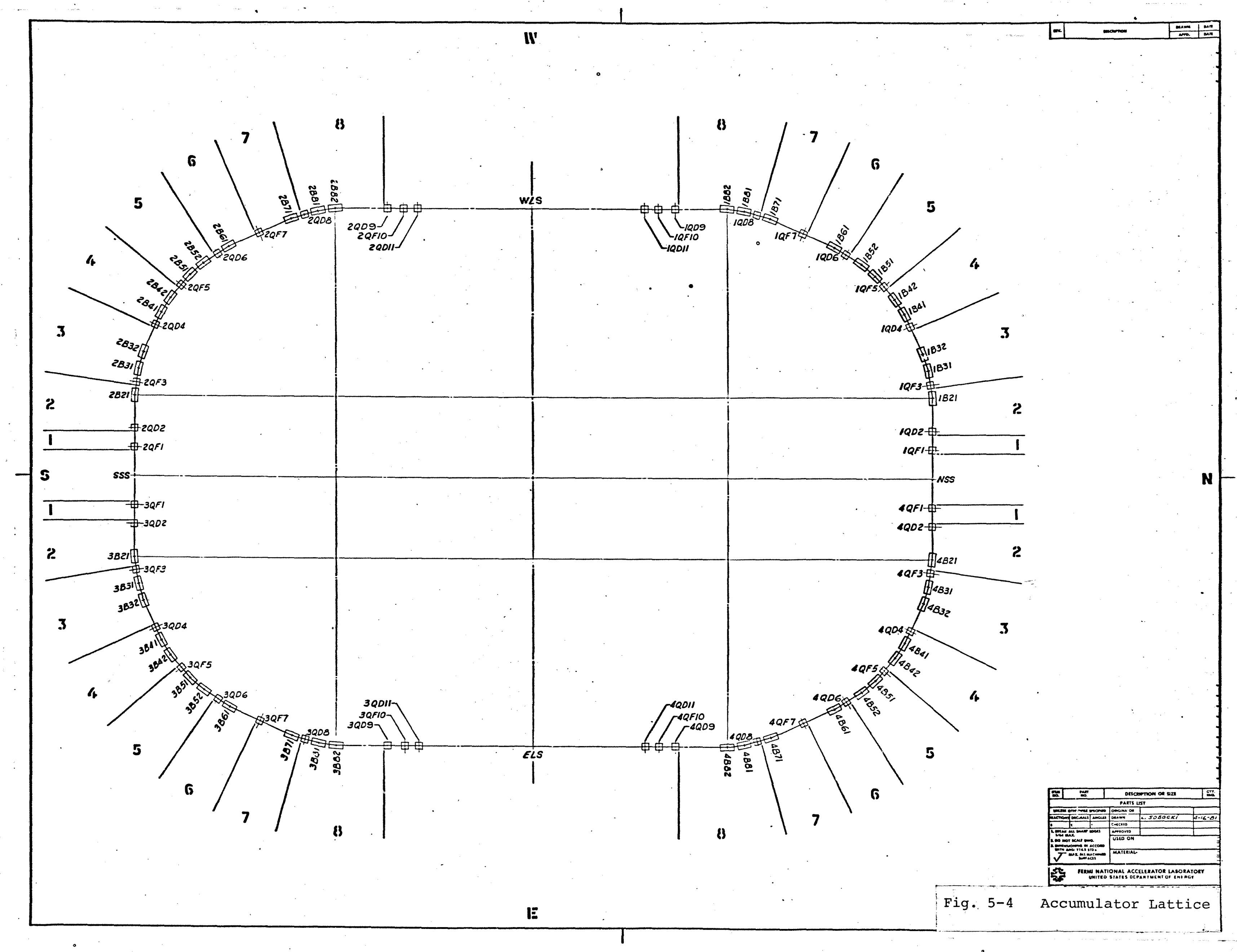




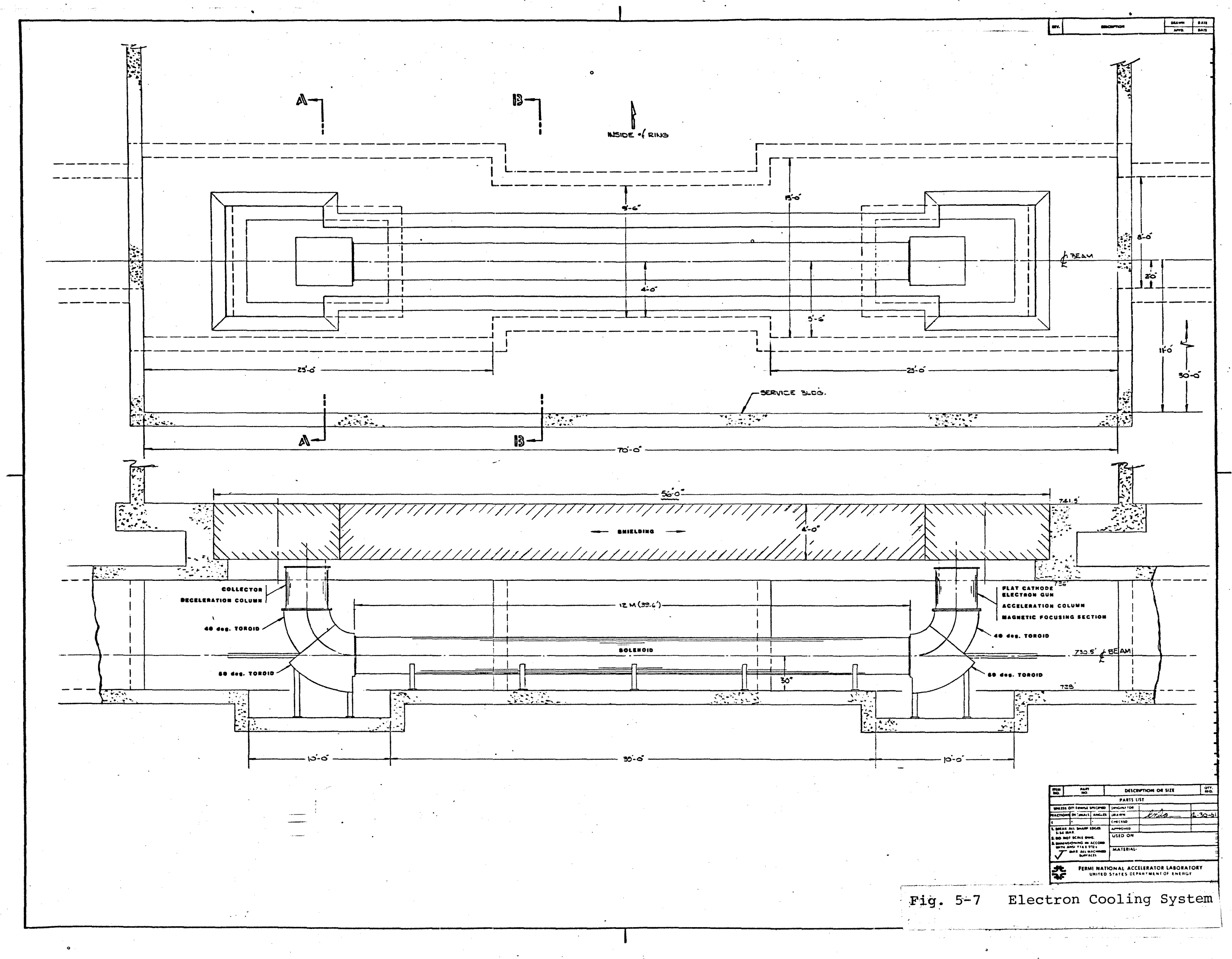


TABLE 5-II ELECTRON COOLING SYSTEM DESIGN PARAMETERS

$\begin{array}{ll}\text { Beam Current (max) } & 10 \mathrm{~A} \\ \text { Cooling Length } & 12 \mathrm{~m} \\ \text { Overall Length } & 16 \mathrm{~m} \\ \text { Solenoid Guide Field (max) } & 2 \mathrm{kG} \\ \text { Magnet Power Requirement (1.5kG) } & 120 \mathrm{~kW} \\ \text { Collection Inefficiency } & <10^{-3} \\ \text { Cathode Diameter } & 5 \mathrm{~cm} \\ \text { Beam Diameter (int. region) } & 5-10 \mathrm{~cm} \\ \text { High Voltage Supply Power (max) } & \\ \quad \quad \text { collector } \quad 3 \mathrm{~kW} \\ \text { gun Perveance } & 2.5 \mathrm{~kW} \\ \text { High-Voltage Insulation } & 1.5 \mu p e r v \\ \text { High-Voltage Switching Range } & \mathrm{SF} 6 \text { (atmospheric) } \\ \end{array}$

(ii) the high-voltage terminals and columns at the gun and collector ends ought to be accessible for maintenance without breaking the high-vacuum system.

A new solenoid is needed in any case because the length is greater ( $12 \mathrm{~m}$ vs. $5 \mathrm{~m}$ for the existing one) and several designs have therefore been developed for constructing long, highly uniform solenoids. The second criterion is one reason for proposing that the cooling system be built with electron gun and collector totally immersed in the solenoid guide field. This allows removal of enough of the solenoid (by sliding off the ends) for direct inspection, baking of the high-voltage section, and modification or repair. The toroid and solenoid-to-beam pipe clearances are also to be made larger. Both gun and collector will be on the same side of the beam. A doglegged gun and collector (as in the existing system) cancels certain abevration of the $\bar{p}$ lattice, which we believe will be managable with electron beams of less than $10 \mathrm{~A}$.

The upgrade from our existing equipment will include major improvement of the high-voltage supply. The basic supply is apparently adequate for reliable $220-\mathrm{kV}$ operation. Most of the control and regulation circuitry needs replacement or rebuilding. The significant new capability that must be built into the supply is to switch rapidly ( $<100 \mathrm{msec}$ ) between stack energy and injection-ejection energy. At $400 \mathrm{MeV}$ ( $218 \mathrm{keV}$ electron energy), this will be an $8.5 \mathrm{kV}$ change, which will be supplied by a new programmable supply floating at cathode potential.

The other important motivation for building a new electron cooling system is to perform accumulation at higher energy than $200 \mathrm{MeV}$; for which the existing system is designed. With electron beams greater than $10 \mathrm{~A}$ at $0.5 \mathrm{~A} / \mathrm{cm}^{2}$, one is near to having cooling times limited by longitudinal electron temperature due to space 
charge (unless the space charge is exactly neutralized). If we take $10 \mathrm{~A}$ as a resonable current limit, a $5 \%$ fraction of the Accumulator circumference $(12 \mathrm{~m})$ must contain electron cooling to achieve the desired cooling times at $400 \mathrm{MeV}$ (see table 5-III).

\section{TABLE 5-III ELECTRON COOLING SYSTEM PERFORMANCE PARAMETERS}

Beam Current

Fraction of Accum. Circumf. Cooled

Transverse Electron Temperature

Longitudinal Electron Temp (max)

$\mathrm{T}_{1} \cdot(200 \mathrm{MeV})$

$\mathrm{T}_{1}(400 \mathrm{MeV})$

$\mathrm{T}_{2}(200 \mathrm{MeV})$

$\mathrm{T}_{2}^{2}(400 \mathrm{MeV})$
$10 \mathrm{~A}$

$5.9 \%$

$0.25 \mathrm{eV}$

$0.1 \mathrm{eV}$

1.5 sec

$6.3 \mathrm{sec}$

$0.98 \mathrm{sec}$

$3.4 \mathrm{sec}$

It may be argued that even higher energy electron cooling is feasible with this 12 m interaction constraint. Keeping these possibilities open dictates much of the system design. A higher guide field is needed in proportion to electron momentum to maintain the same low transverse electron temperature. The solenoid in particular is to be designed for greater heat dissipation. A cathode totally immersed in magnetic field was chosen to give the lowest electron temperatures at higher voltages, as well as allowing smaller high-voltage terminals. These features allow transverse temperatures comparable to those obtained at $110 \mathrm{keV}(200 \mathrm{MeV})$ in the existing device up to beam energies of $750 \mathrm{keV}(1.4 \mathrm{GeV})$.

All supplies and signal lines come directly up into the surface service building. All heavy components will be serviced by lifting up. Two important features are dictated by this: The $90^{\circ}$ toroidal bends (as contrasted to the CERN or Novosibirsk design of $45^{\circ}$ ); and the $U$ configuration of gun/collector.

5.4.2 Electron Cooling and Accumulation Rates. The electron cooling system used for accumulation is assumed to be operating in an ideal manner (i.e., full theoretical damping rates). Cooling takes place in two essentially decouples (largely thanks to the highly nonlinear fall off of electron "friction" force with relative momentum), regions of longitudinal phase space, even though the cooling system is in a dispersion-free section. Sections 5.5 and 5.6 give more detail about the stacking and unstacking processes. Two distinct doses of electron cooling are applied for the stacking cycle.

First the fresh hot batches of $\bar{p}$ 's are cooled for a time $T_{1}$ immediately upon their injection into the Accumulator. The exact value of $T_{1}$ depends critically on the phase-space area of the hot 
beam, the exact manner of approach of the rf stacking bucket to the stack, and the relative height of the stacking bucket to the stack height. The cooling decrement necessary is from 2 to 4 (for 95\% of a Gaussian in momentum). For one e-folding, values of $T_{1}$ are shown in Table 5-III. It is important to note that for an anticipated $40 \pi \times 40 \pi$ beam emmittance $T_{1}$ is dominated by the relative transverse $\bar{p}$ momenta.

The cooled fresh beam is then moved by $\mathrm{rf}$ (see section 5.5) $2 \%$ to the stack. It may be desirable to form the rf buckets while the $T$, cooling is in progress. The gun high voltage is then stepped by $8.5 \mathrm{kV}$ (for $400 \mathrm{MeV} \bar{p}$ ) so that it arrives at the stack ahead of the moving bucket. (It requires $240 \mathrm{nsec}$ to move $2 \%$ ). If the stacking is entirely adiabadic (no dilution), then it is clear that the stack must be cooled by a factor 2 (for time $T_{2}$ ) after each stacking, for a factor 2 cooling during the $T$, step. Alternatively, the fresh beam could simply be parked continguously in momentum next to the stack, with the merging accomplished by electron cooling. Here again, the minimum cooling factor necessary is 2 during $T_{1}$ and 2 during $T_{2}$.

It is not necessary that the stack be maintained during accumulation in a highly condensed state (ultimately determined by equilibrium with inter-beam scattering). A stack momentum width of $\pm 1.0 \times 10^{-3}$ is sufficient and in fact optimal for the cycles described above. The final, ultimate degree of cooling need not be applied to the stack at all. This can be performed after accumulation, on each third of the stack at the ejection energy (see section 5.5.2). Keeping the stack relatively warm allows us to ignore interbeam-scattering effects; for instance, the stack will not appreciably blow up when it is left naked during the $\mathrm{T}_{1}$ step.

Although an optimum stacking cycle requires about the same factor of momentum cooling of the fresh beam ( $T$, step) and, subsequently, the stack $\left(\mathrm{T}_{2}\right.$ step), this does not mean thaat $\mathrm{T}_{1}=$ $T_{2}$. The stack cooling step operates on already transversely cooled particles. Since the $40 \pi$ transverse emittance dominates $T_{1}$, this is an important effect. For our conditions we expect $T_{2}$ will be one-half to one-third of $\mathrm{T}_{1}$.

All expected cooling times for the stacking cycle outlined are shown in Table 5-III. Accumulation to $\bar{p}$ energy up to $400 \mathrm{MeV}$ is possible within an $11 \mathrm{sec}$ cycle. We are developing an exact simulation of the cooling/stacking to predict the maximum accumulator enery allowed by this constraint.

\subsection{RF Stacking and Unstacking}

5.5.1 Injection and Stacking. Antiprotons are injected into the injection orbit of the Electron Accumulator with a kinetic energy of $204 \mathrm{MeV}$, and mornenum spread $\pm 2.26 \times 10^{-3}$. The slightly bunched 
beam is allowed to debunch and is immediately electron-cooled to a momentum spread of $10^{-3}$. This results in a total energy spread of $\mathrm{EB}{ }^{2} \Delta \mathrm{p} / \mathrm{p}=372 \mathrm{keV}$. The rotation period is $1.19 \times 10^{-6}$ sec, resulting in a longitudinal emittance of $0.44 \mathrm{eV}-\mathrm{sec}$. The injected beam is then captured adiabatically in an $h=1, f=$ $841.36 \mathrm{kHz}$ rf bucket with area $0.5 \mathrm{eV}-\mathrm{sec}$. This results in $a$ phase-oscillation period of $4.3 \mathrm{msec}$. Adiabatic capture shold be completed in about $25 \mathrm{msec}$.

The captured beam is decelerated $8.65 \mathrm{MeV}$ to a stacking orbit at $195.35 \mathrm{MeV}$. This requires a frequency swing of $12.35 \mathrm{kHz}$. Deceleration will be done with a synchronous phase angle of 5.74 degrees, resulting in a moving-bucket area reduction of 0.82 . Constant bucket area is maintained by raising the $r f$ voltage to 427 volts. The accelerating voltage is $427 \sin \phi_{s}=42.7$ volts per turn, or $35.9 \mathrm{MeV}$ per second, so the stacking requires 0.24 seconds.

In order to minimize the effect of the moving $r f$ bucket on the existing antiproton stack, the $r f$ voltage can be reduced to a very small value well before the momentum reaches the stack momentum, but at momentum sufficiently close so that electron cooling can pull the released antiprotons into the stack.

5.5.2 RE Unstacking and Extraction Antiprotons are to be removed from the cooled stack for extraction by $r$ unstacking at harmonic-number one. If, for example, three final bunches of antiprotons are desired, a moving bucket with area slightly greater than one-third of the total stack area (longitudinal emittance) is created at the center of the stack and removed at a constant acceleration rate. If the cooled stack has a total momentum spread of $10^{-3}$, then the longitudinal emittance will be $0.433 \mathrm{eV}-\mathrm{sec}$ and the stack energy spread will bl be $\pm 179.25 \mathrm{KeV}$. The synchronous phase angle is 19.27 degrees and the bucket requires application of 100 volts at $827.897 \mathrm{kHz}$ (instantaneous frequency). The accelerating voltage $V$ sin $\phi$ will be 33 volts per turn or $27.3 \mathrm{MeV} / \mathrm{sec}$, so acceleration by the required $8.65 \mathrm{MeV}$ will require $317 \mathrm{msec}$.

At approximately $18 \mathrm{msec}$, the moving bucket has moved $480 \mathrm{kV}$ above the stack and the stack has become sufficiently smooth that it is possible to measure the charge that has been removed by the moving bucket by observing the image current induced in a ring current detector of sufficient bandwidth. This charge is compared with the desired value and the bucket area, which was intentionally slightly too large, can be reduced so that it carries only the intended charge. The charge which is removed from the bucket is sufficiently close to the stack momentum so that it is cooled back into the stack by the electron beam.

Subsequent unstacking buckets will be required to enclose different fractions of the remaining charge, the last one being just adiabatic capture of all of the remaining charge. 
After the unstacked charge fractions have been moved to the extraction orbit, it will be necessary to change the electron energy so that the unstacked fraction of the beam can be cooled before extraction. In order to achieve acceptable antiproton bunch lengths at $1 \mathrm{TeV}$, it necessary that the bunches have longitudinal emittances substantially less than $0.1 \mathrm{eV}$ sec at the start of the several-stage acceleration process. Each extracted bunch will be cooled to an admittance of $0.06 \mathrm{eV}-\mathrm{sec}$ just prior to extraction.

After each bunch has been placed in the extraction orbit at $204 \mathrm{MeV}$, the $\mathrm{rf}$ voltage must be raised to a level such that the bunch length will match an $r f$ bucket in the precoder at $h=14,5.01$ $\mathrm{MHz}$. Since the $\mathrm{h}=14$, buckets are $200 \mathrm{nsec}$ long, a total bunch length of $180 \mathrm{nsec}$ is adequate. A $0.06 \mathrm{eV}-\mathrm{sec}$ bunch $180 \mathrm{nsec}$ long will have an energy half-height $\Delta E=212 \mathrm{keV}$, matched to a bucket with half-height $907 \mathrm{keV}$. At $\mathrm{h}=1$, the required bucket is generated by raising the $\mathrm{rf}$ voltage to $3.4 \mathrm{kV}$. The phase-oscillation period in the final extraction bucket is 1.25 msec, so the adiabatic bunching should be accomplished in about 8 msec.

All $\mathrm{rf}$ voltages in the Electron Ring are to be generated by a single ferrite-loaded low $-Q$ cavity capable of generating precisely controlled frequencies, phases, and voltages up to $5 \mathrm{kV}$ at harmonic number one. 


\section{Colliding Scenario}

6.1 General Plan. At present, the Fermilab accelerator operates at slightly greater than $2.5 \times 10^{13}$ protons per pulse with about 1080 bunches (i.e. 1080 of the 1113 main ring buckets occupied). This results in an average proton number per bunch of about $2.5 \mathrm{x}$ $10^{10}$. In order to achieve the required $10^{11}$ protons per bunch, it is proposed that the protons in several groups of four adjacent bunches (quartets) be coalesced and re-captured in normal ( $h=1113$ ) buckets before injection into the Tevatron. Injection into the Tevatron will be done at $150 \mathrm{GeV}$, so it is reasonable to do the bunch coalescence at fixed magnetic field at $150 \mathrm{GeV}$ just before injection. It is preferable to do the bunch coalescing at relatively high energy rather than at injection energy ( $8 \mathrm{Gev}$ ) for several reasons: The beam size is smaller relative to the available aperture, the ratio of longitudinal emittance to available $\mathrm{rf}$ bucket area is favorable, and the necessity for accelerating heavily populated bunches through transition is eliminated. The advisability of avoiding transition crossing with dense bunches has also been noted in experiments of a similar nature at CERN.

Since it is possible to select which buckets will contain a significant number of protons by selectively expeling unwanted protons before acceleration, the required number of quartets can be established at the desired azimuthal locations before beginning the acceleration cycle. This procedure is absolutely necessary. In order to coalesce the adjacent bunches, it is necessary to reduce their momentum spread to the minimum possible value by lowering the $\mathrm{rf}$ amplitude to an extremely small value. If a large fraction of the buckets contain proton bunches, the resultant beam excitation of the high shunt-impedance accelerating cavities prevents lowering the voltage to the required value. Furthermore, it would be extremely difficult to remove the unwanted protons with sufficient precision at $150 \mathrm{GeV}$ and if those protons were to remain in the accelerator, but not well contained in buckets, the injection process into the Tevatron would almost certainly quench the superconducting magnet.

6.2 Coalescing Scenario. The four step procedure for coalescing quartets is shown in Fig. 6-1. (The procedures described here are at $100 \mathrm{GeV}$ instead of $150 \mathrm{GeV}$ because we have well-established accelerator parameters at $100 \mathrm{GeV}$ and the experiments are slightly less expensive in electric-power cost). Step I shows a series of $\mathrm{h}=1113$ ( $53.102 \mathrm{MHz})$ buckets, four of which contain bunches of protons. The stationary bucket voltage is $1 \mathrm{MV}$, resulting in a bucket height of $144 \mathrm{MeV}$. It is assumed that each of the bunches has a longitudinal emittance of $0.3 \mathrm{eV}-\mathrm{sec}$, consistent with recent measurements. These bunches, initially matched to a 1-MV bucket, will have a half-height of $46.7 \mathrm{MeV}$ and a half width of 4 nsec, roughly as shown. 
Step II shows the $0.3 \mathrm{eV}-\mathrm{sec}$ bunches matched to an $\mathrm{rf}$ bucket that has been reduced in amplitude until the bucket area equals the bunch area. The bunch and bucket height are now $12.5 \mathrm{MeV}$. Shown also in part II is a dashed line representing a subharmonic bucket encompassing seven of the original buckets. Because the original harmonic number $h=1113=(3)(7)(53)$, a 7 th subharmonic bucket $(h=159)$ will remain fixed in phase with respect to the original buckets. (Had the original harmonic number been a prime, this subharmonic operation would have been impossible). The subharmonic bucket shown has a height $\Delta E=66 \mathrm{MeV}$, requiring the application of $30 \mathrm{kV}$ at $7.58 \mathrm{MHz}$. When the $h=1113$ voltage reduction is complete, the voltage creating that bucket is removed and the $h=159$ voltage is applied suddenly at full amplitude.

Step III shows the proton distribution within the subharmonic bucket after slightly more than one-quarter of one synchrotron period. This requires 2000 turns or $41.8 \mathrm{msec}$. The distributions with larger momentum deviation are those which started farthest from the bucket center and have consequently lagged slightly due to synchrotron tune spread. Computer simulations of this rotation have established 2000 turns to be an optimum period for establishing the narrowest charge distribution. Initially the charge in the $h=159$ bucket extends over $4 / 7$ of the bucket Iength. (In $\Delta \phi, \Delta \mathrm{W}$ coordinates, $\Delta \phi=4 \pi / 7$ radians). In a $66-\mathrm{MeV}$ bucket, this distribution should reach a maximum energy deviation of 66 $\sin (\Delta \phi / 2)=51.6 \mathrm{MeV}$. Computer simulations have verified that this indeed happens and the distribution shown in part III is a good representation of the simulation. The rotated charge extends in energy over approximately $104 \mathrm{MeV}$ and in time over about $19 \mathrm{nsec}$ so the phase space area covered is about $2 \mathrm{eV}-\mathrm{sec}$. At this time, the $h=159 \mathrm{rf}$ voltage is removed and $h=1113$ buckets are re-applied at an amplitude which matches as well as possible the rotated distribution. The dashed line in part III represents a 2 eV-sec $h=1113$ bucket, requiring the application of $340 \mathrm{kV}$. Because we have coalesced an even number of bunches in an odd-numbered subharmonic bucket, the center of the coalesced bunches have moved azimuthally $\pi$ radians from the original position and the re-applied $\mathrm{h}=1113$ bucket must be shifted in phase accordingly or the coalesced bunch will arrive at the unstable fixed point.

Part IV of Fig. 6-1 shows the coalesced bunch distribution after the $h=1113 \mathrm{rf}$ voltage has been raised to $1 \mathrm{MV}$. The total bunch width of a $2 \mathrm{eV}-\mathrm{sec}$ distribution matched to a $3.36 \mathrm{eV}-\mathrm{sec}$ bucket ( 1 MV) will be 11 nsec and the energy half-height will be $114 \mathrm{MeV}$. At $100 \mathrm{GeV}$, this amounts to a total $\Delta \mathrm{p} / \mathrm{p}$ of 0.12 percent, small with respect to the momentum aperture of the ring, about $\pm 0.5 \%$.

A density dilution of about a factor of two has occurred in the process, so while the final energy half-height is $114 \mathrm{MeV}$ as opposed to $47 \mathrm{MeV}$ for the original bunches, the peak current, as indicated on a beam current detector, will have increased by only a factor of about 1.3 . 
After acceleration to $1 \mathrm{TeV}$, this distribution is to be stored in buckets generated by about $1.2 \mathrm{MV}$. At $1 \mathrm{TeV}$ the $1.2 \mathrm{MV}$ bucket height will be $495 \mathrm{MeV}$ and a $2 \mathrm{eV}-\mathrm{sec}$ bunch, matched to such a bucket, will have a total length of $5.7 \mathrm{nsec}$.

Computer simulations were done also for coalesence of five adjacent bunches in a seventh subharmonic bucket. In that case, all of the center three bunches and about half of each of the outer two bunches could be recaptured, so there is no advantage over coalescing four bunches. 
7. Buildings and Structures

7.1 Below-Ground Structures

The existing Target Vault and $\bar{p}$ Hall will be utilized with minor modifications. Summed over the injection and extraction lines, the Precooler, and the Accumulator, the total tunnel length in the project is approximately $3000 \mathrm{ft}$. Included in this total are several different kinds of tunnels and special sections, which are as follow:

(i) Regular tunnel. The Precooler and Accumulator quadrants are both an $8 \mathrm{ft}$ by $8 \mathrm{ft}$ cross-section tunnel, with the ring center line $2 \mathrm{ft}$ from the larger-radius wall. The tunnels will be cast to follow the wanderings of the rings. A Precooler quadrant is shown in Fig. 7-1 and the entire Accurnulator tunnel is shown in Fig. 7-2.

(ii) The long straight sections of the two rings will be housed in special structures designed for the functions in these straight sections.

(a) The South straight section of the Precooler, shown in Fig. 7-3, will have the largest span (18 ft) and the longest length $(120 \mathrm{ft})$. The functions here are similar to those in the Main Ring Transfer Hall. Equipment layout in the south straight section was shown in Fig. 4-15. The tunnel is widened upstream for the junction with the 4.5-GeV injection line. Tunnel cross sections are also shown in Fig. 7-3.

(b) The North straight section contains the 5-9 $\mathrm{MHz}$ and the $h=1$ rf system at its upstream end. It contains the $200-\mathrm{MeV}$ test beam injected into its downstream end. If a stochastic accumulator ring is built in the future, transfer between it and the Precooler will take place in this straight section. The structure surrounding it, also shown on Fig. 7-3, is only slightly enlarged from the regular tunnel because these functions require only moving space for component installation. The equipment is shown in Fig. 4-6.

(c) The East straight section contains stochastic kicker and associated power amplifiers and the 8-GeV extraction line. These components necessitate a tunnel widening, as is shown in Fig. 7-4. There is space between electronics racks for access to the ring and for addition cooling power. The equipment is shown in Fig. $4-7$.

(d) The West straight section contains stochastic pickups (which have only small electronics associated with them) and the $53-\mathrm{MHz}$ rf system, located at the upstream end, as shown in Fig. 4-5. The tunnel is widened at this end, as is also shown in Fig. 7-4, to give access to the $r f$ cavities and associated electronics equipment and widened at the other end in case more $\mathrm{rf}$ is needed at some later time. 
(e) The west straight section of the Accurnulator will contain the electron cooling equipment.

(f) The injection tunnel will be 6 ft by $8 \mathrm{ft}$ in cross section, joining the Precooler as shown in Fig. 7-5. An access to the surface will be provided as shown. This beam line rises from the 726-ft $8 \mathrm{in}$. level of the injection line.

(g) The 8-GeV extraction line will join the injection line in a 50-ft stub shown in Fig. 7-5. The three manholes shown will contain focusing magnets for the FODO extraction line, as described in section $4-9$.

\subsection{Above-Ground Structures}

Service buildings will be provided at each long straight section. The North, East, and West straight sections require only buildings of approximately $1440 \mathrm{ft}^{2}$ (gross) and personnel accesses down to the ring. The same is true of the East Accumulator straight section.

The South Precooler straight section will contain power supplies, assembly space, equipment and personnel access, and accelerator control facilities. A structure of $3000 \mathrm{ft}^{2}$ gross space is planned.

The West Accumulator straight section will contain power supplies and equipment for the electron cooling system and will require a structure of apporximately $2000 \mathrm{ft}^{2}$.

\subsection{Utilities and Roads}

Existing electric power and cooling water will be utilized and only short feeders are required. No gas service to the project is planned. The roads to be built are shown in the general site plan of Fig. 1-1. 
8. Experimental Areas

Two interaction regions have been designed for experiments at the collider, one at BO and the other at DO.

\subsection{Bo Experimental Area}

The experimental area at BO will serve the detector to be built by the Colliding Detector Facility, a collaboration of Italian, Japanese and U.S. laboratories. The scale of the project is set by their proposed apparatus, in particular the Central Detector, whose transverse dimensions determine both the depth of the building and its overall width. The area is divided into 2 distinct regions, the Collision Hall, where the experiment is actually performed and the Assembly Area, where the entire apparatus will be constructed and serviced, and where the Central Detector will be stored during operation of the Tevatron fixed-target program. A bypass is provided around the outside of the collison hall for traffic servicing the Main Ring and the Tevatron. It should be noted that the engineering challenge posed by the weight of the detector and the earth pressure on the valls of this underground area is unique in the history of Fermilab. In general, the building is a concrete structure; the floor which carries the detector is a concrete mat about four feet thick. Plan and elevation views of the BO area are shown in Figs. 8-1 and $8-2$.

The central volume of the Collision Hall which houses the Central Detector and a pair of forward-backward toroids is $50 \mathrm{ft}$ long by $50 \mathrm{ft}$ wide and at its deepest point $40 \mathrm{ft}$ high, dimensions set directly by the detector and its requirements for in-place servicing. Extended forward-backward detectors sit in the volumes at either end of the collision area. Since these devices are smaller transversely than the Central Detector, these sections are $35 \mathrm{ft}$ wide by $30 \mathrm{ft}$ high and $25 \mathrm{ft}$ long; their floor level is raised $5 \mathrm{ft}$ from the central region.

The Assembly Area is separated from the Collision Hall by a 35 ft long tunnel whose tranverse size is the minimum needed for passage of the Central Detector. When the accelerator is operating, the tunnel is plugged at the Collision Hall end by a (retractable) $12 \mathrm{ft}$ thick concrete wall. This thickness of radiation shielding is sufficient to allow people to work in the Assembly Area while the Tevatron is running for fixed-target physics.

The Assembly Area consists of three parts, an underground assembly area (at the same level as the Collision Hall), an above-ground construction area, and two floors of electronics, computer and control rooms for the detector on the side closest to the Collision Hall. The area is served by a 50-ton crane that runs the entire length of the building. 


$$
J
$$




$$
\text { C }
$$




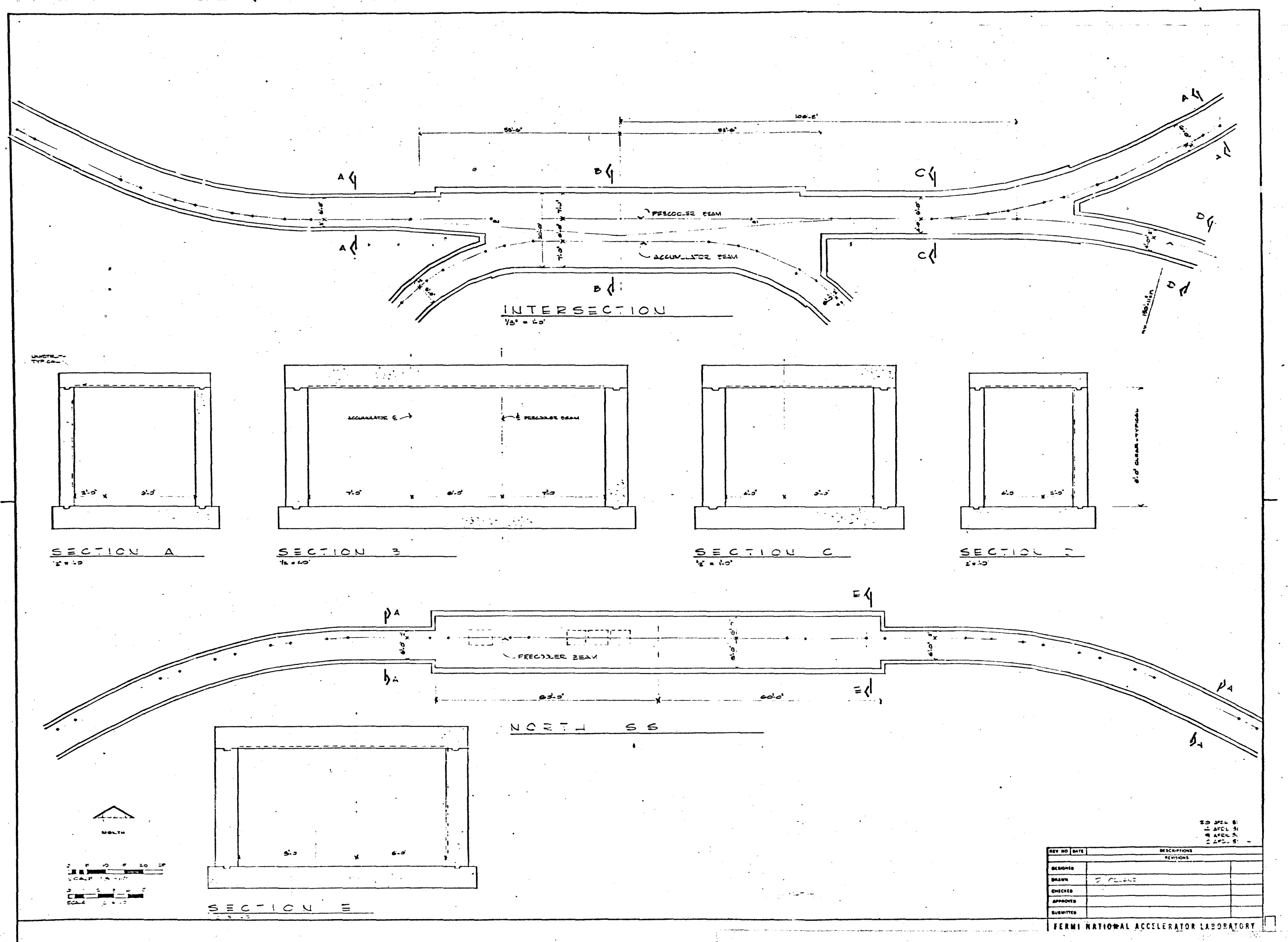

Fig. 7-3 Precooler Tunnel North and South Straight Sections $1 \ldots$ 


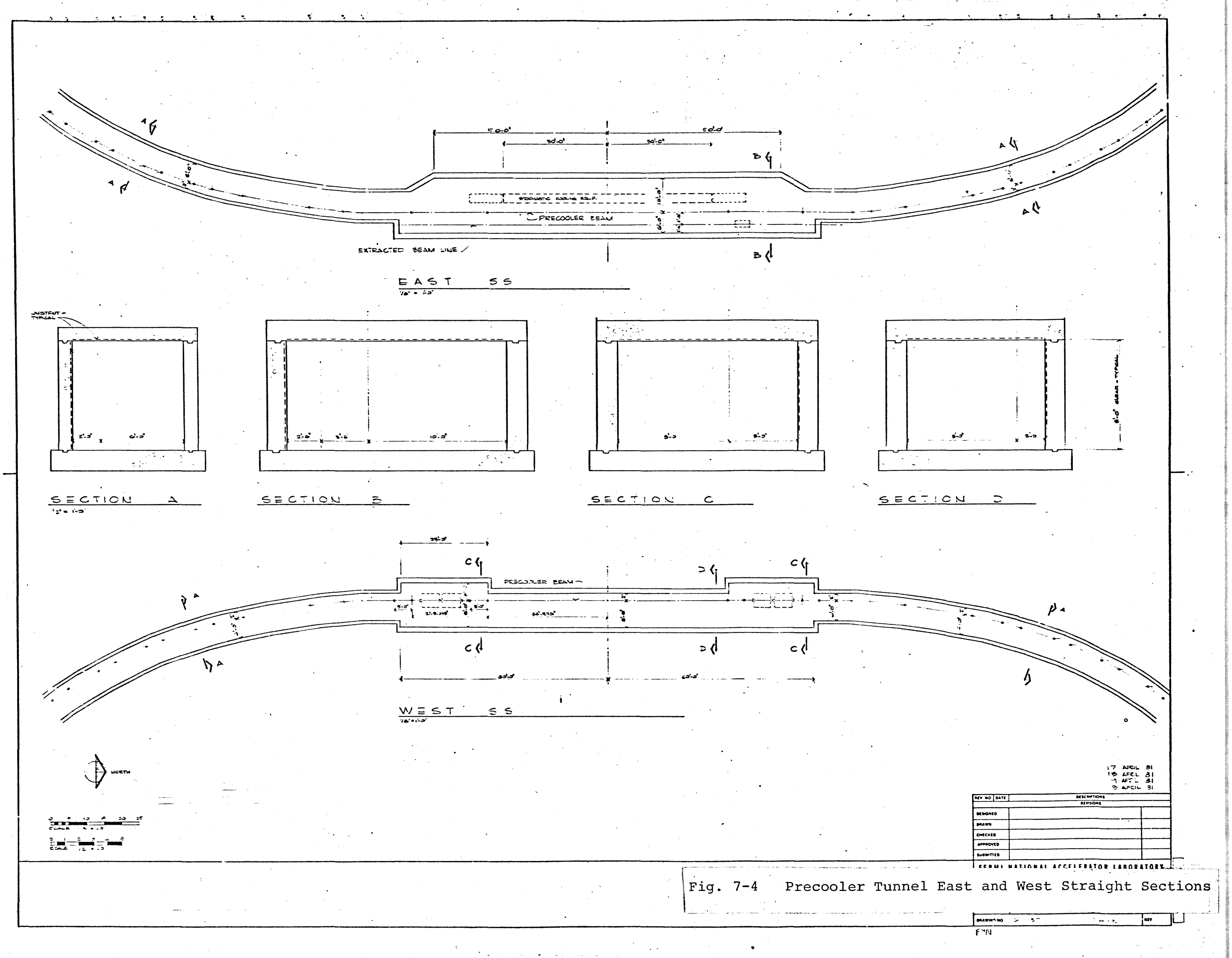




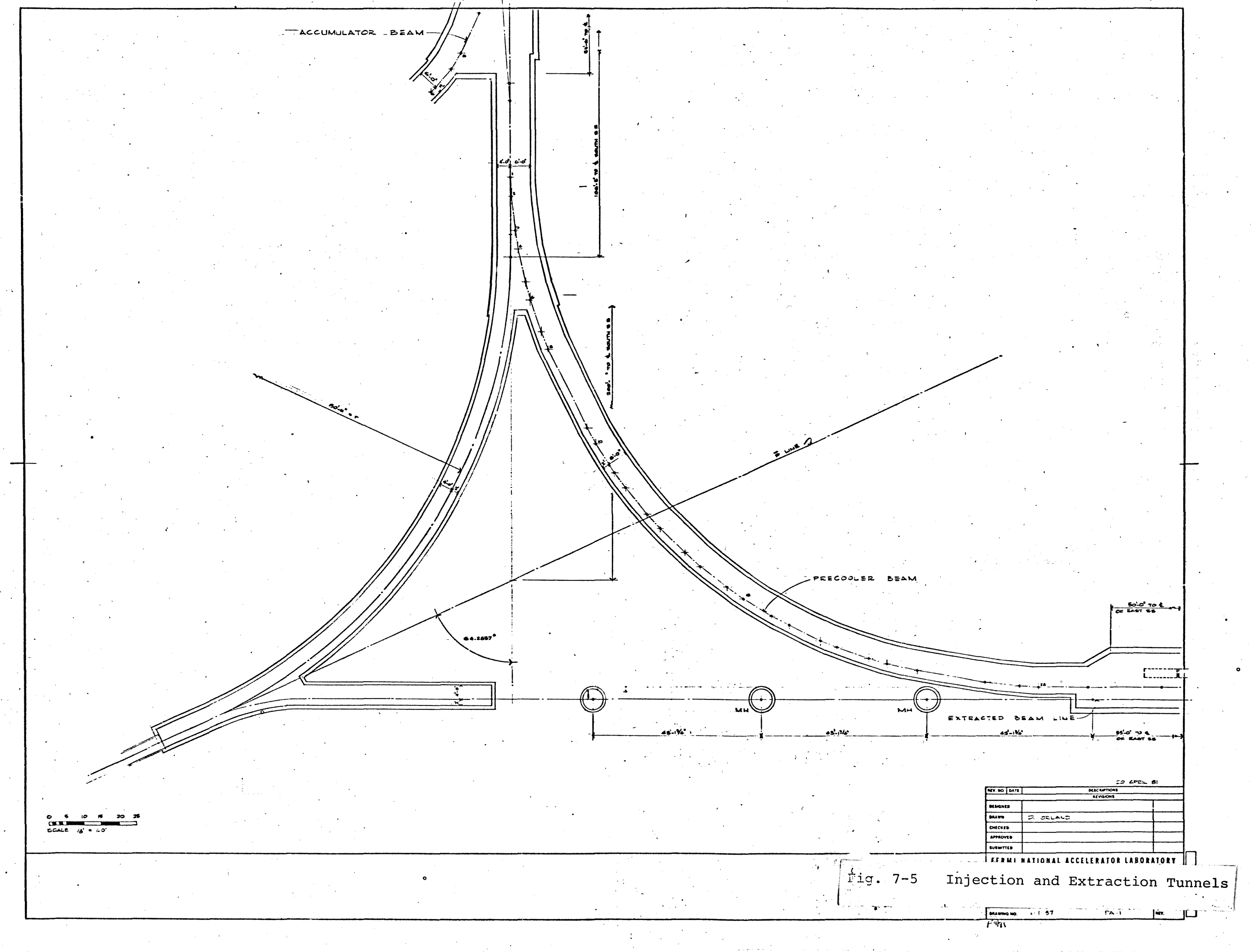


The size of the below-ground assembly area is set by the space needed to construct the Central Detector and to service the Central Detector while constructing the forward-backward detectors. As in the Collision Hall, there are two floor levels which differ by $5 \mathrm{ft}$. The Central Detector sits at the lower level on its own transporter; the forward-backward detectors will be assembled on the higher level and transported to the Collision Hall on a special transfer cart. The two bays at the entrance to the tunnel are at the lower elevation and can both accept either the transfer cart or the concrete shield wall. A labyrinth with a movable plug allows passage for people and light equipment between the Assembly Area and the Collision Hall.

The above-ground section of the assembly building will be used for offices and fabrication of the individual components of the detector. The experiment electronics and control rooms are placed as close to the Collision Hall as possible to reduce the time delays from cable lengths to a minimum.

\subsection{DO Experimental Area}

No specific detector has yet been proposed for the DO interaction region; a nominal detector of diameter $15 \mathrm{ft}$ and length of $20 \mathrm{ft}$ has been considered in the design. The experimental area provided consists of an underground hall $47 \mathrm{ft}$ wide, $24 \mathrm{ft}$ long and $20 \mathrm{ft}$ high. Equipment is lowered to the hall with a 20-ton crane through a hatch with opening $29 \mathrm{ft}$ wide and 20 ft long. The hall is designed to provide an assembly and work area, shielded from the Tevatron beam by $9 \mathrm{ft}$ of high-density concrete. To run the experiment, this shielding is removed to cover the access hatch and the assembled detector is rolled into place. The Do experimental area is shown in Fig. 8-3. 


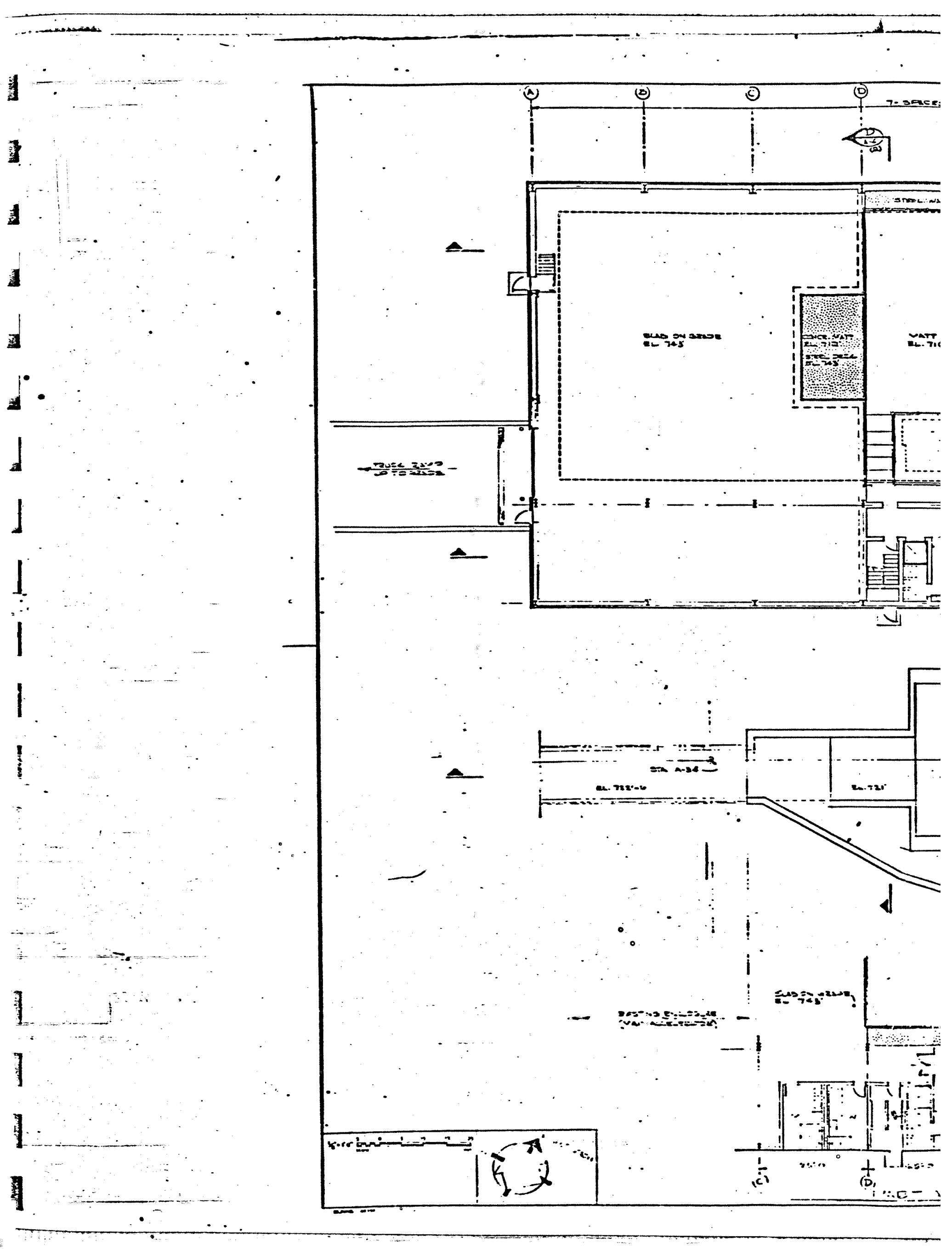




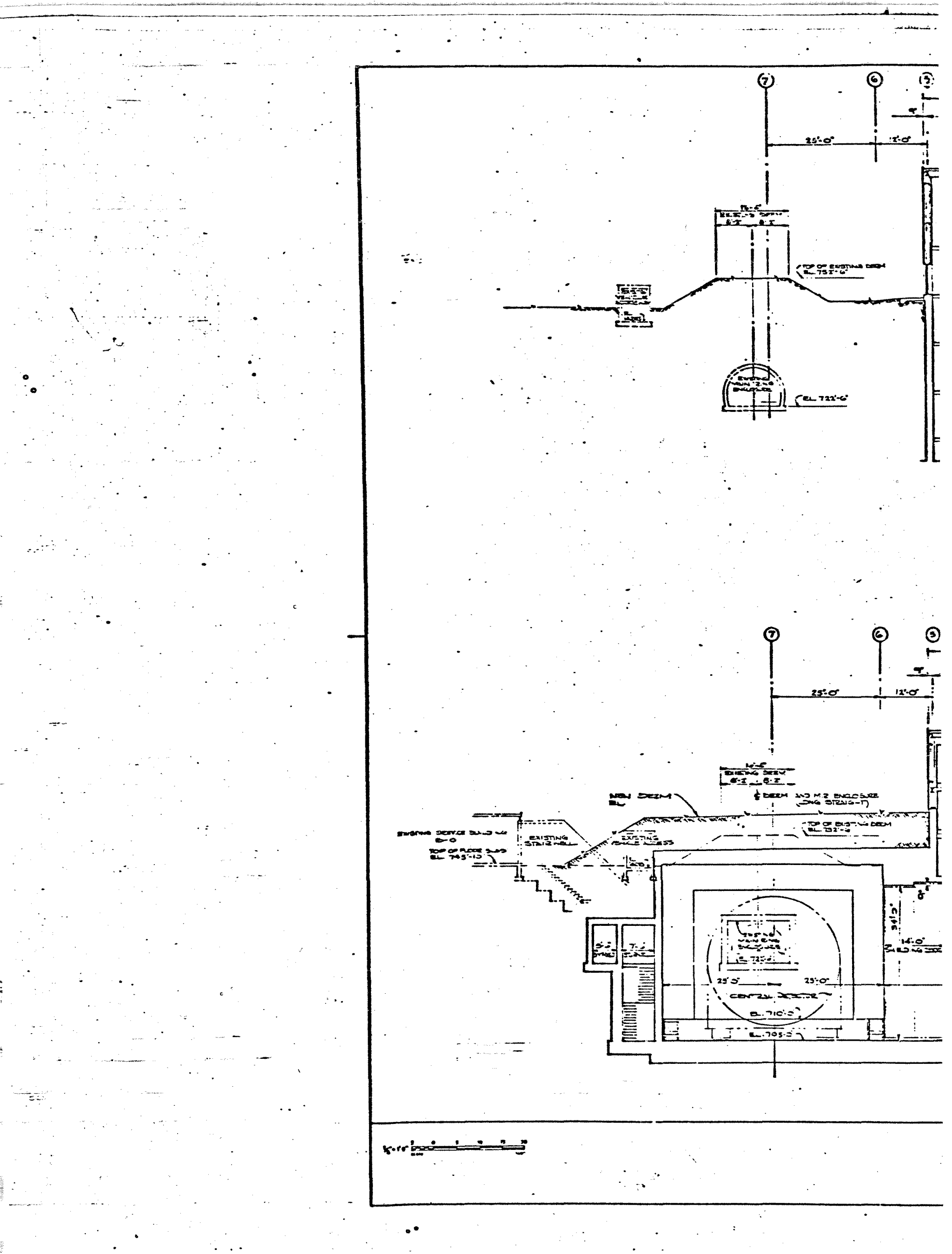


Appendix A

Parameters 


\title{
PROTON-ANTIPROTON SOURCE FOR FERMILAB
}

APRIL, 30, 1981

02: 00 P.M.

\author{
LIST OF TABLES \\ MAIN RING CYCLE \\ TARGETRY \\ PBAR-TRANSPORT TO PRECDOLER \\ PRECOOLER INJECTION \\ RF ROTATION AND STACKING \\ PRECOOLER PARAMETERS \\ STOCHASTIC COOLING \\ DECELERATION IN THE PRECOOLER \\ ELECTRON RING PARAMETERS \\ TRANSFER OF PBARS TO MR
}

(COHPILED BY A. G. RUGGIERO) 


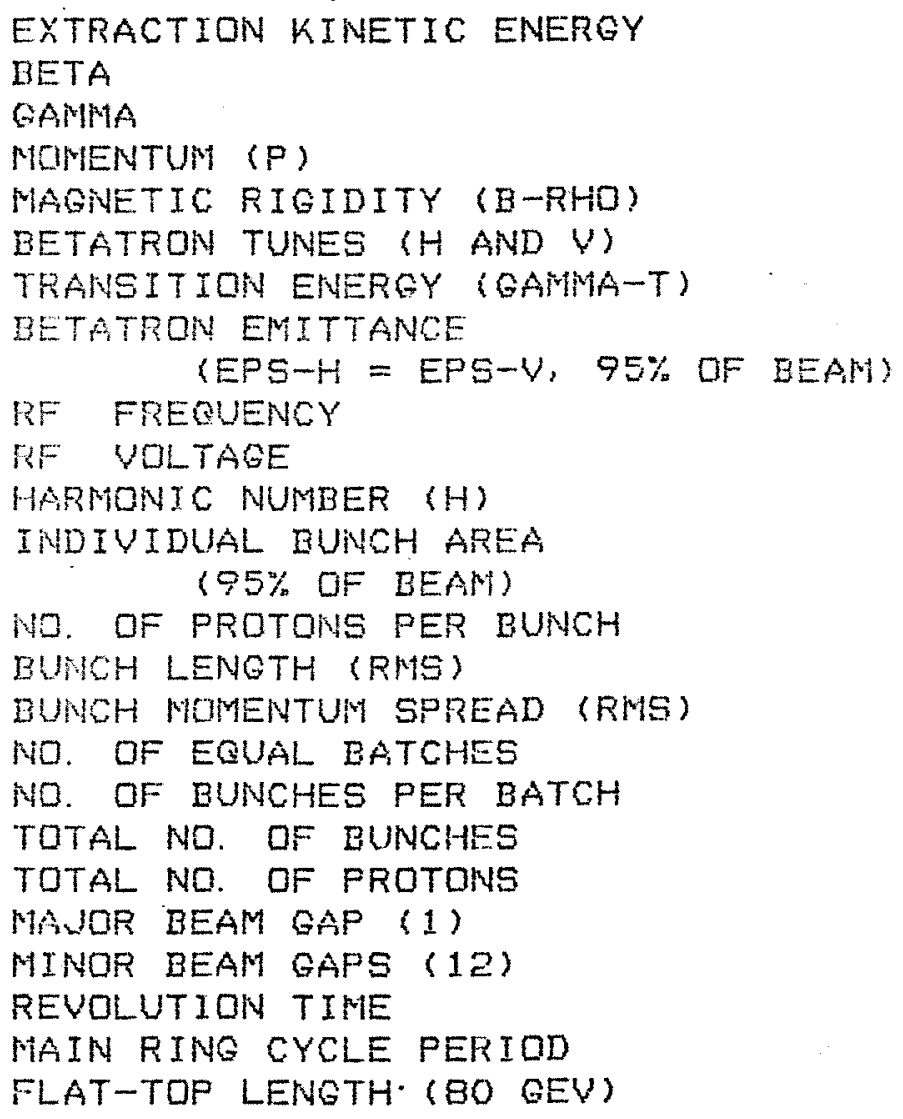

80 GEV

0. 999933

86. 254

80. 933 GEV/C

$2699.5 \mathrm{KO}-\mathrm{M}$

19. 4

18. 75

0.3 PI-MM-MRAD

53. $1 \mathrm{MHZ}$

4. 0 in

1113

0.4 EV-SEC

2. $7 * 10 E \times P 10$

$21 \mathrm{CM}$

3. $7 * 10 E \times P-4$

13

75

975

2. $6325 \div 10 E X P 13$

580 NSEC

185 NSEC

20.96 MICRO-SEC

9. $85 \mathrm{SEC}$

1. 3 SEC 


\section{TARGETRY}

TARGETEY MATERIAL

LENOTH OF TARQET

CROSS-SECTIQN RADIUS

BETAH , PROTON (H AND $V$ )

ALFHAN, PROTON (H AND $U$ )

ETAK, PROTON (DISPERSION)

ETA-PRTHE*, PRDTON

SIOMAK, PROTOIY (RMS SPOT SIZE, $H$ AND $V$ )

NO. OF P-BATCHES/ MR CYCLE

TIME INTERUAL BETWEEN BATCHES

HAIN RINO CYCLE PERIOD

NO. OF PROTONS PER BATCH

PBAR-PRODUCTION MOMENTUM

KINETIC ENERGY

BETA

GAMMIA

MAGNETIC RIGIDITY (B-RHO)

MOMENTUN SPREAD ACCEPTED

FULL DELTA P/P, (UNIFORM DISTRIBUTION)

ENITTANCE ACCEPTED (H AND $V$ )

ANGLE ACCEPTED

BETAK, ANTIPROTON, $(H$ AND $V\rangle$

AL, ANTIPROTON SPOT RADIUS

PP-PBAR INUARIANT CROSS-SECTION

PP INELASTIC CROSS-SECTION

PROTON ABSORPTION LENGTH

ANTIPROTON ABSORPTION LENOTH

YIELD, NO. OF PBAR/ NO. OF $P$ (FROM TARGET ONLY)

EFFECTIVE YIELD INCLUDING COLLECTION LI-LENS

TOTAL NO. OF PBAR/MR CYCLE

PEAR-BUNCH LENGTH (RMS)

PBAR-BUNCH AREA (95\% DF BEAM)

PBAR-BEAM RF BUNCHING

NO. OF PBAR-BUNCHES/BATCH

GAP LENGTH ( 9 BUNCHES)
TUNGSTEN (W)

$5 \mathrm{CM}$

$1 \mathrm{MN}$

1. $\mathrm{OM}$

o. 0

$0.0 \mathrm{in}$

0.0

$0.224 \mathrm{NH}$

13

100 MSEC

9. 85 SEC

2. OESt 10EXP 12

5. 3557 GEV/C

4. 5 GEV

0. 985

5. 796

$178.7 \mathrm{KG}-\mathrm{M}$

1. $0 \%$

5. O PI-MM-MRAD

25 MRAD

O. $8 \mathrm{CM}$

o. $2 \mathrm{MM}$

0. 8 MB/GEV*K2

$33 \mathrm{MB}$

10. $5 \mathrm{cM}$

6. $\mathrm{OCH}$

1. $15 * 10$ EXP-6

$0.8 * 10 E \times P-6$

2. $106 * 10 E \times P 7$

$21 \mathrm{CM}$

○. 15 EV-SEC

52. $31 \mathrm{MHZ}$

75

188 NSEC 
BEAM EMITTANCE (H AND $V$ )

MOMENTUM SPREAD, DP/P (FULL)

20 PI MM-MRAD

$4 \%$

SEQUENCE OF MAGNET SECTORS:

1. VERTICAL TRANSLATION AFTER TARGET

DI V1 De $\quad \begin{array}{lllllll} & \mathrm{D} 1 & \mathrm{D} & \mathrm{Q} 2 & \mathrm{DA} & \mathrm{Q} 1 & \mathrm{D} 4\end{array}$

Q2 D $D$ Q1 DE VI* DI

2. MATCHING PLUS FODO TRANSPORT

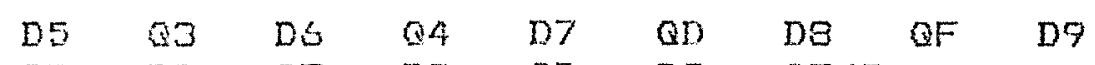

QD D9 GF DP QD DO QF/2

3. MATCHING

$\begin{array}{lllllllll}\text { QF/E D4 } & \text { Q14 } & \text { D14 } & \text { Q13 } & \text { QS } & \text { V3* } & \text { D15 } & \text { Q15 } \\ \text { D16 } & \text { Q16 } & \text { D17 } & \text { Q17 } & \text { Q17 } & \text { D16 } & \text { Q19 } & \text { D19 } & \end{array}$

4. DISPERSION SUPPRESSOR

$\begin{array}{lllllllll}06 & B & D & B & 05 & Q D & 04 & B & 03 \\ Q F & 02 & B & 01 & Q D / 2 & & & & \end{array}$

5. THO REGULAR CELLS

$\begin{array}{lllllll}Q D / 2 & Q & B & D & B & O D & Q F / 2 \\ Q F / 2 & \square O & B & O & B & 0 & Q D / 2 \\ Q D / 2 & D & B & D & B & Q 0 & Q F / 2 \\ Q F / 2 & D O & B & D & B & O & Q D / 2\end{array}$

6. ONE CELL WITH TWO MISSING MAGNETS
$Q D / 200$
B
D B DO
$Q D / 2$

7. INE AND ONE-HALF REGULAR CELL

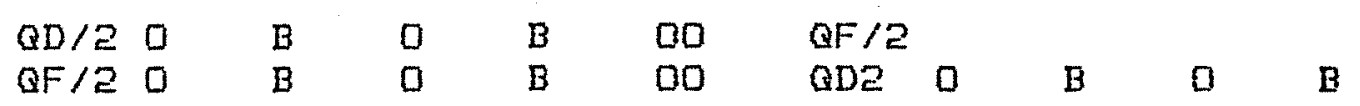

8. LONG STRAIGHT MATCHING

$\begin{array}{lllllllll}D 19 & Q 19 & D 20 & \text { Q20 } & \text { D21 Q21 DE2 Q2E } & \text { DE1 } & \text { Q23 } & \text { DE2 }\end{array}$

9. VERTICAL TRANSLATION

$\begin{array}{llllllllll}V 4 & D 23 & Q 24 & 024 & 025 & D 25 & \text { Q26 } & \text { D26 } & \text { Q27 } & \text { D27 } \\ \text { Q28 } & D 29 & V 5 & D 29 & & & & & & \end{array}$ 


\begin{tabular}{|c|c|}
\hline DRIFTS & LENETHS \\
\hline$D 1$ & -0.915 \\
\hline$D E$ & 3. 8359 \\
\hline 03 & 1.5 \\
\hline D4 & 3.5 \\
\hline D5 & 3.0 \\
\hline$D S$ & 3.1962 \\
\hline $\mathrm{D} 7$ & 1. 6915 \\
\hline $\mathrm{DB}$ & E. 574 \\
\hline 199 & 14.0757 \\
\hline 010 & -- \\
\hline D11 & $-\ldots$ \\
\hline$D \perp 2$ & -- \\
\hline 013 & -- \\
\hline D) 4 & 1. 354 \\
\hline 015 & 12.719 \\
\hline 016 & 0.9144 \\
\hline 017 & 5. 2461 \\
\hline D18 & 0.3049 \\
\hline D 19 & 0.75 \\
\hline 120 & 5. 32814 \\
\hline$D 21$ & 1. 25 \\
\hline DE2 & 3.00 \\
\hline 023 & 3.5046 \\
\hline $\mathrm{D} 24$ & 0.75 \\
\hline 025 & 1. 15113 \\
\hline DES & 0.884 \\
\hline 027 & 0.60754 \\
\hline $\mathrm{D} 23$ & ‥ 1712 \\
\hline $\mathrm{D} 29$ & -1.8288 \\
\hline $0 s$ & 0.5 \\
\hline 0 & 0.3048 \\
\hline 00 & 0.72963 \\
\hline 01 & 0.45 \\
\hline 02 & 2. 2609 \\
\hline$\overline{03}$ & 1.8025 \\
\hline 04 & 0.9083 \\
\hline Q5 & 0.2172 \\
\hline 06 & 0.8172 \\
\hline ס०० & 4. 08243 \\
\hline
\end{tabular}


OUADRUPOLES

Q1

Q2

$Q F / 2$

Q3

Q4

QD

QF

Q13

014

Q15

016

Q17

018

QD

$Q F$

$Q F / 2$

$Q D / 2$

QFE

GD2

Q19

Q20

Q21

Q22

Q23

Q24

Q25

Qอ여

927

Q28

VERTICAL DIPOLES

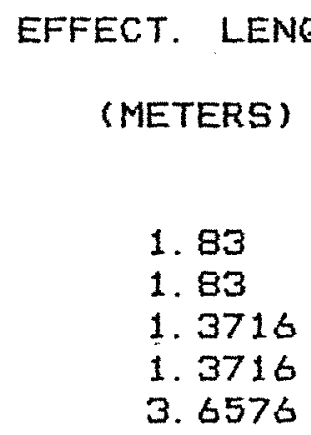

0.6096

1. 2192

0. 3048

o. 6076

D. 6096

0.6095

o. 6096

0.6096

0.6096

o. 6096

0.6096

o. 6096

o. 6096

o. 6096

D. 6096

o. 3049

o. 3049

o. 6096

o. 6096

o. 6096

o. 6096

1. 2192

1. 2192

0. 6096

o. 6096

1. 2192

0. 6095

1. 2192

0. 6096

$\begin{array}{ll}\text { V1 } & 1.83 \\ \text { V1* } & 1.83 \\ \text { V3* } & 1.3716 \\ \text { V4 } & 1.3716 \\ \text { V5 } & 3.6576\end{array}$

STRENGTH

(B'/B-RHO) M和至

o. 5025

-0. 41262

o. 1602

-0. 52436

o. 34452

$-0.1602$

o. 1602

$-0.005059$

$-0.5$

0. 4727

$-0.1632$

o. 2584

$-0.53522$

0.54216

o. 54216

$-0.53522$

o. 4042

$-0.42353$

0. 47357

$-0.799$

o. 82195

o. 52407

$-0.849$

o. 82608

$-0.80589$

o. 78407

$-0.89608$

o. 72807

STRENGTH

(B/B-RHO)

IM

UP

0.05726

DOWN

o. 05726

DOWN

o. 058357

UP $\quad 0.021884$

( $\mathrm{B} / \mathrm{B}-\mathrm{RHO})$

$/ M$

o. 0409 


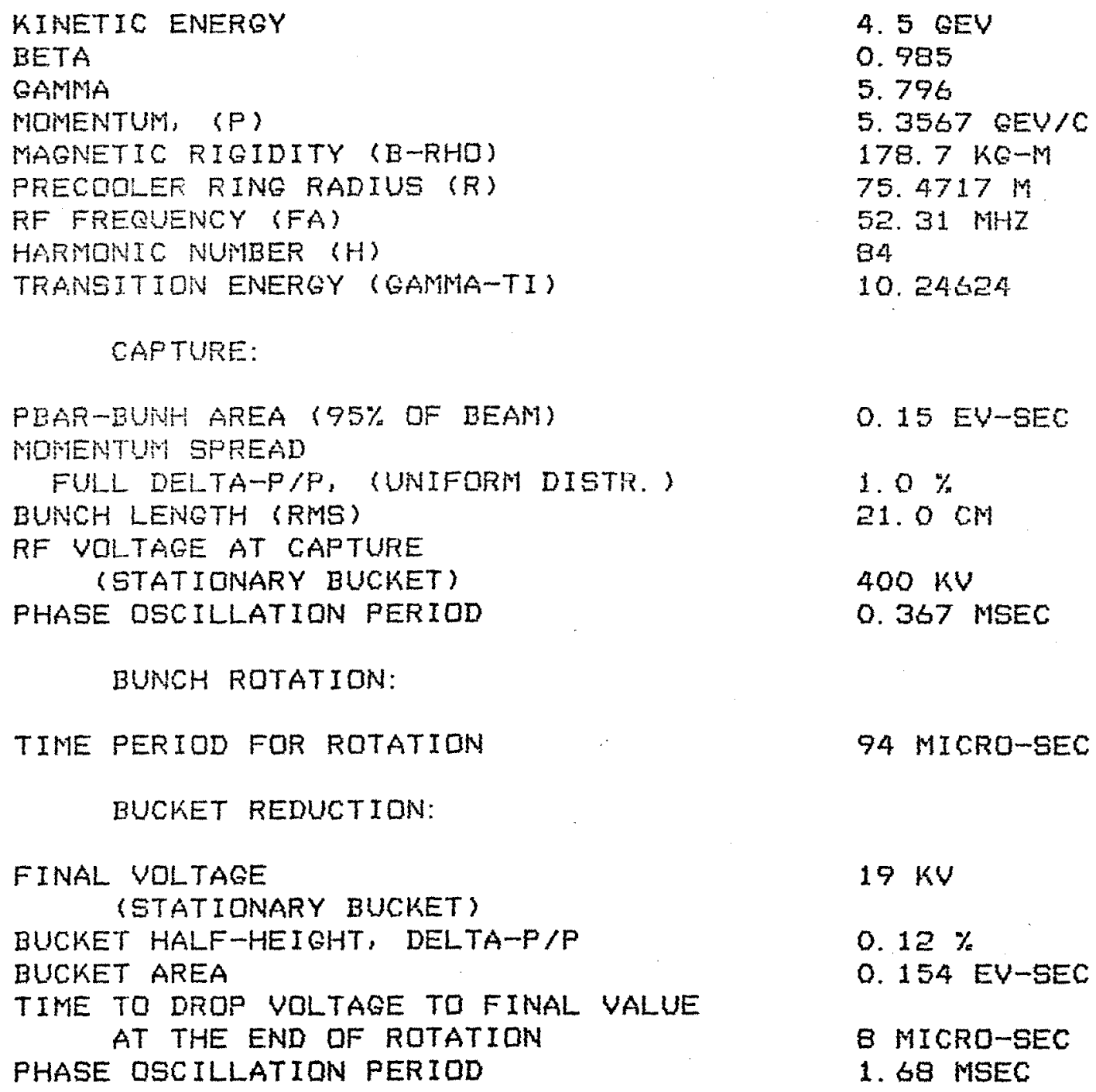

BUNCH ROTATION:

TIME PERIOD FOR ROTATION

94 MICRO-SEC

BUCKET REDUCTION:

FINAL VOLTAGE (STATIONARY BUCKET)

BUCKET HALF-HEIGHT, DELTA-P/P

BUCKET AREA

TIME TO DROP VOLTAGE TO FINAL VALUE AT THE END DF ROTATION

PHASE OSCILLATION PERIOD

$19 \mathrm{KV}$

0. $12 \%$

o. 154 EV-SEC

8 MICRO-SEC

1. 68 MSEC

TRANSFORMATION TO MOUING BUCKET:

RF VDLTAGE FOR MOUING BUCKET

RF PHASE FOR MOUING BUCKET

MOUINO BUCKET AREA

MOUING BUCKET HALF-HEIGHT, DP/P

PHASE DSCILLATION PERIOD

TIME FOR TRANSFORMATION
33. $\mathrm{O} \mathrm{KV}$ 173 DEGREES

O. 154 EV-SEC

o. $18 \%$

1. 29 MSEC

1. 6 MSEC 
STACKING WITH MOVING BUCKET:

$\begin{array}{ll}\text { MOMENTUN VARIATION SWEPT, DP/P } & 4.0 \% \\ \text { ENERGY UARIATION } & 213 \mathrm{MEV} \\ \text { ENERGY GAIN PER TURN } & 4 \mathrm{KEV} \\ \text { MO. OF REVOLUTION DURING STACKING } & 53.000 \\ \text { TIME FOR STACKING } & 85 \mathrm{MSEC} \\ \text { RF FREQUENCY SWING (DF/F) } & 8.0 \% 10 E X P-4 \\ \text { VARIATION OF RF FREQUENCY } & 500 \mathrm{HZ} / \mathrm{MSEC}\end{array}$

TRANSFORMATION TO STATIONARY BUCKET:

$\begin{array}{lc}\text { RF UOLTAOE FOR STATIONARY BUCKET } & 19 \mathrm{kV} \\ \text { RF PHASE FOR STATIONARY BUCKET } & 180 \text { DEQREES } \\ \text { STATIONARY BUCKET AREA } & 0.15 A \text { EV-SEC } \\ \text { STATIONARY BUCKET HALF-HEIGHT, DP/P } & 0.12 \% \\ \text { PHASE OSCILLATION PERIOD } & 1.68 \text { HSEC } \\ \text { TIME FOR TRANSFORMTION } & 1.6 \mathrm{MSEC}\end{array}$

ADIABATIC DEBUNCHING

FINAL VOLTAGE

$0.0 \mathrm{~V}$

TIME REQUIRED TO TURN OFF RF

FINAL BEAM MOMENTUM SPREAD, DP/P (FULL)

1. 5 MSEC

0. $17 \%$

DVERALL STACKING PARAMETERS

NO. OF PULSES STACKED/ MAIN RING CYCLE

NO. OF PBARS PER PULSE

FINAL MOMENTUM SPREAD, DP/P (FULL)

STACKING EFFICIENCY \& INCLUDING

DILUTION DURING BUNCH ROTATION)

FRACTION OF OVERALL BEAM LOSS

13

1. $62 *$ 1OEXP 6

2. $16 \%$

0. 88

5. $0 \%$

RF CAVITIES REQUIREMENT

NO. OF CAVITIES REQUIRED ( MR KIND)

VOLTAGE CAN BE PROGRAMMED BY PARAPHASING

2

MODEST FREQUENCY TUNING RANGE

TOTAL LENGTH DF SYSTEM

4. $3 \mathrm{M}$ 
A. GENERAL

TOP KINETIC ENERGY

BETA

GAMMA

MOMENTUM (P)

MAGNETIC RIGIDITY (B-RHO)

BENDINO FIELD (B)

BENDINE RADIUS (RHO)

AVERAGE RADIUS (R)

REVOLUTION TIME: 80 GEV 4. 5 QEV $200 \mathrm{MEV}$

SUPERPERIODICITY

FOCUSSING STRUCTURE

NORMAL CELL STRUCTURE

HORIZONTAL BETATRON TUNE

VERTICAL BETATRON TUNE

TRANSITION ENERGY (GAMMA-T)

NATURAL GHROMATICITY: HORIZONTAL

VERTICAL
8. 0 GEV

0.99448

9. 5264

8. 8839 GEV/C

$296.5 \mathrm{KG}-\mathrm{M}$

12. $127 \mathrm{KG}$

24. $449255 \mathrm{M}$

75. 4717

628. $71 \mathrm{KHZ}$

622. $72 \mathrm{KHZ}$

$357.73 \mathrm{KHZ}$

2

SEPARATED FUNCTION FODO

11. 415

11. 393

10. 246

$-18.35$

$-17.68$

\section{B. MAGNETS}

NUMBER OF DIPOLES

LENGTH OF DIPOLES

EFFECTIVE LENGTH OF DIPDLES

SAGITTA

112

$-$

1. $3716 \mathrm{M}$

$0.962 \mathrm{cM}$

QUADRUP OLES:

\begin{tabular}{|c|c|c|}
\hline TYPE & & NUMBEF \\
\hline QF & & 24 \\
\hline$Q D$ & & 28 \\
\hline 191 & & 4 \\
\hline $1 \mathrm{QP}$ & & 4 \\
\hline $1 Q 3$ & & 4 \\
\hline QD1 & & 4 \\
\hline QF 1 & & 4 \\
\hline $\mathrm{QDE}$ & $F T$ & 4 \\
\hline QFE & & 4 \\
\hline QF9 & & 4 \\
\hline $2 Q 1$ & & 4 \\
\hline 202 & & 4 \\
\hline 203 & & 4 \\
\hline
\end{tabular}

EFFECT. LENGTH

$$
2 \text { FT }
$$

1. $3716 \mathrm{M}$

1. 143

1. 524

0. 9906

o. 7874

$\begin{array}{ll}2 & F T \\ 2 & \\ 4 & \\ 4 & \\ 4 & \\ 4 & \end{array}$

STRENGTH (B'/B-RHO)

$$
\begin{array}{rl}
.542162 & M-2 \\
-.535217 \\
.292781 \\
-.380244 \\
.455736 \\
-.468417 \\
.403642 \\
-.42353 \\
.40420 \\
.308953 \\
-.359801 \\
.361397 \\
-.406104
\end{array}
$$


c. DRIFT LENGTHS

\begin{tabular}{|c|c|}
\hline 0 & 3048 \\
\hline 00 & 72963 \\
\hline 000 & 4. 08243 \\
\hline LL & 10. 00000 \\
\hline L11 & 1. 96582 \\
\hline LI & 1. 1159 \\
\hline LE & 2. 67062 \\
\hline L3 & $\therefore 2667$ \\
\hline 01 & .45 \\
\hline ㅁ & 2. 26083 \\
\hline 03 & 1. 80250 \\
\hline 04 & 0.90833 \\
\hline 05 & 0.217213 \\
\hline 05 & .817217 \\
\hline LL & 9.9238 \\
\hline Le* & 2.55632 \\
\hline anat: & 4. 10783 \\
\hline $00 \%$ & 64073 \\
\hline$L 4$ & 77763 \\
\hline$L 5$ & 9144 \\
\hline LG & 1. 64192 \\
\hline
\end{tabular}

D. LATTICE STRUCTURE

D1. CELLS:

\begin{tabular}{|c|c|c|c|c|c|c|}
\hline$B B$ & oO & $B$ & 0 & $B$ & 0 & \\
\hline$B E *$ & 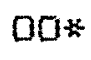 & $B$ & 0 & $B$ & 0 & \\
\hline $\mathrm{C}$ & QD & $\mathrm{BB}$ & $Q F$ & QF & $\mathrm{BB}$ & $\mathrm{QD}$ \\
\hline $\mathrm{CI}$ & QD1 & OOOK & $Q F_{1}$ & $Q F_{1}$ & . $\mathrm{BB}$ & $\mathrm{QDZ}$ \\
\hline $\mathrm{Cl}$ & QD2 & $B B$ & $\mathrm{QFZ}$ & QFZ &.$B B$ & $Q D$ \\
\hline $\mathrm{C3}$ & $Q D$ &.$B B$ & $Q F$ & $Q F$ & 000 & $\mathrm{QD}$ \\
\hline \multirow[t]{2}{*}{$\mathrm{cB}$} & $\mathrm{QD}$ & 01 & B & 02 & $\mathrm{QF}$ & \\
\hline & QF & 03 & B & 04 & $Q D$ & \\
\hline DFG & $Q D$ & Q5 & B & 0 & $B$ & 06 \\
\hline
\end{tabular}

CELL LENGTH: $\quad 9.3841 \mathrm{M}$

D2. LONE STRAIGHT SECTION:

WITH DISPERSIDN

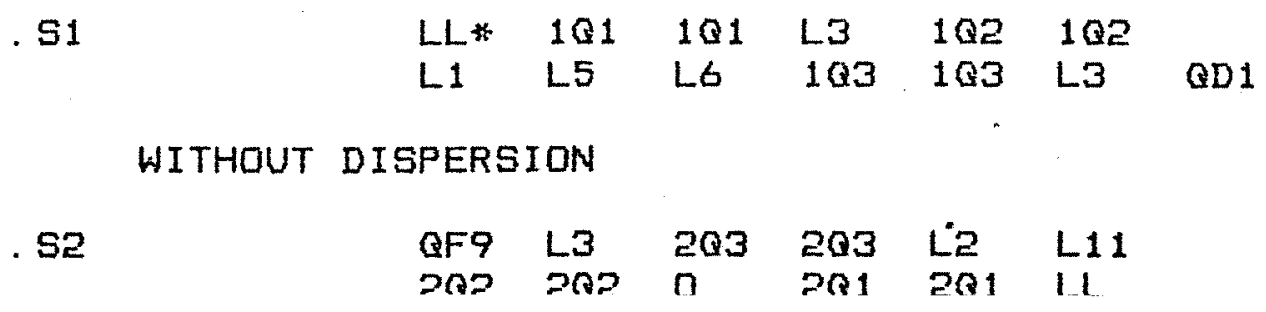




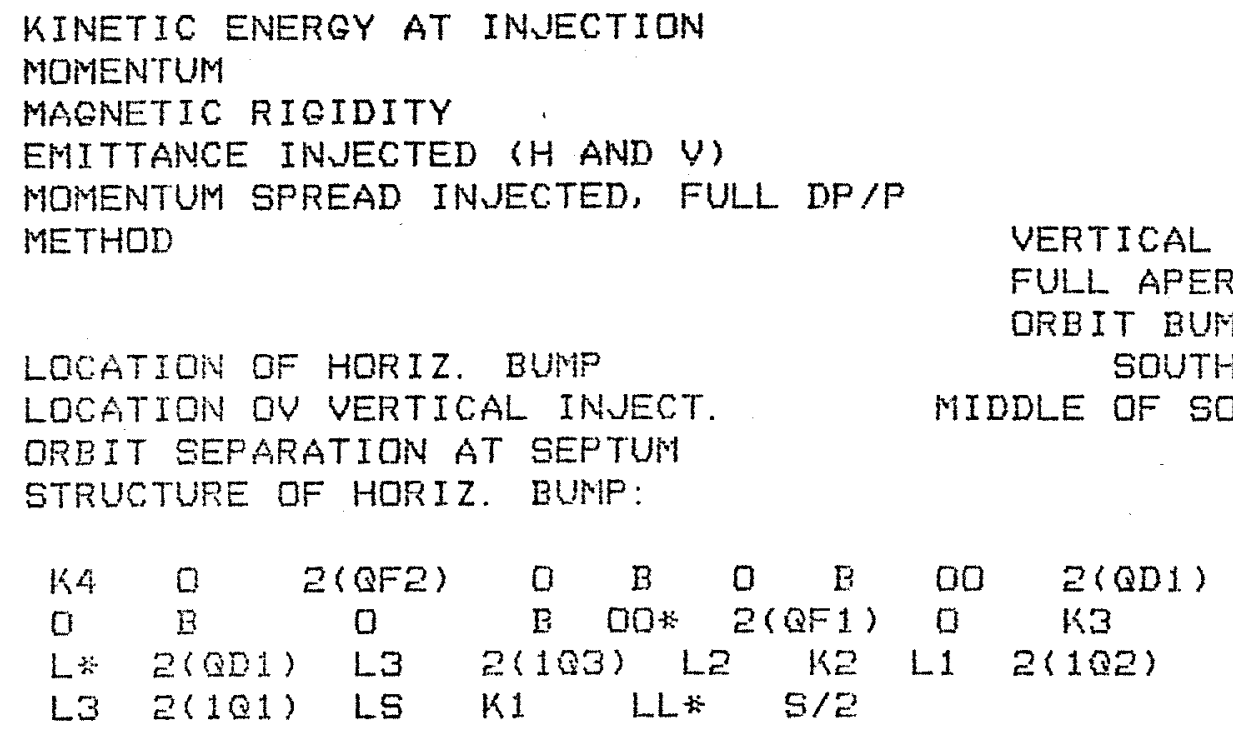

KICKERS:

$k 1$

$k 2$

k3

4. 0

$\begin{array}{lccccl}\text { EFF. LENGTH } & 2.00 & 1.8288 & 1.596715 & 0.477 & \mathrm{M} \\ \text { STRENGTH } & 0.35 & 0.35 & 0.35 & 0.35 & \mathrm{KG} \\ \text { RISE TIME } & 180 & 180 & 180 & 180 & \text { NSEC } \\ \text { H. APERT. } & 10 . & 3.0 & 7.0 & 3.0 & \text { IN } \\ \text { U. APERT. } & 2.5 & 4.0 & 3.0 & 1.5 & \text { IN }\end{array}$
4. 5 GEV
5. 3567 GEV/C 178. $7 \mathrm{KG}-M$ $2 O P I-M M-M R A D$ 1. $0 \%$

INJECTION ON A FULL APERTURE HORIZONTAL BUNP LONG STRAIGHT 6. $5 \mathrm{CH}$

SEPTUM MAGNET: $S$

SEPTUM THICKNESS

EFFECTIVE LENGTH (2*S/2)

STRENGTH

INJECTION ANGLE

VERTICAL SEPARATION BETWEEN BEAM AXIS

DRIFT ELEMENTS:

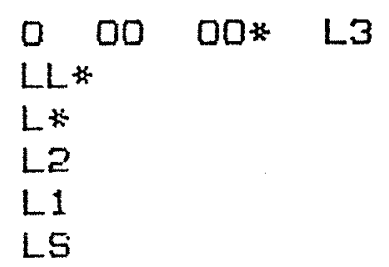

$10 \mathrm{MM}$

$12 \mathrm{FT}$

4. OKG

BO MRAD

50 IN
SEE TABLE 7
4. $095 \mathrm{M}$
2. 206315
0.72752
1.1159
2. 00

QUADRUP OLES:

QF1 QD1 $1 Q 1 \quad 1 Q 2 \quad 1 Q 3 \quad$ QF2 $\quad$ QD2 
MODE

BEAM

NO. OF COOLINO STEPS (SEE TABLE 9) PRECDOLEF RADIUS

TRANSITION ENERGY (GANHA-T)

NO. OF COOLING DEVICES

PICK-UP LONG STRAIOHT SECTION

KICKER LONG STRAIGHT SECTION

NO. OF PARTICLES COOLED

NOTCH FILTER

NO. OF TANKS OF PICK-UPS/KICKERS

NO. OF PICK-UPS/KICKERS PER TANK

TOTAL NO. OF PICK-UPS/KICKERS

INPEDANCE PER PICK-UP

PER KICKER

LENGTH PER PICK-UP/KICKER

OVERALL TRANSVERSE DIMENSION OF TANKS

NO. OF PREMPLIFIERS

NO. OF MAJOR AMPLIFICATION STATIONS

AMPLIFIER TOTAL RATED POWER

PRE-AMP NOISE LEVEL

DISTANCE BETWEEN PICK-UPS AND KICKERS NORMALIZED TO CIRCUNFERENCE

LOCATION OF PICK-UP STATION

LOCATIDN OF KICKER STATION

TIME DISTANCE BETWEEN PICK-UPS

AND KICKERS COLLECTION POINT

IN STRAIGHT L INE
MONENTUM

DEBUNCHED

3

75. $4717 \mathrm{M}$

10. 24624

1

20. $M$

20. $M$

2. O* 10EXP 7

CIRCUMFERENCE LENOTH

SHORTED

8

32

256

$30 \mathrm{OHM}$

BO GHM

$5 \mathrm{cM}$

$1 \mathrm{FT}$

6

1

10. $\mathrm{KW}$

1. $\mathrm{B} \mathrm{DB}$

0.4

WEST LONG STRAIGHT

EAST LDNG STRAIGHT

470 NSEC 
D3. ARC SECTOR:

$\begin{array}{llllll}A R C & . C 1 & . C 2 & . C 3 & . C & \\ . C & . C & . C & . C 8 & . D F 9\end{array}$

D4. QUADRANT STRUCTURE:
$.5 P H$
.51 . ARC . SE

D5. SUPERFERIOD:

. SPH REFLECT (. SPH)

E. LATTIC E FUNCTIONS

BETA,H BETA,V ETA

MAXIMA REGULAR CELL:

MAX 16.

MIN
60. $22 M$

2. 5
$56.80 \mathrm{~m}$

15.

2. 5
$-2.74 M$

1. 3

0.6

MIDDLE OF LONE STRAIGHT "WITH" DISPERSION (. S1)

9. 9842

10. 0506

$-2.7427$

MIDDLE OF LONG STRAIGHT "WITHDUT" DISPERSION (. SE)

10. 3516

6. 0182

0.00 


\section{CODLING STEPS:}

STEP

KINETIC ENERGY, GEV

BETA

GAMMA

ETA

REVOLUTION FREQ. KHZ

BANDWITH, MHZ LOW

LOWER HARMONIC

UPPER HARMONIC

INITIAL DP/P, FULL $(\%)$

FINAL DP/P, FULL $(\%)$

COOLING TIME, SEC

OVERALL LDOP GAIN (DB)

POWER AT KICKERS (RMS) : AMPLIFIER NOISE (KW) SCHOTTKY SIGNALS (KW)

BEAM TRANSIT TIME FROM P. U. TO KICKERS (NSEC)
\#1

4. 5

0. 985

5. 796

0. 021

6อ2. 72

100

500

160

803

2. 0

‥ 288

4. 5

236

5. 0

ค. 8

640
\#2

2. 4

‥ 957

3. 558

D. 070

606. 28

100

500

164

825

D. 494

o. 133

1. 25

230

1. 6

o. 1

658
\#3

0. 9

o. 860

1. 959

0. 251

543. 70

100

500

183

920

o. 272

o. 0464

o. 75

220

0. 08

o. 015

733 


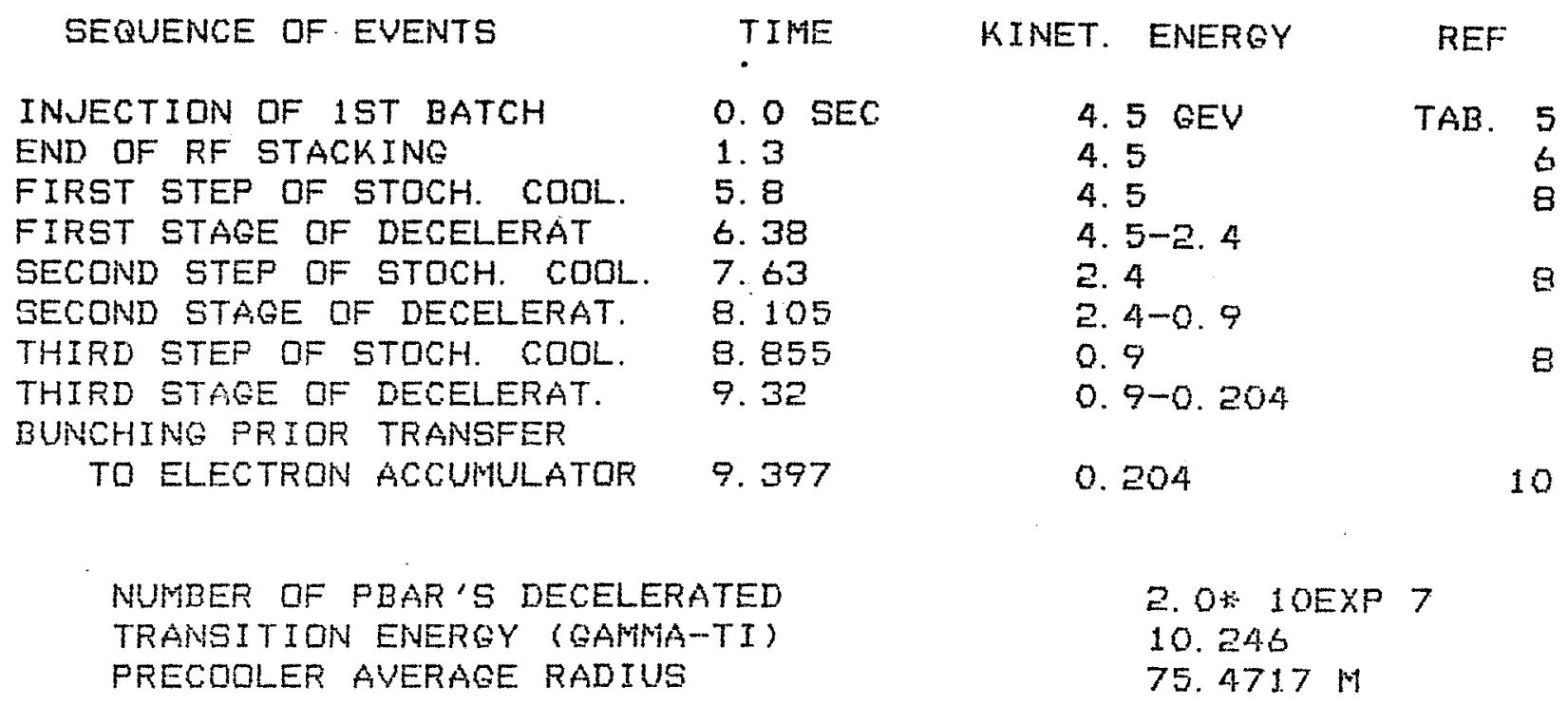

FIRST STAGE QF DECELERATION (4.5 - 2. 4 GEV)

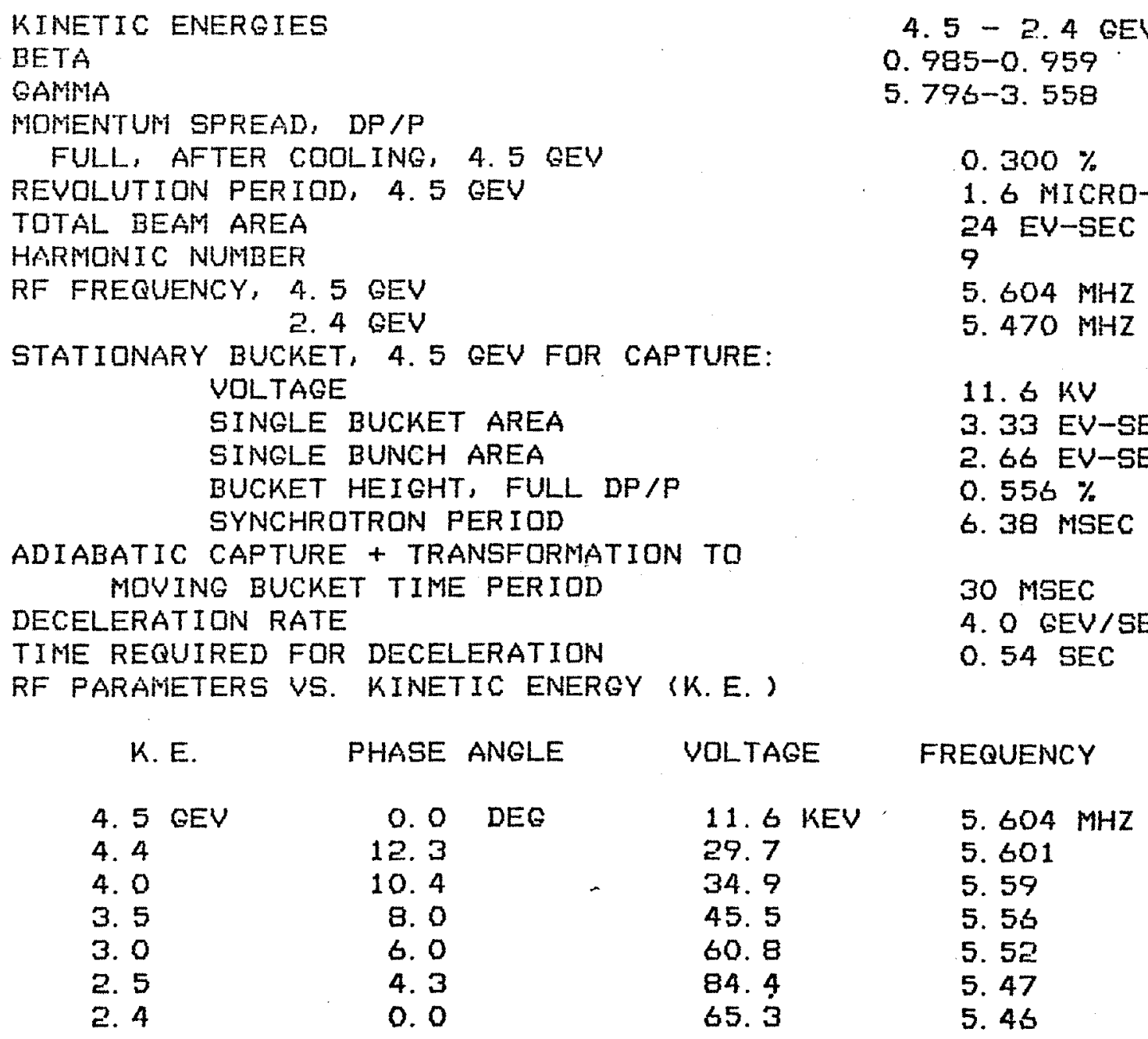


MOUING BUCKET AREA (SINGLE)

STATIONARY BUCKET, 2. 4 GEV:

VOLTAGE

PHASE ANGLE

BUCKET AREA (SINGLE)

BUCKET HEIGHT, FULL DP/P

SYNCHROTRON PERIOD

TRANGFORMATION TO STATIONARY BUCKET

PLUS ADIABATIC DEBUNCHING TAKES

TOTAL TIME FOR IST STAGE OF DECELERAT.

FINAL MOMENTUM SPREAD, 2. 4 GEV

DEBUNCHED AND FULL, DP/P
3. 33 EV-SEC

65. $3 \mathrm{KEV}$

0. O DEG

3. 33 EV-SEC

$0.93 \%$

1. 14 MSEC

10 MSEC

0. 58 SEC

0. $578 \%$

SECOND STAGE OF DECELERATION (2. 4 - 0.9 GEV)
KINETIC ENERGIES
2. 4 - 0.9 GEV
BETA
$0.959-0.860$
GAMIMA
3. $558-1.959$
MOHENTUM SPREAD, DP/P
FULL, AFTER CODLING, 2. 4 GEV
REVOLUTION PERIOD, 2. 4 GEV
0. $13 \%$
1. 65 MICRO-SEC
TOTAL BEAM AREA
HARMONIC NUMBER
RF FREQUENCY, 2. 4 GEV
0.9 GEV
STATIONARY BUCKET, 2. 4 GEV FOR CAPTURE:
6. 8 EV-SEC
10
6. $067 \mathrm{MHZ}$
5. $436 \mathrm{MHZ}$
VOLTAGE
SINGLE BUCKET AREA
BUCKET HEIGHT, FULL DP/P
SYNCHROTRON PERIOD
4. $54 \mathrm{KV}$
0. 75 EV-SEC
$0.12 \%$
4. 1 MSEC
ADIABATIC CAPTURE + TRANSFORMATION TO MOVING BUCKET TIME PERIOD
DECELERATION RATE
TIME REQUIRED FOR DECELERATION
RF PARAMETERS VS. KINETIC ENERGY (K.E.)
30 MSEC
4. $O$ GEV/SEC
0.435 SEC
K.E. PHASE ANGLE VDLTAGE FREQUENCY

$\begin{array}{lrll}2.4 \text { GEV } & 0.0 \text { DEG } & 4.54 \mathrm{KV} & 6.067 \mathrm{MHZ} \\ 2.0 & 16.8 & 21.9 & 5.99 \\ 1.5 & 12.6 & 29.00 & 5.835 \\ 1.0 & 8.0 & 45.5 & 5.54 \\ 0.9 & 0.0 & 35.0 & 5.437\end{array}$
MOVING BUCKET AREA (SINGLE)
0.75 EV-SEC
STATIONARY BUCKET, 0.9 GEV:
VOLTAGE
PHASE ANGLE
BUCKET HEIGHT, FULL DP/P
SYNCHROTRON PERIOD
TRANSFORMATION TO STATIONARY BUCKET
PLUS ADIABATIC DEBUNCHING TAKES
TOTAL TIME FOR ZND STAGE OF DECELERATION
FINAL MOMENTUM SPREAD, 0.9 GEV
DEBUNCHED AND FULL, DP $/ P$
$30.2 \mathrm{kV}$
0.0 DEG
o. $47 \%$
0.61 MSEC
10 MSEC
o. 475 SEC
o. $28 \%$ 
THIRD STAGE DF DECELERATION $(0.9-0.2$ GEV $)$

\section{KINETIC ENERGIES}

BETA

GAMMA

MOMENTUM SPREAD, DP/P

FULL, AFTER CODLING, 0.9 GEV

REVOLUTION PERIOD, 0.9 GEV

TOTAL BEAM AREA

HARMONIC NUMBER

RF FREQUENCY, 0.9 OEV

O. 2 GEV

STATIONARY BUCKET, 0.9 EEV FOR CAPTURE:

VOLTAGE

SINGLE BUCKET AREA

BUCKET HEIGHT, FULL DP/P

SYNCHROTRON PERIOD

ADIABATIC CAPTURE + TRANSFORMATION TO

NOUTNG BUCKET TIME PERIOD

DECELERATION RATE

TIME REQUIRED FOR DECELERATION

RF PARAIIETERS US. KINETIC ENERGY (K.E.)

K. E.

PHASE ANGLE

VOLTAGE

0.9 GEV

0.6

0. 4

0. 3

0. 2
D. O DEG

21.

17.

15. 5

0.0
1. $15 \mathrm{kV}$

8. 8

10. 8

11. 9

5. 0
$0.9-0.204$ GEV

0. $860-0.570$

1. $959-1.217$

$0.046 \%$

1. 84 MICRO-SEC

1. 15 EV-SEC

14

7. $61 \mathrm{MHZ}$

5. $01 \mathrm{NHZ}$

1. $17 \mathrm{kV}$

0. 09 EV-SEC

o. $08 \%$

2. 6 MSEC

45 MSEC

2. 0 GEV/SEC

0.41 SEC

FREQUENEY

7. $61 \mathrm{MHZ}$

7. 01

6. 31

5. 78

5. 01

MOVING BUCKET AREA (SINGLE)

0. 09 EV-SEC

STATIONARY BUCKET, 200 MEV:

VOLTAGE

BUCKET AREA (SINGLE)

BUCKET HEIOHT, FULL DP $/ P$

SYNCHROTRON PERIOD

TRANSFORMATION TO STATIONARY BUCKET

PLUS ADIABATIC DEBUNCHINO TAKES

TOTAL TIME FOR JRD STAGE OF DECELERATION

FINAL TOTAL BEAM AREA AT 200 MEV

AFTER DEBUNCHING

5. $\mathrm{OKV}$

0.09 EV-SEC

o. $19 \%$

0. 61 MSEC

10 MSEC

0.465 SEC

1. 25 EV-SEC 
A. GENERAL

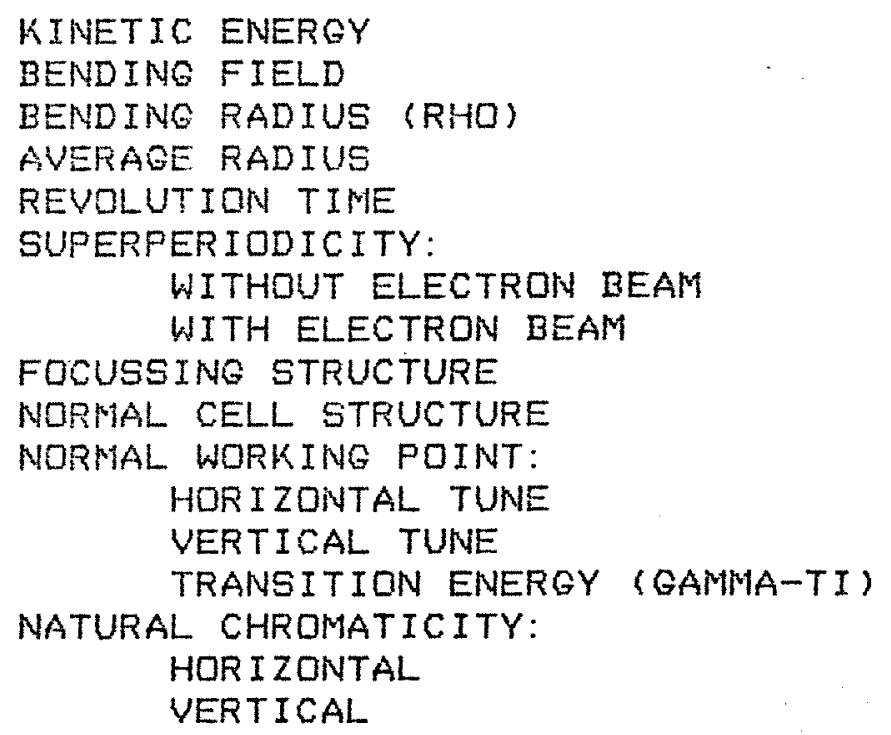

B. MAGNETS

NUMEER OF DIPOLES

LENGTH OF DIPOLES

EFFECTIVE LENGTH OF DIPOLES

NUMBER OF QUADRUPOLES

LENGTH OF QUADRUPOLES

EFFECTIVE LENGTH OF QUADRUPOLES

QUADRUPOLE GRADIENTS AT 1.4 GEV:

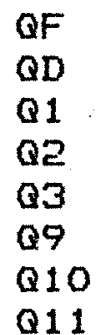

$0.2-1.4$ GEV

2. $35-7.79 \mathrm{KG}$

9. $17 \mathrm{M}$

32. $35 \mathrm{M}$

1197-740 NSEC

2

1

SEPARATED FUNCTION FODO

4. 102

5. 390

4. 089

$-7.410$

$-6.409$
44
48. 00 IN
51. 52 IN
44
24. 00 IN
26. 64 IN 


\section{APERTURE AND ACCEPTANCE}

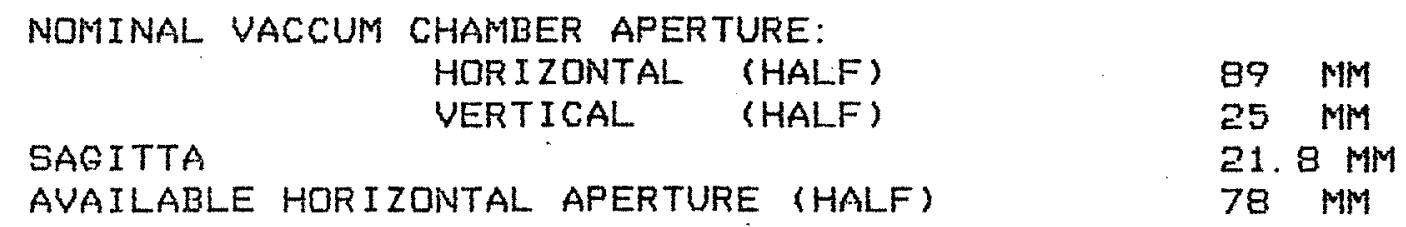

LATTICE FUNCTIONS

$\begin{array}{lcccc} & \text { MAXIMA } & \text { IN DIPOLE } & \text { L. S. } & \text { S. S. } \\ \text { BETA H } & 48.23 M & 19.50 M & 12.93 \mathrm{M} & 10.37 \mathrm{M} \\ \text { BETA V } & 19.44 & 13.25 & 10.11 & 11.48 \\ \text { ETA } & 3.65 & 3.55 & 0.06 & 3.51\end{array}$

ACCEPTANCE (USING BEAM SIZE IN DIPOLES)

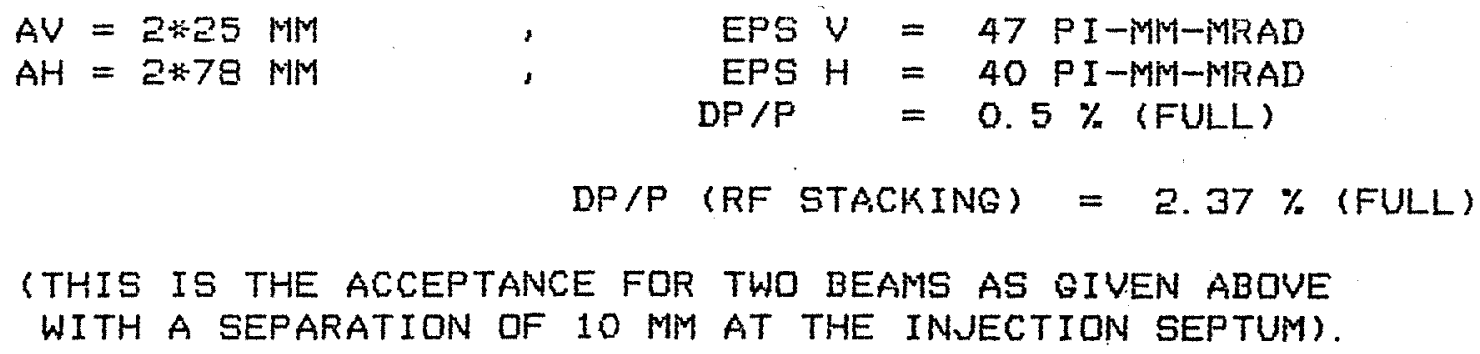


FINAL BUNCHING AT 204 MEV •

TOTAL BEAM AREA

HARMONIC NUMBER

RF FREQUENCY

STATIONARY BUCKET:

VOLTAGE

SYNCHROTRON PERIOD

BUCKET AREA

BUCKET HEIQHT, FULL DP/P

TIME FOR ADIABATIC CAPTURE

VOLTAGE JUMP

BUCKET AREA

BUCKET HEIGHT, FULL DP/P

SYNCHROTRON PERIOD

TIME TO RAISE VDLTAGE

9O DEE. BUNCH ROTATION

FINAL MOMENTUM SPREAD, FULL DP/P

FINAL BUNCH LENGTH, FULL
1. 3 EV-SEC

1

$360.36 \mathrm{KHZ}$

2. $0 \mathrm{KV}$

3. 8 MSEC

3. $O$ EV-SEC

0. $46 \%$

10 MSEC

FROM 2. 0 TO

3. 85

4. 14 EV-SEC

0. $64 \%$

2. 65 MSEC

10 MICRD-SEC

0.67 MSEC

o. $45 \%$

1. O MICRD-SEC 
EXTRACTION METHOD:

SINGLE TURN

FAST

FULL APERTURE

EXTRACTION OCCURS HORIZONTALLY TO

DUTSIDE, AT UPSTREAM END DF EAST

LDNG STRAIGHT SECTION

TRANSPORT CHANNEL: KINETIC ENEROY

EMITTANCE (H AND $V$ ) 2.0 PI-MM-MRAD

MONENTUM SPREAD $(+/-\rangle$ O. $0.1 \%$

KICKERS:

$\begin{array}{lll} & \# 1 & \\ \text { LOCATION } & & \\ \text { FIELD } & 250 \mathrm{H} & \\ \text { RISE TIME } & 1.5 \mathrm{MICRO} \text {-SEC } & 1.5 \mathrm{MICRO-SEC} \\ \text { APERTURE, H } & & \\ \text { EFFECT. LENGTH } & 2.00 \mathrm{M} & 2.00 \mathrm{M}\end{array}$

SEQUENCE OF MAGNET SECTORS:

1. TRANSLATOR

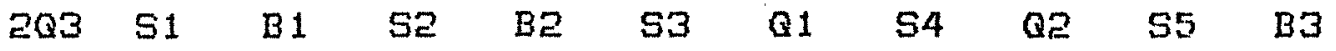

2. LUNG STRAIGHT TRANSPORT

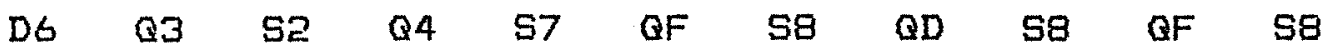

QD $\quad S 9$

3. BEND LEFT

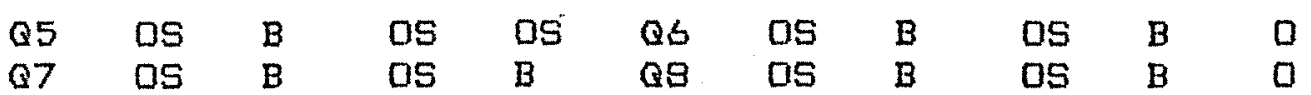

$09 / 2$

4. MATCHING AND VERTICAL TRANSLATIDN

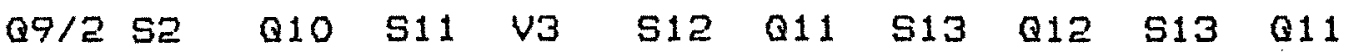

512 V3* 
5. MATCHING FODO

QS Q13 $\quad 014 \quad 014 \quad 54 \quad$ QF/2

6. MATCHING PLUS FODO TRANSPORT

QF/2 519 QD 519 QF 519 QD 519 QF 518 QD

517 Q18 $516 \quad Q 17$ S15 (IN THE MIDDLE OF V1*)

7. VERTICAL TRANSLATION TO-TARGET

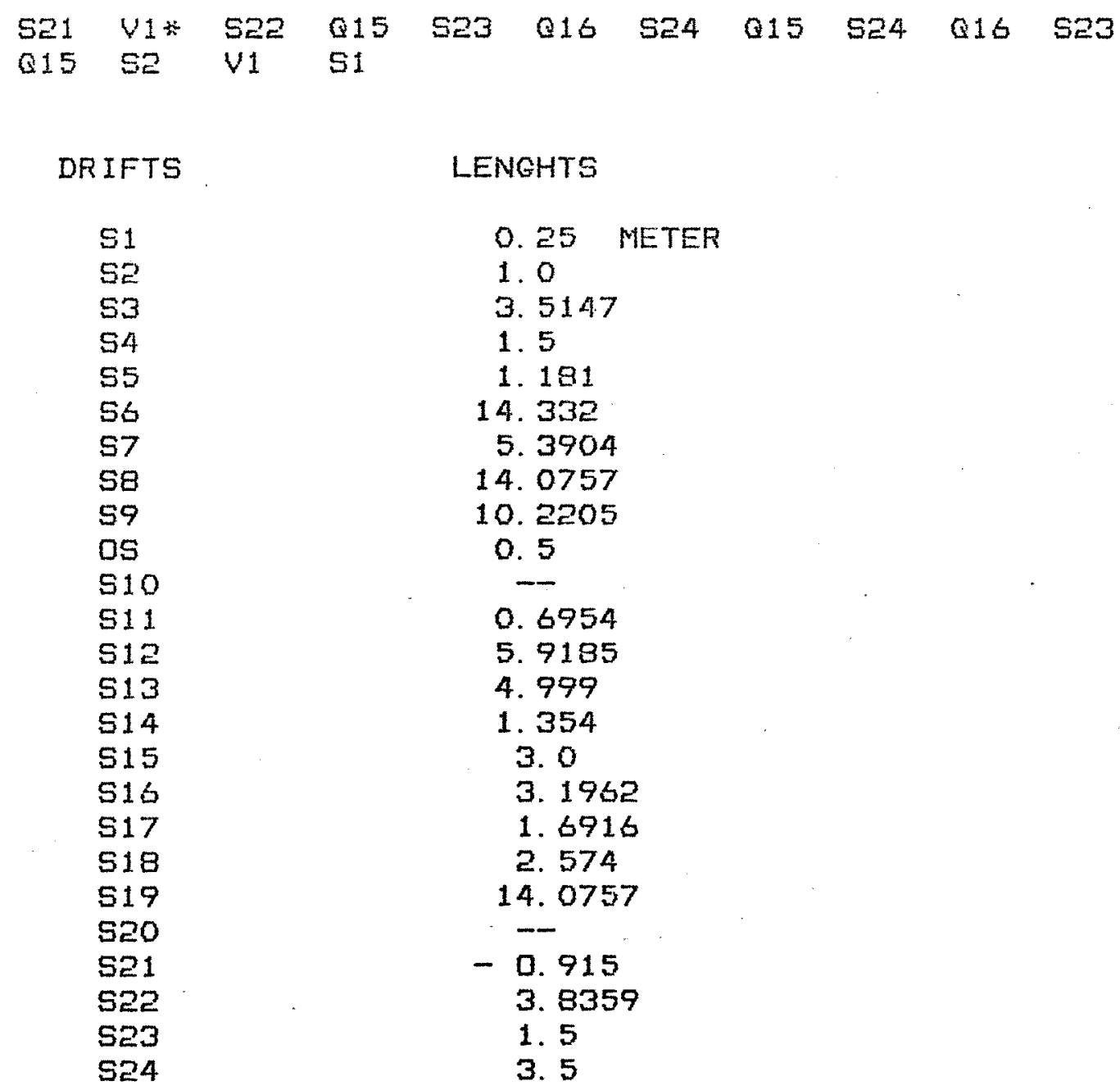


QUADRUPOLES

Q1

Q2

Q3

Q4

QF

QD

Q5

Q6

Q7

98

Q9/2

Q10

Q11

Q12

Q13

Q14

$Q F / 2$

Q17

Q18

Q15

Q16
EFFECT. LENGTH

\section{(METER)}

0. 6096

o. 6096

n

"

$"$

"1

"

$"$

1. 2192

o. 6096

$"$

1. 2192

o. 6096

$"$

"

"

o. 3048

o. 6096

"

"

1. 2192
STRENGTH

( $\left.B^{\prime} / B-R H O\right)$

/Mำ

o. 5296

$-0.4697$

o. 42314

$-0.4295$

o. 1602

$-0.1602$

o. 4216

$-0.3443$

o. 32715

o. 2784

o. 43036

$-0.4687$

$-0.5485$

o. 4423

$-0.45869$

o. 34931

o. 1602

$-0.52436$

o. 34452

o. 5025

$-0.41262$
HORIZ. DIPOLES

B1

$\mathrm{B} 2$

B3

$B$

VERT. DIPOLES
EFFECT. LENGTH

(METER)
STRENGTH

$(B / B-R H O)$
$/ M$
0. 033727
o. 054172
o. 062523
0. 040929

1. 00

1. 1217

1. 675

1. 3716
EFFECT. LENGTH

(METER)
STRENGTH

( $B / B-R H O)$

$/ M$

1. 3716

1. 3716

1. 83

1. 83
UP 0.036928

DOWN 0.036928

UP 0.05726

DOWN 0.05726 
C. STRUCTURE

C1. CURVED SECTION

ELEMENTS IN CURVED SECTION

LENGTH

$\begin{array}{ll}\text { DIPOLE } & \text { (B) } \\ \text { QUADRUPQLE } & \text { (Q) } \\ \text { DRIFT SPACE } & \text { (Q) } \\ \text { DRIFT SPACE } & \text { (DO) }\end{array}$

$4 \mathrm{FT}$

2 FT

$1 \mathrm{FT}$

2 FT

CELL STRUCTURE:

$(Q D) \square(B) \square(B) \square D$

$(Q F) O(B) O(B) D O$

CELL LENGTH

$28 \mathrm{FT}$

CE. SHORT STRAIGHT

$\begin{array}{ccc}\text { DRIFT } & \text { SPACE } & (S S) \\ " 1 & " & (S 1) \\ " & " & (S 2) \\ " & " & (S 3)\end{array}$
6. $90 \mathrm{FT}$
2. $00 \mathrm{FT}$
6. $56 \mathrm{FT}$
5. 77 FT

C3. LDNG STRAIGHT

$\begin{array}{ccc}\text { DRIFT } & \text { SPACE } & \text { (LS) } \\ " 1 & " & \text { (L1) } \\ " & " & \text { (L2) } \\ " & " & (L 3)\end{array}$

$31.80 \mathrm{FT}$

2. $\mathrm{OO} F \mathrm{FT}$

2. $62 \mathrm{FT}$

12. $00 \mathrm{FT}$

64. DISPERSION SUPPRESSOR

$\begin{array}{ll}\text { DRIFT SPACE } & \text { (D1) } \\ \| & \text { (D2) }\end{array}$

1. $10 \mathrm{FT}$

$6.90 \mathrm{FT}$

C5. QUADRANT STRUCTURE (Q)

$$
\begin{aligned}
& S S(Q 11) S 1(Q 10) S 2(B) 0(Q 9) D(B) 0(B) \\
& 53(Q D) D(B) 0(B) 00(Q F) 0(B) O(B) \\
& Q Q(Q D) D 1(B) D 2(Q F) D 2(B) D 1(Q D) Q(B) \\
& \text { O(B )L3(Q3)L2(Q2)L1(Q1)LS }
\end{aligned}
$$

C6. RING STRUCTURE

$$
Q(R E F L E C T \text { Q } Q \text { (REFLECT Q) }
$$

LENTGH OF CENTRAL ORBIT

203. $2296 \mathrm{M}$

666.76 FT 

Appendix B

Precooler Orbit Listing 


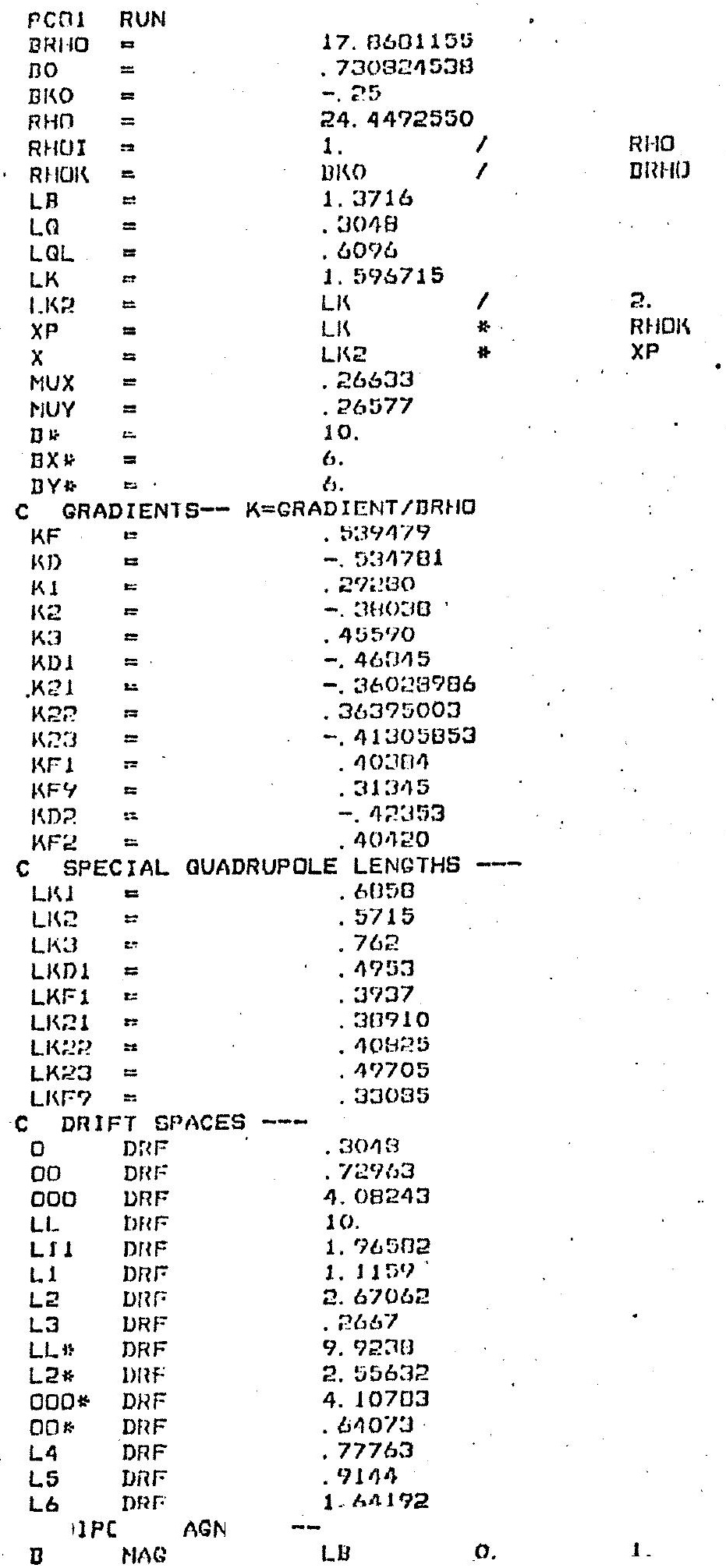




\begin{tabular}{|c|c|c|c|c|c|c|c|c|c|c|c|c|}
\hline 1 & PCE & INI & $\ldots$ & & & & & & & & & \\
\hline B & BN- & & סט & $\mathrm{B}$ & 0 & B & 0 & & & & & \\
\hline BRBN & BNIL & & 0 & BK & a & BK & 0 & & & & & \\
\hline BB K & LINL & & $0(j):$ & $n$ & 17 & $B$ & 0 & & & & & \\
\hline חט & DNL & & $0:$ & H & 0 & B & 06 & & & & & \\
\hline of & BNIL & & (a) & $\mathrm{BB}$ & af & & & & & & & \\
\hline $\mathrm{DF}^{\mathrm{F} *}$ & BNII. & & and & אמנומ & $Q F=1$ & & . & & & & & \\
\hline$D F=1$ & BNIL & & QDI & QuJo* & QF 1 & & & & & & & \\
\hline FDi & BNIL & & QFi & $D B$ & an & & & & & & & \\
\hline. $\mathrm{FD}$ & DNII. & & AF & $B B$ & OD & & & & 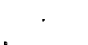 & & & \\
\hline$c$ & BMIL & & $\mathrm{DF}$ & $F=D$ & & & & & & & & \\
\hline$c_{1}$ & DML & & $\mathrm{DF}=1$ & $F D_{1}$ & & & & & & & & \\
\hline C2 & DML & & one & $\mathrm{BD}$ & $N=2$ & QFP & מנו . & QD & & & & \\
\hline .03 & BML & & QD & VB & $O F=$ & $\mathrm{Gr}=$ & טDo & QD & & & & \\
\hline. $\mathrm{CD}$ & UNL & & QD & 1 & D & o? & $\theta F$ & $Q F=$ & 03 & $B$ & 04 & QD \\
\hline DF? & BNL & & QD & פמה . & OFף & & & & & & & \\
\hline ARC & BML & & (c) & $\mathrm{C} 2$ &. $\cos$ & . c &. $\mathrm{c}$ & . $c$ & . c &. $\mathrm{cB}$ & . DFQ & \\
\hline .51 & UML & & LLF & 101 & In1 & L3 & $1 Q 2$ & $i 02$ & ii & LS & Lo & 103 \\
\hline .52 & DNL & -1 & $\begin{array}{l}\text { LL } \\
0\end{array}$ & $2 Q 1$ & 201 & 0 & 202 & 202 & L11 & L2 & 203 & $2 Q 3$ \\
\hline. $\mathrm{SPH}$ & DNL & & .51 & . ARC & S? & & & & & & & \\
\hline $\mathrm{Mr}$ & DMLL & & $\mathrm{cg}$ & $G D$ & 9נו & & & & & & . & \\
\hline S51 & BNLL & -1 & .51 & DF 1 & QF 1 & CCOR & & & & & & \\
\hline .552 & DNIL & & $\mathrm{CB}$ & . DFG & .52 & & & & & & & \\
\hline
\end{tabular}

c NORMAL CELLS ---

\begin{tabular}{|c|c|c|c|c|c|c|c|c|c|}
\hline DO & SUB & & & & & & & & \\
\hline $\mathrm{QF}$ & $\operatorname{Mn} B$ & LO & & $\mathrm{KF}$ & & 1. & & & \\
\hline DR. & $\operatorname{MISG}$ & LCA & & $K D$ & & 1. & & & \\
\hline \multirow[t]{2}{*}{$c$} & MrN & .6 & & & & & & & \\
\hline & {$[: N]$} & & & & & & & 1 MUI & MUY \\
\hline CR & REF & c & 6 & $n r$ & HD & & 3 & 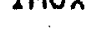 & the \\
\hline QD? & NAG & Lo & & KDE & & 1. & & & \\
\hline QF2 & MAG & L. (A & & KF2 & & 1. & & & \\
\hline $\operatorname{ccs} 3$ & MNM & . BD* & CD2 &. $\mathrm{Ce}$ &. $\cos$ & & & & \\
\hline $\operatorname{CCJR}$ & REF & $\mathrm{cco}$ & & & & ' & & & \\
\hline & CYC &. $\mathbf{C}$ & & & & & & & \\
\hline
\end{tabular}

\section{P DISPERSION SUPPRESSOR -..-}

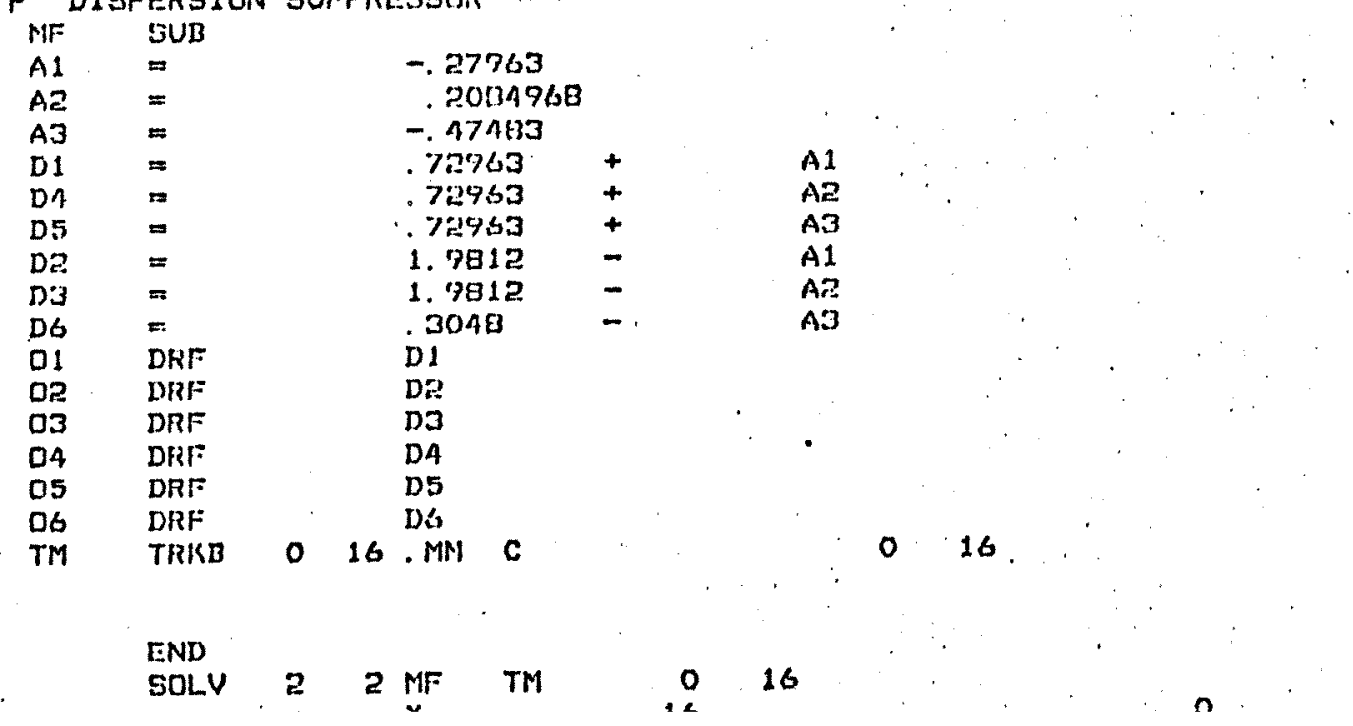


SYNCH RUN PCBI

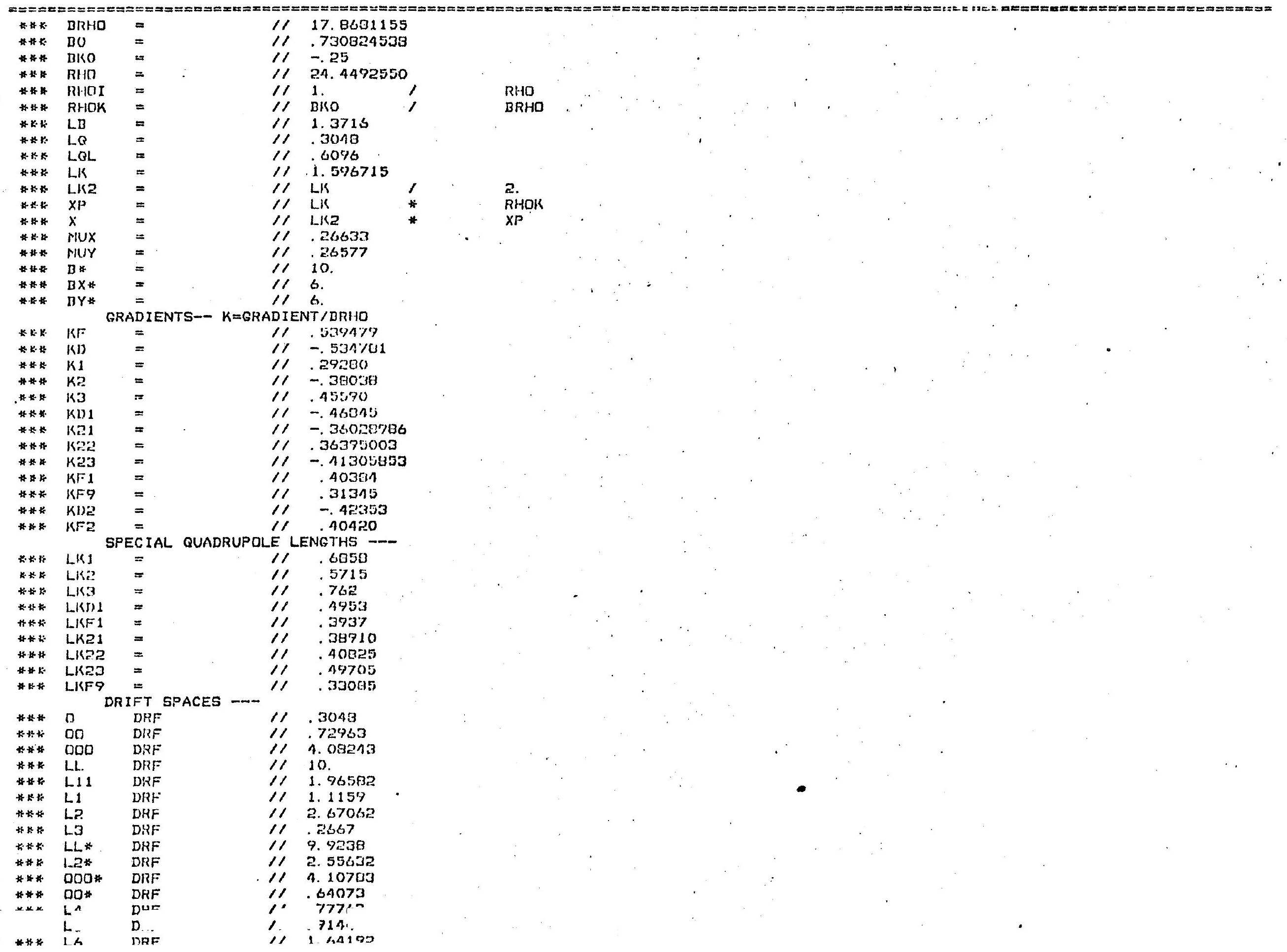


P STRAIGHT SECTION NO. 1 --- WITH DISPERSION

\begin{tabular}{|c|c|c|c|}
\hline 101 & $\operatorname{NAS}$ & LKI & $k 1$ \\
\hline 102 & MNG & LKS & $\mathrm{Ke}$ \\
\hline 183 & MNC & LKa & $\mathrm{k} 3$ \\
\hline OD 1 & NIAG & LKDI & KD1 \\
\hline$Q F_{1}$ & MNG & LKF 1 & KFI \\
\hline
\end{tabular}

QF1 MING 1 LKF1 KFI 1 .

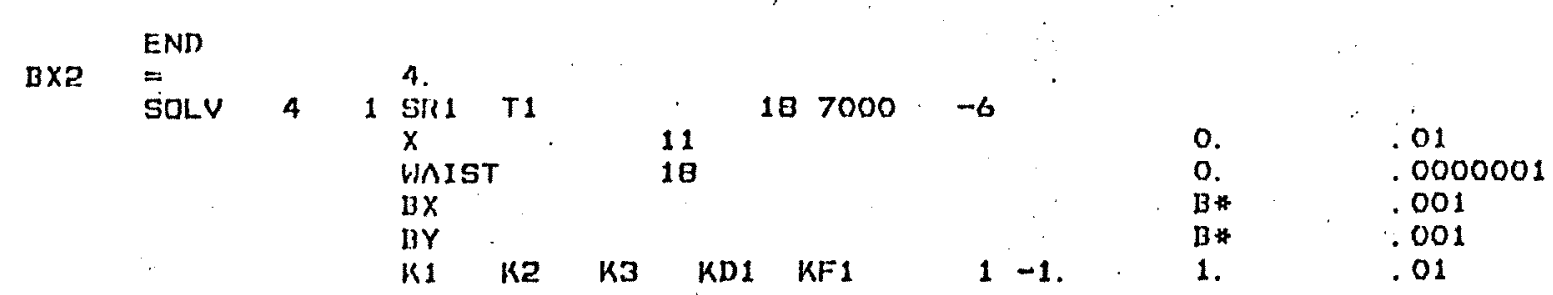

C STRAIGHT SECTION NO. 2 -- WITHOUT DISPERSION

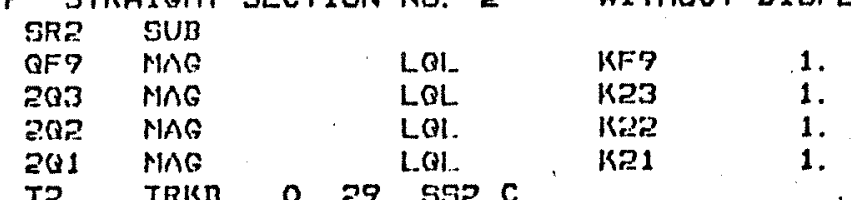

TS TRKB 0 29 LOA.

END

SOLV 4.1 SR2 T2 0.29

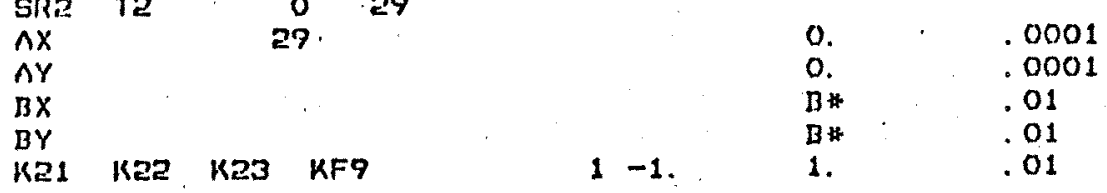

C BETATRON FUNCTIONS THROUGH ONE QUADRANT, STARTING AT CENTER OF NO. 1 STRAIGHT CYC $\quad-2.5 P H$

FIN 
LATTICE DEFINITION --

\begin{tabular}{|c|c|c|c|c|c|c|c|c|c|c|c|c|c|c|}
\hline & & & & & & & & & & & & & & \\
\hline$* * *$ & . & BNL & & 11 & סם & $B$ & 0 & $\boldsymbol{B}$ & 0 & . & & t. & & \\
\hline$H *$ & BUII & DNL & & 11 & 0 & UK & D & BK & 0 & & & & & \\
\hline$x \leqslant$ & $.13 \mathrm{H}$ & DNIL & & 11 & $00 \%$ & II & 0 & B & D & & & & & \\
\hline t*t & . DB9 & BNL & & 11 & 05 & B & 0 & B & DS & & & & & \\
\hline$t-4$ & . DF & DNL & & 11 & QD & $\mathrm{HB}$ & QF & & & & & & & \\
\hline 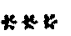 & DF* & BNIL & & 11 & RDI & BHD * & $\mathrm{QF} 1$ & & & & & & & \\
\hline \#KK & . DF 1 & BNL & & 11 & QD) 1 & $000 *$ & QF 1 & & & & & & & \\
\hline$* * *$ & FDI & BML & & 11 & $Q F 1$ &.$B D *$ & QDE & & & & & & & \\
\hline$* * *$ & FD & BML & & 11 & $\mathrm{QF}$ &. $\mathrm{DB}$ & $Q D$ & & & & & . & & \\
\hline$\hbar *$ & . C & BNL & & 11 &. $\mathrm{DF}$ &.$F D$ & & & & & & & & \\
\hline * &. $\mathrm{Cl}$ & BNL & & 11 & . DF1 & FDI & & & & & & & . & \\
\hline$* * *$ &. $\mathrm{C2}$ & BML & & 11 & QD2 & $.4 B$ & QFE & QF? & . $\mathrm{BB}$ & $Q D$ & & & & \\
\hline *** &. $\mathrm{c3}$ & BNL & & 11 & $\mathrm{QD}$ & $.3 B$ & QF & $\mathrm{QF}$ & QDO & $Q D$ & & & & \\
\hline **\# & CE & BML & & 11 & $Q D$ & 01 & B & 02 & $\mathrm{QF}$ & $Q F$ & 吗 & $B$ & Q4. & $Q D$ \\
\hline \#* & . DFG & BNL & & 11 & QD & $.11 B 9$ & QFq & & & & & & & \\
\hline$\# * *$ & . ARC & BNL & & 11 &.$C 1$ &. $\mathrm{CE}$ &. $\mathrm{c3}$ &.$C$ &. $\mathrm{C}$ &. $\mathrm{C}$ & . C & . C8 & . DFG & \\
\hline $4 * 4$ & .51 & BML & & $\begin{array}{l}11 \\
11\end{array}$ & $\begin{array}{l}\text { LL* } \\
103\end{array}$ & $\begin{array}{l}\text { 1Q1 } \\
\text { L3 }\end{array}$ & $\begin{array}{l}1 \times 1 \\
\text { OD } 1\end{array}$ & L3 & $1 Q 2$ & $1 \mathrm{GP}$ & LI & $L 5$ & L6 & 103 \\
\hline $\begin{array}{r}* * 4 \\
*\end{array}$ & .52 & BML & -1 & 11 & $\frac{L L}{0}$ & $\begin{array}{l}2 \times 1 \\
\text { Qr=y }\end{array}$ & $2 Q 1$ & 0 & $2 Q 2$ & 202 & L11 & La & 203 & 203 \\
\hline 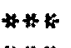 & $.5 P H$ & BML & & 11 & .51 & AIRC & SP & & & & . & & & \\
\hline$* 4$ & . MNI & BML & & 11 & . $\mathrm{CB}$ & & . BD7 & & & & & • & & \\
\hline$* * 4$ & .551 & DML & -1 & 11 & .51 & DF 1 & QF 1 & CCOR & & & & & & \\
\hline **** & . SS2 & BML & & 11 &. $\mathrm{CB}$ & . DFG & .52 & & & & & & . & \\
\hline
\end{tabular}




\begin{tabular}{|c|c|c|c|c|c|c|c|c|c|c|c|c|c|}
\hline POS & & $S(M)$ & MUX & NUY & BETAX (M) & DETAY (M) & ETAX(M) & $\operatorname{ETAY}(M)$ & ETAS (M) & $A L \ln \ln x$ & ALPHAY & DETAX & DETAY \\
\hline $\begin{array}{l}0 \\
1 \\
2 \\
3 \\
4\end{array}$ & $\begin{array}{l}\text { LL* } \\
1 Q 1 \\
\text { LQ1 } \\
\text { L3 }\end{array}$ & $\begin{array}{r}0.0000 \\
9.9238 \\
10.6096 \\
11.2954 \\
11.5621\end{array}$ & $\begin{array}{r}0.00000 \\
.12150 \\
.13007 \\
.13700 \\
.14073\end{array}$ & $\begin{array}{r}0.00000 \\
.12399 \\
.12709 \\
.13201 \\
.13396\end{array}$ & $\begin{array}{r}9.98016 \\
17.84797 \\
18.52135 \\
12.76701 \\
10.16300\end{array}$ & $\begin{array}{l}10.05056 \\
19.94920 \\
24.24133 \\
36.98583 \\
44.66923\end{array}$ & $\begin{array}{l}-2.74271 \\
-2.74271 \\
-2.55603 \\
-2.02140 \\
-1.75309\end{array}$ & $\begin{array}{l}0.00000 \\
0.00000 \\
0.00000 \\
0.00000 \\
0.00000\end{array}$ & $\begin{array}{l}0.00000 \\
0.00000 \\
0.00000 \\
0.00000 \\
0.00000\end{array}$ & 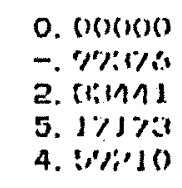 & $\begin{array}{r}0.00000 \\
-.98739 \\
-5.70830 \\
-13.72037 \\
-15.08502\end{array}$ & $\begin{array}{r}.00000 \\
.00000 \\
.53815 \\
1.00305 \\
1.00305\end{array}$ & $\begin{array}{l}0.00000 \\
0.00000 \\
0.00000 \\
0.00000 \\
0.00000\end{array}$ \\
\hline $\begin{array}{l}5 \\
6 \\
7 \\
9 \\
9\end{array}$ & $\begin{array}{l}102 \\
102 \\
\text { L1 } \\
\text { L5 } \\
\text { Lo }\end{array}$ & $\begin{array}{l}12.1336 \\
12.7051 \\
13.8210 \\
14.7354 \\
16.3773\end{array}$ & $\begin{array}{l}.15214 \\
.16825 \\
.20685 \\
.24259 \\
.30571\end{array}$ & $\begin{array}{l}13562 \\
.13721 \\
.14092 \\
.14502 \\
.15677\end{array}$ & $\begin{array}{l}\text { 6. } 52372 \\
\text { 5. } 11048 \\
\text { 4. } 22569 \\
\text { 3. } 96874 \\
\text { 4. } 56533\end{array}$ & $\begin{array}{l}56.79947 \\
55.71285 \\
41.05851 \\
30.75299 \\
16.07742\end{array}$ & $\begin{array}{r}-1.27874 \\
-.96406 \\
-.47765 \\
-.07944 \\
.63597\end{array}$ & $\begin{array}{l}0.00000 \\
0.00000 \\
0.00000 \\
0.00000 \\
0.00000\end{array}$ & $\begin{array}{l}0.00000 \\
0.00000 \\
0.00000 \\
0.00000 \\
0.00000\end{array}$ & 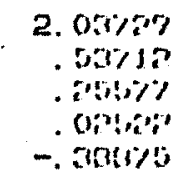 & $\begin{array}{r}-5.25590 \\
7.07787 \\
6.05444 \\
5.21581 \\
3.70995\end{array}$ & $\begin{array}{l}.67691 \\
43571 \\
.43571 \\
.43571 \\
.43571\end{array}$ & $\begin{array}{l}0.00000 \\
0.00000 \\
0.00000 \\
0.00000 \\
0.00000\end{array}$ \\
\hline $\begin{array}{l}10 \\
11 \\
12 \\
13 \\
14\end{array}$ & $\begin{array}{l}103 \\
103 \\
\text { L3 } \\
\text { QD } 1 \\
\text { OD1 }\end{array}$ & $\begin{array}{l}17.1393 \\
17.9013 \\
18.1680 \\
18.6633 \\
19.1586\end{array}$ & $\begin{array}{l}.33269 \\
.37241 \\
.39632 \\
.46677 \\
.54767\end{array}$ & $\begin{array}{l}.16504 \\
.17212 \\
.17397 \\
.17644 \\
.17876\end{array}$ & $\begin{array}{r}4.08731 \\
\text { 2. } 12979 \\
1.49119 \\
.93153 \\
1.15503\end{array}$ & $\begin{array}{l}\text { 14. } 62227 \\
21.90304 \\
26.95321 \\
33.62608 \\
33.15831\end{array}$ & $\begin{array}{l}.87122 \\
.88097 \\
.84282 \\
.81549 \\
.89124\end{array}$ & $\begin{array}{l}0.00000 \\
0.00000 \\
0.00000 \\
0.00000 \\
0.00000\end{array}$ & $\begin{array}{l}0.00000 \\
0.00000 \\
0.00000 \\
0.00000 \\
0.00000\end{array}$ & 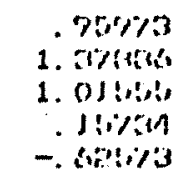 & $\begin{array}{r}-1.60598 \\
-8.77714 \\
-9.72736 \\
-3.44819 \\
4.35616\end{array}$ & $\begin{array}{r}.16808 \\
-.14305 \\
-.14305 \\
.04796 \\
.24453\end{array}$ & $\begin{array}{l}0.00000 \\
0.00000 \\
0.00000 \\
0.00000 \\
0.00000\end{array}$ \\
\hline $\begin{array}{l}15 \\
16 \\
17 \\
18 \\
19\end{array}$ & $\begin{array}{l}\text { OOO* } \\
O F 1 \\
O F 1 \\
O O * \\
B\end{array}$ & $\begin{array}{l}23.2645 \\
23.6602 \\
24.0539 \\
24.6946 \\
26.0662\end{array}$ & $\begin{array}{r}.68044 \\
.68265 \\
.69179 \\
.68965 \\
.69736\end{array}$ & $\begin{array}{l}.22060 \\
.22960 \\
.23929 \\
.20423 \\
.20132\end{array}$ & $\begin{array}{l}\text { 25. } 62542 \\
29.38567 \\
20.572488 \\
24.50056 \\
16.94351\end{array}$ & $\begin{array}{l}\text { 7. } 53544 \\
6.56816 \\
6.50713 \\
7.10115 \\
7.12548\end{array}$ & $\begin{array}{l}1.89572 \\
1.93200 \\
1.84803 \\
1.61536 \\
1.15601\end{array}$ & $\begin{array}{l}0.00000 \\
0.00000 \\
0.00000 \\
0.00000 \\
0.00000\end{array}$ & $\begin{array}{l}0.00000 \\
0.00000 \\
0.00000 \\
0.00000 \\
.07740\end{array}$ & $\begin{array}{r}-5.07175 \\
-1.01150 \\
3.31170 \\
3.011918 \\
2.16110\end{array}$ & $\begin{array}{r}1.88141 \\
.62632 \\
-.46829 \\
-.58835 \\
-.82480\end{array}$ & $\begin{array}{r}.24453 \\
-.06121 \\
-.36313 \\
-.36313 \\
-.30702\end{array}$ & $\begin{array}{l}0.00000 \\
0.00000 \\
0.00000 \\
0.00000 \\
0.00000\end{array}$ \\
\hline $\begin{array}{l}20 \\
21 \\
22 \\
23 \\
24\end{array}$ & $\begin{array}{l}\mathrm{O} \\
\mathrm{B} \\
\mathrm{O} \\
\mathrm{QDZ} \\
\mathrm{QD} 2\end{array}$ & $\begin{array}{l}26.3710 \\
27.7426 \\
29.0474 \\
28.3522 \\
28.6570\end{array}$ & $\begin{array}{l}.70236 \\
.72007 \\
.72528 \\
.73104 \\
.73700\end{array}$ & $\begin{array}{l}.28649 \\
.30653 \\
.31034 \\
.31400 \\
.31776\end{array}$ & $\begin{array}{r}\text { 15. } 47721 \\
\text { 9. } 94450 \\
\text { в. } 80506 \\
\text { ․ } 17060 \\
\text { 9. } 21477\end{array}$ & $\begin{array}{r}\text { 9. } 69539 \\
\text { 12. } 37420 \\
13.06476 \\
13.26272 \\
12.44914\end{array}$ & $\begin{array}{r}1.06243 \\
.60001 \\
.60354 \\
.53947 \\
.49467\end{array}$ & $\begin{array}{l}0.00000 \\
0.00000 \\
0.00000 \\
0.00000 \\
0.00000\end{array}$ & $\begin{array}{l}.07740 \\
.12593 \\
.12573 \\
.12593 \\
.12593\end{array}$ & 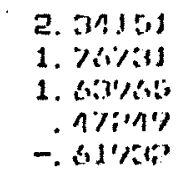 & $\begin{array}{r}-.88092 \\
-1.10545 \\
-1.16019 \\
.51928 \\
2.11809\end{array}$ & $\begin{array}{l}-.30702 \\
-.25090 \\
-.25090 \\
-.17743 \\
-.11096\end{array}$ & $\begin{array}{l}0.00000 \\
0.00000 \\
0.00000 \\
0.00000 \\
0.00000\end{array}$ \\
\hline $\begin{array}{l}25 \\
26 \\
27 \\
29 \\
29\end{array}$ & $\begin{array}{l}00 \\
B \\
0 \\
B \\
0\end{array}$ & $\begin{array}{l}29.3865 \\
30.7582 \\
31.0630 \\
32.4346 \\
32.7394\end{array}$ & $\begin{array}{l}.75037 \\
.77150 \\
.77567 \\
.79169 \\
.79479\end{array}$ & $\begin{array}{r}.32039 \\
.35671 \\
.36820 \\
.13078 \\
.44776\end{array}$ & $\begin{array}{r}\text { 7. } 20818 \\
11.55965 \\
12.16050 \\
15.29376 \\
16.07465\end{array}$ & $\begin{array}{l}\text { 9. } 57194 \\
\text { 5. } 47048 \\
\text { 4. } 77834 \\
\text { 2. } 68253 \\
\text { 2. } 44198\end{array}$ & $\begin{array}{l}.41370 \\
.30005 \\
.28333 \\
.24660 \\
.24699\end{array}$ & $\begin{array}{l}0.00000 \\
0.00000 \\
0.00000 \\
0.00000 \\
0.00000\end{array}$ & $\begin{array}{l}.12593 \\
.14557 \\
.14559 \\
.16010 \\
.16010\end{array}$ & 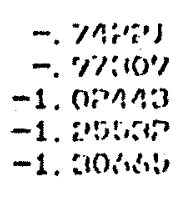 & $\begin{array}{r}1.79651 \\
1.20362 \\
1.06718 \\
.45842 \\
.32092\end{array}$ & $\begin{array}{r}-.11096 \\
-.05485 \\
-.05485 \\
.00127 \\
.00127\end{array}$ & $\begin{array}{l}0.00000 \\
0.00000 \\
0.00000 \\
0.00000 \\
0.00000\end{array}$ \\
\hline $\begin{array}{l}30 \\
31 \\
32 \\
33 \\
34\end{array}$ & $\begin{array}{l}\text { QF2 } \\
\text { QF2 } \\
00 \\
B \\
0\end{array}$ & $\begin{array}{l}33.0442 \\
33.3190 \\
34.0786 \\
35.4502 \\
35.7550\end{array}$ & $\begin{array}{l}.79777 \\
.80082 \\
.00747 \\
.83103 \\
.81177\end{array}$ & $\begin{array}{r}.47005 \\
.48962 \\
.52012 \\
.57166 \\
.57807\end{array}$ & $\begin{array}{r}\text { 15. } 27074 \\
15.27643 \\
11.81696 \\
6.73112 \\
5.95115\end{array}$ & $\begin{array}{l}\text { 2. } 37492 \\
\text { 2. } 57556 \\
\text { 3. } 64019 \\
\text { 7. } 07643 \\
\text { 8. } 09361\end{array}$ & $\begin{array}{l}.24275 \\
.22942 \\
.18698 \\
.14569 \\
.14506\end{array}$ & $\begin{array}{l}0.00000 \\
0.00000 \\
0.00000 \\
0.00000 \\
0.00000\end{array}$ & $\begin{array}{l}.16010 \\
.16010 \\
.16010 \\
.16907 \\
.16907\end{array}$ & 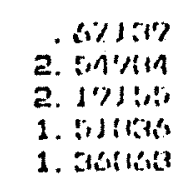 & $\begin{array}{r}-.10447 \\
-.54574 \\
-.91340 \\
-1.58939 \\
-1.74122\end{array}$ & $\begin{array}{l}-.02900 \\
-.05617 \\
-.05817 \\
-.00206 \\
-.00206\end{array}$ & $\begin{array}{l}0.00000 \\
0.00000 \\
0.00000 \\
0.00000 \\
0.00000\end{array}$ \\
\hline $\begin{array}{l}35 \\
36 \\
37 \\
38 \\
39\end{array}$ & $\begin{array}{l}B \\
0 \\
Q D \\
Q D \\
O D\end{array}$ & $\begin{array}{l}37.1266 \\
37.4314 \\
37.7362 \\
38.0410 \\
38.7707\end{array}$ & $\begin{array}{r}.07462 \\
.91182 \\
.93098 \\
.95014 \\
.96763\end{array}$ & $\begin{array}{r}.50091 \\
.60215 \\
.60522 \\
.60829 \\
.61689\end{array}$ & $\begin{array}{l}\text { 3. } 02142 \\
\text { 2. } 64307 \\
\text { 2. } 47919 \\
\text { 2. } 64210 \\
\text { 3. } 69756\end{array}$ & $\begin{array}{l}\text { 13. } 77439 \\
15.27907 \\
16.07576 \\
15.31147 \\
11.92402\end{array}$ & $\begin{array}{l}.18070 \\
.19718 \\
.21671 \\
.25117 \\
.34311\end{array}$ & $\begin{array}{l}0.00000 \\
0.00000 \\
0.00000 \\
0.00000 \\
0.00000\end{array}$ & $\begin{array}{r}17786 \\
.17796 \\
.17786 \\
.17786 \\
.17786\end{array}$ & 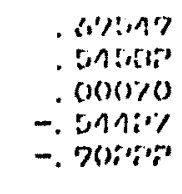 & $\begin{array}{r}-2.39393 \\
-2.54287 \\
-.02748 \\
2.49329 \\
2.14940\end{array}$ & $\begin{array}{l}.05405 \\
.05405 \\
.08784 \\
.12601 \\
.12601\end{array}$ & $\begin{array}{l}0.00000 \\
0.00000 \\
0.00000 \\
0.00000 \\
0.00000\end{array}$ \\
\hline $\begin{array}{l}40 \\
41 \\
42 \\
43 \\
44\end{array}$ & $\begin{array}{l}D \\
0 \\
B \\
0 \\
\text { RF }\end{array}$ & $\begin{array}{l}40.1423 \\
40.4471 \\
41.8187 \\
42.1235 \\
42.4283\end{array}$ & $\begin{array}{l}1.03076 \\
1.03716 \\
1.05790 \\
1.06125 \\
1.05432\end{array}$ & $\begin{array}{l}.64107 \\
.64661 \\
.69962 \\
.71641 \\
.73491\end{array}$ & $\begin{array}{r}7.09321 \\
8.09876 \\
13.74832 \\
15.25500 \\
15.04492\end{array}$ & $\begin{array}{l}\text { 6. } 90623 \\
6.00557 \\
\text { 3. } 13275 \\
\text { 2. } 73705 \\
\text { 2. } 56461\end{array}$ & $\begin{array}{r}.55431 \\
.60982 \\
.89796 \\
.97057 \\
1.01824\end{array}$ & $\begin{array}{l}0.00000 \\
0.00000 \\
0.00000 \\
0.00000 \\
0.00000\end{array}$ & $\begin{array}{l}.20267 \\
.20267 \\
.24462 \\
.24462 \\
.24462\end{array}$ & 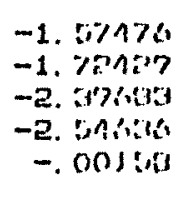 & $\begin{array}{r}1.51775 \\
1.37153 \\
.71968 \\
.57199 \\
.00991\end{array}$ & $\begin{array}{l}18212 \\
.18212 \\
.23824 \\
.23824 \\
.07322\end{array}$ & $\begin{array}{l}0.00000 \\
0.00000 \\
0.00000 \\
0.00000 \\
0.00000\end{array}$ \\
\hline $\begin{array}{l}45 \\
46 \\
47 \\
49\end{array}$ & $\begin{array}{l}Q F \\
Q Q D \\
Q D \\
Q D\end{array}$ & $\begin{array}{l}42.7331 \\
46.3155 \\
47.1203 \\
47.4251\end{array}$ & $\begin{array}{l}1.06740 \\
1.17838 \\
1.19749 \\
1.21659\end{array}$ & $\begin{array}{l}.75345 \\
.86286 \\
.86545 \\
.86904\end{array}$ & $\begin{array}{r}\text { 15. } 25886 \\
\text { 2. } 64071 \\
\text { 2. } 495131 \\
\text { 2. } 65003\end{array}$ & $\begin{array}{r}2.72656 \\
15.18103 \\
15.95660 \\
15.18292\end{array}$ & $\begin{array}{r}1.01483 \\
.62508 \\
.61132 \\
.62811\end{array}$ & $\begin{array}{l}0.00000 \\
0.00000 \\
0.00000 \\
0.00000\end{array}$ & $\begin{array}{l}.24462 \\
.24462 \\
.24462 \\
.24462\end{array}$ & $\begin{array}{r}\text { 2. 51:151 } \\
.511614 \\
-.00(1617 \\
-.51980\end{array}$ & $\begin{array}{r}-.55015 \\
-2.50060 \\
-.00160 \\
\text { 2. } 49771\end{array}$ & $\begin{array}{r}-.09547 \\
-.09547 \\
.00496 \\
.10564\end{array}$ & $\begin{array}{l}0.00000 \\
0.00000 \\
0.00000 \\
0.00000\end{array}$ \\
\hline
\end{tabular}




\begin{tabular}{|c|c|c|c|c|c|c|c|c|c|c|c|c|c|}
\hline POS & & $S(M)$ & NUIX & NUY & BETAX (M) & BETAY $(M)$ & ETAX (M) & $\operatorname{ETAY}(M)$ & $\operatorname{ETAS}(M)$ & Al $\ln x$ & ALPHAY & DETAX & DETAY \\
\hline $\begin{array}{l}50 \\
51 \\
52 \\
53 \\
54\end{array}$ & $\begin{array}{l}D \\
D \\
D \\
0 \\
Q F\end{array}$ & $\begin{array}{l}49.5283 \\
49.8311 \\
51.2027 \\
51.5075 \\
51.8123\end{array}$ & $\begin{array}{l}\text { 1. } 29699 \\
1.30337 \\
1.32407 \\
1.32742 \\
1.33049\end{array}$ & $\begin{array}{l}.90226 \\
.90995 \\
.96241 \\
.97945 \\
.97944\end{array}$ & $\begin{array}{r}\text { 7. } 10790 \\
\text { 8. } 11641 \\
\text { 13. } 76743 \\
15.27357 \\
16.06599\end{array}$ & $\begin{array}{l}\text { 6. } 76354 \\
\text { 5. } 88785 \\
\text { 3. } 05016 \\
\text { 2. } 66707 \\
\text { 2. } 50097\end{array}$ & $\begin{array}{r}.88947 \\
.93777 \\
1.19798 \\
1.26438 \\
1.29852\end{array}$ & $\begin{array}{l}0.00000 \\
0.00000 \\
0.00000 \\
0.00000 \\
0.00000\end{array}$ & $\begin{array}{l}20097 \\
.20897 \\
.34854 \\
.34954 \\
.34654\end{array}$ & 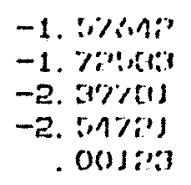 & $\begin{array}{r}1.51044 \\
1.36256 \\
.70307 \\
.55374 \\
.00039\end{array}$ & $\begin{array}{l}.16175 \\
.16175 \\
.21787 \\
.21787 \\
.00521\end{array}$ & $\begin{array}{l}0.00000 \\
0.00000 \\
0.00000 \\
0.00000 \\
0.00000\end{array}$ \\
\hline $\begin{array}{l}55 \\
56 \\
57 \\
58 \\
59\end{array}$ & $\begin{array}{l}\text { QF } \\
\text { OO } \\
B \\
0 \\
B\end{array}$ & $\begin{array}{l}\text { 52. } 1171 \\
52.8468 \\
54.2184 \\
54.5232 \\
55.8948\end{array}$ & $\begin{array}{l}\text { 1. } 33356 \\
\text { 1. } 34221 \\
\text { 1. } 36577 \\
\text { 1. } 37150 \\
\text { 1. } 12735\end{array}$ & $\begin{array}{l}1.01742 \\
1.05456 \\
1.09736 \\
1.10373 \\
1.12446 .\end{array}$ & $\begin{array}{r}\text { 15. } 27522 \\
11.81531 \\
6.73121 \\
5.85136 \\
\text { 3. } 02192\end{array}$ & $\begin{array}{r}\text { 2. } 66660 \\
3.73106 \\
7.13624 \\
\text { B. } 13607 \\
13.71313\end{array}$ & $\begin{array}{r}1.26753 \\
1.11599 \\
.86971 \\
.82351 \\
.65416\end{array}$ & $\begin{array}{l}0.00000 \\
0.00000 \\
0.00000 \\
0.00000 \\
0.00000\end{array}$ & $\begin{array}{l}34854 \\
.34854 \\
.40397 \\
.40399 \\
.44499\end{array}$ & 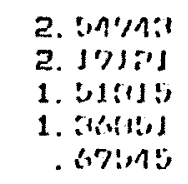 & $\begin{array}{r}-.55288 \\
-.91014 \\
-1.56640 \\
-1.71391 \\
-2.34724\end{array}$ & $\begin{array}{l}-.20770 \\
-.20770 \\
-.15159 \\
-.15159 \\
-.09547\end{array}$ & $\begin{array}{l}0.00000 \\
0.00000 \\
0.00000 \\
0.00000 \\
0.00000\end{array}$ \\
\hline $\begin{array}{l}60 \\
61 \\
62 \\
63 \\
64\end{array}$ & $\begin{array}{l}0 \\
Q D \\
Q D \\
O D \\
B\end{array}$ & $\begin{array}{l}56.1996 \\
56.5044 \\
56.8092 \\
57.5388 \\
58.9104\end{array}$ & $\begin{array}{l}\text { 1. } 44155 \\
1.46370 \\
1.49295 \\
1.52034 \\
1.56346\end{array}$ & $\begin{array}{l}\text { 1. } 12782 \\
\text { 1. } 13091 \\
\text { 1. } 13400 \\
\text { 1. } 14269 \\
1.16730\end{array}$ & $\begin{array}{l}\text { 2. } 64358 \\
\text { 2. } 47973 \\
\text { 2. } 64278 \\
\text { 3. } 69834 \\
7.09413\end{array}$ & $\begin{array}{r}15.19011 \\
15.95982 \\
15.17997 \\
11.77654 \\
6.73440\end{array}$ & $\begin{array}{l}.62506 \\
.61132 \\
.62911 \\
.70519 \\
.86347\end{array}$ & $\begin{array}{l}0.00000 \\
0.00000 \\
0.00000 \\
0.00000 \\
0.00000\end{array}$ & $\begin{array}{l}44499 \\
.44499 \\
.44499 \\
.44499 \\
.48934\end{array}$ & $\begin{array}{r}.515011 \\
.000121 \\
-.51140 \\
-.701011 \\
-1.57177\end{array}$ & $\begin{array}{r}-2.49191 \\
.00660 \\
2.50742 \\
2.15716 \\
1.51315\end{array}$ & $\begin{array}{r}-.09547 \\
.00496 \\
.10564 \\
.10564 \\
.16175\end{array}$ & $\begin{array}{l}0.00000 \\
0.00000 \\
0.00000 \\
0.00000 \\
0.00000\end{array}$ \\
\hline $\begin{array}{l}65 \\
66 \\
67 \\
48 \\
69\end{array}$ & $\begin{array}{l}D \\
B \\
D \\
Q F \\
Q F\end{array}$ & $\begin{array}{l}59.2152 \\
60.5869 \\
60.9916 \\
61.1964 \\
61.5012\end{array}$ & $\begin{array}{l}1.56786 \\
1.59060 \\
1.59395 \\
1.59702 \\
1.60010\end{array}$ & $\begin{array}{l}\text { 1. } 17502 \\
1.22789 \\
1.24509 \\
1.26427 \\
1.28345\end{array}$ & $\begin{array}{r}8.09968 \\
13.74714 \\
15.25578 \\
16.04560 \\
15.25738\end{array}$ & $\begin{array}{l}\text { 5. } 85736 \\
\text { 3. } 02135 \\
\text { 2. } 64036 \\
\text { 2. } 47567 \\
\text { 2. } \$ 4090\end{array}$ & $\begin{array}{l}.93777 \\
1.19798 \\
1.26438 \\
1.29352 \\
1.26753\end{array}$ & $\begin{array}{l}0.00000 \\
0.00000 \\
0.00000 \\
0.00000 \\
0.00000\end{array}$ & $\begin{array}{l}.48934 \\
.54891 \\
.54891 \\
.54891 \\
.54891\end{array}$ & 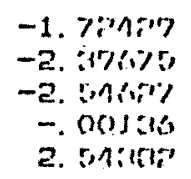 & $\begin{array}{r}1.36427 \\
.70015 \\
.54981 \\
-.00042 \\
-.55074\end{array}$ & $\begin{array}{r}.16175 \\
.21787 \\
.21787 \\
.00521 \\
-.20770\end{array}$ & $\begin{array}{l}0.00000 \\
0.00000 \\
0.00000 \\
0.00000 \\
0.00000\end{array}$ \\
\hline $\begin{array}{l}70 \\
71 \\
72 \\
73 \\
74\end{array}$ & $\begin{array}{l}00 \\
B \\
0 \\
B \\
0\end{array}$ & $\begin{array}{l}62.2308 \\
63.6024 \\
63.9072 \\
65.2786 \\
65.5836\end{array}$ & $\begin{array}{l}\text { 1. } 60075 \\
\text { 1. } \$ 3333 \\
\text { 1. } 64106 \\
1.67385 \\
1.71101\end{array}$ & $\begin{array}{l}\text { 1. } 32091 \\
\text { 1. } 36392 \\
\text { 1. } 37030 \\
\text { 1. } 39103 \\
1.39139\end{array}$ & $\begin{array}{r}11.80597 \\
\text { 6. } 73122 \\
5.65301 \\
\text { 3. } 02794 \\
\text { 2. } 64791\end{array}$ & $\begin{array}{r}3.70730 \\
7.11872 \\
\text { B. } 12260 \\
13.72673 \\
15.21167\end{array}$ & $\begin{array}{r}1.11599 \\
.66971 \\
.82351 \\
.65416 \\
.62506\end{array}$ & $\begin{array}{l}0.00000 \\
0.00000 \\
0.00000 \\
0.00000 \\
0.00000\end{array}$ & $\begin{array}{l}54891 \\
.60426 \\
.60426 \\
.64536 \\
.64536\end{array}$ & 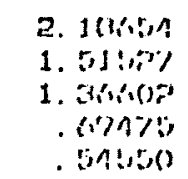 & $\begin{array}{r}-.91063 \\
-1.57244 \\
-1.72113 \\
-2.35973 \\
-2.50556\end{array}$ & $\begin{array}{l}-.20770 \\
-.15159 \\
-.15159 \\
-.09547 \\
-.09547\end{array}$ & $\begin{array}{l}0.00000 \\
0.00000 \\
0.00000 \\
0.00000 \\
0.00000\end{array}$ \\
\hline $\begin{array}{l}75 \\
76 \\
77 \\
78 \\
79\end{array}$ & $\begin{array}{l}Q D \\
Q D \\
O D \\
B \\
D\end{array}$ & $\begin{array}{l}65.8894 \\
66.1932 \\
66.9228 \\
68.2944 \\
68.5992\end{array}$ & $\begin{array}{l}\text { 1. } 73011 \\
\text { 1. } 74921 \\
1.79659 \\
\text { 1. } 92961 \\
\text { 1. } 83600\end{array}$ & $\begin{array}{l}1.39748 \\
1.40056 \\
1.40923 \\
1.43372 \\
1.44140\end{array}$ & $\begin{array}{l}\text { 2. } 48645 \\
\text { 2. } 65036 \\
\text { 3. } 70835 \\
\text { 7. } 10688 \\
\text { 8. } 11273\end{array}$ & $\begin{array}{r}15.98072 \\
15.21336 \\
11.81510 \\
6.77525 \\
5.89741\end{array}$ & $\begin{array}{l}.61132 \\
.62811 \\
.70519 \\
.89647 \\
.93777\end{array}$ & $\begin{array}{l}0.00000 \\
0.00000 \\
0.00000 \\
0.00000 \\
0.00000\end{array}$ & $\begin{array}{l}.64536 \\
.64536 \\
.64536 \\
.68971 \\
.68971\end{array}$ & 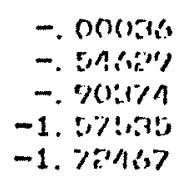 & $\begin{array}{l}-.00143 \\
\text { 2. } 50297 \\
2.15455 \\
1.51410 \\
1.36598\end{array}$ & $\begin{array}{l}.00496 \\
.10564 \\
.10564 \\
.16175 \\
.16175\end{array}$ & $\begin{array}{l}0.00000 \\
0.00000 \\
0.00000 \\
0.00000 \\
0.00000\end{array}$ \\
\hline $\begin{array}{l}80 \\
81 \\
82 \\
83 \\
84\end{array}$ & $\begin{array}{l}B \\
D \\
Q F \\
Q F \\
D D\end{array}$ & $\begin{array}{l}69.9708 \\
70.2756 \\
70.5804 \\
70.8852 \\
71.6149\end{array}$ & $\begin{array}{l}\text { 1. } 85671 \\
1.86006 \\
1.86313 \\
1.86620 \\
\text { 1. } 87486\end{array}$ & $\begin{array}{l}1.49080 \\
1.51003 \\
1.52902 \\
1.54832 \\
1.58600\end{array}$ & $\begin{array}{l}13.76 .205 \\
15.26033 \\
16.05708 \\
15.26664 \\
11.60947\end{array}$ & $\begin{array}{l}\text { 3. } 05184 \\
\text { 2. } 56742 \\
\text { 2. } 50008 \\
\text { 2. } 56442 \\
3.72824\end{array}$ & $\begin{array}{l}1.19798 \\
1.26439 \\
1.29952 \\
1.26753 \\
1.11599\end{array}$ & $\begin{array}{l}0.00000 \\
0.00000 \\
0.00000 \\
0.00000 \\
0.00000\end{array}$ & $\begin{array}{l}.74920 \\
.74920 \\
.74920 \\
.74920 \\
.74920\end{array}$ & 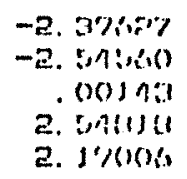 & $\begin{array}{r}.70540 \\
.55583 \\
.00238 \\
-.55059 \\
-.90744\end{array}$ & $\begin{array}{r}.21787 \\
.21797 \\
.00521 \\
-.20770 \\
-.20770\end{array}$ & $\begin{array}{l}0.00000 \\
0.00000 \\
0.00000 \\
0.00000 \\
0.00000\end{array}$ \\
\hline $\begin{array}{l}85 \\
86 \\
87 \\
88 \\
89\end{array}$ & $\begin{array}{l}B \\
D \\
B \\
0 \\
O D\end{array}$ & $\begin{array}{l}72.9865 \\
73.2913 \\
74.6629 \\
74.9677 \\
75.2725\end{array}$ & $\begin{array}{l}1.99943 \\
1.90717 \\
1.96005 \\
1.97725 \\
1.99640\end{array}$ & $\begin{array}{l}1.62898 \\
1.63526 \\
1.65603 \\
1.65939 \\
1.66249\end{array}$ & $\begin{array}{l}\text { 6. } 72726 \\
5.04797 \\
\text { 3. } 02075 \\
2.64284 \\
\text { 2. } 47937\end{array}$ & $\begin{array}{r}7.12201 \\
8.11971 \\
13.69799 \\
15.16031 \\
15.92083\end{array}$ & $\begin{array}{l}.86971 \\
.82351 \\
.65416 \\
.62506 \\
.61132\end{array}$ & $\begin{array}{l}0.00000 \\
0.00000 \\
0.00000 \\
0.00000 \\
0.00000\end{array}$ & $\begin{array}{l}.80463 \\
.80463 \\
.84573 \\
.84573 \\
.84573\end{array}$ & 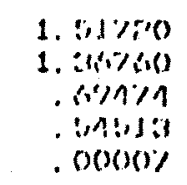 & $\begin{array}{r}-1.56298 \\
-1.71032 \\
-2.34298 \\
-2.48749 \\
.00904\end{array}$ & $\begin{array}{r}-.15159 \\
-.15159 \\
-.09547 \\
-.09547 \\
.00496\end{array}$ & $\begin{array}{l}0.00000 \\
0.00000 \\
0.00000 \\
0.00000 \\
0.00000\end{array}$ \\
\hline $\begin{array}{l}70 \\
91 \\
92 \\
93 \\
94\end{array}$ & $\begin{array}{l}Q D \\
O D \\
B \\
D \\
B\end{array}$ & $\begin{array}{l}75.5773 \\
76.3069 \\
77.6785 \\
77.9833 \\
79.3549\end{array}$ & $\begin{array}{l}\text { 2. } 01556 \\
\text { 2. } 05304 \\
\text { 2. } 09615 \\
\text { 2. } 10255 \\
\text { 2. } 12327\end{array}$ & $\begin{array}{l}1.66559 \\
1.67429 \\
1.69095 \\
1.70668 \\
1.75958\end{array}$ & $\begin{array}{r}2.64276 \\
3.69931 \\
7.09766 \\
8.10391 \\
13.75706\end{array}$ & $\begin{array}{r}15.15083 \\
11.75487 \\
6.72428 \\
5.81737 \\
3.02087\end{array}$ & $\begin{array}{r}.62811 \\
.70519 \\
.89847 \\
.93777 \\
1.19798\end{array}$ & $\begin{array}{l}0.00000 \\
0.00000 \\
0.00000 \\
0.00000 \\
0.00000\end{array}$ & $\begin{array}{l}.84573 \\
.84573 \\
.99008 \\
.99000 \\
.94965\end{array}$ & 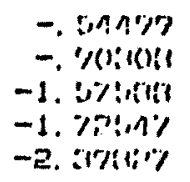 & $\begin{array}{r}2.50199 \\
2.15237 \\
1.50954 \\
1.36092 \\
.69802\end{array}$ & $\begin{array}{l}.10564 \\
.10564 \\
.16175 \\
.16175 \\
.21787\end{array}$ & $\begin{array}{l}0.00000 \\
0.00000 \\
0.00000 \\
0.00000 \\
0.00000\end{array}$ \\
\hline $\begin{array}{l}95 \\
96 \\
97 \\
98\end{array}$ & $\begin{array}{l}0 \\
G F\end{array}$ & $\begin{array}{c}79.6597 \\
79.9645 \\
265 \\
80.9989\end{array}$ & $\begin{array}{l}\text { 2. } 12662 \\
\text { 2. } 12969 \\
.15 \\
2.14141\end{array}$ & $\begin{array}{l}1.77679 \\
1.79596 \\
1 . \quad 2 \\
1.85252\end{array}$ & $\begin{array}{l}\text { 15. } 26464 \\
16.05499 \\
.26 \\
11.81295\end{array}$ & $\begin{array}{r}\text { 2. } 64109 \\
2.47751 \\
1391 \\
271794\end{array}$ & $\begin{array}{l}\text { 1. } 26438 \\
1.29852 \\
126 \\
11500\end{array}$ & $\begin{array}{rr}0.00000 \\
0.00000 \\
\text { c } 000 \\
n \text { nnnn }\end{array}$ & $\begin{array}{l}.94965 \\
.94965 \\
949 \\
04 n=\end{array}$ & $\begin{array}{l}-2 . \operatorname{lin} 116 \\
-.00145 \\
2 .\end{array}$ & $\begin{array}{r}54796 \\
-00230 \\
530: \\
-.2\end{array}$ & $\begin{array}{l}21787 \\
005=1 \\
207\end{array}$ & $\begin{array}{l}\text { o. } 00000 \\
\text { o. onnnn } \\
\text { o. C }\end{array}$ \\
\hline
\end{tabular}




\begin{tabular}{|c|c|c|c|c|c|c|c|c|c|c|c|c|c|}
\hline PQS & & $S(M)$ & NuX & NUY & BETAX (N) & DETAY (M) & ETAX(M) & $\operatorname{ETAY}(M)$ & $\operatorname{ETAS}(M)$ & $N \| N X$ & ALPHAY & DETAX & DETAY \\
\hline $\begin{array}{l}100 \\
101 \\
102 \\
103 \\
104\end{array}$ & $\begin{array}{l}O \\
B \\
0 \\
Q D \\
Q D\end{array}$ & $\begin{array}{l}82.6753 \\
84.0469 \\
84.3517 \\
84.6565 \\
84.9613\end{array}$ & $\begin{array}{l}\text { 2. } 17370 \\
\text { 2. } 22647 \\
\text { 2. } 24362 \\
\text { 2. } 26272 \\
\text { 2. } 28182\end{array}$ & $\begin{array}{l}\text { 1. } 90182 \\
\text { 1. } 92251 \\
\text { 1. } 92586 \\
1.92894 \\
1.93202\end{array}$ & $\begin{array}{l}\text { 5. } 95619 \\
\text { 3. } 02090 \\
\text { 2. } 65035 \\
\text { 2. } 48652 \\
\text { 2. } 55006\end{array}$ & $\begin{array}{r}\text { 8. } 13985 \\
\text { 13. } 75428 \\
15.23745 \\
16.01737 \\
15.24005\end{array}$ & $\begin{array}{l}.82351 \\
.65416 \\
.62506 \\
.61132 \\
.62811\end{array}$ & $\begin{array}{l}0.00000 \\
0.00000 \\
0.00000 \\
0.00000 \\
0.00000\end{array}$ & $\begin{array}{l}\text { 1. } 00500 \\
1.04610 \\
1.04610 \\
1.04610 \\
1.04610\end{array}$ & 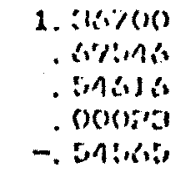 & $\begin{array}{r}-1.72429 \\
-2.36334 \\
-2.50927 \\
-.00050 \\
2.50836\end{array}$ & $\begin{array}{r}-.15159 \\
-.09547 \\
-.09547 \\
.00496 \\
.10564\end{array}$ & $\begin{array}{l}0.00000 \\
0.00000 \\
0.00000 \\
0.00000 \\
0.00000\end{array}$ \\
\hline $\begin{array}{l}105 \\
106 \\
107 \\
108 \\
109\end{array}$ & $\begin{array}{l}01 \\
B \\
02 \\
Q F \\
Q F\end{array}$ & $\begin{array}{l}85.4113 \\
86.7829 \\
89.0438 \\
89.3196 \\
89.6534\end{array}$ & $\begin{array}{l}\text { 2. } 30636 \\
\text { 2. } 35558 \\
\text { 2. } 39273 \\
\text { 2. } 37580 \\
\text { e. } 39097\end{array}$ & $\begin{array}{l}\text { 1. } 73709 \\
1.75398 \\
\text { 2. } 04223 \\
\text { 2. } 06116 \\
\text { 2. } 00008\end{array}$ & $\begin{array}{r}\text { 3. } 24031 \\
6.260133 \\
15.262 .97 \\
16.05129 \\
15.26100\end{array}$ & $\begin{array}{r}13.07941 \\
7.65301 \\
2.47413 \\
2.50790 \\
2.67786\end{array}$ & $\begin{array}{r}.67565 \\
.35893 \\
1.22462 \\
1.24280 \\
1.19864\end{array}$ & $\begin{array}{l}0.00000 \\
0.00000 \\
0.00000 \\
0.00000 \\
0.00000\end{array}$ & $\begin{array}{l}1.04810 \\
1.08880 \\
1.08880 \\
1.08890 \\
1.08890\end{array}$ & 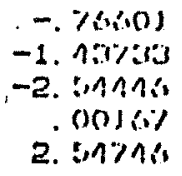 & $\begin{array}{r}2.29305 \\
1.65334 \\
.55111 \\
-.00296 \\
-.55765\end{array}$ & $\begin{array}{r}.10564 \\
.16175 \\
.16175 \\
-.04298 \\
-.24556\end{array}$ & $\begin{array}{l}0.00000 \\
0.00000 \\
0.00000 \\
0.00000 \\
0.00000\end{array}$ \\
\hline $\begin{array}{ll}1 & 10 \\
1 & 11 \\
1 & 12 \\
1 & 13 \\
1 & 14\end{array}$ & $\begin{array}{l}Q 3 \\
D \\
04 \\
Q D \\
Q D\end{array}$ & $\begin{array}{l}91.4559 \\
92.8275 \\
93.7358 \\
94.0406 \\
94.3454\end{array}$ & $\begin{array}{l}\text { 2. } 42551 \\
\text { ᄅ. } 16513 \\
\text { 2. } 51001 \\
\text { ᄅ. } 52717 \\
\text { e. } 54833\end{array}$ & $\begin{array}{l}\text { 2. } 13251 \\
\text { 2. } 17875 \\
\text { 2. } 18984 \\
\text { 2. } 19290 \\
\text { 2. } 19597\end{array}$ & $\begin{array}{l}\text { 7. } 67191 \\
\text { 4. } 03505 \\
\text { 2. } 64132 \\
\text { 2. } 47820 \\
\text { 2. } 64204\end{array}$ & $\begin{array}{r}6.27875 \\
11.12420 \\
15.31292 \\
16.09640 \\
15.31695\end{array}$ & $\begin{array}{l}.75603 \\
.45786 \\
.28579 \\
.23470 \\
.19533\end{array}$ & $\begin{array}{l}0.00000 \\
0.00000 \\
0.00000 \\
0.00000 \\
0.00000\end{array}$ & $\begin{array}{l}\text { 1. } 08890 \\
\text { 1. } 12250 \\
\text { 1. } 12250 \\
\text { 1. } 12250 \\
\text { 1. } 12250\end{array}$ & 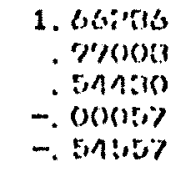 & $\begin{array}{r}-1.44008 \\
-2.08706 \\
-2.52438 \\
-.00333 \\
2.51837\end{array}$ & $\begin{array}{l}-.24556 \\
-.18944 \\
-.18944 \\
-14716 \\
-.11223\end{array}$ & $\begin{array}{l}0.00000 \\
0.00000 \\
0.00000 \\
0.00000 \\
0.00000\end{array}$ \\
\hline $\begin{array}{l}115 \\
115 \\
117 \\
118 \\
119\end{array}$ & $\begin{array}{l}05 \\
B \\
0 \\
B \\
06\end{array}$ & $\begin{array}{l}94.5626 \\
95.9342 \\
96.2390 \\
97.6106 \\
98.4278\end{array}$ & $\begin{array}{l}\text { 2. } 56093 \\
\text { 2. } 61590 \\
\text { 2. } 62104 \\
\text { 2. } 64752 \\
\text { 2. } 65936\end{array}$ & $\begin{array}{l}\text { 2. } 19031 \\
\text { 2. } 21821 \\
\text { 2. } 22131 \\
\text { 2. } 26527 \\
\text { 2. } 30618\end{array}$ & $\begin{array}{r}\text { 2. } 90222 \\
5.61357 \\
6.46726 \\
11.43511 \\
15.27433\end{array}$ & $\begin{array}{r}\text { 14. } 24543 \\
\text { 日. } 49009 \\
\text { 7. } 45333 \\
\text { 3. } 99595 \\
\text { 2. } 65176\end{array}$ & $\begin{array}{r}.17096 \\
.05557 \\
.07846 \\
-.00000 \\
-.00000\end{array}$ & $\begin{array}{l}0.00000 \\
0.00000 \\
0.00000 \\
0.00000 \\
0.00000\end{array}$ & $\begin{array}{l}\text { 1. } 12250 \\
1.12947 \\
1.12949 \\
1.12921 \\
1.12921\end{array}$ & 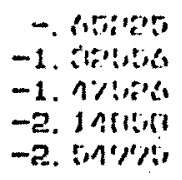 & $\begin{array}{r}2.41424 \\
1.77523 \\
1.62619 \\
.96340 \\
.55894\end{array}$ & $\begin{array}{l}-.11223 \\
-.05611 \\
-.05611 \\
-.00000 \\
-.00000\end{array}$ & $\begin{array}{l}0.00000 \\
0.00000 \\
0.00000 \\
0.00000 \\
0.00000\end{array}$ \\
\hline $\begin{array}{l}.120 \\
121 \\
122 \\
123 \\
124\end{array}$ & $\begin{array}{l}\text { OFq } \\
\text { QF } \\
0 \\
203 \\
203\end{array}$ & $\begin{array}{r}99.0374 \\
99.6470 \\
99.9518 \\
100.5614 \\
101.1710\end{array}$ & $\begin{array}{l}\text { 2. } 66534 \\
\text { 2. } 67149 \\
\text { 2. } 67511 \\
\text { 2. } 68365 \\
\text { 2. } 67213\end{array}$ & $\begin{array}{l}\text { 2. } 34557 \\
\text { 2. } 33196 \\
\text { 2. } 39618 \\
\text { 2. } 41865 \\
\text { 2. } 43912\end{array}$ & $\begin{array}{l}16.63720 \\
14.37666 \\
12.51548 \\
10.85077 \\
12.70157\end{array}$ & $\begin{array}{l}\text { 2. } 42427 \\
\text { 3. } 10295 \\
\text { 3. } 73173 \\
4.74143 \\
4.52767\end{array}$ & $\begin{array}{l}-.00000 \\
-.00000 \\
-.00000 \\
-.00000 \\
-.00000\end{array}$ & $\begin{array}{l}0.00000 \\
0.00000 \\
0.00000 \\
0.00000 \\
0.00000\end{array}$ & $\begin{array}{l}\text { 1. } 12921 \\
1.12921 \\
1.12921 \\
1.12921 \\
1.12921\end{array}$ & 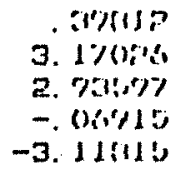 & $\begin{array}{r}-.17160 \\
-.99401 \\
-1.17735 \\
-.34810 \\
.68092\end{array}$ & $\begin{array}{r}-.00000 \\
.00000 \\
.00000 \\
-.00000 \\
-.00000\end{array}$ & $\begin{array}{l}0.00000 \\
0.00000 \\
0.00000 \\
0.00000 \\
0.00000\end{array}$ \\
\hline $\begin{array}{l}125 \\
126 \\
127 \\
128 \\
129\end{array}$ & $\begin{array}{l}\operatorname{L2} \\
\operatorname{L11} \\
202 \\
202 \\
0\end{array}$ & $\begin{array}{l}103.8416 \\
105.8075 \\
105.4171 \\
107.0267 \\
107.3315\end{array}$ & $\begin{array}{l}\text { 2. } 71223 \\
\text { 2. } 71904 \\
\text { 2. } 72062 \\
\text { 2. } 72243 \\
\text { 2. } 72362\end{array}$ & $\begin{array}{l}\text { 2. } 56290 \\
\text { 2. } 44338 \\
\text { 2. } 65979 \\
\text { 2. } 67082 \\
\text { 2. } 67420\end{array}$ & $\begin{array}{l}35.37746 \\
59.76350 \\
60.21664 \\
45.69035 \\
35.22539\end{array}$ & $\begin{array}{r}3.17632 \\
5.16273 \\
7.10217 \\
11.63209 \\
15.47991\end{array}$ & $\begin{array}{l}-.00000 \\
-.00000 \\
-.00000 \\
-.00000 \\
-.00000\end{array}$ & $\begin{array}{l}0.00000 \\
0.00000 \\
0.00000 \\
0.00000 \\
0.00000\end{array}$ & $\begin{array}{l}\text { 1. } 12921 \\
\text { 1. } 12921 \\
1.12921 \\
\text { 1. } 12921 \\
\text { 1. } 12921\end{array}$ & 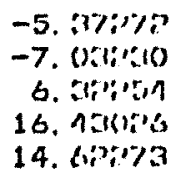 & $\begin{array}{r}-.18241 \\
-.81789 \\
-2.50478 \\
-5.59854 \\
-6.43173\end{array}$ & $\begin{array}{r}-.00000 \\
-.00000 \\
.00000 \\
.00000 \\
.00000\end{array}$ & $\begin{array}{l}0.00000 \\
0.00000 \\
0.00000 \\
0.00000 \\
0.00000\end{array}$ \\
\hline $\begin{array}{l}130 \\
131 \\
132 \\
133\end{array}$ & $\begin{array}{l}2 Q 1 \\
\text { EQ1 } \\
\text { LL } \\
\text { REFL }\end{array}$ & $\begin{array}{l}107.9411 \\
108.5507 \\
118.5507 \\
237.1013\end{array}$ & $\begin{array}{l}\text { 2. } 72697 \\
\text { 2. } 73149 \\
\text { 2. } 35374 \\
\text { 5. } 70748\end{array}$ & $\begin{array}{l}\text { 2. } \$ 7939 \\
\text { 2. } 68367 \\
\text { 2. } 84745 \\
5.69489\end{array}$ & $\begin{array}{r}24.13221 \\
20.01194 \\
10.35156 \\
9.98616\end{array}$ & $\begin{array}{r}21.64973 \\
22.63451 \\
0.01817 \\
10.05056\end{array}$ & $\begin{array}{r}-.00000 \\
-.00000 \\
-.00000 \\
-2.74271\end{array}$ & $\begin{array}{l}0.00000 \\
0.00000 \\
0.00000 \\
0.00000\end{array}$ & $\begin{array}{l}\text { 1. } 12921 \\
1.12921 \\
1.12921 \\
\text { 2. } 25842\end{array}$ & $\begin{array}{r}\text { 6. } 07103 \\
.76104 \\
.00(100) \\
-.00600\end{array}$ & $\begin{array}{r}-3.20444 \\
1.66163 \\
.00000 \\
.00000\end{array}$ & $\begin{array}{l}.00000 \\
.00000 \\
.00000 \\
.00000\end{array}$ & $\begin{array}{l}0.00000 \\
0.00000 \\
0.00000 \\
0.00000\end{array}$ \\
\hline
\end{tabular}

\section{CIRCUMFERENCE $=474.2027 \mathrm{M}$ RADIUS $=\quad 75.4717 \mathrm{M}$ $(D S / S) /(D P / P)=.0095251$}

\section{THETX $\approx \quad 0.28318532$ RAD} THETY $(132)=0.00000000$ RAD
NUX $=11.41496$ NUY $=11.38979$
DNUX/(D) $/$ / $)=-18.28241$
DNUY/(IN)/N) $=-17.87367$

TGAM $=\left(\begin{array}{ll}10.24624, & 0.00000\end{array}\right)$

\begin{tabular}{|c|c|c|c|c|c|c|c|c|c|c|c|c|c|c|}
\hline $\begin{array}{l}\text { MAXIMA } \\
\text { MININA }\end{array}$ & $\begin{array}{l}- \text { BETXI } \\
-- \text { DETXI }\end{array}$ & $\begin{array}{r}1271 \\
131\end{array}$ & $\begin{array}{l}= \\
=\end{array}$ & $\begin{array}{r}80.21664 \\
.93153\end{array}$ & $\begin{array}{l}\text { BETYC } \\
\text { BETY }\end{array}$ & 5) & $\begin{array}{l}= \\
=\end{array}$ & $\begin{array}{r}56.77947 \\
2.37962\end{array}$ & $\begin{array}{l}\text { ETAXY } \\
\text { ETAXS }\end{array}$ & 118 & $\begin{array}{r}-2.74271 \\
-.00000\end{array}$ & $\begin{array}{l}\text { FinYi } \\
\text { linys }\end{array}$ & $\begin{array}{l}133) \\
133)\end{array}$ & $=$ \\
\hline *** & FIN & 0 & 0 & $\begin{array}{l}/ / \text { CORE USE } \\
\text { STORE } \\
\text { INFF }\end{array}$ & $\begin{array}{l}\text { SUMNIARY } \\
\text { IELEMEENT } \\
\text { IELENENT }\end{array}$ & $\begin{array}{l}\text { STDR } \\
\text { DEFII }\end{array}$ & $\begin{array}{l}\text { AGE? } \\
\text { NITI }\end{array}$ & ONS? & MA & $\begin{array}{r}\times \text { IMUN1 } \\
9600 \\
400\end{array}$ & $\begin{array}{l}(\text { LMAX) } \\
(\operatorname{MAX})\end{array}$ & 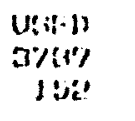 & & $\begin{array}{r}\text { UNUSED } \\
5811 \\
248\end{array}$ \\
\hline
\end{tabular}


Appendix C

Accumulator Orbit Listing 
16 APRIL 81. DE JOHNSON.

THIS HAS REAL EFFECTIVE LENGTHS INCLUDTNG SAGITTA

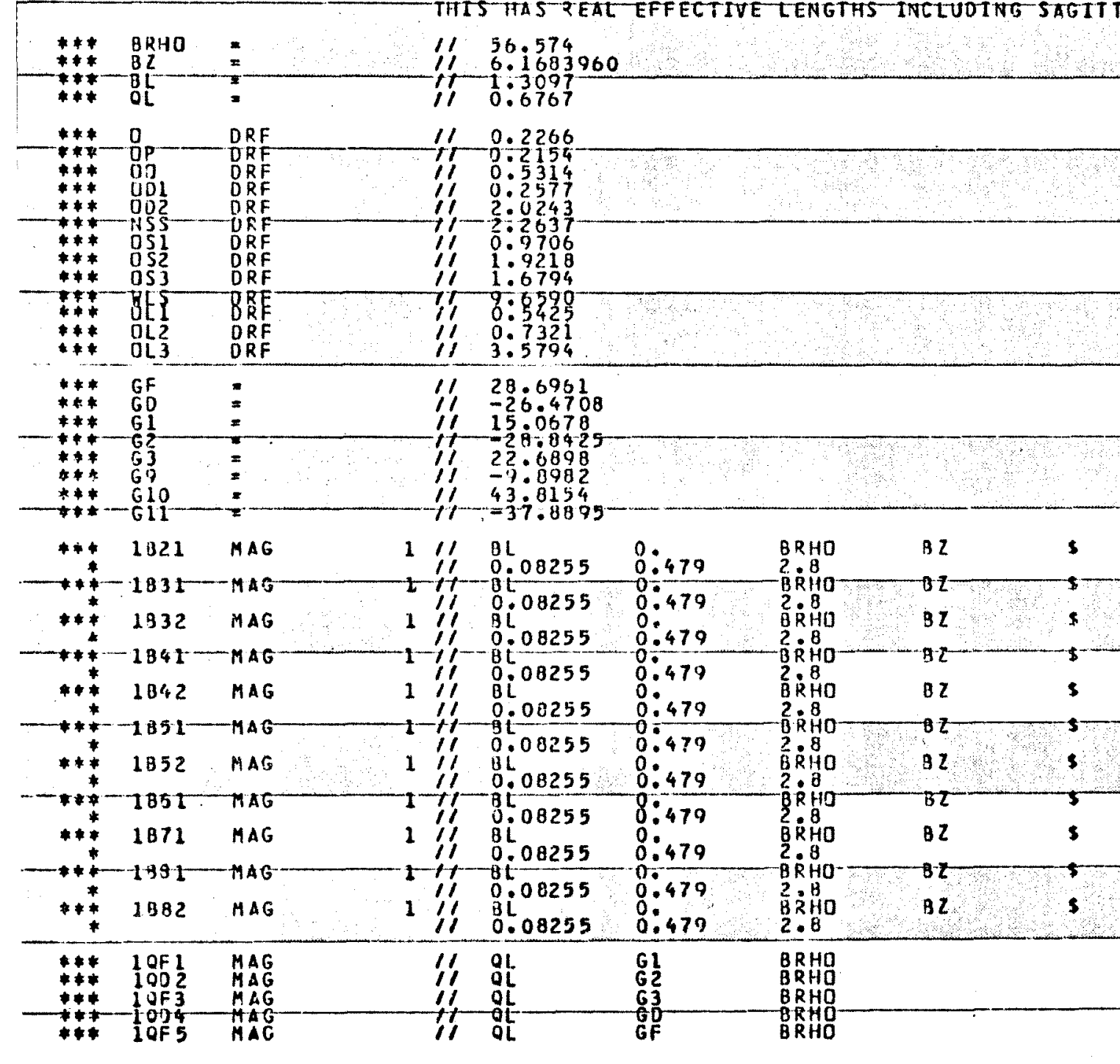




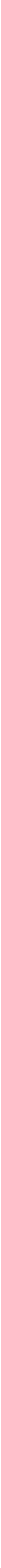


